DOI: $10.24275 /$ uama. 7004.7670

\author{
UNIVERSIDAD AUTÓNOMA METROPOLITANA, \\ Unidad Azcapotzalco \\ DIVISIÓN DE CIENCIAS SOCIALES Y HUMANIDADES \\ Maestría en Planeación y Políticas Metropolitanas
}

\title{
MUJER Y SATISFACCIÓN RESIDENCIAL. LA MIRADA DE QUIENES HABITAN EN EL CONJUNTO URBANO RANCHO SANTA ELENA. CUAUTITLÁN, ESTADO DE MÉXICO.
}

\author{
PRESENTA: \\ ARIADNA NIETO GUZMÁN
}

Tesis para optar por el Grado de Maestra en Planeación y Políticas Metropolitanas

\author{
Miembros del Jurado: \\ Dra. María Teresa Esquivel Hernández \\ Directora de tesis \\ Dra. Guénola Medeleine Francoise Capron \\ Dra. Esther Maya Pérez
}

Ciudad de México, Febrero de 2017

"Esta tesis fue elaborada con el apoyo económico de Conacyt". 


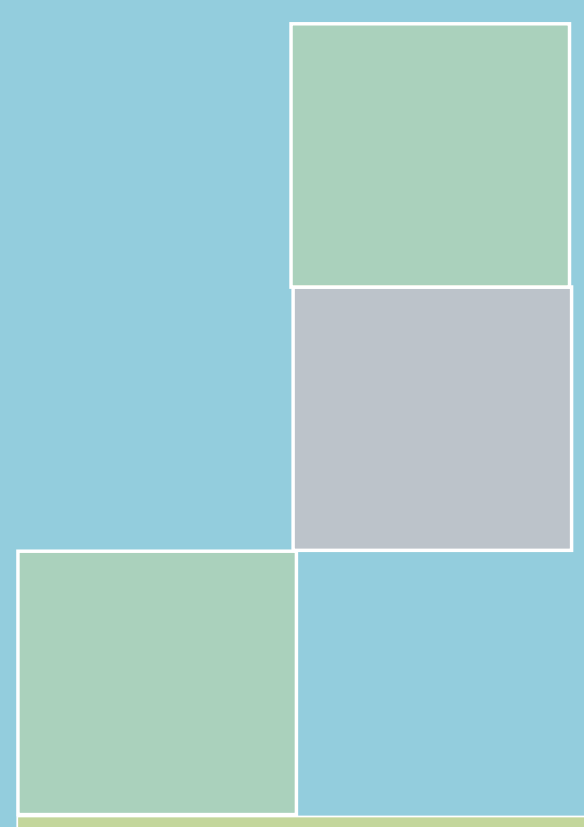

Mujer y satisfacción residencial. La mirada de quienes habitan en el Conjunto Urbano Rancho Santa Elena. Cuautitlán, Estado de México.

Tesis para optar por el grado de Maestra en Planeación y Políticas Metropolitanas

PRESENTA:

Ariadna Nieto Guzmán

Matrícula: 2043804015

Miembros del jurado:

Dra. María Teresa Esquivel Hernández

Directora de tesis

Dra. Guénola Madeleine Francoise Capron

Dra. Esther Maya Pérez

Febrero, 2017 


\section{Resumen:}

La presente tesis es resultado de una investigación realizada entre enero y septiembre de 2016; el tema de este trabajo nace de la inquietud de conocer el grado de satisfacción residencial de las amas de casa que habitan en el Conjunto Urbano Rancho Santa Elena, ubicado en el municipio de Cuautitlán en el Estado de México. Este documento aporta conocimiento sobre los elementos que inciden en mayor medida sobre el grado de satisfacción que las mujeres experimentan hacia su vivienda y que pueden ser considerados para la elaboración de una política habitacional más adecuada.

Palabras clave: vivienda, conjuntos urbanos, ambiente residencial, satisfacción residencial. 
[...] Muere lentamente

quien se transforma en esclavo del hábito repitiendo todos los días los mismos senderos, quien no cambia de rutina, no se arriesga a vestir un nuevo color o no conversa con quien desconoce...

Muere lentamente quien no cambia la vida cuando está insatisfecho con su trabajo, o su amor, quien no arriesga lo seguro por lo incierto para ir tras de un sueño quien no se permite, por lo menos una vez en la vida, huir de los consejos sensatos... ¡Vive hoy! ¡Arriesga hoy! ¡Haz hoy!

Pablo Neruda 


\section{PRESENTACIÓN}

La presente tesis es resultado de una investigación realizada entre enero y septiembre de 2016; el tema de este trabajo nace de la inquietud de conocer el grado de satisfacción residencial de las amas de casa que habitan en el Conjunto Urbano Rancho Santa Elena, ubicado en el municipio de Cuautitlán en el Estado de México. Este documento aporta conocimiento sobre los elementos que inciden en mayor medida sobre el grado de satisfacción que las mujeres experimentan hacia su vivienda y que pueden ser considerados para la elaboración de una política habitacional más adecuada.

Este trabajo no habría sido posible sin el apoyo de la Dra. María Teresa Esquivel Hernández a quien agradezco su paciencia, disposición y el tiempo dedicado a asesorar este trabajo.

Aprovecho este espacio, para dedicar esta tesina de manera especial a mis padres y hermano, gracias por enseñarme que no existen límites cuando se trata de alcanzar un sueño. Gracias Dani por compartir conmigo tu fe y tus ganas de vivir; por ser un ejemplo de vida, dedicación y perseverancia. A Ricardo, a quien agradezco el apoyo y amor incondicional, así como las tardes de esfuerzo y sacrificio dedicadas a este trabajo.

También a los Doctores Jorge Larenas Salas, Luis Iturra, Mariela Gaete y Ricardo Tapia Zarricueta del Instituto de la Vivienda de la Universidad de Chile, por su hospitalidad, las clases y las entrevistas que amablemente me otorgaron.

De igual forma, dejo constancia de gratitud a la Dra. Margarita Camarena Luhrs del Instituto de Investigaciones Sociales de la UNAM, por brindarme su confianza, sabiduría y la oportunidad de formar parte de un increíble proyecto. Así como a las mujeres de Rancho Santa Elena que compartieron su tiempo y experiencias, porque sin su apoyo y participación no hubiese sido posible concluir esta investigación. 


\section{ÍNDICE}

PRESENTACIÓN

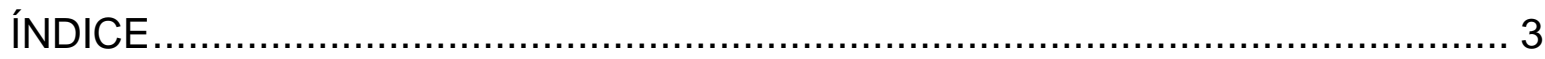

ÍNDICE DE CUADROS, GRÁFICAS, PLANOS, IMÁGENES Y FOTOGRAFÍAS.... 6

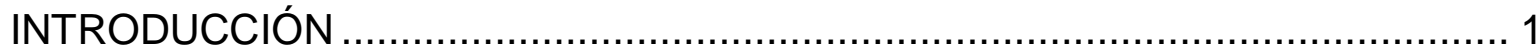

CAPÍTULO 1. VIVIENDA: UNA PERSPECTIVA GENERAL.............................. 16

1.1. La vivienda como derecho .............................................................. 17

1.2. El crecimiento urbano y la demanda de vivienda .................................... 19

1.3. El problema de la vivienda ................................................................. 20

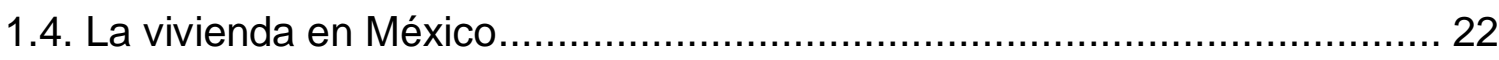

1.5. Del Estado regulador al facilitador: consecuencias de la omisión del Estado

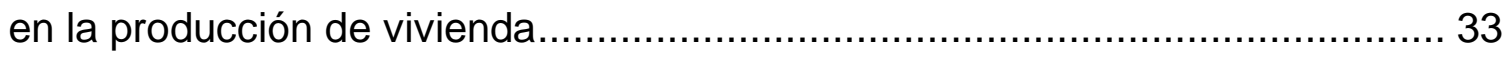

1.6. La vivienda y los problemas de segunda generación ................................. 41

CAPÍTULO 2. VIVIENDA, SATISFACCIÓN RESIDENCIAL Y GÉNERO ............. 45

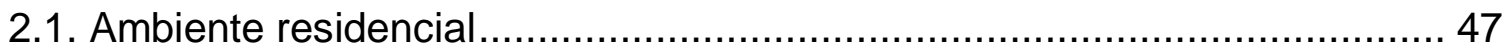

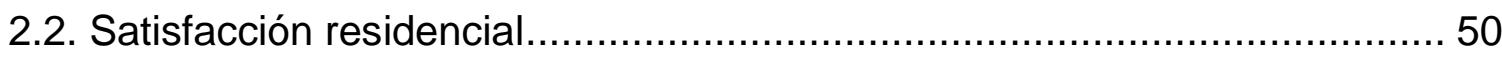

2.3 Las mujeres como sujeto de investigación .............................................. 57

CAPÍTULO 3. EL MUNICIPIO DE CUAUTILTLÁN Y EL CONJUNTO URBANO

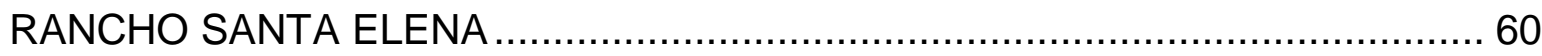

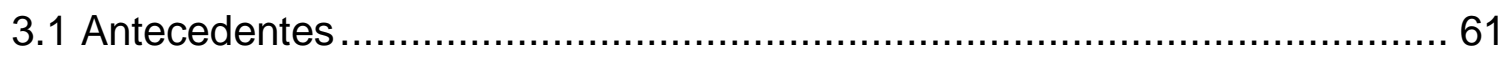

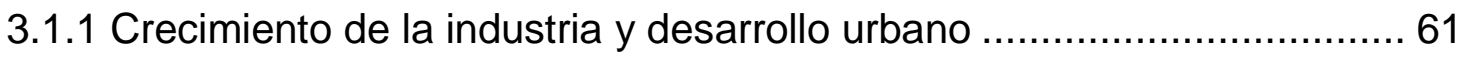

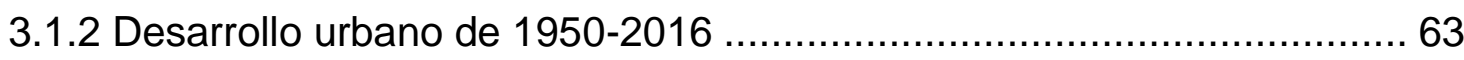

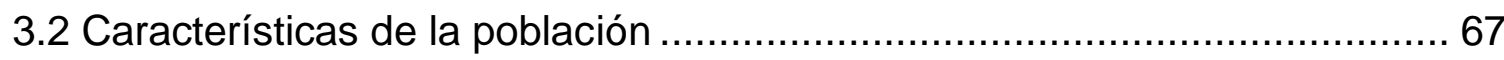

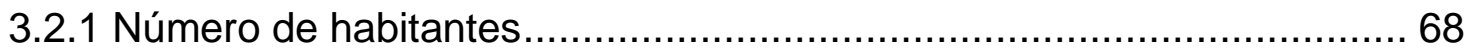

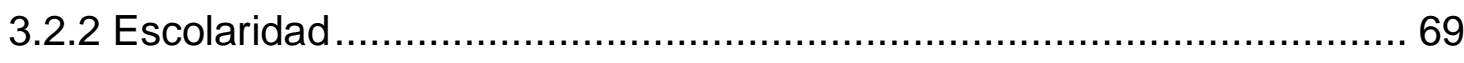

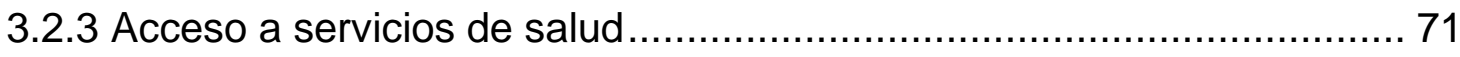

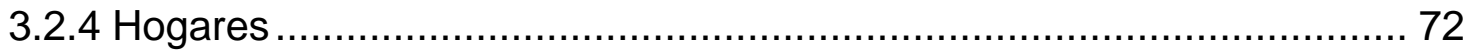

3.2.5 Actividades económicas de la población............................................... 74

3.3 Condiciones y características de las viviendas ....................................... 75

3.3.1 Número y tipos de vivienda ............................................................. 75 
3.3.2 Promedio de ocupantes por vivienda ................................................ 79

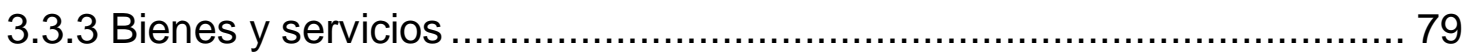

3.4 El Conjunto Urbano Rancho Santa Elena ............................................. 82

3.4.1 Inserción del conjunto en el contexto urbano y estructura organizativa. 82

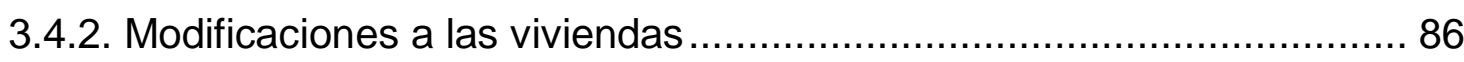

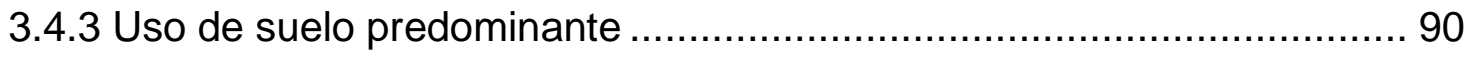

3.4.4 Accesos, transporte y vías de comunicación ..................................... 92

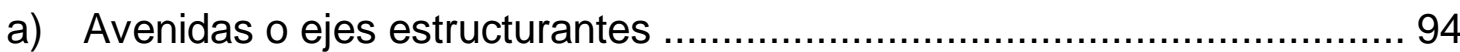

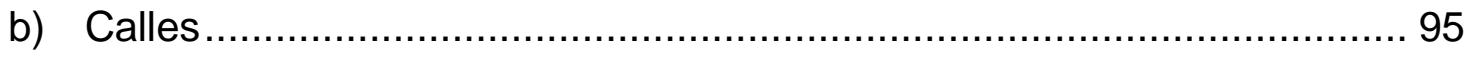

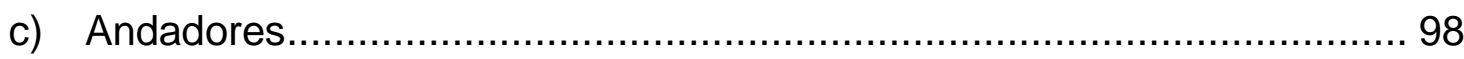

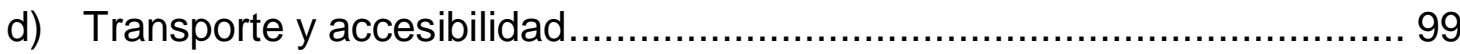

3.4.5 Equipamiento y estado de conservación......................................... 102

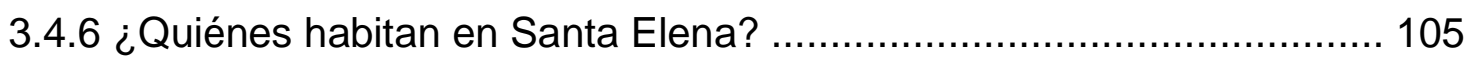

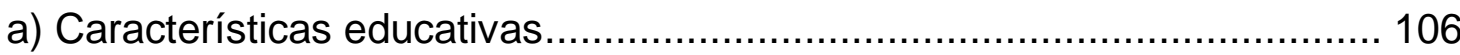

b) Características económicas y derechohabiencia a servicios de salud ..... 106

c) Características de las viviendas......................................................... 108

CAPÍTULO 4. VIVIENDA Y SATISFACCIÓN RESIDENCIAL, LA MIRADA DE QUIENES HABITAN EN EL CONJUNTO URBANO RANCHO SANTA ELENA. 110

4.1. Datos generales de la población encuestada .......................................... 110

4.2 Situación de la vivienda anterior ........................................................ 112

4.2.1 Evaluación de la vivienda anterior ............................................... 114

4.3. Características de la vivienda actual .................................................... 119

4.3.1 Actividades difíciles de realizar dentro de la vivienda ....................... 121

4.3.2 Evaluación de la vivienda actual .................................................. 122

4.3.3 Calificación de los espacios que componen la vivienda ..................... 125

4.3.4 Problemas con la vivienda y cambios a realizar ............................... 127

4.3.5 índice de Satisfacción con la vivienda actual ................................... 128

4.4. Percepción del entorno, relaciones vecinales ...................................... 129

4.5. Percepción del conjunto habitacional ................................................. 130

4.5.1 Evaluación del Conjunto Urbano....................................................... 132

4.5.2 Actividades difíciles de realizar .................................................... 133 
4.6. Administración y organización de los bienes de la comunidad 134

4.7. Relación con instituciones................................................................. 139

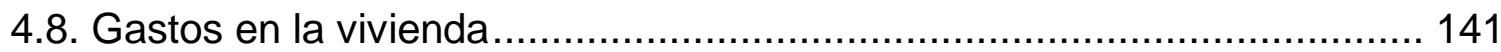

4.8.1 Deseo de quedarse o mudarse .................................................. 145

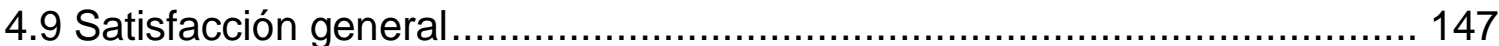

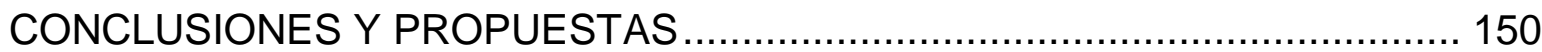

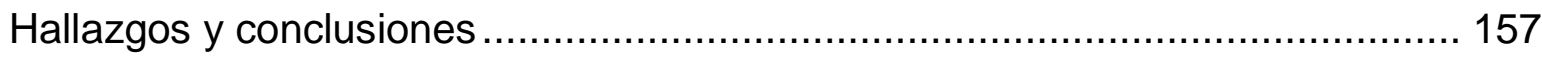

a) Sobre la vivienda anterior y la vivienda actual .................................... 157

b) Percepción del entorno, relaciones vecinales ........................................ 161

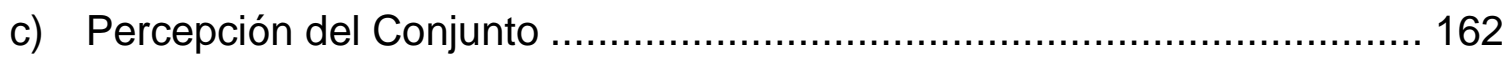

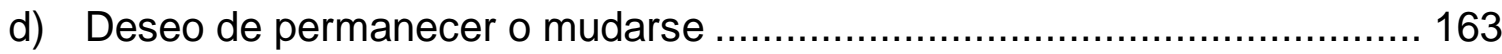

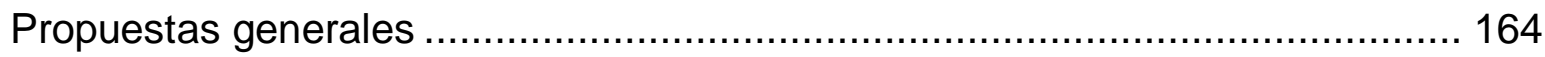

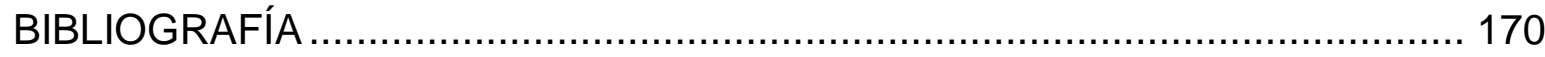

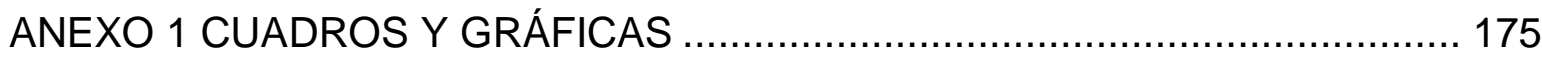

ANEXO 2 INSTRUMENTOS DE INVESTIGACIÓN....................................... 178

ANEXO 2 A FICHA DE OBSERVACIÓN EN TERRENO …......................... 178

ANEXO 2 B ENCUESTA DE SATISFACCIÓN RESIDENCIAL PARA EL CONJUNTO URBANO RANCHO SANTA ELENA $2016 \ldots \ldots \ldots \ldots \ldots \ldots \ldots \ldots \ldots . . . . . . . . . . . . . . . .180$

ANEXO 2 C GUIÓN DE ENTREVISTAS EN PROFUNDIDAD ...................... 187

ANEXO 3 CUADRO RESUMEN DE LAS ENTREVISTAS A PROFUNDIDAD Y

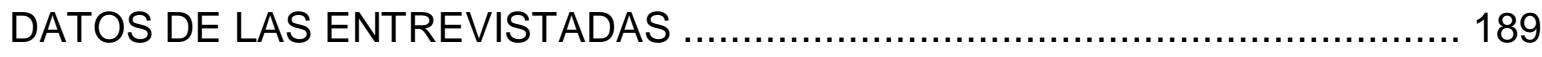


ÍNDICE DE CUADROS, GRÁFICAS, PLANOS, IMÁGENES Y FOTOGRAFÍAS

Cuadro 1. Organismos públicos de fomento a la vivienda, según año de creación.

Cuadro 2. Población total e incremento porcentual, 1990-2010 municipio de Cuautitlán y total municipios conurbados a la ZMCM

Cuadro 3. Porcentajes de la Condición de alfabetismo de la población de 15 años y más según sexo y grupos quinquenales de edad municipio de Cuautitlán, 2010

Cuadro 4. Nivel de escolaridad de la población de 15 años y más, según porcentaje

Cuadro 5. Derechohabiencia a servicios de salud, según sexo e institución de salud

Cuadro 6. Porcentajes de población en hogares censales, según tipo y clase de hogar censal.

Cuadro 7. Población de 12 años y más según condición de actividad económica y sexo

Cuadro 8. Total de viviendas particulares habitadas e incremento porcentual de 1995 a 2010, municipio de Cuautitlán

Cuadro 9. Porcentajes de viviendas particulares según condición de habitación, respecto al total del Estado de México

Cuadro 10. Conjuntos Urbanos ubicados en el municipio de Cuautitlán, según fecha de autorización, número de viviendas, tipo de vivienda y empresa promotora

Cuadro 11. Número de personas según tipo de vivienda que ocupaban y satisfacción con la vivienda.

Cuadro 12. Número de baños y dormitorios, según porcentaje de encuestados.

Cuadro 13. Respuestas a la pregunta ¿En general qué tan satisfecho se siente con su vivienda?, según porcentaje. 
- Gráficas

Gráfica 1. Pirámide de edad del municipio de Cuautitlán, 2010

Gráfica 2. Porcentaje de población según año en que llegó a vivir al Conjunto Urbano Rancho Santa Elena

Gráfica 3. Porcentajes de población según modo de adquisición de la vivienda

Gráfica 4. Porcentajes de población según lugar de procedencia

Gráfica 5. Resultados a la pregunta ¿Considera que su vivienda anterior le permitía llevar una vida de familia satisfactoria?

Gráfica 6. Actividades que son difíciles de realizar en la vivienda según porcentaje

Gráfica 7. Motivo por el que eligió la vivienda

Grafica 8. Respuestas a la pregunta ¿Qué es lo que más les gusta de su vivienda?, según porcentaje.

Gráfica 9. Respuestas a la pregunta ¿Qué es lo que menos le gusta de su vivienda?, según porcentaje.

Gráfica 10. Promedio de evaluación de diferentes aspectos de la vivienda

Gráfica 11. Cambios que desearía realizar a la vivienda según porcentaje

Gráfica 12. Motivos por los que no puede convivir bien con sus vecinos

Gráfica 13. Evaluación de aspectos del Conjunto Urbano

Gráfica 14. Actividades difíciles de realizar

Gráfica 15. Proporción de los ingresos que destinan al pago de la hipoteca o de la renta de la vivienda

Gráfica 16. Aumento de los gastos básicos de la vivienda: agua, luz y transporte

Gráfica 17. Nota general del conjunto 
- Infografías

Infografía 1. Bienes y servicios en la vivienda según porcentajes de tenencia y carencia, Cuautitlán 2010

Infografía 2. Datos sobre la tenencia de la vivienda anterior y tipo de vivienda

Infografía 3. Características de la población y de las viviendas, Conjunto Urbano Santa Elena 2010

- Imágenes y fotografías

Imagen 1. Matriz de sistema habitacional Haramoto

Fotografías 1, 2 y 3 . Modificaciones realizadas a las viviendas.

Fotografía 4. Negocio de vídeo y fotografía

Fotografía 5. Negocios ubicados sobre la Avenida Santa Elena

Fotografía 6. Peletería y gimnasio ubicados en sobre la calle San Valentín

Fotografía 7. Cerrajería ubicada sobre la calle Teyahualco

Fotografías 8 y 9 . Mercado público y locales comerciales

Fotografías 12 y 13 . Calles cerradas de las manzanas 2 y 3.

Fotografías 14, 15, 16 y 17. Rejas colocadas en los frentes de las viviendas

Fotografía 18. Basura ubicada en Avenida Santa Lucía

Fotografía 19. Autos estacionados sobre Avenida San José

Fotografía 20. Desechos de construcción ubicados sobre Avenida Santa Lucía

Fotografía 21. Coladera y parte de banqueta rotas ubicadas en la calle Condominio 52

Fotografías 22 y 23 . Vista de las fachadas de Santa Elena 
Fotografías 24, 25, 26 y 27. Interior y fachadas de las viviendas ubicadas en el Sector de Bajos de Mena, Santiago de Chile.

- Planos

Plano 1. Ubicación de los Conjuntos Urbanos del Municipio de Cuautitlán

Plano 2. Ubicación del Conjunto Urbano Rancho Santa Elena

Plano 3. Usos de suelo Conjunto Urbano Rancho Santa Elena 2016

Plano 4. Restricciones de los accesos y calles del Conjunto Urbano Rancho Santa Elena.

Plano 5. Disponibilidad de rampa para silla de ruedas, Santa Elena, 2016 


\section{INTRODUCCIÓN}

La profundización de los procesos de urbanización mundial, ha sido uno de los temas más relevantes en las últimas décadas debido a la serie de implicaciones políticas, sociales y económicas que conlleva. Aunque se trata de un tema que compete a todas las ciudades en el mundo, la región de América Latina y el Caribe se ha convertido en un caso excepcional debido a su acelerado crecimiento. De acuerdo con datos del Banco Interamericano de Desarrollo, ${ }^{1}$ el porcentaje de urbanización de esta región pasó de $40 \%$ en 1950 a $80 \%$ en el 2010 ; dicho proceso estuvo acompañado de un impresionante crecimiento de la población urbana que durante estas décadas pasó de tener una población de 70 millones, a casi 500 millones de habitantes (BID, 2015).

Estos cambios demográficos se asocian principalmente a dos factores: uno, relacionado con la mejora de las condiciones de la salud pública que propiciaron la disminución de las tasas de mortalidad y el aumento de la esperanza de vida; y dos, los altos niveles de las tasas de fecundidad registrados en la región entre los años cincuenta y sesenta.

El auge poblacional propiciado por las migraciones campo-ciudad afectó de manera importante a ciudades como Lima, Bogotá, Sao Paulo y México -en esta última, la población se incrementó 5 veces-, ya que la rápida expansión de los espacios urbanos comprometía la capacidad de respuesta de los gobiernos locales para satisfacer las necesidades de la nueva población que se encontraba en la búsqueda de mejorar sus condiciones de vida. En el caso de Lima por ejemplo, el crecimiento de 8 veces su área urbana se debió a la creación de nuevos barrios y distritos que permitieron albergar a la población que entre 1940 y 1980 registró un crecimiento de casi 10 veces (ibid).

\footnotetext{
${ }^{1}$ Banco Interamericano de Desarrollo (2015). ¿Cómo fue la evolución urbanística en la Región? [Vídeo] Curso en línea: Desarrollo Urbano y Vivienda, Semana1. Los retos de la urbanización. Disponible en la plataforma EDX en: https://www.edx.org/
} 
La rapidez con la que crecieron las ciudades en las últimas décadas dio como resultado que estos espacios se desarrollaran de manera abrupta $y$ desorganizada, marcadas por el deterioro del entorno y sobre todo, por una profunda desigualdad social. ${ }^{2}$ Bajo este contexto, podemos señalar que el nuevo desafío al que nos enfrenta esta transición, consiste en garantizar la mejora de la calidad de vida de la población, ya que el escenario actual se encuentra marcado por la inequidad y una profunda desigualdad y pobreza social (ibídem).

En estos cambios, la vivienda es un elemento que juega un papel fundamental, no sólo porque constituye la base de los asentamientos humanos, sino porque forma parte de las necesidades básicas de abrigo, seguridad y privacidad, establecidas en la Declaración Universal de los Derechos Humanos (1948). ${ }^{3}$ Se trata de un espacio, que permite la reproducción de diferentes formas de comunicación e integración, indispensables para el desarrollo de las relaciones humanas; en ella se intercambian y reproducen gesticulaciones, elementos culturales, de comportamiento y supervivencia que fortalecen el sentimiento de pertenencia, permiten el dominio del sentido común y la interiorización de nociones prácticas que son útiles en distintos y numerosos ámbitos de la vida cotidiana (Pérez, 1999: 4).

En México, los cambios sociodemográficos experimentados entre 1940 y 1980 estuvieron acompañados de transformaciones importantes en los patrones de urbanización, debido a la expansión de la ciudad y los flujos migratorios provenientes del campo.

\footnotetext{
2 Banco Interamericano de Desarrollo (2015) Consecuencias de urbanizar sin instrumentos [Vídeo] Curso en línea: Desarrollo Urbano y Vivienda, Semana 2. Ordenamiento territorial y planificación urbana. Disponible en la plataforma EDX en: https://www.edx.org/

${ }^{3}$ Documento que enuncia en su artículo 25 que toda persona tiene derecho a un nivel de vida adecuado que le asegure, así como a su familia, la salud y el bienestar, y en especial la alimentación, el vestido, la vivienda, la asistencia médica y los servicios sociales necesarios... (Declaración Universal de los Derechos Humanos. Consultado el: 30 de junio de 2015, página web de Naciones Unidas: http://www.un.org/es/documents/udhr/).
} 
Durante este periodo se inició en la Ciudad de México una etapa de construcción de vivienda masiva, es decir, viviendas nuevas edificadas bajo la modalidad de conjuntos habitacionales, que tenían como principal objetivo dar respuesta a la demanda de vivienda impuesta por el crecimiento poblacional y la expansión de la industria (Amado, 2009: 28); y que paralelamente dio lugar al fuerte crecimiento de urbanización popular con orígenes en asentamientos irregulares que no ha logrado ser detenido por la producción mercantil de vivienda.

A esto se suma la insuficiente oferta de suelo destinado a la vivienda, especialmente para los sectores más pobres de la población, que no pueden cubrir los costos de escrituración y de adquisición de una vivienda bajo los mecanismos de la producción habitacional formal (SEDESOL, 2010: biblio

3). Estos hechos, actualmente forman parte de las preocupaciones de los gobiernos internacionales que buscan encontrar nuevos caminos para alcanzar la sostenibilidad de las ciudades.

Las políticas de vivienda impulsadas por el gobierno de nuestro país, contaron hasta finales de los años ochenta, con la participación directa del Estado en relación al fomento, construcción y financiamiento. Etapa en que los organismos públicos contaban con reservas territoriales, en las que llevaban a cabo la construcción de sus unidades habitacionales.

Sin embargo, la entrada al neoliberalismo representó un reto importante para el aparato administrativo mexicano y sus instituciones, ya que mientras la estrategia económica de sustitución de importaciones requería de un alto grado de intervencionismo estatal para la regularización de la actividad económica, el neoliberalismo obligaba a replantear el papel del Estado, afectando también su participación en la producción de vivienda a nivel nacional. 
Esto dio como resultado que, en los últimos años, el acceso a la vivienda de interés social se haya llevado a cabo con una importante participación del sector inmobiliario privado. Produciendo con ello, una gran cantidad de viviendas en los municipios metropolitanos ${ }^{4}$ en donde las empresas inmobiliarias se han encargado de la adquisición del suelo, la construcción de viviendas, la promoción y los mecanismos de financiamiento, en un contexto en el que el Estado ha fungido como un actor distante en la producción de estos espacios (Esquivel, 2005). Lo que se ha materializado en la edificación de diversos conjuntos habitacionales, proyectados en el territorio sin una adecuada planeación o previsión para la dotación de servicios e infraestructura (Esquivel, 2006).

El Estado de México ha sido uno de los receptores más importantes de la expansión de la ciudad en los últimos años. Muchos de los municipios conurbados a la Ciudad de México han crecido de manera importante gracias a la enorme cantidad de viviendas edificadas en su territorio que fueron impulsadas por una política habitacional que incentivó el desarrollo urbano de determinados municipios mediante la construcción de Conjuntos Urbanos. Éstos modificaron la imagen de los municipios y trajeron consigo grandes problemáticas para las administraciones locales, las que hasta el día de hoy, cuentan con escasa capacidad para incidir en el diseño de dichos proyectos.

Diversos estudios han demostrado que la política habitacional implementada, ha generado importantes problemáticas que no solamente están relacionadas con su contribución al crecimiento urbano, sino que tienen que ver también, con la modificación de los modos de vida de las familias mexiquenses. Algunas de las consecuencias de este tipo de urbanización identificadas hasta el momento son los problemas asociados a la localización, a la accesibilidad, a la inversión de tiempo y dinero para transportarse a la ciudad, a la falta de

\footnotetext{
${ }^{4}$ La participación del sector inmobiliario privado en la producción de vivienda social, también está presente en las ciudades medias del país.
} 
equipamiento, la calidad de los materiales empleados en la fabricación y a las reducidas dimensiones de la vivienda.

En el caso particular del municipio de Cuautitlán resulta sorprendente encontrar conjuntos habitacionales de más de 5 mil viviendas, construidos no hace más de 16 años, que se encuentran en un estado de deterioro físico y social muy importante, lo cual habla de la necesidad de considerar y cuestionar la calidad de los espacios construidos, así como los mecanismos de asignación de las viviendas y la falta de una política integral que tenga en cuenta lo que sucede a nivel de la vida cotidiana una vez que las casas son entregadas a los beneficiarios.

Esto se debe principalmente a que las políticas habitacionales de la región Latinoamericana, se han caracterizado por la ausencia de una visión integral y a largo plazo (BID, 2011). En tanto que el diseño de la vivienda se limita a la consideración de los costos económicos y ganancias, sin tener en cuenta que con ello, se traslada a los futuros usuarios diversas problemáticas relacionadas con la reparación y el mantenimiento de los espacios habitacionales; trayendo como consecuencia que los costos para conservar una vivienda sean cada vez más altos (Hasse y Dunowicz, 2005: 87).

Para esta investigación, se decidió incluir a las mujeres amas de casa como objeto principal de estudio, debido a que se considera que la visión de las mujeres puede ser una herramienta importante a la hora formular propuestas que reconozcan un enfoque distinto en las políticas de vivienda, pero sobre todo, porque la participación de este sector de la población, aporta elementos que permiten adecuar las viviendas a los nuevos papeles que los hombres y mujeres juegan dentro de la sociedad y generar soluciones a los problemas que actualmente presentan los Conjuntos Urbanos.

Como señala Ducci (1994), las mujeres juegan un papel importante en el desarrollo de las sociedades: a nivel demográfico por ejemplo, sabemos que el 
aumento en el nivel educativo de este sector, ha dado lugar a su incorporación en los mercados de trabajo y con ello, a la disminución de la natalidad.

Aunque algunas corrientes de pensamiento sugieren que la desintegración familiar es resultado de esta incorporación a las actividades productivas, diversos estudios han demostrado que las tareas realizadas por las mujeres en el ámbito laboral son trascendentales, especialmente para los sectores populares de la población, donde las mujeres fungen como proveedoras y muchas veces como el único sostén económico del hogar (Ducci, 1994: 75).

Lo anterior ha dado lugar a una serie de transformaciones no sólo de la estructura familiar, sino también de la dinámica dentro de ellas. Debido a que el acceso a recursos económicos ha permitido que las mujeres se desliguen poco a poco de su papel de mujer-esposa-ama de casa, para convertirse en una mujer trabajadora con posibilidades de independizarse no sólo económicamente de sus esposos o parejas, sino también, con la posibilidad de acceder a mayores niveles de educación. Esto a su vez, implica una transformación en la manera en que ellas perciben y viven el espacio urbano; ya que las mujeres que trabajan y que al mismo tiempo se encargan del hogar, tienen necesidades y formas distintas de conducirse en la ciudad (Fernández, 1996).

Incluso aquellas mujeres que se dedican de manera exclusiva a las tareas reproductivas realizadas en casa, desarrollan estrategias y prácticas de habitar específicas para poder acceder a los espacios y servicios que las urbes ofrecen. Por eso, para algunos países europeos, se ha vuelto importante administrar y gestionar las ciudades pensando en quién y cómo se utilizan.

La importancia de incluir la perspectiva de género en la evaluación de políticas y en la planeación de las ciudades, radica precisamente en este papel que las mujeres juegan en el hogar, en la familia, en la realización de tareas 
domésticas, y en otras actividades relacionadas de manera directa con la vida cotidiana de los habitantes.

Cristina Sánchez Mejorada (1996) señala que en los sectores populares, las mujeres desempeñan un rol muy valioso a nivel político, ya que la organización social es una herramienta que en muchas ocasiones les permite mejorar sus condiciones de vida y las de sus familias. Siendo ellas, quienes participan en organizaciones vecinales o políticas que les permiten alcanzar el objetivo de satisfacer las necesidades de consumo y habitabilidad de sus barrios o colonias. Por lo que las condiciones en el ámbito doméstico pueden ser factores que estimulen su participación en organizaciones, para dar solución a los problemas que enfrentan en lo privado.

Es importante tener en cuenta que la vivienda ha adquirido en los últimos años otros significados que van más allá de su función de habitar, debido a que ésta se ha convertido en la inversión más importante y en el patrimonio principal de las familias. No obstante, la rigidez con la que actualmente se construye las viviendas se ha convertido en un impedimento para que este espacio logre adaptarse a los cambios de la sociedad, convirtiéndose en muchas ocasiones en una barrera para la integración, la autonomía e incluso para alcanzar niveles de igualdad entre hombres y mujeres (Ayuntamiento de Fuenlabrada, España, 2007: 18).

Estas razones nos invitan a reflexionar sobre las implicaciones de las intervenciones y soluciones en materia de vivienda planteadas en nuestro país en los últimos años, ya que éstas impactan de manera distinta a la población según el sexo y la edad de los habitantes. Y sobre todo, de la importancia de implementar modalidades de construcción de vivienda que permitan satisfacer las necesidades básicas de las familias y que contribuyan realmente, a mejorar la calidad de vida de la población. 
Para ello, resulta relevante conocer los resultados de la política habitacional en términos cualitativos, es decir, más allá del número de viviendas construidas o de sus características físicas, lo que interesa rescatar son las percepciones que tienen los habitantes sobre su vivienda. De ahí que surjan los siguientes cuestionamientos: ¿Cómo las mujeres que habitan en el Conjunto Urbano Rancho Santa Elena, evalúan sus viviendas, el conjunto habitacional, las relaciones vecinales y su entorno?; ¿Qué papel juega la variable: tiempo de habitar en la vivienda, en el agrado que sienten las mujeres hacia su vivienda y entorno?; y ¿Qué elementos podemos obtener de esta evaluación, para proponer mejoras en la política habitacional actual?

Para dar respuesta a estas interrogantes se parte de la siguiente hipótesis: A mayor tiempo de habitar en Santa Elena, menor es el deseo de permanecer aquí y menor es el grado de satisfacción con el conjunto habitacional, ya que quienes han habitado en este espacio durante un periodo prolongado, han sido testigos de los cambios que ha sufrido el conjunto habitacional y que discrepan con las expectativas que tenían a su llegada.

Esta tesis se enmarca en una reflexión basada en lo que acontece actualmente en el marco de la política habitacional mexicana; esta discusión tiene su base en la problemática actual de lo que se ha llamado los problemas de las familias "con techo", es decir, sin dejar de lado la preocupación sobre el déficit de vivienda, esta tesina pretende analizar los problemas actuales de las familias que han accedido a una vivienda producida bajo estos marcos de reglamentación y que presentan problemáticas asociadas a la pésima calidad de las viviendas producidas y a su localización desfavorable.

El objetivo de este trabajo consiste en evaluar la satisfacción residencial de las mujeres amas de casa que habitan en el Conjunto Urbano Rancho Santa Elena, ubicado en el municipio de Cuautitlán, Estado de México, buscando identificar elementos que contribuyan a mejorar la política habitacional actual. 
El término satisfacción residencial tiene sus orígenes en la llamada psicología ambiental, ${ }^{5}$ disciplina que cuestiona la carencia de sentido humano y social de los espacios urbanos, en especial de las viviendas de localización periférica que empezaron a surgir en los años sesenta y en las que generalmente se omiten los factores sociales y psicológicos que conllevan situaciones como el cambio del ambiente residencial, la ruptura de los vínculos afectivos entre los vecinos, así como las concepciones imaginarias y simbólicas que tienen los habitantes de su lugar de residencia (Hidalgo, 1988).

Aunque la satisfacción residencial forma parte de una concepción mucho más amplia conocida como calidad residencial, ${ }^{6}$ este trabajo se centra únicamente en el análisis de la dimensión cualitativita de dicho concepto: la satisfacción residencial, entendida como el nivel de agrado o desagrado que las personas sienten por el ambiente donde residen, incluyendo la vivienda y su entorno (Haramoto en Arends, 2012: 5).

Esta perspectiva resulta de mayor interés para esta investigación porque lo que se pretende rescatar son las opiniones y valoraciones que los usuarios hacen a su vivienda -que si bien, también parten de una reflexión de aspectos objetivos como son las características de la vivienda y su entorno- incluye otros elementos como la familia y las relaciones vecinales que se desarrollan alrededor del espacio habitable.

Aspecto que se considera, ha sido hasta ahora ignorado por las políticas mexicanas de vivienda y que juega un papel fundamental a la hora de entender los

\footnotetext{
${ }^{5}$ Una rama de la psicología que nace a partir de la necesidad de evaluar las interacciones que las personas establecen con el medio ambiente. Preocupación que surge en la década de los 70's debido a los problemas ambientales derivados de las sociedades industriales (Valdeiglesias y Aguilar, s/f: 5).

${ }^{6}$ De acuerdo con Carolina Pedrotti (2015: 44) la calidad residencial es entendida como el conjunto de características, atributos objetivos de un espacio residencial (no sólo de la vivienda) posibles de estimar, cualificar, calificar de manera interrelacionada (esto es al interior del espacio, entre sus componentes, y además del propio espacio con el área urbana).
} 
problemas que presentan los espacios habitacionales de gran magnitud, como son los Ilamados Conjuntos Urbanos localizados en la periferia de la Ciudad de México.

Pese a que el principal objetivo de esta investigación se centra en el estudio del aspecto subjetivo de la calidad residencial, sí se brinda una visión general de los acontecimientos más relevantes relacionados con los cambios en las políticas habitacionales y económicas que influyeron en estas trasformaciones.

Para el estudio de la satisfacción residencial es necesario tomar en cuenta tres niveles que vinculan al habitante con su hábitat: la vivienda, los vecinos y el conjunto habitacional; ya que el nivel de agrado experimentado hacia la vivienda y su entorno, se relaciona de manera estrecha con las características del espacio habitable, las características personales y de la comunidad en las que se insertan.

Para logar captar información relacionada con los tres elementos mencionados, esta investigación se llevó a cabo mediante técnicas de investigación cualitativa y cuantitativa.

En un primer momento se realizaron visitas de campo para reconocer el lugar e identificar mediante observación, las características del espacio en el que se realizaría la investigación. Posteriormente se procedió a registrar los hallazgos en una ficha de observación del terreno en la que se describen las condiciones y características físico-espaciales del Conjunto Urbano Rancho Santa Elena, tales como localización en el municipio, tamaño del conjunto (número de viviendas), estructura vial predominante, tipo de equipamiento dentro del conjunto (comunitario, áreas verdes, educacional, de esparcimiento, comercio), estado de conservación del equipamiento, proximidad a centros de equipamiento, accesos (cercanos a los servicios de transporte) y cambios realizados al conjunto habitacional. 
En un segundo momento se recurrió al análisis de los principales resultados del Censo de Población y Vivienda 2010 a nivel municipal y AGEB urbana, que ofrecen un panorama general de las características de la población y sus viviendas. Estos datos, permiten conocer la distribución de la población según sexo, edad, características educativas, promedio de habitantes por vivienda y acceso a servicios de salud. Información que es muy valiosa, dado que las características sociodemográficas de la población influyen en las necesidades y demandas que requieren ser atendidas.

Así mismo, se analizaron datos relacionados con el número de viviendas, el acceso a servicios de agua potable, drenaje y electricidad. Finalmente se procedió a la aplicación de la Encuesta de Satisfacción Residencial para el Conjunto Urbano Rancho Santa Elena 2016. Se trata de un cuestionario compuesto por 42 preguntas estructuradas en 8 secciones en las que se evalúan los siguientes aspectos:

Sección 1: situación habitacional anterior

Sección 2: características de la vivienda actual

Sección 3: evaluación de la satisfacción con la vivienda

Sección 4: relaciones vecinales.

Sección 5: percepción del Conjunto Urbano.

Sección 6: evaluación de la satisfacción con el Conjunto Urbano.

Sección 7: gastos en la vivienda

Sección 8: administración y organización de los bienes comunales.

La encuesta contempla dos tipos de escala de evaluación: una de tipo conceptual donde las respuestas refieren a una escala de 1 a 3 : donde 1 es lo más negativo y 3 lo más positivo; y otra de carácter numérico, en esta se pide al entrevistado que califique una situación en una escala de 1 a 6 clasificada de la siguiente manera: 1) Muy malo, 2) Malo, 3) Cumple mínimamente, 4) Más que suficiente, 5) Bueno y 6) Excelente (Haramoto, 2002: 26). 
Para llevar a cabo estas tareas, se decidió retomar la metodología propuesta por el Instituto de la Vivienda (INVI) de Santiago de Chile (2002); que fue utilizada, en el análisis de la satisfacción residencial de los usuarios del Programa de Viviendas Básicas de ese país. Aunque se trata de dos soluciones habitacionales distintas, los instrumentos elaborados por el INVI comprenden una guía para la observación del conjunto habitacional y una encuesta diseñada para medir distintos aspectos de la satisfacción residencial (consultar anexo) que pueden ser utilizados sin mayor complicación para el análisis de la satisfacción residencial en los Conjuntos Urbanos mexicanos.

Se decidió retomar esta metodología, debido a que permite el análisis de las tres dimensiones que de acuerdo con autores como Amérigo y Haramoto son esenciales para entender y analizar el grado de satisfacción de los habitantes de determinado espacio: la familia y la vivienda; el entorno cercano a la vivienda y el conjunto habitacional.

Los instrumentos elaborados por el equipo de investigación chileno, se basan en la amplia experiencia que tiene este país en el estudio de la satisfacción residencial y han sido utilizados en diversas ocasiones como la fuente primaria de variadas investigaciones. De acuerdo con el Doctor Luis Iturra, investigador del INVI Chile, ${ }^{7}$ los primeros trabajos desarrollados en torno al concepto de satisfacción residencial en ese país, nacieron debido a la preocupación de los académicos y autoridades por la calidad de las viviendas construidas, así como por la influencia de las corrientes europeas relacionadas con la llamada psicología ambiental que durante la década de los sesenta, mostraron interés en evaluar las nuevas formas de construcción de la época. Estas corrientes, buscaban rescatar el lado subjetivo del problema de la vivienda, yendo más allá del análisis del número de viviendas o de las carencias y características físicas del espacio residencial.

${ }^{7}$ Entrevista realizada al Doctor Luis Iturra, investigador del Instituto de la Vivienda, Chile el 2 de junio de 2016. 
La ficha de observación del terreno, permite hacer una valoración más objetiva de las condiciones y características del Conjunto Urbano, ya que no depende de las percepciones de los usuarios, sino que parte del análisis que realiza el propio investigador, basado en una serie de conocimientos que le permiten ofrecer una visión libre de opiniones y sentimientos.

Lo anterior resulta de vital importancia a la hora de realizar estudios de satisfacción residencial, porque si bien, en este tipo de trabajos se da prioridad a las percepciones y opiniones de los usuarios, se tiene claro que para que una investigación cuente con un grado aceptable de credibilidad, se deben aportar una serie de elementos objetivos que permitan comparar y equilibrar la información cualitativa que se obtiene de las perspectivas de los usuarios de la vivienda, con los datos objetivos que resultan de un análisis cuantitativo.

Este trabajo se encuentra dividido en 5 capítulos que dan cuenta de los resultados de esta investigación y del trabajo de campo llevado a cabo entre los meses de enero y septiembre de 2016. En el primer capítulo denominado VIVIENDA: UNA PERSPECTIVA GENERAL se presenta un panorama general sobre los cambios acontecidos alrededor del tema de la vivienda en México, se explica cuáles fueron los procesos más significativos y qué es lo que dio lugar a la aparición de un nuevo modelo de construcción de vivienda en el Estado de México.

En el segundo capítulo EL ESTUDIO DE LA VIVIENDA que constituye el marco teórico de la investigación, se proporciona una explicación de lo que se entiende por satisfacción residencial y cuáles son los elementos indispensables para su análisis.

El tercer apartado de este trabajo denominado: EL MUNICIPIO DE CUAUTILTLÁN Y EL CONJUNTO URBANO RANCHO SANTA ELENA, se encuentra dividido en dos secciones: en la primera, se expone una breve 
descripción sobre el municipio en el que se llevó acabo esta investigación, enfatizando los cambios acontecidos en materia de desarrollo urbano en los últimos años. Los datos históricos descritos en este capítulo se complementan con un análisis sociodemográfico que permite conocer el estado actual del municipio.

En la segunda sección, se realiza una descripción de las características físico-espaciales del Conjunto Urbano Rancho Santa Elena que fueron registradas en la ficha de observación del terreno; apoyada de un conjunto de fotografías que fueron tomadas como parte del trabajo de observación realizado. Además, se exponen los resultados de los análisis de datos a nivel AGEB $^{8}$ urbana, que proporcionan una visión objetiva de la población que reside en el lugar y sobre las características de sus viviendas.

En el capítulo 4 VIVIENDA Y SATISFACCIÓN RESIDENCIAL, LA MIRADA DE QUIENES HABITAN EN EL CONJUNTO URBANO RANCHO SANTA ELENA, se exponen los principales hallazgos de esta investigación, es decir, los resultados de la Encuesta de Satisfacción Residencial y de las entrevistas a profundidad.

Este capítulo da cuenta de los resultados obtenidos a partir de la Encuesta de Satisfacción Residencial y de las entrevistas en profundidad y se divide en 5 apartados: 1) Datos generales de la población encuestada; 2) Situación de la vivienda anterior; 3) Vivienda actual y satisfacción con la vivienda; 4) Evaluación del entorno inmediato a la vivienda; y 5) Satisfacción residencial.

A través de estas secciones, se da respuesta a las preguntas de investigación planteadas con anterioridad, permitiendo conocer el grado de satisfacción con la vivienda de las mujeres amas de casa que residen en el

${ }^{8}$ De acuerdo con INEGI, el Área Geoestadística Básica Urbana o AGEB es aquella extensión territorial, ocupada por un conjunto de manzanas que, generalmente son de 1 a 50, delimitadas por calles, avenidas, andadores o cualquier otro rasgo fácil de identificar en el terreno y cuyo uso de suelo sea principalmente habitacional, industrial, de servicios y comercial, sólo se asignan al interior de localidades urbanas (INEGI, 2010: 2). 
Mujer y satisfacción residencial. La mirada de quienes habitan en el Conjunto Urbano Rancho Santa Elena. Cuautitlán, Estado de México.

Conjunto Urbano Rancho Santa Elena, así como el conjunto de elementos que influyen en la conformación de las perspectivas y opiniones de las encuestadas.

Finalmente, en el capítulo 5 CONCLUSIONES Y PROPUESTAS, se exponen las conclusiones de esta investigación y se realizan una serie de recomendaciones (basadas en las respuestas de la población encuestada) que se considera pueden contribuir a mejorar la política mexicana de vivienda actual. 


\section{CAPÍTULO 1. VIVIENDA: UNA PERSPECTIVA GENERAL}

La vivienda ha sido considerada a lo largo de la historia como uno de los elementos más significativos en la vida del hombre, pues se trata de un espacio que responde a nuestra instintiva necesidad de protección y abrigo; y que influye de manera decisiva en aspectos como la salud, la alimentación, la economía, la educación y el grado de vulnerabilidad social de la población (BID, 2012).

A nivel social, se le confiere la importancia de ser un bien imprescindible para el desarrollo de las funciones familiares y un espacio integrador de diversas funciones sociales (Gazmuri, 2013: 41). Sus características se definen a partir de las condiciones climáticas, su ubicación geográfica, las técnicas disponibles para su construcción, los valores sociales, los estilos de vida, entre otros elementos que reflejan las condiciones económicas, políticas y culturales de cada sociedad (s/a, 51).

Aunque los primeros registros de construcciones utilizadas para este fin datan de hace más de cien mil años, no fue hasta la Revolución Industrial en que las ciudades comenzaron a crecer a gran velocidad; el desarrollo masivo de la industria, los avances tecnológicos, la aparición de novedosos medios de transporte, entre otros cambios políticos y sociales influyeron de forma sustancial en aspectos como la arquitectura, las artes, la construcción y en todas las manifestaciones culturales de la vida contemporánea (Dimatre, 1998).

Propiciando con ello, cambios sustanciales en la forma de concebirla y generando nuevos problemas asociados a la capacidad de la población para acceder a ella, las políticas de vivienda implementadas por los Estados y la calidad de su estructura física.

El propósito de este capítulo es proporcionar un panorama general de la vivienda en México y en el mundo, para así poder entender cómo es que llegamos 
a la problemática actual y la importancia de analizar aspectos cualitativos relacionados como la satisfacción residencial que experimentan los individuos respecto a su ambiente residencial.

\subsection{La vivienda como derecho}

Actualmente la vivienda es considerada un elemento fundamental del desarrollo urbano no sólo porque constituye la base de los asentamientos humanos, sino porque forma parte de las necesidades básicas de abrigo, seguridad y privacidad establecidas en la Declaración Universal de los Derechos Humanos (1948). ${ }^{9}$

El derecho a una vivienda adecuada ${ }^{10}$ se halla enumerado en distintas convenciones internacionales, como la recomendación 115 de la Organización Internacional del Trabajo, la Convención sobre los Derechos del Niño (artículo 27) y las Conferencias Hábitat I y II. ${ }^{11}$ En los que se señala la importancia de interpretar este derecho más allá de la posibilidad de disponer de un techo y cuatro paredes; dado que la vivienda es un espacio que permite la reproducción de diferentes formas de comunicación e integración indispensables para el desarrollo de las relaciones humanas. $Y$ es en este espacio donde se intercambian y reproducen gesticulaciones, elementos culturales, de comportamiento y supervivencia que fortalecen el sentimiento de pertenencia, permiten el dominio

${ }^{9}$ Documento que enuncia en su artículo 25 que toda persona tiene derecho a un nivel de vida adecuado que le asegure, así como a su familia, la salud y el bienestar, y en especial la alimentación, el vestido, la vivienda, la asistencia médica y los servicios sociales necesarios... (Declaración Universal de los Derechos Humanos. Consultado el: 30 de junio de 2015, página web de Naciones Unidas: http://www.un.org/es/documents/udhr/).

${ }^{10}$ De acuerdo con las Naciones Unidas, el derecho a una vivienda adecuada abarca las siguientes libertades: la protección contra el desalojo forzoso y la destrucción y demolición arbitrarias del hogar; el derecho de ser libre de injerencias arbitrarias en el hogar, la privacidad y la familia; el derecho de elegir la residencia y determinar dónde vivir; y el derecho a la libertad de circulación. (Naciones Unidas, 2010).

11 Derecho a la vivienda. La guía de Derecho. Consultado el: 4 de julio de 2015. Disponible en: http://derecho.laguia2000.com/parte-general/derecho-a-la-vivienda\#ixzz3f1s5varH. 
del sentido común y la interiorización de nociones prácticas que son útiles en distintos y numerosos ámbitos de la vida cotidiana (Pérez, 1999: 4).

Pese a su importancia, se tiene conocimiento de que poco más de 1, 000 millones de personas en el mundo habitan en condiciones de hacinamiento, en tugurios improvisados y bajo circunstancias peligrosas e inadecuadas que ponen en riesgo la salud y la vida de las personas. Por lo que este tema se ha posicionado como una de las preocupaciones internacionales más relevantes de las últimas décadas, particularmente, para los distintos Estados alrededor del mundo, que han asumido la obligación de asegurar una vivienda y condiciones adecuadas para su población (Naciones Unidas, 2010: 1).

Lo anterior motivó a que la Asamblea General de Naciones Unidas convocara durante el año 2011 a una tercera Conferencia de Vivienda y Desarrollo Urbano Sostenible, denominada Hábitat III, con la que se pretende renovar el compromiso de las naciones sobre la urbanización sustentable, mediante el establecimiento de una Nueva Agenda Urbana que concuerde con los objetivos del desarrollo. Dado que Naciones Unidas ha manifestado desde siempre un interés y preocupación por la calidad de los asentamientos humanos, se han realizado en los últimos meses de 2015 una serie de foros y conferencias, en distintos países del mundo (entre los que se encuentran México y Chile) con los que se busca recoger propuestas y experiencias, determinar los logros alcanzados, abordar los problemas urbanos emergentes, así como buscar soluciones a las preocupaciones actuales, en torno a temas relevantes como las políticas de vivienda, el desarrollo urbano y la sostenibilidad ambiental, considerando el entorno global en el que se insertan las ciudades. ${ }^{12}$

\footnotetext{
12 Ministerio de Vivienda y Urbanismo, Santiago de Chile. ¿Qué es hábitat III? Disponible en:
} http://www.habitat3.cl/que-es-habitat-3/ (Consultado el 12 de noviembre de 2015) 


\subsection{El crecimiento urbano y la demanda de vivienda}

La expansión de las ciudades y el crecimiento de la población urbana, han sido sin duda los mayores problemas sociales y económicos a los que se han enfrentado los gobiernos de los países latinoamericanos en los últimos años (Hasse y Dunowicz, 2005: 87); dicho crecimiento ha significado un aumento del déficit habitacional y ha traído consigo nuevos retos para la gestión de los espacios urbanos, relacionados con la calidad de los espacios habitacionales, la movilidad y el transporte, la seguridad, los espacios públicos, entre otros temas que han ocupado un espacio importante en las agendas gubernamentales alrededor del mundo, en donde encontrar nuevos caminos hacia la sustentabilidad ${ }^{13}$ de las urbes es el principal objetivo.

Lo anterior, se debe a que se espera una profundización del proceso de urbanización para las próximas décadas; de acuerdo con datos de las Naciones Unidas (en BID: 2011) el promedio mundial de urbanización de las ciudades para 2050 ascenderá a 69\%, siendo América Latina y el Caribe (ALC) la región que registre los mayores porcentajes de urbanización (89\%).

De acuerdo con el Banco Interamericano de Desarrollo (2011), la población urbana que habita en esta región se ha duplicado en las últimas décadas, pasando de $41 \%$ en 1950 a $80 \%$ en 2010 ; lo preocupante en este asunto, es que el crecimiento de la población urbana no ha significado necesariamente una mejora en las condiciones de vida para sus habitantes; de manera contraria, la rápida urbanización ha acarreado importantes déficits de infraestructura urbana, siendo el rubro de la vivienda uno de los más afectados por dicho crecimiento. Sobre todo,

\footnotetext{
${ }^{13}$ De acuerdo con el Banco Interamericano de Desarrollo, una ciudad sostenible es aquella que garantiza la calidad de vida los ciudadanos presentes sin afectar la de los futuros habitantes y que es capaz de equilibrar las metas económicas, ambientales y sociales entre las generaciones presentes y futuras. BID (2011), Sostenibilidad Urbana en América Latina y el Caribe, páginas 10 y 11. Recuperado el: 06 de noviembre de 2015. https://publications.iadb.org/handle/11319/2784?locale-attribute=es
} 
porque el crecimiento de las zonas urbanas de los países latinoamericanos ha venido acompañado por un paulatino proceso de abandono por parte del Estado de la política habitacional, propiciando que el sector inmobiliario participe de manera incontrolada en la producción de vivienda. Situación que se ha materializado en la edificación de diversos conjuntos habitacionales que se proyectan en el territorio sin una adecuada planeación o previsión para la dotación de servicios e infraestructura (Esquivel: 2006).

\subsection{El problema de la vivienda}

La concepción tradicional de lo que conocemos como el problema de vivienda, se centra en la descripción de las necesidades cuantitativas de vivienda de un país o región; y aunque esta visión fue la guía de las políticas de vivienda de los países latinoamericanos durante varias décadas, hoy se reconoce que el problema va mucho más allá de la necesidad de reducir el déficit habitacional.

De acuerdo con Naciones Unidas (2012), actualmente son tres elementos los que definen la situación de la vivienda:

1. La cantidad de viviendas existentes (o lo que se conoce como stock habitacional).

2. La cantidad que hace falta en función del número de hogares (déficit cuantitativo)

3. El número de viviendas que incumplen los estándares mínimos de habitabilidad que permiten una calidad de vida digna y adecuada (déficit cualitativo).

En otras palabras, el problema de vivienda refiere a la incapacidad económica de la población para tener acceso a una vivienda y al número de personas que residen en viviendas inadecuadas con pésimas condiciones de 
habitabilidad. René Coulomb señala que la habitabilidad de una vivienda está en función de la calidad de los materiales utilizados en su construcción, de la superficie habitable, de la disponibilidad de los servicios, pero también, se relaciona con la proximidad o lejanía con el empleo, los equipamientos (educativos, de salud, recreativos), así como de la calidad de los espacios abiertos y la convivencia. De ahí que el derecho a la vivienda aparezca más como el derecho a la ciudad y que la política habitacional tenga la tarea de aprender a hacer ciudad, es decir, vivienda en ciudades donde la gente viva, trabaje, estudie y se divierta en un mismo espacio. ${ }^{14}$

Aunque hasta ahora se ha hecho un esfuerzo importante para tratar de reducir el déficit habitacional de los países latinoamericanos, la escasez de vivienda seguirá siendo uno de los mayores desafíos a los que se enfrente la región; además, del importante reto que implica atender las graves deficiencias que impiden garantizar un hábitat adecuado -o condiciones de habitabilidad- para toda la población. Evaluar las carencias habitacionales resulta aún más complicado que estimar las carencias cuantitativas, puesto que se trata de un fenómeno complejo y multicausal. Si bien en muchos países se ha mejorado el sistema de recopilación de datos y se han unificado algunos criterios, el tipo de información recabada todavía está lejos de permitir un análisis comparado y aceptado del fenómeno (ONU-Hábitat, 2012: 63).

Las mediciones y estudios realizados hasta el momento, se centran en aspectos cuya cuantificación es más sencilla; lo que deja fuera a criterios de carácter subjetivo como la privacidad, la habitabilidad, el diseño de la vivienda y otros temas relacionados con el entorno que son determinantes para la calidad de vida (ONU-Hábitat, 2012: 62).

\footnotetext{
14 Véase. La vivienda en México: construyendo análisis y propuestas, Primera edición: octubre de 2006, Centro de Estudios Sociales y de Opinión Pública Cámara de Diputados / LIX Legislatura. Páginas 15-22.
} 


\subsection{La vivienda en México}

En México los cambios sociodemográficos experimentados entre 1940 y 1980 estuvieron acompañados de transformaciones importantes en los patrones de urbanización, debido a los procesos relacionados con la expansión de la ciudad y los flujos migratorios provenientes del campo. ${ }^{15}$ Durante este periodo, se inició en la Ciudad de México una etapa de construcción de vivienda masiva; que se trataba de viviendas nuevas edificadas bajo la modalidad de conjuntos habitacionales y que tenían como principal objetivo dar respuesta a la demanda de vivienda impuesta por el crecimiento poblacional (Amado, 2009: 28).

La Unidad Habitacional Miguel Alemán construida en 1947, se convirtió en el primer multifamiliar de América Latina destinado para las familias de los trabajadores del Estado. El conjunto habitacional diseñado por el arquitecto Mario Pani (influenciado por las ideas de Le Corbusier), se convirtió en el principal referente de la época para la construcción otros desarrollos como el Conjunto Habitacional Nonoalco Tlatelolco y el Multifamiliar Juárez, así como para otros conjuntos edificados a lo largo del continente ciudad. De ahí en adelante, los conjuntos habitacionales construidos se ubicarían en lo que en ese entonces se consideraba la periferia urbana del Distrito Federal, es decir, en el sur y oriente de la ciudad (Connolly en Amado 2009: 28).

Para mediados de los años cuarenta, el suelo de la reserva federal ubicado en las orillas de la ciudad comenzó a ser insuficiente, razón por la que se desplazó la construcción de conjuntos habitacionales hacia el norte de la ciudad, es decir, hacia los municipios conurbanos y cerca de las principales vías de comunicación que conectaban a estos municipios con la ciudad (Connolly en Amado 2009: 28), incentivados a su vez, por las políticas de industrialización (como la Ley de

\footnotetext{
${ }^{15}$ La población migrante se asentó principalmente en los suelos de menor costo, provocando que estos nuevos centros de población se vieran envueltos en serios problemas de conectividad, accesibilidad, suministro de servicios y equipamiento urbano.
} 
Protección a las Industrias Nuevas y Necesarias de 1944) implementadas por el Gobierno del Estado de México y los gobiernos municipales, que favorecieron la creación de una estructura industrial diversificada e incrementaron la demanda de vivienda de estos espacios.

A nivel nacional, las primeras intervenciones estatales para garantizar el derecho a la vivienda estuvieron orientadas a favorecer a la clase trabajadora; en 1865 se establecieron por primera vez normas relacionadas con lo que posteriormente conoceríamos como el derecho a la vivienda, antecedente que se puede encontrar en el reglamento del decreto que concedía facilidades a la inmigración extranjera y en el que se establecía la obligación de los patrones de proporcionar alojamiento a los trabajadores (Amado, 2009).

Después de haber sido plasmado en la Ley Federal de Trabajo en 1931, el derecho a la vivienda fue incluido en la Constitución en 1936 y se estableció como garantía individual hasta 1986 (Amado, 2009).

Al entrar en la etapa urbanización y del desarrollo industrial, el Estado asumió como tarea primordial en materia de vivienda, la construcción de infraestructura de seguridad social que permitiera atender la creciente demanda de vivienda:

Después de la segunda guerra mundial se produjo un cambio en la composición y distribución del país, en 4 décadas su fisionomía cambió debido entre otras cosas a la industrialización, el proceso de sustitución de importaciones el desarrollo estabilizador y el robustecimiento del estado que fueron las causas más significativas del desarrollo nacional hasta la época de 1970, periodo en que se produjo una importante urbanización acelerada y una explosión demográfica, trayendo como consecuencia el incremento de la demanda de la vivienda, la acumulación del déficit habitacional, la proliferación de asentamientos 
irregulares en los principales centros urbanos del país... (Del Rivero y

Romero; 2010: 19).

Cuadro 1. Organismos públicos de fomento a la vivienda, según año de creación.

\begin{tabular}{|c|c|}
\hline Institución & Año \\
\hline Banco Nacional Hipotecario Urbano y de Obras Públicas & 1933 \\
\hline Instituto Mexicano del Seguro Social (IMSS) & 1943 \\
\hline Banco Nacional de Obras y Servicios Públicos, S.N.C. (BANOBRAS) & 1946 \\
\hline Fondo para el Fomento de la Habitación Popular & 1946 \\
\hline Fondo de Habitaciones Populares & 1949 \\
\hline Instituto Nacional para el Desarrollo de la Comunidad y de la Vivienda (INDECO) & 1954 \\
\hline Primero programas de vivienda para trabajadores de Petróleos Mexicanos (PEMEX) & 1958 \\
\hline Instituto de Seguridad y Servicios Sociales de los Trabajadores del Estado (ISSSTE) & 1960 \\
\hline Fondo de Operación y Financiamiento Bancario a la Vivienda (FOVI) & 1963 \\
\hline Banco de México & 1963 \\
\hline Instituto del Fondo Nacional de la Vivienda para los Trabajadores (INFONAVIT) & 1972 \\
\hline $\begin{array}{l}\text { Fondo de la Vivienda del Instituto de Seguridad y Servicios Sociales de los Trabajadores } \\
\text { del Estado (FOVISSSTE) }\end{array}$ & 1974 \\
\hline Fideicomiso del Fondo Nacional de Habitantes Populares (FONHAPO) & 1981 \\
\hline Fondo Nacional de la Vivienda Rural (FONAVIR) & 1987 \\
\hline FOVI se convierte en la Sociedad Hipotecaria Federal, Sociedad Nacional de Crédito & 2001 \\
\hline
\end{tabular}

Elaboración propia con base en Sánchez 2012.

Hasta finales de los años ochenta, el eje de la política de vivienda contó con la participación directa del Estado en relación al fomento, construcción y financiamiento de vivienda. Etapa en que los organismos públicos contaban con reservas territoriales, en las que llevaban a cabo la construcción de sus unidades habitacionales.

Sin embargo, la década de los años 90 dio inicio con dos hechos importantes que contribuyeron a la transformación de los Estados latinoamericanos. Por un lado, las ideas impulsadas por el neoliberalismo 
responsabilizaban al Estado y a su rol protagónico de las crisis económicas de las que fueron objeto estos países. Aunado esto, el fin de las dictaduras llevó a que se expandiera la idea de reformar al Estado para convertirlo en un instrumento eficaz y eficiente que permitiera el tránsito a la democracia (Fleury, 2003).

Las discusiones en la academia giraban en torno a la idea de que los Estados estaban en crisis y que era necesaria una reforma que redujera su tamaño, que lo tornara más ágil, flexible, eficiente y responsable con la sociedad, pero, ¿cómo lograrlo? La respuesta a esta pregunta llegó desde dos distintos enfoques: los neoliberales defendían la reducción del Estado al mínimo para abrir paso al mercado; los socialistas por su parte, defendían la idea de un Estado fuerte que asegurara los derechos sociales que el mercado no era capaz de garantizar (Fleury, 2003: 2).

La propuesta más importante desde el punto de vista neoliberal, provino de organismos internacionales como el Fondo Monetario Internacional y el Banco Mundial, quienes formularon una serie de propuestas conocidas bajo el nombre de Consenso de Washington; mismas que pretendían ser una especie de fórmula para los países latinoamericanos que como México, enfrentaban fuertes crisis económicas.

Este Consenso, preconizaba entre otras cosas el libre mercado acompañado de una mínima intervención estatal. De acuerdo con estas medidas, una vez superados los desequilibrios fiscales se lograría reducir la pobreza, la desigualdad y los rezagos sociales en América Latina, beneficiando a los sectores sociales más desprotegidos.

No obstante, los resultados de este intento de receta pronto se hicieron notar, por lo que empezó a reconocerse que el Estado era necesario, pues la regulación pública y las políticas dirigidas por él, ofrecían contribuciones que no podrían provenir del mercado. 
En este sentido, la realidad demostró que las propuestas neoliberales no contribuyeron a reducir la pobreza y la desigualdad de los países latinoamericanos, al contrario de lo que se esperaba, actualmente nos encontramos con evidentes rezagos sociales y económicos que cada vez son más profundos.

En nuestro país, la entrada del neoliberalismo coincidió con el fin del modelo económico de sustitución de importaciones que empezaba a mostrarse ineficaz ante la nueva realidad global. Los embates de dicha política se hicieron evidentes: la expansión económica perdió impulso y las dificultades para sustituir importaciones fueron cada vez más frecuentes. Situación que nos llevó a ser cada vez más dependientes de los ingresos provenientes de la exportación del petróleo. ${ }^{16}$

La crisis financiera de 1982 obligó a implementar una serie de reformas económicas que posicionaron al sector privado y al mercado, como los principales agentes en la inversión para industrialización.

Bajo este contexto podemos decir, que la entrada del neoliberalismo representó un reto importante para el aparato administrativo mexicano y sus instituciones. Mientras que la estrategia económica de sustitución de importaciones, requería de un alto grado de intervencionismo estatal para la regularización de la actividad económica; el neoliberalismo obligaba a replantar el papel del Estado mexicano que además, se enfrentaba ante diversos dilemas relacionados con la expansión de la industria y el crecimiento de las ciudades, que como ya se señalaba, desde los años cuarenta atravesaban una serie de procesos

16 Véase. El desarrollo económico y la migración en México. Disponible en: http://www.juridicas.unam.mx/publica/librev/rev/derhum/cont/33/pr/pr32.pdf (Consultado el: 12 de julio de 2015) 
relacionados con la expansión de la ciudad y los flujos migratorios provenientes del campo. ${ }^{17}$

Para poner un ejemplo, encontramos que durante ese periodo algunos municipios del Estado de México (como Cuautitlán Izcalli, Cuautitlán, Ecatepec, Naucalpan, Coacalco, etc.) experimentaron una serie de trasformaciones derivadas principalmente de la instalación de nuevas industrias en su territorio.

Durante este periodo los financiamientos otorgados a nuestro país por parte del Fondo Monetario Internacional (FMI) estuvieron condicionados a las ideas neoliberales, que requerían fomentar la rentabilidad de las inversiones en materia de vivienda. Las reglas impuestas por los organismos internacionales obligaron al Estado a abandonar su papel interventor en la producción, financiamiento y mantenimiento de las viviendas para crear las condiciones que mejoraran la eficacia del mercado (Esquivel, 2006: 86).

Algunos autores consideran que las primeras transformaciones en la política habitacional se pueden ubicar en el gobierno de Carlos Salinas de Gortari; pues durante su mandato, se impulsó el Programa para el Fomento y Desregulación de la Vivienda (1992) que básicamente consistió en acatar los lineamientos del FMI en los que se establecía la necesidad de disminuir el papel regulador del Estado en las actividades habitacionales (Bolis, en Esquivel, 2006: 86).

También se llevaron a cabo modificaciones en materia de vivienda y desarrollo urbano que tuvieron importantes consecuencias: tales como las reformas a leyes relacionadas con el suelo de origen social que permitieron a ejidatarios y comuneros la negociación de sus terrenos de manera privada; facilitando así, la incorporación de suelo rural al suelo urbano donde generalmente

\footnotetext{
${ }^{17}$ La población migrante se asentó principalmente en los suelos de menor costo, provocando que estos nuevos centros de población se vieran envueltos en serios problemas de conectividad, accesibilidad, suministro de servicios y equipamiento urbano.
} 
suelen desarrollarse los conjuntos habitacionales e Intensificando la participación del sector inmobiliario en la producción de un tipo de vivienda estándar, caracterizada por la mala calidad de sus materiales, diseño y tamaño que ha impactado de manera importante en el diseño arquitectónico y urbano de los conjuntos (Maya; 2001: 8).

A lo anterior se sumaron las diversas políticas nacionales y locales (entre ellas el Bando 2) que facilitaron a las empresas constructoras de viviendas el acceso a terrenos de bajo costo. Situación que, aunada a los factores ya señalados, han contribuido a transformar las condiciones del mercado habitacional de la Zona Metropolitana de la Ciudad de México.

De tal forma que en los últimos años el acceso a la vivienda de interés social se ha llevado a cabo con una importante participación del sector inmobiliario privado. Se han producido una gran cantidad de viviendas en los municipios metropolitanos, en donde las empresas inmobiliarias se han encargado de la adquisición del suelo, la construcción de viviendas, la promoción y los mecanismos de financiamiento, en un contexto en el que el Estado ha fungido como un actor distante en la producción de estos espacios ${ }^{18}$ (Esquivel, 2005).

Así, las empresas inmobiliarias fueron supliendo al Estado en su papel de promotor de vivienda de interés social, convirtiéndolo poco a poco en un instrumento que facilita y deja en manos de los organismos privados, la

${ }^{18}$ En los años 80, gracias a la crisis del Fordismo, surge el mercado como mecanismo principal de producción de las ciudades Latinoamericanas. De acuerdo con Pedro Abramo, esta crisis se va a manifestar en la tendencia a la flexibilización urbana y la caída del financiamiento estatal en materia de vivienda. En este contexto, el mercado inmobiliario se fue convirtiendo en el actor fundamental de la promoción y producción habitacional; en una fuerza determinante del proceso de coordinación social del uso del suelo y la producción de la estructura urbana de las grandes urbes en Latinoamérica. Según este autor, las ciudades latinoamericanas se caracterizan por su estructura "com-fusa" propiciada por la existencia de un mercado formal e informal que se yuxtaponen en la producción de la estructura urbana y que promueven un doble movimiento de compactación y difusión del uso del suelo. Véase, Abramo Pedro (2002) (2012) "La ciudad comfusa, mercado y producción de la estructura urbana en las grandes metrópolis latinoamericanas", en Eure, Vol. XXXVIII, núm. 111, pp. 35-69. 
producción habitacional. Acarreando importantes consecuencias sociales y económicas para sus habitantes.

Podemos decir que la política de vivienda mexicana actual es exitosa en términos cuantitativos ya que la construcción de conjuntos habitacionales localizados en la periferia de la ciudad ha permitido reducir el déficit habitacional existente, sin embargo a nivel cualitativo se trata de una política que no ha tenido los resultados esperados, ya que se ha pensado como una como solución que brinda a las familias cuatro paredes y un techo pero que no necesariamente asegura condiciones de habitabilidad necesarias para mejorar su calidad de vida (Coulomb, 2006: 35).

La estrategia de la administración de Vicente Fox privilegió a los criterios financieros y destacó la función del mercado como instancia rectora del sector, dejando en segundo plano el objetivo de proporcionar una vivienda digna para la población. Esto asignó a las constructoras el papel de constituirse en la columna vertebral sobre la que descansan el conjunto de actividades productivas. Los promotores privados se han conformado en grandes consorcios que monopolizan la producción habitacional de viviendas de interés social en nuestro país. Estas empresas inmobiliarias incorporan proyectos habitacionales que van desde la adquisición del suelo, la urbanización, la construcción de viviendas, e incluso el financiamiento de a través de los llamados créditos puente. La actuación de estas inmobiliarias se ha cristalizado en la construcción de grandes conjuntos habitacionales localizado en las periferias de las ciudades mexicanas donde encuentran mayor disponibilidad de suelo barato (Esquivel, 2006: 87-89).

Anteriormente el INFONAVIT y el FOVISSSTE edificaban sus viviendas a través de la contratación de empresas constructoras que eran vigiladas por los organismos habitacionales, actualmente el control constructivo se ha perdido dándole la libertad a las empresas de elegir la calidad de los materiales y su construcción. 
Otra de las modificaciones significativas que ha tenido el INFONAVIT es que ha ido desplazando su atención hacia los sectores de la población con mayores recursos, es decir, a la población que recibe más de cinco salarios mínimos, debido a la manera en que actúan los promotores privados, el producto que ofrecen y las características de financiamiento.

Esta forma de actuar se ha cristalizado en la construcción de conjuntos habitacionales caracterizados por su localización alejada de los centros de las ciudades. Desarrolladas a partir de agrupamientos de viviendas que incluyen menos elementos de equipamiento, servicios de infraestructura, áreas verdes, etc. a través de este diseño se ofrece a los destinatarios la promesa de la mejora de sus condiciones de vida y el sueño de tener una vivienda en propiedad (Esquivel, 2006: 94).

El artículo $4^{\circ}$ de la Constitución Política de los Estados Unidos Mexicanos establece el derecho de toda familia de disfrutar de una vivienda digna y decorosa como elemento indispensable para su pleno desarrollo y bienestar; sin embargo, diversos estudios han constatado que este derecho no se cumple ya que las condiciones habitacionales de muchas familias se consideran inadecuadas, ya sea por su tamaño, calidad, ubicación u otros aspectos.

Que este derecho este establecido en la constitución confiere al estado la responsabilidad de garantizar este derecho; respondiendo a esta obligación el Estado mexicano ha establecido a través de la política de vivienda ciertas estrategias basadas principalmente en la construcción de nuevas viviendas y en el mejoramiento de las ya existentes; asumiendo que el acceso a una vivienda nueva conlleva inmediatamente al mejoramiento de las condiciones de vida de la población, no obstante esto no necesariamente refleja la calidad constructiva de las viviendas recibidas pues el marco de actuación establecido para los inmobiliarios privados ha permitido reducir el déficit habitacional pero no mejorar las condiciones de la población, los resultados de las encuestas aplicadas nos 
permiten señalar que las familias están dispuestas a sacrificar la calidad de su espacio habitacional por el hecho de tener una vivienda propia aunque existen factores que reducen el grado de satisfacción con el entorno habitable.

El abandono por parte del estado de su papel de promotor habitacional ha estimulado el crecimiento de un impresionante número de viviendas en los últimos años, el crecimiento de la producción privada conlleva a riesgos en cuanto a la calidad de estas y a que no sea precisamente la población más necesitada la que tiene acceso a los beneficios de las instituciones públicas (Puebla, 2006: 137).

Claudia Puebla (2006: 138-139) distingue dos grandes etapas en el desarrollo del sistema institucional de vivienda ${ }^{19}$ que se encuentran enmarcadas por las diferentes tendencias en la forma de actuación gubernamental en la política social:

1. 1970 a 1980: caracterizada por la instrumentación de programas habitacionales y la producción y distribución de viviendas, bajo el control de las instituciones públicas de vivienda.

2. A partir de 1990 hasta nuestros días: caracterizada por una importante desregulación del sector habitacional y por una mayor intervención de los agentes privados financieros, promotores y constructores que se desenvuelven en una serie de estrategias facilitadoras promovidas por las agencias internacionales.

Esta forma de actuación ha traído como consecuencia que la población de escasos recursos no pueda acceder a una vivienda a través de los fondos de vivienda ya que la necesidad de recuperar las inversiones ha terminado por

\footnotetext{
${ }^{19}$ Integrado por tres tipos de instituciones: 1) Las que destinan sus programas hacia los sectores de clase media como la sociedad hipotecaria federal (anteriormente fondo de operación y financiamiento bancario a la vivienda [FOVI]); 2) Las que atienden a los trabajadores asalariados (Fondos de vivienda INFONAVIT Y FOVISSSTE) y 3) Las que dirigen sus programas a la población de menores recursos principalmente no asalariada (Organismos estatales como el instituto nacional para el desarrollo de la comunidad y la vivienda popular y el fideicomiso fondo nacional de habitaciones populares).
} 
modificar el nivel de ingresos de la población beneficiaria, es decir solamente tienen acceso aquellos que cuentan con suficiente poder adquisitivo. En el año 2004 el INFONAVIT reconoció que el promedio de ingresos de los beneficiarios era de seis veces el salario mínimo, dejando fuera a cerca del $60 \%$ de los derechohabientes que perciben menos de tres salarios mínimos, la adopción del criterio del libre mercado ha desfavorecido a la población de menores recursos, lo cual significa que el estado mexicano no está atendiendo a los sectores más necesitados con lo cual se ha venido perdiendo el carácter social de la política habitacional y se limita el ejercicio al derecho a la vivienda (Puebla, 2006:144).

Con lo anterior, el Estado ha perdido su capacidad de conducción de la política habitacional, lo cual dificulta la organización del desarrollo de sistema de vivienda que se ha ido conformando por una multiplicidad de actores que actúan sin una línea articulada; estos organismos están asignados a distintos sectores del presupuesto gubernamental lo cual no permite al gobierno federal coordinar de manera adecuada la actuación de organismos habitacionales para que logren cumplir los organismos planteados tanto en la Ley Federal de vivienda como en el programa sectorial correspondiente; contrariamente los agentes privados han logrado coordinarse con las principales instituciones habitacionales, ahora convertidas en entes financieros, que conducen a través de su oferta crediticia a un tipo de vivienda desarrollada por los promotores constructores privados.

De manera que esto ha resultado en un gran negocio surgido a partir del abandono de las funciones de regulación y financiamiento por parte de los organismos que se han convertido en facilitadores de condiciones para los grandes inmobiliarios y los nuevos agentes que fungen como intermediarios financieros y que a través de los créditos de las instituciones públicas han desarrollado un mercado especifico de vivienda de interés social a lo largo y ancho de todo el país. 
Otra de las grandes problemáticas que presenta la política de habitacional actual se relaciona con su falta total de vinculación con las políticas de desarrollo urbano federal, estatal y municipal mismas que se encuentran también desarticuladas entre sí; lo cual ocasiona la continuación de expansión urbana sin una lógica integral que conlleva a ejercer una mayor presión sobre los gobiernos locales que deben asumir la obligación de dotar de servicios a los pobladores (Puebla, 2006:147).

\subsection{Del Estado regulador al facilitador: consecuencias de la omisión del Estado en la producción de vivienda}

Como se señalaba en párrafos anteriores, el Estado Mexicano ha tenido una mala participación para resolver el problema de la vivienda y en el proceso de desarrollo urbano en general; el papel que ha jugado en la producción de vivienda de interés social se ha caracterizado principalmente por impulsar políticas de vivienda que tratan de dar respuesta a las necesidades de vivienda de los sectores más pobres de la sociedad, sin embargo, se ha otorgado poca importancia a las dimensiones cualitativas de la vivienda y se ha apostado al éxito cuantitativo de las políticas, es decir, al número de viviendas construidas (Maya; 2001: 8).

La implementación de la Política de Desarrollo Industrial favoreció la migración de la población hacia el Estado de México, situación que llevó al gobierno de este estado a decretar la Ley de Fraccionamientos de Terrenos del Estado de México con la que se modificó el concepto tradicional de la vivienda; dando paso a al concepto de las edificaciones habitacionales con áreas verdes empastadas, lugares de estacionamiento y divisiones establecidas para sala, comedor, recámaras, baños, entre otros dentro de la vivienda (Esquivel: 2006). 
A partir de 1975 se construyen en el Estado de México los primeros conjuntos multifamiliares en régimen condominal promovidos principalmente por el INFONAVIT en municipios de alta urbanización como Tlalnepantla y Ecatepec. Durante las décadas siguientes, la tipología de vivienda se trasformó en respuesta a los programas de financiamiento desarrollados por las instituciones federales de vivienda y su relación con los niveles de ingreso de la población (Ortega y Villafaña, 2007: 52).

En 1979 se decreta el Reglamento de Construcciones de Inmuebles en Condominio que en su artículo 24 define a los Conjuntos Habitacionales de Interés Social sin establecer alguna limitación en cuanto al número de viviendas que podían ser edificadas en un mismo predio. Sin embargo, establecía como necesario la dotación de equipamiento y obras de urbanización progresivas que permitieran el adecuado funcionamiento de los conjuntos y su integración a la estructura urbana.

En la década de los años 80 los programas de vivienda de interés social financiados por el INVONAVIT, FOVISSSTE entre otros, configuraron algunos de los espacios del Estado de México con desarrollos multifamiliares en régimen condominal principalmente de tipo vertical, observándose con ello, una reducción paulatina de la superficie cubierta por los programas arquitectónicos, situación que llevó a la modificación e incremento de las densidades habitacionales establecidas en los Planes de Desarrollo Urbano (Ortega y Villafaña, 2007: 52).

Con estos antecedentes y bajo la normatividad que regía a los fraccionamientos, surgen en la década de los años 90 las unidades habitacionales más grandes de la periferia metropolitana, presentando una importante cantidad de problemáticas asociadas a la falta de servicios y equipamiento que eran necesarios para albergar a su población. 
Si analizamos históricamente las dimensiones de la vivienda en México, sucede algo peculiar; en los primeros años del siglo $X X$ se presentó un incremento en sus dimensiones; sin embargo, a partir de 1980 éstas volvieron a disminuir... El desarrollo de la vivienda social podría llevarnos a cuestionar hasta dónde se puede llegar antes de buscar replantear los esquemas de vivienda unifamiliar económica en las periferias de las ciudades (Sánchez, 2012: 21).

Con la promoción de la segunda ley de Asentamientos Humanos en 1993, se crea la figura de Conjunto Urbano como una nueva medida que contempla la dotación obligatoria de infraestructura urbana y que busca responder a las demandas que no habían sido atendidas por los antiguos fraccionamientos (Pedrotti, 2015: 64). De acuerdo con la Secretaría de Desarrollo Urbano y Metropolitano del Estado de México, los Conjuntos Urbanos son parte de una modalidad

en la ejecución del desarrollo urbano, que tiene por objeto estructurar, ordenar o reordenar, como una unidad espacial integral, el trazo de la infraestructura vial, la división del suelo, la zonificación y normas de usos y destinos del suelo, la ubicación de edificios y la imagen urbana de un sector territorial de un centro de población o de una región. ${ }^{20}$

Bajo esta figura se produjo durante la época de los noventas un boom habitacional en el Estado de México que incentivó el desarrollo urbano de determinados municipios, modificando su imagen urbana y trayendo consigo problemáticas para las administraciones municipales que, hasta el momento, cuentan con poca capacidad para incidir en el diseño de dichos proyectos (Esquivel, s.f.: 6).

20 Secretaría de Desarrollo Urbano y Metropolitano del Estado de México, Conjuntos Urbanos. Disponible en: http://portal2.edomex.gob.mx/sedur/desarrollo habitacionales/index.htm (Consultado el: 18 de julio de 2015). 
Quizás, el mayor hueco que se puede encontrar en esta reglamentación radica en la poca rigurosidad normativa establecida para definir el tamaño máximo y la ubicación de los nuevos conjuntos habitacionales; ya que su autorización depende únicamente de la disponibilidad de agua potable en y no existe algún otro principio que lo limite.

Si bien el factor del agua es un elemento esencial, no se advierte como criterio complementario, que la localización responda a las tendencias de crecimiento de la metrópoli, o más en concreto, que se considere la relación entre la ubicación del predio y la estructura urbana preexistente, o incluso -en el caso de su dimensión- que el volumen de la demanda se localice en ese municipio, o al menos en esa área de referencia. Si a esto se le suma el establecimiento de la figura de áreas urbanizables no programadas, es lógico que la urbanización haya quedado librada al mejor precio obtenido por el promotor (suelo barato), tratándose por lo general de predios lejanos o con dificultades de acceso (Pedrotti, 2015: $69)$.

De tal forma que la construcción de grandes Conjuntos Urbanos, ha ocasionado que se agraven los principales problemas que padecen estos municipios, como la dotación de agua potable, la saturación vial y problemas de disposición de aguas residuales que son depositadas principalmente en campos de cultivo y de reserva ecológica, que a su vez, propician problemas de salud pública. Atentando con ello, a lo establecido en el artículo $4^{\circ}$ Constitucional y, violando la Ley General del Equilibrio Ecológico y Protección al Ambiente, así como la Ley General de Asentamientos Humanos con la que supuestamente se pretende ordenar el territorio.

Como señala María Teresa Esquivel en su estudio denominado Política habitacional y calidad de vida: impacto de los nuevos desarrollos habitacionales (2006), las viviendas construidas en el marco de la política habitacional facilitadora, no sólo han traído consecuencias importantes para el territorio, sino 
también para la población. Ya que los nuevos megos proyectos como el que se ha señalado, han contribuido a la expansión de la mancha urbana, modificando los paisajes urbanos y los modos de vida de las familias mexicanas (Esquivel; 2006:83).

Problemas asociados a la localización, a la accesibilidad, a la inversión de tiempo y dinero para transportarse a la ciudad, la falta de equipamiento, la calidad de los materiales empleados en la fabricación y las reducidas dimensiones de la vivienda, son algunas de las consecuencias que Esquivel ha identificado, ya que con el objetivo de obtener mayores ganancias económicas, los inmobiliarios han recurrido a reducir los espacios útiles de la vivienda; propiciado (además de lo ya señalado) que las familias se enfrenten a condiciones de hacinamiento.

Ante las diminutas dimensiones de la vivienda (no más de 60 metros cuadrados), las familias se han visto forzadas a utilizar distintos espacios de la casa como dormitorios; la carencia de intimidad, ha expulsado a las calles a los integrantes más jóvenes de las familias, por lo que es común observar que los grandes conjuntos urbanos, se conviertan en espacios reproductores de conflictos sociales como la violencia. A diferencia de los grandes conjuntos que eran construidos tradicionalmente por INFONAVIT, los nuevos espacios habitacionales incluyen cada vez menos elementos de equipamiento, espacios públicos, etc.; pues lo promotores inmobiliarios se limitan a proporcionar los elementos mínimos indispensables (Esquivel; 2006: 89).

Las empresas inmobiliarias han sabido bien realizar un diseño urbano atractivo para la población y a través de éste se les vende la promesa de una mejora en sus condiciones de vida y sobre todo el sueño siempre acariciado de las familias por obtener una vivienda en propiedad" (Esquivel; 2005).

Esta situación se complica aún más, si consideramos que desde hace mucho tiempo los municipios mexicanos se encuentran en la contradicción 
existente entre las leyes locales y federales ${ }^{21}$ que definen sus atribuciones; mismas que se han incrementado, pero no así los recursos con los que cuentan para ejecutarlas. A esto, se suma la obsolescencia del diseño institucional del municipio, así como la escasa capacidad de organización, preparación y análisis de los asuntos a atender que someten a los municipios urbanos a una debilidad estructural y de gestión que les impide promover una cogestión de políticas públicas y ejecutar los programas con la eficiencia y eficacia esperadas (Cabrero y Gil; 2010: 159 y 165).

Aunque constitucionalmente el municipio es el encargado de autorizar los permisos de construcción de los fraccionamientos urbanos y de dotar de servicios a la población, éstos se ven muchas veces obligados a negociar con los desarrolladores de vivienda la dotación de servicios e infraestructura en un marco jurídico complicado, con el que se perjudica la calidad de la vivienda construida (Esquivel, 2006).

Lo anterior es producto también, de la nueva reglamentación implementada para el manejo y construcción de los llamados Conjuntos Urbanos, pues aunque esta Ley contempla la dotación obligatoria de equipamiento para todos los tipos de vivienda, fueron eliminados otro tipo de requerimientos que anteriormente estaban presentes en la Ley estatal de Asentamientos Humanos, tales como: la dotación de guarderías y unidades médicas. Asimismo, se produjeron cambios relevantes en cuanto los procedimientos de autorización de los conjuntos habitacionales, ya que con el objetivo de "simplificar los trámites administrativos" se conjuntó en un solo acto la autorización de inicio de ejecución de obras de urbanización, equipamiento e infraestructura primaria, con la enajenación o gravamen de lotes y la promoción del conjunto urbano; lo cual, perjudica en mayor medida a los

\footnotetext{
${ }^{21}$ Véase. Azuela, Antonio (2010) "La hechura de la urbanización. Notas para la historia reciente del Derecho Urbanístico", en: Garza Gustavo y Martha Schteingart (coords.) Los grandes problemas de México, II Desarrollo Urbano y Regional, El Colegio de México.
} 
futuros usuarios de la vivienda porque en muchas ocasiones llegan a habitar la casa sin contar aún con el equipamiento necesario (Pedrotti, 2015: 71 y 72).

Otro aspecto importante de resaltar, es que la actuación de las inmobiliarias privadas ha creado un importante desbalance entre la oferta de vivienda (de la cual existe una sobreproducción) y la demanda de población que puede tener acceso a pagarla.

Con esto la producción de la vivienda se ha monopolizado y ha perdido su orientación social, pues al estar en manos de grandes promotores privados, se ha dejado de lado los intereses de la población sustituyéndolos por los de los desarrolladores, que se orientan solo a percibir ganancias económicas.

Un estudio realizado por el Centro Mario Molina $^{22}$ en el que se miden los impactos ambientales, económicos y sociales asociados a la vivienda de interés social, permite comprobar las aseveraciones anteriores, pues de acuerdo con este Centro, las viviendas de México tienen una sustentabilidad media-baja, lo cual implica un cumplimiento mínimo de la normatividad a nivel nacional; y un nivel de administración e integración social muy pobre.

Razón por la cual es importante hacer énfasis, en que la producción de la vivienda no debe limitarse únicamente a su construcción, sino que se debe pensar en todas las consecuencias sociales y económicas que puede traer consigo. Ya que como ha señalado uno los grandes teóricos de la sociología, el espacio tiene gran relevancia en la estructuración de la vida social, por lo que debe ser visto como una estructura fundamental, que puede servir a los actores para potenciar sus capacidades (Giddens en Galindo; 2010: 154).

\footnotetext{
22 Atendiendo la necesidad de generar una herramienta para diagnosticar el desempeño ambiental, económico y social de la vivienda y su espacio urbano en México, el Centro Mario Molina desarrolló el Índice de Sustentabilidad de la Vivienda y su Entorno (ISV).
} 
La mayor parte de los municipios no están preparados para el reto que significa este tipo de urbanización de grandes dimensiones y se enfrenta con fuertes problemas para regular de manera eficiente el acelerado crecimiento urbano y para dotar de equipamiento e infraestructura a la población que llega a su territorio (Esquivel, s.f.: 7).

En nuestro país, la calidad de la vivienda de interés social se ha venido midiendo en función del número de viviendas que se pueden construir, y no en el bienestar que generan en la población.

Los grandes conjuntos urbanos son una suerte de producto que la gente consume por necesidad, se trata de viviendas que mantienen una sustentabilidad actual y futura mínima. La periferia de la ciudad de México ha pasado de ser un espacio rural a una "compleja trama de espacios "rururbanos" que ponen a prueba la capacidad de las infraestructuras viales, energéticas, transporte, agua, etcétera con los que cuenta al ciudad (Maya; 2001: 1-7).

Apostar a la continuación de este modelo de producción habitacional conlleva a resolver aparentemente a corto plazo las necesidades de la población, pero no contempla que genera problemas sociales, urbanos y políticos que desembocan en problemas fiscales a nivel local que no solo afectan la calidad de vida de los habitantes, sino que también repercuten a nivel regional como es el caso de las grandes metrópolis (Maya; 2001: 1-7).

Esta forma de hacer política bajo la mano de la iniciativa privada y mediante un marco de reglamentación débil no satisface el rezago de la vivienda digna, al contrario, genera problemas sociales, urbanos y ambientales que empiezan a ser cada vez más graves e irreversibles (Maya; 2001: 6). 


\subsection{La vivienda y los problemas de segunda generación}

Como se mencionó en párrafos anteriores, para las décadas de los 70 y 80 's el surgimiento de organismos públicos de interés social dedicados a la construcción de unidades habitacionales de interés social, se erige como la alternativa de acceso a la vivienda para los sectores más pobres de la sociedad.

No obstante, la ausencia de una visión a largo plazo ha sido una constante de las políticas habitacionales de los países latinoamericanos; en tanto que el diseño de la vivienda se ha limitado a considerar los costos económicos y las ganancias sin tener en cuenta que con ello, se trasladaba el problema de reparación a los futuros usuarios, trayendo como consecuencia que los costos para conservar una vivienda sean cada vez más altos impidiendo su mantenimiento y acelerando la degradación de las construcciones y de su entorno (Hasse y Dunowicz, 2005: 87).

Como señalan Hasse y Dunowicz, en el estudio Diseño y gestión de la vivienda social (2005), el deterioro de las viviendas es uno de los mayores problemas de los conjuntos habitacionales de vivienda social y que está relacionado no sólo con la calidad de los materiales con los que se construyen las viviendas, sino que también es resultado de decisiones públicas (a nivel nacional, regional y municipal) que involucran a las instancias de gobierno en todo el proceso productivo, relacionándolas a partir de las políticas, planes y programas, gestión y construcción sin incluir su uso y mantenimiento posteriores.

Esta situación no ha sido contemplada por los proyectos arquitectónicos y que afectan de manera negativa el desempeño de las viviendas, en las condiciones de habitabilidad y en su durabilidad. Aunque hasta el momento la mayoría de los programas sociales consideran el mantenimiento de las viviendas como una variable opcional, autores como Hasse y Duniwicz sugieren que se trata 
de un elemento que no debe ser pasado a segundo término, ya que al hacerlo se acrecientan y agravan los problemas de los conjuntos habitacionales.

Una forma de evaluar las condiciones de los conjuntos habitacionales propuesta por los autores señalados implica considerar la seguridad, la habitabilidad, la durabilidad y la economía de los conjuntos habitacionales. Los primeros tres rubros, están relacionados con las condiciones estructurales de la vivienda (el confort acústico, los techos, cubiertas, instalaciones de agua, electricidad, gas y superficies interiores), lo que permite observar algunos aspectos que evidencian el deterioro de los inmuebles, como manchas de humedad, fisuras, grietas, filtraciones hacia el interior de las viviendas, etc.

Aspectos que en su mayoría tienen origen no sólo en la construcción y diseño de la vivienda, sino también en su emplazamiento, pues aunque se trata de desarrollos inmobiliarios de gran tamaño y densidad, su ubicación periférica los separa de los lugares de comercio, servicio y trabajo, lo que lleva a los usuarios a cambiar el uso de suelo y transformarlo de habitacional a comercial o mixto, muchas veces sin autorización de las autoridades municipales pero con el objetivo de facilitar el abasto de alimentos servicio educativos y otros tipos de comercio (Amado, 2009: 17 - 21).

La manera en que las viviendas fueron construidas, afectan la privacidad de los usuarios y de las familias, ya que los materiales utilizados no aíslan adecuadamente el ruido ni el calor haciéndolas poco confortables en condiciones de clima extremo, además de que afectan la privacidad de los habitantes.

Otro tipo de transformaciones comúnmente observadas son las ampliaciones y construcciones tanto en el interior como en el exterior de la vivienda, pues en la mayoría de los casos las viviendas de los conjuntos habitacionales se encuentran construidas de manera lineal y son de un tamaño 
reducido; lo cual obliga a los usuarios a modificar los espacios arquitectónicos con el fin de adaptarlos a sus necesidades cotidianas (Amado, 2009: 17 - 21).

A pesar de que se trata de un tema que aqueja a diversas ciudades alrededor del mundo, las autoridades del gobierno, los académicos y las organizaciones a nivel mundial continúan mirando la problemática habitacional desde la perspectiva del déficit habitacional existente, lo que fuese llamado en 1987 el Año Internacional de Los Sin Techo (Hasse y Dunowicz, 2005: 87) y que actualmente han sido denominados por el Banco Interamericano de Desarrollo (BID) como problemas de segunda generación. ${ }^{23}$

Y que refieren a las problemáticas que en los últimos años han perseguido a los habitantes de estos conjuntos; instituciones como el BID señalan que las interrogantes y problemáticas actuales, giran en torno a las dificultades relacionadas con la calidad de las viviendas, de los servicios y equipamiento en los conjuntos habitacionales, y de otros problemas sociales como la delincuencia, la violencia intrafamiliar entre otros problemas sociales asociados a las concentraciones de conjuntos de vivienda social (Rodríguez y Sugranyes, 2004: $54)$.

La producción en masa de grandes conjuntos habitaciones de interés social ha generado un enorme stock de viviendas sociales inadecuadas que requieren atención (Rodríguez y Sugranyes, 2004: 54). Problemática que había sido advertida a finales de la década de los noventa por una serie de autores chilenos, quienes mostraban las consecuencias económicas, políticas y sociales de la política habitacional de dicho país y que como Ducci señalaban que:

Este modelo, aplicado una década anterior en Chile, mostró "el lado obscuro" de la política de vivienda chilena ya que generó verdaderos

\footnotetext{
${ }^{23}$ Véase. Rojas, Eduardo (2009) Prevenir la nueva informalidad en: Rojas, Eduardo (Editor) (2009). Construir Ciudades. Mejoramiento de barrios y calidad de vida urbana, Banco Interamericano de Desarrollo, FCE, Washington DC. 114-138
} 
Mujer y satisfacción residencial. La mirada de quienes habitan en el Conjunto Urbano Rancho Santa Elena. Cuautitlán, Estado de México.

ghetos caracterizados por un acelerado deterioro no sólo de las viviendas, sino de los propios conjuntos, falta de equipamiento, abandono de espacios públicos e inseguridad. Esto nos fue advertido desde fines de los años noventa y, sin embargo, el modelo se aplicó en nuestro país sin ser cuestionado. El problema se vuelve más preocupante, si recordamos que hoy en día continúa esta forma de producción del espacio urbano en periferias cada vez más alejadas de los centros no sólo en las metrópolis mexicanas, sino también en ciudades medias de todo el territorio nacional (Ducci 1997 en Esquivel, s.f.: 30).

Considerando lo expuesto hasta ahora, el presente trabajo pretende contribuir a la búsqueda de soluciones que permitan alcanzar el objetivo establecido por las Naciones Unidas de dotar a la población de una vivienda adecuada; partiendo de la evaluación que los habitantes realizan a su vivienda, mediante el uso del índice de satisfacción residencial que ha sido utilizado en diversas investigaciones como un indicador de la calidad de vida ${ }^{24}$ de la población, proponiendo a partir de sus experiencias soluciones que permitan reducir los problemas a los que se enfrentan los habitantes de los Conjuntos Urbanos y que pueden ser utilizados en una futura reformulación de la actual política de vivienda.

\footnotetext{
${ }^{24}$ El concepto calidad de vida, ha sido objeto de diversas discusiones académicas debido a que se trata de un concepto de significado subjetivo que puede ser interpretado de distintas maneras, puesto que responde a las percepciones e interpretaciones de los individuos. Dado que el propósito de esta investigación no es ahondar en las discusiones que se han generado en torno a la definición del concepto, para propósitos de esta investigación hablaremos de calidad de vida para referirnos al estado de satisfacción general, derivado de la realización de las potencialidades de la persona; [y que] posee aspectos subjetivos y aspectos objetivos. Es una sensación subjetiva de bienestar físico, psicológico y social. Incluye como aspectos subjetivos la intimidad, la expresión emocional, la seguridad percibida, la productividad personal y la salud percibida. Como aspectos objetivos el bienestar material, las relaciones armónicas con el ambiente físico y social y con la comunidad, y la salud objetivamente percibida (Rubén Ardila; 2003: 163).
} 


\section{CAPÍTULO 2. VIVIENDA, SATISFACCIÓN RESIDENCIAL Y GÉNERO}

La vivienda ha sido objeto de numerosos estudios multidisciplinarios entre los que destacan los urbanísticos, psicológicos, geográficos y sociológicos; estos últimos desarrollados en torno a la llamada sociología de la vivienda, cuyo enfoque tradicional, se fundamenta en la aplicación del aparato conceptual básico de la sociología aplicado al estudio de la vivienda (Del Pino, 2014: 22).

Los primeros trabajos realizados bajo esta óptica, se centraron en gran medida en: 1) el análisis de su valor social, 2) la relación entre vivienda y localidad y 3) en la política de vivienda (relacionada con los grupos de interés y presión alrededor de la industria habitacional). ${ }^{25}$ Años más tarde, temas como las políticas de vivienda y su relación con el aparato económico; las relaciones entre vivienda y vida familiar- vinculadas a la arquitectura-; y la relación entre vivienda- comunidad; se convirtieron en las tres áreas acaparadas por los investigadores. Algo que fue muy criticado por autores como Merton (1951) y Foley (1980) quienes abogaban por el reconocimiento de la importancia del ambiente construido (también conocido como habiente residencial), y por un análisis multidisciplinario que permitiese el diálogo con otras ramas de las ciencias sociales como la psicología y la antropología (Del Pino, 2014: 22).

El gran giro de las investigaciones sociales relacionadas con la vivienda, se produjo con el ascenso de las posturas neoliberales en la década de los ochenta. La influencia de este fenómeno mundial tuvo importantes consecuencias en el debate sociológico sobre la vivienda que, a partir de entonces, se orientó hacia el análisis de temas parciales como la caída del sector público en el sistema residencial, los procesos de privatización, los efectos sociales de la privatización, el análisis de la demanda, etc. (Del Pino, 2014:23).

\footnotetext{
${ }^{25}$ Autores como Wirth (1947) pensaban que esto constituía una gran laguna en el estudio de la vivienda, pues consideraba que para lograr un estudio sociológico adecuado, era necesario erigir una perspectiva sociológica apropiada de los problemas de la vivienda, más allá de la mera aplicación mecánica de los conceptos de la sociología (Del Pino, 2014: 22).
} 
Desde los años noventa, la sociología de la vivienda se caracterizó por su diversidad temática y por su pluralidad de enfoques. Para esta disciplina, la vivienda adquiere un lugar importante en el desarrollo de las sociedades, en la medida en que se constituye como un espacio social dentro del territorio.

Por este motivo, resulta sumamente importante analizar la manera en que la vivienda (como objeto) se relaciona con la sociedad (las relaciones que se generan a partir de ella y el significado que ésta adquiere para los individuos). Pues se trata de un espacio en el que se integran organizaciones espaciales internas: las de los usos que se hacen de ella, y estructuras externas: relacionadas con la forma en que ésta se inscribe dentro de la localidad y la estructura institucional de la sociedad (Del Pino, 2014: 26).

Aunque resulta evidente la deuda con el problema de la distribución y las cuestiones asociadas (como la forma de tenencia, el papel del estado o las políticas públicas), en los últimos lustros se ha realizado un esfuerzo notable en otros campos, como en el de la formulación teórica. En este terreno, se han realizado esfuerzos por generar un enfoque de integración, que permita formular los problemas de vivienda dentro de un esquema amplio que permita analizar tanto las cuestiones micro como las macro, teniendo en cuenta las implicaciones socio espaciales de la vivienda. La creación de un enfoque integrado permite combinar en el análisis las cuestiones macro estructurales (elementos como las clases o el estado) con cuestiones micro, de reproducción en el hogar. Sin embargo, esta combinación no siempre es sencilla. Así, resulta difícil incorporar aspectos subjetivos acerca de la construcción del espacio dentro de estudios macro; tampoco resulta fácil, en consecuencia, presentar la vivienda como espacio de consumo vinculado a aspectos simbólicos del habitar, cuyo desentrañamiento hermenéutico escapa del análisis objetivista de la distribución de viviendas, el análisis de los hogares o las políticas públicas (Del Pino, 2014: 23-24). 
Aspectos que hasta el momento se han sido dejados de lado por las políticas mexicanas de vivienda y que sin duda juegan un papel fundamental a la hora de entender los problemas que presentan actualmente los espacios habitacionales de gran magnitud, como son los llamados Conjuntos Urbanos localizados en la periferia de la Ciudad de México. $Y$ que se han convertido en temas relevantes en los últimos años, debido a la gran cantidad de problemas que actualmente enfrentan las familias que ya han alcanzado el anhelado sueño de tener una casa propia y que ahora, se enfrentan a nuevos conflictos relacionados con las condiciones de las mismas, la calidad de los materiales utilizados para su construcción, entre otras cuestiones cualitativas que van más allá del déficit habitacional.

Además de la sociología, la psicología ambiental es otra de las ciencias que ha hecho aportaciones relevantes al estudio de la vivienda, como el concepto de satisfacción residencial que constituye un importante acercamiento al problema cualitativo de la vivienda, en la medida que permite conocer la evaluación que las personas realizan a su ambiente residencial y ofrece información valiosa que generalmente no es captada por los métodos objetivos o cualitativos tradicionales.

\subsection{Ambiente residencial}

Cuando hablamos del ambiente residencial hacemos referencia a las condiciones físicas, sociales y económicas de un lugar o colectividad que son características de un espacio temporal delimitado (Delgado, 2013: 25, 26 y 27). Éste otorga sentido al hábitat residencial, debido a que se conforma a partir de dos dimensiones que lo definen:

1. La dimensión física del ambiente residencial que hace referencia a las características físicas del sistema habitacional; 
2. Y una dimensión social que alude a las actividades cotidianas que realizan los usuarios del hábitat residencial en los diferentes espacios que lo componen.

De esta manera, el ambiente residencial se concibe mediante la integración de tres componentes: la vivienda, el barrio y los vecinos. El concepto de barrio se entiende desde esta perspectiva, como el área próxima a la vivienda en la que se incluyen aspectos físicos como la infraestructura y el equipamiento; y aspectos sociales como las relaciones vecinales y de convivencia que establecen los habitantes. En definitiva, el barrio no haría referencia al área geográfica que lo delimita, sino más bien a la percepción del sujeto y a su sentido de pertenencia al mismo (Delgado, 2013: 25).

Para Haramoto, el ambiente residencial forma parte de un conjunto de sistemas que permiten la existencia de una relación inseparable entre el habitante y su hábitat, e involucra dimensiones psico-sociales y físico-espaciales.

\section{Imagen 1. Matriz de sistema habitacional Haramoto}

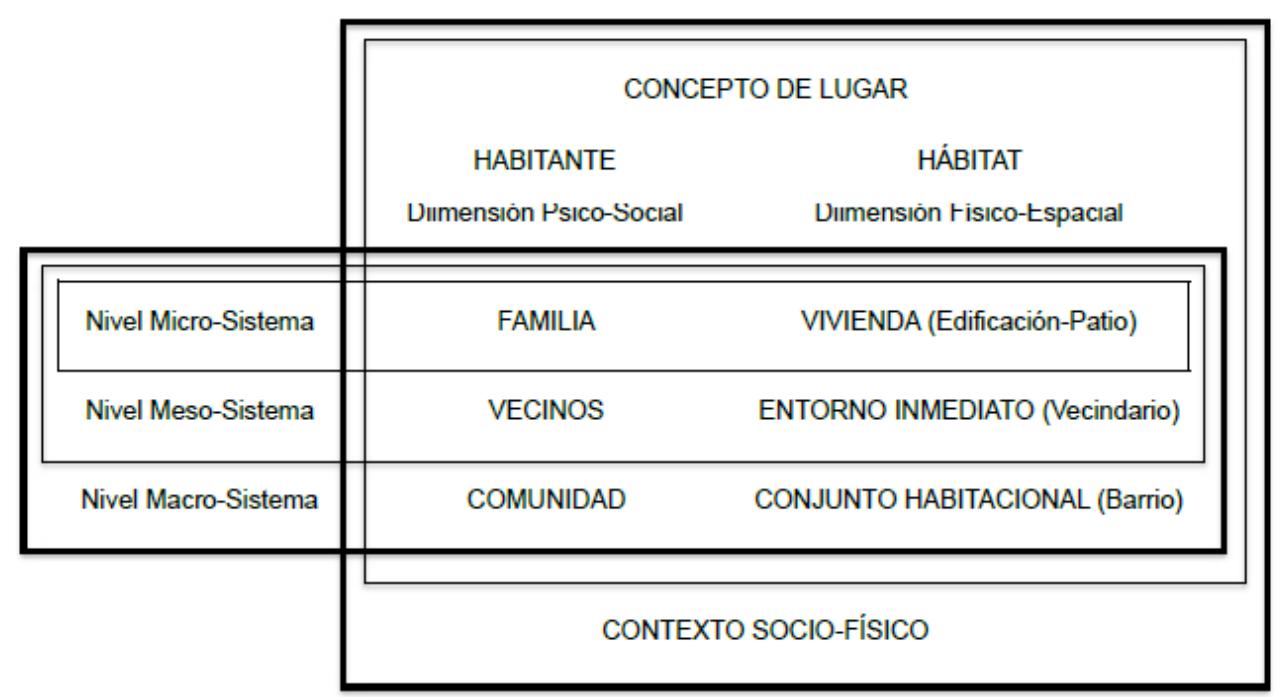

Fuente: Francisca Delgado (2013: 25) 
Partiendo del concepto de lugar propuesto por Canter y otros autores, plantea un esquema (imagen 1), que contempla el análisis de la satisfacción residencial a partir de tres niveles o escalas territoriales:

a) El microsistema: refiere al núcleo familiar y a la vivienda. Desde esta óptica, el sistema habitacional se extiende más allá de los límites de la vivienda ya que se considera que éste se enmarca dentro de un contexto socio-físico mayor que comprende al contexto cultural, socio-económico, político y físico-ambiental. Para Haramoto, la vivienda es entonces el lugar de dominio privado, donde ocurre la relación de la familia y sus integrantes con su hábitat, y que hace referencia no sólo al espacio construido asignado a la casa, sino también, se incluye a los servicios, la infraestructura disponible, los accesos al conjunto habitacional y los pasillos que rodean a la vivienda (Delgado, 2013).

b) El mesosistema: de la relación con los vecinos y el entorno directo a la vivienda. Este último, corresponde a los lugares que se comparten fuera de la casa que permiten la interacción entre las familias o vecinos (áreas comunes, pasillos, escaleras, etcétera).

c) El macrosistema: que se relaciona con la comunidad y el conjunto habitacional. Este incorpora a todas las viviendas del conjunto, las calles, equipamientos, espacios públicos, etcétera que forman parte del contexto territorial más amplio, por ejemplo: el municipio. En este sentido, el conjunto residencial es de dominio público, puesto que pertenece a todos los habitantes e incluye las relaciones de la comunidad y el barrio (Haramoto, 1990 en Delgado, 2013: 24). 


\subsection{Satisfacción residencial}

Se entiende por satisfacción residencial, al nivel de agrado o desagrado que las personas sienten por el ambiente donde residen, incluyendo la vivienda y su entorno (Haramoto en Arends, 2012:5).

De acuerdo con Carolina Pedrotti (2015: 44), la satisfacción residencial constituye uno de los elementos esenciales para la medición y evaluación de la calidad residencial del espacio habitable. Esta última, entendida como el conjunto de características, atributos objetivos de un espacio residencial (no sólo de la vivienda) posibles de estimar, cualificar, calificar de manera interrelacionada (esto es al interior del espacio, entre sus componentes, y además del propio espacio con el área urbana).

Se trata de un término que tiene sus orígenes en la llamada psicología ambiental, ${ }^{26}$ disciplina que cuestiona la carencia de sentido humano y social de los espacios urbanos, en especial de las viviendas de localización periférica que empezaron a surgir en los años sesenta y en las que generalmente, se omiten los factores sociales y psicológicos que conllevan situaciones como el cambio del ambiente residencial, la ruptura de los vínculos afectivos entre los vecinos, así como las concepciones imaginarias y simbólicas que tienen los habitantes de su lugar de residencia (Hidalgo, 1988).

Las aportaciones hechas desde la psicología al urbanismo, comenzaron a ser relevantes durante el periodo señalado, debido a que en esta época se logra incorporar con mayor fuerza la dimensión social en los programas de planificación. Los trabajos dirigidos por Herbert Hans en 1959 y Lee Rainwater en 1966, marcaron la pauta en los estudios de satisfacción residencial.

\footnotetext{
${ }^{26}$ Una rama de la psicología que nace a partir de la necesidad de evaluar las interacciones que las personas establecen con el medio ambiente. Preocupación que surge en la década de los 70's debido a los problemas ambientales derivados de las sociedades industriales (Valdeiglesias y Aguilar, s/f: 5).
} 
Las investigaciones de Rainwater fueron producto del fracaso de la urbanización Pruitt-Igoe ${ }^{27}$ en las áreas deprimidas de Boston; éstas revelaron que la insatisfacción experimentada por los habitantes de este conjunto habitacional estaba condicionada de manera importante por las malas condiciones de la vivienda, aunque en algunos casos se compensaba por un grado mayor de satisfacción proveniente del arraigo con el lugar donde se localizaba el conjunto habitacional (Amérigo, s/f: 2). Los altos índices de violencia, la transformación de los espacios públicos y la carencia de sentimientos de pertenencia, llevaron al fracaso de esta urbanización que significó para muchos, el final de la llamada Arquitectura Moderna y fue un claro ejemplo de lo catastrófico que resulta aplicar modelos arquitectónicos sin considerar las realidades, lenguajes y necesidades de la población.

Tal como lo dejaron ver Colin Rowe y Fred Koetter en su libro Collage City (1984): Ia arquitectura moderna, como construcción psicológica y modelo físico, se ha vuelto trágicamente absurda... La ciudad de Le Corbusier, la famosa ciudad de los CIAM y publicitada por la Carta de Atenas; la antigua ciudad de liberación es cada día más inadecuada" (Rowe y Koetter en García, s/f).

Cabe señalar, que las investigaciones surgidas a partir de los trabajos anteriores, basadas en los preceptos de la psicología y la sociología, estuvieron enfocadas principalmente, en el análisis de las interacciones entre los individuos y su ambiente residencial. La mayoría apoyados en una perspectiva metodológica que consideraba a la satisfacción residencial desde dos perspectivas distintas:

1) como variable de la calidad del espacio habitable, 0

\footnotetext{
${ }^{27}$ Proyecto de vivienda pública construido entre 1955 y 1966 en la ciudad estadounidense de Saint Louis, Missouri, con el objetivo de alojar a más de 2,500 familias que residían en áreas de viviendas precarias. Aunque el diseño arquitectónico y urbanístico fue considerado como una de las obras más relevantes de la arquitectura moderna influenciada por las ideas de Le Corbusier, fue declarado veinte años más tarde como inhabitable y derribado por el Departamento Federal de Vivienda, debido a los altos índices de delincuencia y vandalismo que se presentaban en el lugar (García, Silvia, s/f.).
} 
2) como variable predictora de los comportamientos que se desarrollan en el hábitat.

Sin embargo, no fue hasta los trabajos de María Amérigo, que estas variables fueron utilizadas de manera integral en el abordaje de la satisfacción residencial. Las propuestas de esta autora, se contrastaron de manera empírica en una serie de proyectos de investigación financiados por el Instituto de Vivienda de Madrid entre 1987 y 1992 (Amérigo, s/f).

El modelo propuesto por Amérigo ha sido el referente principal para el desarrollo de investigaciones en distintos países, ${ }^{28}$ ya que éste contempla la evaluación que los individuos realizan al ambiente en el que residen, considerando atributos físicos y sociales.

La orientación teórica que ha guiado el desarrollo empírico de los trabajos de satisfacción residencial hasta ahora realizados, considera a la satisfacción residencial desde el afecto o los sentimientos que los individuos experimentan hacia el lugar en el que residen. Como señala Amérigo (1994), se trata de una visión que busca representar la interacción entre el individuo y su ambiente residencial, comprendido por elementos físicos y sociales. Es decir, de los distintos elementos que van más allá del espacio físico de la vivienda y que involucran aspectos sociales como la relación con los vecinos y los diferentes grupos sociales. (Amérigo, 1994: 31).

En los estudios de satisfacción residencial, el objeto de estudio no se limita a la vivienda, sino que engloba tres elementos fundamentales que son: vivienda, barrio y vecinos. De acuerdo con Amérigo, los primeros estudios de satisfacción residencial desarrollados en las zonas más deprimidas de las ciudades, terminaron por convertirse en estudios limitados que sólo determinaban los

\footnotetext{
${ }^{28}$ Especialmente en Chile donde se han realizado estudios en torno a las distintas soluciones de vivienda que el gobierno ha implementado (Hidalgo, 1998; Andrade et al, 2007; Moyano, 1994).
} 
elementos y condiciones básicas que debían ser tomados en cuenta en las políticas de vivienda para evitar los conflictos entre vecinos.

Las investigaciones de esta autora, tuvieron como propósito principal demostrar que la satisfacción residencial constituye un indicador subjetivo de la calidad de vida de la población y que, por lo tanto, la posesión material de un bien, no garantiza la satisfacción de los individuos (Algaba, 2003). Es decir, la satisfacción que experimentan los habitantes sobre su ambiente residencial no está determinada por los estándares objetivos de un proyecto de vivienda (como el diseño, el número de viviendas, la distribución, etc.), sino más bien depende de la valoración que los individuos realicen a cada uno de los componentes del ambiente residencial (Delgado, 2013: 34).

Los trabajos desarrollados por Amérigo, demostraron que las variables que inciden en la satisfacción de los individuos con respecto a sus entornos inmediatos son múltiples y dinámicas, es decir, responden a construcciones sociales que orientan las aspiraciones que los individuos tienen a lo largo de su vida y que modifican sus expectativas con el paso del tiempo. De esta manera, se entiende que los elementos que contribuyen a su satisfacción con el entorno, no dependan únicamente de las comodidades que éstos puedan llegar a experimentar dentro de la vivienda (Delgado, 2013: 34).

Aunque Amérigo no se cuestiona en sus trabajos si los resultados obtenidos pueden ser utilizados para orientar las políticas sociales en esta materia; en países latinoamericanos como en Chile, se ha hecho uso de este concepto para identificar algunas de las problemáticas que enfrentan los habitantes en las viviendas producidas por el Estado.

El trabajo de María Elena Ducci (1994) concluye, a partir del análisis de la satisfacción residencial, que si bien las familias de menores recursos tienen claro que los programas de vivienda representan una posibilidad casi única de acceder 
a una vivienda, también están conscientes de que éstas les generan problemas importantes que requieren de medidas específicas para mejorar su situación habitacional. Tras considerar a las mujeres como su objeto de estudio, la Dra. Ducci logró identificar problemas como el hacinamiento, la mala calidad de las viviendas, la falta de privacía y de espacios que permitan incorporar a la mujer a mercados de trabajo cercanos a la vivienda (Ducci, 1994: 86-88).

Edwin Haramoto coincide con Amérigo en que, para el análisis de la satisfacción residencial se deben considerar aspectos que van más allá de la valoración de la vivienda. Estos autores encuentran una estrecha relación entre el concepto de satisfacción residencial y el de calidad de vida, debido a que ambos se basan en las percepciones y valoraciones personales de los individuos y permiten medir los niveles de complacencia que las personas perciben del ambiente en que viven, abarcando desde la vivienda hasta su entorno (Andrade et al, 2007: 52).

En general, las investigaciones realizadas en torno a este tema han revelado hasta el momento, que el grado de satisfacción que las personas sienten hacia su vivienda y su entorno, se encuentra más determinado por factores psicosociales como las relaciones vecinales y el apego; que por las características propias de la vivienda. Por lo cual, las percepciones del ambiente residencial que poseen los usuarios...distan en muchas ocasiones de la que poseen aquéllos que diseñan y planifican, tales ambientes (Amérigo, s/f: 7).

Por tal motivo, la satisfacción residencial sobre el ambiente residencial no puede ser garantizada de manera exclusiva por los estándares objetivos de un proyecto de vivienda (densidad, diseño, accesibilidad a los servicios, distribución de la casa, normas de construcción, etc.), sino que depende en mayor medida de las evaluaciones que los habitantes realicen al ambiente residencial. 
En este sentido, se utiliza el concepto de satisfacción residencial como criterio para evaluar las actitudes de la población hacia la solución habitacional otorgada (que pese a su subjetividad, ha sido utilizado de forma recurrente para evaluar la situación habitacional de diversos asentamientos) y como un indicador de la calidad residencial, que como mencionamos con anterioridad, forma parte de los criterios que conforman la definición de calidad vida (Delgado, 2013: 33).

Para los estudios evaluativos de un ambiente residencial, la satisfacción es un constructo clave, puesto que es un buen indicador del éxito de las edificaciones y su entorno a partir de las percepciones, actitudes $y$ comportamientos de los residentes. La satisfacción se considera como un estado de equilibrio afectivo con el hábitat residencial, que se expresa en conductas tales como el deseo de permanecer en el lugar, en oposición a mudarse del mismo (Galster, 1987 en Delgado, 2013: 33).

Por estas razones, se considera que el estudio de la satisfacción residencial resulta una herramienta útil para analizar los Conjuntos Urbanos producidos en el Estado de México, pues de acuerdo con las investigaciones revisadas, proporciona un conjunto de datos valiosos para las administraciones gubernamentales que normalmente no son captados por los métodos objetivos o cuantitativos (Amérigo, s/f: 7.).

Como se ha señalado a lo largo de este documento, los Conjuntos Urbanos conforman espacios que generalmente se insertan en el territorio sin considerar las características de lo que les rodea, lo que nos hace preguntamos, ¿cómo evalúan su vivienda, la relación con los vecinos y su entorno, quienes habitan en estos conjuntos? Pues se trata de espacios con características distintas a los lugares que hasta ahora han sido estudiados por otros investigadores. 
Aunque en nuestro país la Sociedad Hipotecaria Federal ha recurrido al uso de Índices de Satisfacción Residencial en diversos trabajos, ${ }^{29}$ se cree que se trata de estudios muy generales, que no contemplan aspectos que pueden llegar a ser relevantes en la búsqueda de soluciones a los problemas planteados, tales como las características específicas de la población (escolaridad, niveles de ingreso, entre otros), el tiempo que se tiene habitando en determinado espacio, entre otros factores, que pueden ser útiles para la comparación entre diferentes Conjuntos. Además, se trata de investigaciones normalmente realizadas a poco tiempo de que la vivienda ha sido adquirida (un año aproximadamente), por lo que no dan cuenta de las percepciones de los habitantes tras años de residir en un mismo lugar, ni de las valoraciones generadas alrededor de los espacios que componen el entorno inmediato a su vivienda, ni tampoco de los tipos de relaciones que los habitantes establecen con sus vecinos.

Elementos que sin duda, resultan relevantes para el análisis de la satisfacción residencial debido a que la vivienda, el barrio (entendido como el área donde el individuo establece sus redes sociales y sobre la que construye un sentimiento de pertenencia) y los vecinos, son factores bajo los cuales se construye el punto de vista que los usuarios tienen ante su vivienda; siendo de

\footnotetext{
${ }^{29}$ La Sociedad Hipotecaria Federal, realiza anualmente una encuesta de Satisfacción Residencial, con el objetivo de evaluar el grado de satisfacción de la población que adquirió una vivienda nueva en el último año, obtenida mediante financiamientos hipotecarios. Con ello se busca [...] informar a los participantes del mercado de la vivienda los resultados de esta investigación anual con el fin de propiciar políticas públicas, así como estrategias privadas, tendientes a mejorar la calidad de las viviendas, ciudades y la atención al cliente final". Sin embargo, el público objetivo de la encuesta ha variado en los últimos años de aplicación, mientras que en 2011 la encuesta estaba dirigida a los hogares con un ingreso máximo de 6.28 salarios mínimos (de 2010), para el año 2012 y los periodos subsecuentes la encuesta fue aplicada a hombres y mujeres de 18 años o más residentes de los conjuntos habitacionales seleccionados Sociedad Hipotecaria Federal, Resultados Relevantes de la Encuesta de Satisfacción Residencial, Dirección de Estudios Económicos de la Vivienda en México, Disponible en:

http://www.shf.gob.mx/Transparencia/TranspFocalizada/Paginas/ResultadosEncuestaResidencial.a spx (Consultado el: 28 de noviembre de 2015). Motivos por los cuales se trata de información que no puede ser comparada en el tiempo.
} 
vital importancia la consideración de las opiniones y sentimientos subjetivos que produce el entorno residencial a sus habitantes (Amérigo en Arends, 2012: 5).

\subsection{Las mujeres como sujeto de investigación}

Diversas investigaciones (Román y Velázquez, 2009; Ducci, 1994; Ayuntamiento de Fuenlabrada España, 2007) han dado cuenta de la importancia de incorporar a las mujeres en el desarrollo, planeación e implementación de políticas públicas; especialmente en aquéllas relacionadas con la vivienda y el desarrollo urbano. Esto, debido a que existen diversos aspectos como la incorporación de las mujeres al mercado laboral que exigen un replanteamiento profundo de las tipologías de vivienda (Ayuntamiento de Fuenlabrada España, 2007: 10).

Como señala Ducci (1994), las mujeres juegan un papel importante en el desarrollo de las sociedades: a nivel demográfico por ejemplo, sabemos que el aumento en el nivel educativo de este sector, ha dado lugar a su incorporación en los mercados de trabajo y con ello, a la disminución de la natalidad.

Aunque algunas corrientes de pensamiento sugieren que la desintegración familiar es resultado de esta incorporación a las actividades productivas, diversos estudios han demostrado que las tareas realizadas por las mujeres en el ámbito laboral son trascendentales, especialmente para los sectores populares de la población, donde las mujeres fungen como proveedoras y muchas veces como el único sostén económico del hogar (Ducci, 1994: 75).

Lo anterior ha dado lugar a una serie de transformaciones no sólo de la estructura familiar, sino también de la dinámica dentro de ellas. Debido a que el acceso a recursos económicos ha permitido que las mujeres se desliguen poco a poco de su papel de mujer-esposa-ama de casa, para convertirse en una mujer trabajadora con posibilidades de independizarse no sólo económicamente de sus esposos o parejas, sino también, con la posibilidad de acceder a mayores niveles 
de educación. Esto, a su vez, implica una transformación en la manera en que ellas perciben y viven el espacio urbano; ya que las mujeres que trabajan y que al mismo tiempo se encargan del hogar, tienen necesidades y formas distintas de conducirse en la ciudad (Fernández, 1996). Incluso aquellas mujeres que se dedican de manera exclusiva a las tareas reproductivas realizadas en casa, desarrollan estrategias y prácticas de habitar específicas para poder acceder a los espacios y servicios que las urbes ofrecen. Por eso para algunos países europeos, se ha vuelto importante administrar y gestionar las ciudades pensando en quién y cómo se utilizan.

La importancia de incluir la perspectiva de género en la evaluación de políticas y en la planeación de las ciudades, radica precisamente en este papel que las mujeres juegan en el hogar, en la familia, en la realización de tareas domésticas, y en otras actividades relacionadas de manera directa con la vida cotidiana de los habitantes. Cristina Sánchez Mejorada (1996) señala que en los sectores populares, las mujeres desempeñan un rol muy valioso a nivel político, ya que la organización social es una herramienta que en muchas ocasiones les permite mejorar sus condiciones de vida y las de sus familias. Siendo ellas, quienes participan en organizaciones vecinales o políticas que les permiten alcanzar el objetivo de satisfacer las necesidades de consumo y habitabilidad de sus barrios o colonias. Por lo que las condiciones en el ámbito doméstico pueden ser factores que estimulen su participación en organizaciones, para dar solución a los problemas que enfrentan en lo privado.

Esta lucha por la tierra, la vivienda, los servicios básicos, los equipamientos colectivos y en general por sus derechos como persona $y$ como mujer, es una reacción frente a situaciones de exclusión y de carencia que aquejan a importantes sectores de la población y que derivan de una expansión de las situaciones de pobreza y en un progresivo desentendimiento con el Estado en el campo del consumo colectivo. Para muchas mujeres la organización se constituye además de una instancia asociada a su estrategia de supervivencia material, en 
un espacio afectivo, de pertenencia e identidad grupal, de expresividad, de socialización y de intercambio de experiencias" (Sánchez-Mejorada, 1996: 151).

Es importante tener en cuenta que la vivienda ha adquirido en los últimos años otros significados que van más allá de su función de habitar, debido a que ésta se ha convertido en la inversión más importante y en el patrimonio principal de las familias. No obstante, la rigidez con la que actualmente se construyen las viviendas, se ha convertido en un impedimento para que este espacio logre adaptarse a los cambios de la sociedad, convirtiéndose en muchas ocasiones en una barrera para la integración, la autonomía e incluso para alcanzar niveles de igualdad entre hombres y mujeres (Ayuntamiento de Fuenlabrada España, 2007: 18).

Estas razones nos invitan a reflexionar sobre las implicaciones de las intervenciones y soluciones en materia de vivienda planteadas en nuestro país en los últimos años, ya que éstas impactan de manera distinta a la población según el sexo y la edad de los habitantes. En este sentido, [...] pensar formas de incorporar a las mujeres en el diseño de los barrios, preguntando cuáles son sus necesidades, sus expectativas y su situación vital, es una medida que puede mejorar enormemente la vida colectiva futura (Ayuntamiento de Fuenlabrada España, 2007: 18).

Por ello, consideramos que incluir la visión de las mujeres en esta investigación puede ser una herramienta importante a la hora formular propuestas que reconozcan un enfoque distinto en las políticas de vivienda, pero sobre todo, porque la participación de este sector de la población, aporta elementos que permiten adecuar las viviendas a los nuevos papeles que los hombres y mujeres juegan dentro de la sociedad y generar soluciones a los problemas que actualmente presentan los Conjuntos Urbanos. 


\section{CAPÍTULO 3. EL MUNICIPIO DE CUAUTILTLÁN Y EL CONJUNTO URBANO RANCHO SANTA ELENA}

El municipio de Cuautitlán se encuentra ubicado en la zona oriente del Estado de

Figura 1. Localización del municipio de Cuautitlán

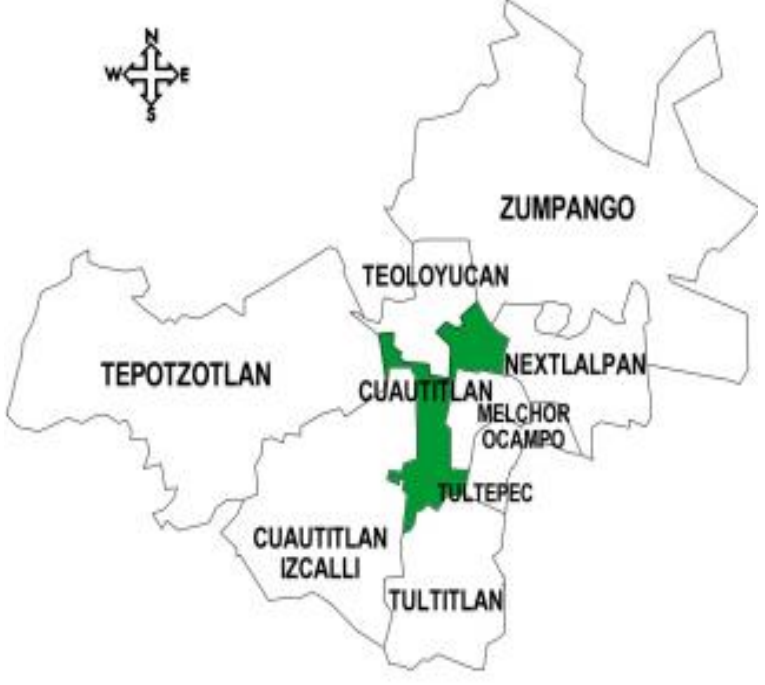

Fuente. Plan Municipal de Desarrollo Urbano del municioio de Cuautitlán 2008.
México, colinda al norte con los municipios de Teoloyucan y Zumpango; al sur con el municipio de Tultitlán; al poniente con Cuautitlán Izcalli y Tepotzotlán; y al oriente con Melchor Ocampo y Tultepec.

Pertenece a la Zona Metropolitana del Valle de Cuautitlán-Texcoco que está conformada por 59 municipios, de los cuales 35 (incluido Cuautitlán), forman parte de la Zona Metropolitana del Valle de México. La importancia de esta área radica en su alto potencial para ser receptora de nueva población y del futuro crecimiento de la metrópoli, debido a que gran parte de su territorio está constituido por usos de suelo agrícola ( $51 \%$ de la superficie total), siendo únicamente $16 \%$ la superficie urbanizada (PRDUVCT, 2005:60).

El municipio ha estado desde siempre, fuertemente vinculado a los procesos de expansión y crecimiento de la ciudad; su localización geográfica le permite jugar un papel importante en el desarrollo de las actividades industriales y comerciales de la zona. Recientes descubrimientos arquitectónicos ${ }^{30}$ revelaron

\footnotetext{
30 Véase. Instituto Nacional de Antropología e Historia. Boletín N 182, 12 de julio de 2016. Disponible

en: http://www.inah.gob.mx/images/boletines/pdf//article/5396/20160712_boletin_182.pdf (Consultado el: 1 de agosto de 2016).
} 
que Cuautitlán, fue durante la época prehispánica ${ }^{31}$ uno de los centros religiosos, políticos y comerciales más relevantes de la parte noroccidental del Valle.

Al crearse el Estado de México durante la etapa de Independencia, pasó a formar parte de la administración política del distrito IV de México. Y en la década de los años treinta, comenzaron los primeros trabajos de modernización de los servicios de infraestructura (especialmente de drenaje y dotación de agua potable) de la entonces llamada Villa de Cuautitlán, que ya contaba con servicios de electricidad (Fragoso, García y Palacios, 2010).

Hasta finales de 1957 su territorio estuvo conformado por una Villa, 7 pueblos, 3 barrios, 6 haciendas, 38 ranchos, una ranchería y 2 colonias; y habitaban en él poco más de 13, 622 personas (Ídem).

\subsection{Antecedentes}

\subsubsection{Crecimiento de la industria y desarrollo urbano}

Durante el periodo gubernamental de Gustavo Baz Prada (1957-1963) muchos de los municipios del Estado de México, vieron transformada seriamente su vocación agrícola, al ceder amplias cantidades de terreno a las grandes industrias. E desarrollo industrial del municipio estuvo fuertemente respaldado por diversas leyes estatales y municipales $^{32}$ que tuvieron como objetivo orientar la modernización del Estado de México e impulsar el desarrollo de las actividades urbano-industriales como motores de desarrollo y crecimiento económico,

\footnotetext{
${ }^{31}$ En el periodo que comprende de 1350 a 1519 después de Cristo el municipio pasa a formar parte de la Triple Alianza y dominaba una amplia zona a su alrededor (ibid).

32 Prueba de ello, fueron las expropiaciones realizadas por Carlos Hank González entre 1969-1975, con las que se brindaron nuevos espacios a la planta industrial del Estado de México (Osorio, 2006: 7).
} 
especialmente en la franja norte integrada por los municipios de Cuautitlán, Cuautitlán Izcalli, Tultitlán, Naucalpan, Tlalnepantla y Ecatepec (Osorio, 2006: 7).

Un factor que favoreció de manera decisiva el crecimiento de la planta industrial de Cuautitlán y su consecuente desarrollo urbano, fue la construcción de la autopista México-Querétaro a finales de 1960. Esta obra de infraestructura vial incentivó la creación de empresas e industrias nuevas que buscaban aprovechar la conectividad que la autopista proporcionaba; a finales de 1970 se habían establecido en Cuautitlán cinco nuevos espacios fabriles de gran importancia, como la Laminadora Mexicana (Osorio, 2006: 7).

En agosto de 1969 se construyó el parque industrial "La Luz", sobre una superficie fraccionada de terrenos ejidales. Aquí se generaron 39 lotes de aproximadamente $11,800 \mathrm{~m}^{2}$, que albergan a poco más de 31 industrias y dos naves industriales. El Complejo Industrial de Cuamatla (que cuenta con 39 de los establecimientos más grandes de la zona, tres naves industriales y cuatro terrenos baldíos) fue construido en 1971 en una superficie de terreno de 1, 028,494.44 $\mathrm{m}^{2}$ que pertenecían a la ex hacienda de Cuamatla, localizada en los límites de los municipios de Cuautitlán y Cuautitlán Izcalli (Osorio, 2006: 7).

Las obras de mejoramiento de la infraestructura vial llevadas a cabo por las autoridades municipales en 1990, incentivaron la construcción de nuevas plantas industriales en los años subsecuentes -la mayoría asentadas sobre terrenos ejidales y pequeñas propiedades de uso agrícola-, de manera que para 1994, el municipio contaba con un total de 153 establecimientos industriales que lo colocaban como el sexto municipio con mayor aportación al Producto Interno Bruto estatal (con 2.39\%), después de Tlalnepantla, Naucalpan, Toluca, Ecatepec y Cuautitlán Izcalli (Osorio, 2006: 8). 


\subsubsection{Desarrollo urbano de 1950-2016}

El desarrollo habitacional del municipio suscitado entre 1950 y 1970 es resultado en gran parte- de la promoción de dos tipos de fraccionamientos: uno producto de las promociones inmobiliarias dirigidas por este sector y otro, que surge de las concesiones de lotes otorgadas por el gobierno estatal a los campesinos del ejido de Cuautitlán. ${ }^{33}$

Otro de los acontecimientos que alteró el desarrollo económico y social de este municipio, fue la creación ${ }^{34}$ en 1971 del municipio 121 conocido bajo el nombre de Cuautitlán Izcalli; que fue erigido sobre antiguos territorios de los municipios de Cuautitlán, Tepotzotlán y Tultitlán. Con esta medida Cuautitlán cedió más de la mitad de su territorio, ocasionándole pérdidas de recursos naturales, humanos y de una gran cantidad de ingresos que obtenía a través de la recaudación de impuestos (Fragoso et al, 2010).

Durante este periodo (1979-1988) se registró el mayor crecimiento urbano del municipio, con esto la estructura urbana se vio rebasada ya que no se contaba con la infraestructura, ni el equipamiento que eran requeridos por la dinámica de población de la época.

El crecimiento de la industria señalado anteriormente, dio origen a importantes movimientos inmigratorios de población que venía en busca de oportunidades laborales; lo cual, acarreó serios problemas relacionados con el incremento de la demanda de vivienda, asentamientos irregulares, así como la insuficiencia de los servicios públicos y de infraestructura. La llegada de las industrias y la tendencia de crecimiento del área urbana, provocaron la transformación original del uso de suelo en este municipio, desplazando los usos

\footnotetext{
${ }^{33}$ Según datos del Instituto Nacional de Geografía y Estadística (INEGI) para este año, el municipio albergaba a una población de 41,156 habitantes, misma que fue incrementando de manera progresiva, gracias a las transformaciones suscitadas en torno a su estructura económica y territorial.

${ }^{34}$ Mediante el decreto número 50 expedido por el Congreso local, el 23 de junio de 1973.
} 
agrícolas y pecuarios por los de vivienda, industria, comercios, servicios y equipamiento urbano (PDUMC, 2008).

Esto se debe principalmente, al incremento sustancial de la demanda de vivienda por parte de la población metropolitana en edad de formar una familia, tal como se admite en el Programa Municipal de Desarrollo Urbano de Cuautitlán (2008).

"Esta situación ha traído como consecuencia una mezcla incompatible de zonas homogéneas (agrícolas y pecuarias) con áreas habitacionales, distritos comerciales, de servicios y de equipamientos, que inciden de manera negativa en el desarrollo urbano del municipio, dada la carencia de un Plan de Desarrollo Urbano acorde a las necesidades propias y particulares que presenta el municipio" (PDUMC, 2008).

Junto con los municipios de Naucalpan, Tlalnepantla y Ecatepec, Cuautitlán concentra en la actualidad el $60 \%$ de la ocupación industrial, el comercio y los servicios de la llamada Región del Valle de Cuautitlán-Texcoco (RVCT). Pese a ello, los datos indican que el sector industrial de esta zona ha ido perdiendo fuerza en los últimos años, debido al alto costo de los servicios de transporte, la lejanía entre las viviendas y las fuentes de trabajo, así como al aumento del congestionamiento vial y otros factores, que han contribuido a la reducción de la productividad de los trabajadores de estas industrias (PRDUVCT, 2005:57).

Para la década de los años noventa, el municipio ya adolecía de una falta de integración, acentuada por el incremento demográfico y urbano, que se tradujo en la localización de nuevos asentamientos humanos, que rodearon a la Cabecera Municipal y las localidades de Santa María Huecatitla y San Mateo Ixtacalco, así como la ubicación de áreas industriales, como el Corredor Industrial TultitlánCuautitlán. 
Este crecimiento se generó principalmente por el desarrollo de conjuntos habitacionales creados entre 1995 y 2009 como: Misiones, Rancho Santa Elena, Rancho San Blas, Hacienda Cuautitlán, Paseos de Cuautitlán, Villas de Cuautitlán, entre otros.

Durante este periodo la población tuvo incremento de $244 \%$ asociado en su mayoría al número de conjuntos urbanos construidos. Esto ha dado lugar a que el municipio enfrente dificultades para proveer de servicios públicos y urbanos a toda la población; a grandes rasgos actualmente, enfrenta problemas de insuficiencia en la cobertura de recolección de basura, mantenimiento adecuado de áreas verdes, mantenimiento de drenajes y alcantarillas, instalación y mantenimiento de alumbrado público (Osorio, 2006: 6).

Cabe señalar, que su colindancia con los municipios de Cuautitlán Izcalli y Tepotzotlán (donde se situaron grandes parques industriales) lo ha convertido en objeto de transformaciones físicas importantes, relacionadas con el desarrollo de vías de comunicación y transporte, que permiten conectar a los municipios con los parques industriales. Asimismo, las empresas inmobiliarias han aprovechado la infraestructura urbana introducida por las industrias (carreteras, servicios de drenaje, tuberías de agua potable, pavimentado de calles, etc.) para construir alrededor de estos espacios, una serie de conjuntos urbanos, que de alguna manera, dan respuesta a la demanda de vivienda de la zona.

El actual límite de crecimiento urbano del municipio ya ha sido rebasado, como producto del desarrollo urbano y el asentamiento de población proveniente de otros lugares; lo que ha dado lugar a la expansión del área urbana sobre las áreas agropecuarias, especialmente en la zona sur del municipio. Como resultado de lo anterior, el municipio se ha visto inmerso en conflictos de límites municipales que se han agravado por la conformación vial y la heterogeneidad de su población y de los asentamientos humanos. 
Otro elemento que generó un gran impacto en el municipio, fue la creación del Ferrocarril Suburbano, estación Cuautitlán. Antes y después de su inauguración (en el año 2009) un número importante de inmobiliarias anunciaba sus conjuntos habitacionales, ofreciendo como ventaja la cercanía con este medio de transporte que conecta al municipio con la Ciudad de México. Aumentando con ello a $51 \%$ la superficie de suelo urbanizado y reduciendo a $29 \%$ el suelo de tipo agrícola. De acuerdo con Plan de Desarrollo Municipal de Cuautitlán 2013-2015, se espera que para el año 2020 la población del municipio se duplique (COESPO)..$^{35}$

Actualmente, el Plan de Desarrollo Municipal (2016-2018) reconoce la existencia de 18 Conjuntos Urbanos de distintas características y dimensiones ubicados lejos de la cabecera municipal, pero cercanos a la estación del Tren Suburbano. Entre los que destaca el Conjunto Urbano Rancho Santa Elena por su tamaño en cuanto a número de viviendas y población que alberga (véase plano 1).

Finalmente, es importante señalar que en los últimos 15 años, el municipio ha experimentado importantes cambios demográficos asociados a diversos factores como el desarrollo de zonas industriales en la zona y el consecuente incremento de la demanda habitacional que propiciaron su transición de la categoría de zona rural a municipio metropolitano. Entre 1990 y el año 2000 la tasa anual de crecimiento de Cuautitlán fue de 5.8\%, una de las tasas más altas registradas en la región durante este periodo, ${ }^{36}$ para el año 2005 el municipio ya contaba con un total de 110,345 habitantes y para 2010 la población habría

${ }^{35}$ Consejo Estatal de Población. Disponible en: http://portal2.edomex.gob.mx/coespo/index.htm. (Consultado el 18 de junio de 2015).

36 De acuerdo con el Plan Regional de Desarrollo Urbano del Valle de Cuautitlán-Texcoco (PRDUVCT, 2005: 51) durante el periodo de 1990-2000 Cuautitlán fue uno de los municipios que junto con Chalco, Nextlalpan e Ixtapaluca, alcanzaron tasas de crecimiento de población superiores al $5 \%$, siendo las más altas de la Región (destacando el caso de Ixtapaluca que alcanzó una tasa de $11.37 \%$ para los años señalados). 
incrementado a 140,059 habitantes, es decir, en tan sólo una década la población de Cuautitlán tuvo un incremento porcentual de $84.7 \%$ (cuadro 2).

Plano 1. Ubicación de los Conjuntos Urbanos del Municipio de Cuautitlán.
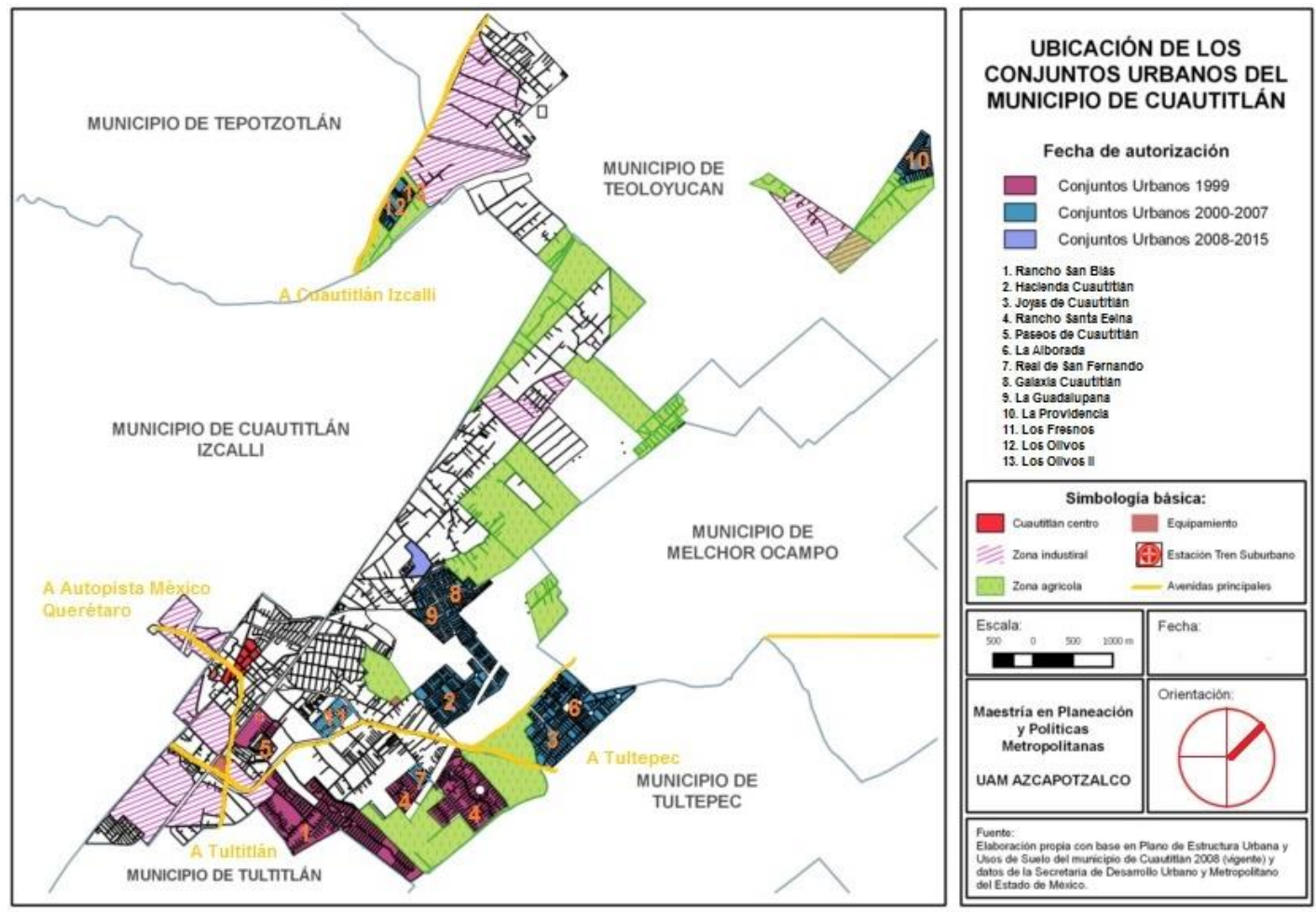

municipio

Elaboración propia con base en el mapa de Estructura urbana y usos de suelo de http://seduv.edomexico.gob.mx/planes_municipales/cuautitlan/E-2\%20Layout1\%20(.pdf ${ }^{37}$.

\subsection{Características de la población}

Este apartado tiene como objetivo exponer información general del municipio de Cuautitlán, con el fin de contextualizar el trabajo de investigación llevado a cabo para la realización de esta tesis.

37 Nota. Este plano sólo muestra los Conjuntos Urbanos que fueron autorizados entre 1999 y la fecha actual; fue elaborado a partir de la cartografía geo estadística urbana del INEGI 2010. 


\subsubsection{Número de habitantes}

De acuerdo con datos del Instituto Nacional de Estadística y Geografía (INEGI) la población actual del municipio de Cuautitlán asciende a 140, 059 personas; de éstas $50.7 \%$ son mujeres y $49.3 \%$ son hombres.

Cuadro 2. Población total e incremento porcentual, 1990-2010 municipio de Cuautitlán y total municipios conurbados a la ZMCM

\begin{tabular}{|c|c|c|c|c|c|c|c|}
\hline \multirow{2}{*}{ Zona } & $\begin{array}{c}\text { Población } \\
\text { total }\end{array}$ & $\begin{array}{c}\text { Población } \\
\text { total }\end{array}$ & $\begin{array}{c}\text { Incremento } \\
\mathbf{1 9 9 0 - 2 0 0 0}\end{array}$ & $\begin{array}{c}\text { Incremento } \\
\text { porcentual } \\
\mathbf{1 9 9 0 - 2 0 0 0}\end{array}$ & $\begin{array}{c}\text { Población } \\
\text { Total 2010 }\end{array}$ & $\begin{array}{c}\text { Incremento } \\
\mathbf{2 0 0 0 - 2 0 1 0}\end{array}$ & $\begin{array}{c}\text { Incremento } \\
\text { porcentual } \\
\mathbf{2 0 0 0 - 2 0 1 0}\end{array}$ \\
\cline { 2 - 8 } & $\mathbf{1 9 9 0}$ & $\mathbf{2 0 0 0}$ & $\mathbf{2 0 0 0}$ & & & & \\
\hline $\begin{array}{c}\text { Total municipios conurbados a } \\
\text { la ZMCM }\end{array}$ & $7,297,758$ & $9,745,094$ & $2,447,336$ & $11,168,301$ & $1,423,207$ & 14.6 \\
\hline Cuautitlán & 48,858 & 75,836 & 26,978 & 55.2 & 140,059 & 64,223 & 84.7 \\
\hline
\end{tabular}

Elaboración propia con base en INEGI Censos de Población y vivienda 1990-2010.

Pese a que el promedio de edad del municipio es de 27 años, los porcentajes reflejados en la gráfica 1, indican que la población de esta región se encuentra conformada en su mayoría por niños (19.20\%), adolescentes (18.71\%) y adultos maduros (18.08\%). ${ }^{38}$

En lo que respecta a la distribución de la población según rangos de edad y sexo, encontramos que existen más hombres que mujeres en los rangos de los 0 a los 24 años de edad; sin embargo a partir de los 25 años, esta situación se invierte y es más el número de mujeres en edad adulta y en la vejez. Esto resulta

\footnotetext{
${ }^{38} \mathrm{La}$ Organización Mundial de la Salud (OMS) define a las diferentes etapas de la vida humana de acuerdo al conjunto de cambios fisiológicos y momentos sociales por los que atraviesa una persona. De acuerdo con este organismo, los Preescolares son aquellas personas de 0 a 6 años de edad y los Escolares (etapa conocida también como Niñez Intermedia) son los que se ubican en el rango de 7 a 11 años. Para fines de este trabajo, se decidió agrupar en una sola categoría nombrada Niños para referirse a los dos grupos de edades anteriormente mencionados.

Por otra parte, siguiendo las definiciones establecidas por la OMS, entenderemos por Adolescentes a cualquier sujeto cuya edad este comprendida entre los 10 y los 20 años de edad; y hablaremos de Adultos Maduros para hacer referencia a las personas que poseen entre 35 y 59 años de edad. Véase. http://www.sld.cu/galerias/pdf/sitios/pdvedado/prescolar.pdf
} 
relevante ya que se sabe que la edad es una variable que repercute de manera directa en el tipo de necesidades y demandas de la población.

Gráfica 1. Pirámide de edad del municipio de Cuautitlán, 2010

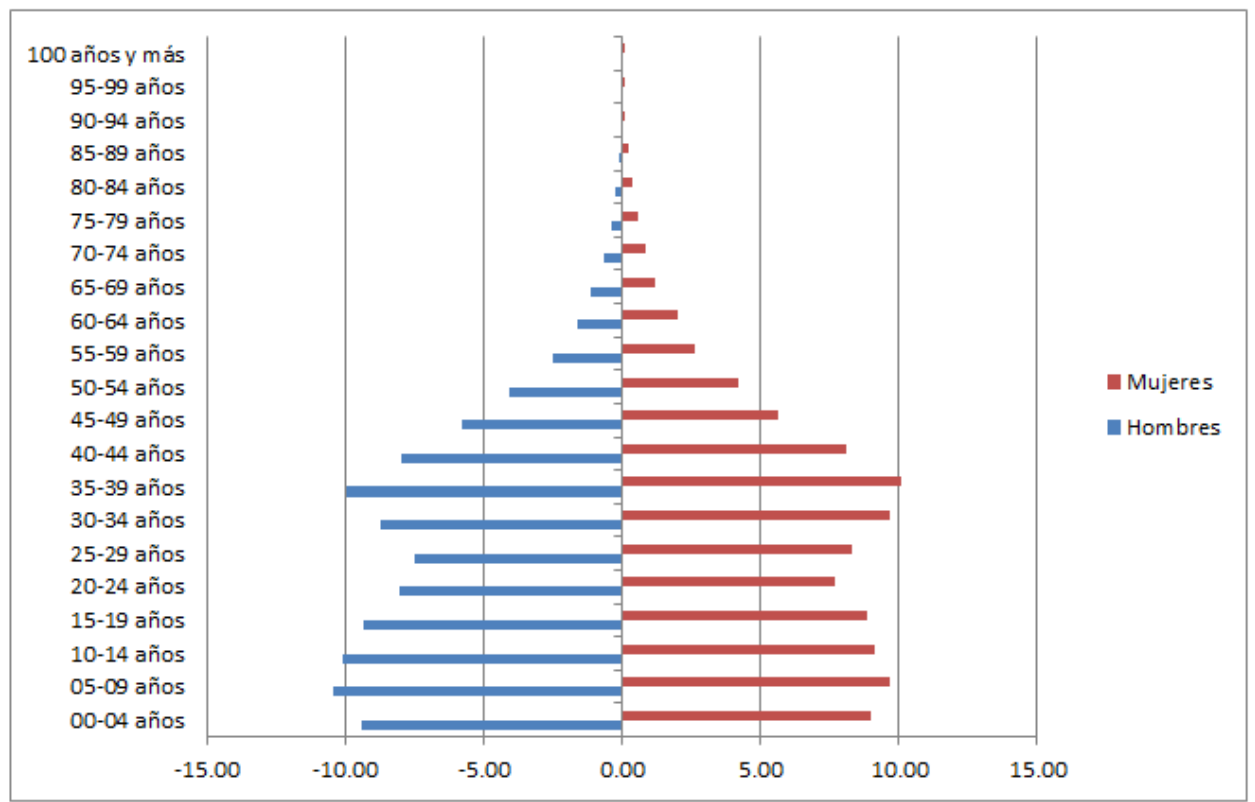

Elaboración propia con datos del INEGI.

\subsubsection{Escolaridad}

De acuerdo con la Organización de las Naciones Unidas para la Educación, la Ciencia y la Cultura (UNESCO por sus siglas en inglés), la educación es uno de los derechos más importantes debido a que constituye una herramienta que promueve la libertad, la autonomía personal y genera grandes beneficios para el desarrollo. ${ }^{39}$ Se trata de un elemento que permite incrementar las potencialidades individuales, provee nuevos conocimientos y brinda a los individuos la posibilidad de desarrollar sus proyectos de vida de manera más armónica, acceder a mejores

\footnotetext{
${ }^{39}$ http://www.unesco.org/new/es/right2education
} 
oportunidades laborales y ejercer de forma plena sus derechos (CONAPO, 2002:14).

Para el INEGI conocer el nivel educativo de una población, resulta útil en la evaluación y dirección de políticas públicas, planes y programas gubernamentales. De acuerdo con este Instituto, la condición de alfabetismo es un factor que incide de manera directa en el grado de desarrollo de una nación y se define a partir de la capacidad o no, que tiene la población de 15 años y más para leer o escribir un recado (INEGI, 2010: 62).

Cuadro 4. Nivel de escolaridad de la población de 15 años y más, según porcentaje

\begin{tabular}{|c|c|c|c|c|c|c|}
\hline \multirow{2}{*}{ Nivel de escolaridad } & Total & \% Total & Hombres & \%Hombres & Mujeres & \% Mujeres \\
\cline { 2 - 7 } & $\mathbf{9 7 , 2 1 9}$ & $\mathbf{1 0 0}$ & $\mathbf{4 7 , 1 7 5}$ & $\mathbf{1 0 0}$ & $\mathbf{5 0 , 0 4 4}$ & $\mathbf{1 0 0}$ \\
\hline Sin escolaridad & 1,940 & 2.00 & 642 & 1.36 & 1,298 & 2.59 \\
\hline Educación básica & 43,030 & 44.26 & 20,797 & 44.08 & 22,233 & 44.43 \\
\hline $\begin{array}{c}\text { Estudios técnicos o comerciales con } \\
\text { primaria terminada }\end{array}$ & 789 & 0.81 & 164 & 0.35 & 625 & 1.25 \\
\hline Educación media superior & 29,738 & 30.59 & 14,540 & 30.8 & 15,198 & 30.37 \\
\hline Educación superior & 21,166 & 21.77 & 10,755 & 22.8 & 10,411 & 20.80 \\
\hline
\end{tabular}

Nota. No se incluyen los datos de la categoría no especificado.

Elaboración propia con base en INEGI Censo de Población y Vivienda 2010.

En el caso del municipio de Cuautitlán encontramos que $97.9 \%$ de los habitantes de 15 años y más es alfabeta, siendo mayor el porcentaje de mujeres que saben leer y escribir (51.17\%). El $72.42 \%$ de las personas que no saben leer ni escribir son mujeres y en general, los mayores porcentajes de analfabetismo corresponden a hombres y mujeres de más 50 años edad (véase cuadro 3 disponible en los anexos).

Pese a que la condición de analfabetismo es algo que afecta de manera significativa la vida de cualquier persona, es importante destacar que, en el caso de los adultos mayores, esta situación se convierte muchas veces en un 
impedimento considerable, ya que deben afrontar la vejez bajo circunstancias que los exponen a un grado mayor de vulnerabilidad.

En lo que respecta al Nivel y grado de escolaridad ${ }^{40}$ de la población, encontramos que el grado promedio de escolaridad de la población de 15 años y más de 10.38 años. 44\% de los habitantes del municipio contaba al año 2010 con educación básica, $30.59 \%$ con educación media, $21.77 \%$ con superior. Conocer el nivel de escolaridad de la población permite evaluar la demanda educativa en los distintos niveles del Sistema Educativo Nacional y establecer planes que permitan la ampliación y mejoramiento de los servicios (INEGI, 2010: 65).

\subsubsection{Acceso a servicios de salud}

Los datos mostrados en el cuadro 5 revelan que en el municipio de Cuautitlán, solamente $65.60 \%$ de la población tiene acceso a servicios de salud. Mientras que $34.40 \%$ no es derechohabiente. ${ }^{41}$

Cuadro 5. Derechohabiencia a servicios de salud, según sexo e institución de salud

\begin{tabular}{|c|c|c|c|}
\hline Condición de derechohabiencia & Total & Hombres & Mujeres \\
\hline Total & $\mathbf{1 4 1 , 0 2 3}$ & $\mathbf{6 9 , 5 3 4}$ & $\mathbf{7 1 , 4 8 9}$ \\
\hline IMSS & 69,664 & 34,441 & 35,223 \\
\hline ISSSTE & 6,669 & 3,048 & 3,621 \\
\hline ISSSTE estatal & 1,898 & 877 & 1,021 \\
\hline Pemex, Defensa o Marina & 768 & 378 & 390 \\
\hline Seguro Popular o para una Nueva Generación & 7,182 & 3,154 & 4,028 \\
\hline Institución privada & 2,274 & 1,179 & 1,095 \\
\hline Otra institución & 4,058 & 1,923 & 2,135 \\
\hline No derechohabiente & 44,672 & 22,180 & 22,492 \\
\hline No especificado & 3,838 & 2,354 & 1,484 \\
\hline
\end{tabular}

Elaboración propia con base en INEGI, Censo de Población y Vivienda, 2010.

Nota: La suma de los derechohabientes en las distintas instituciones de salud puede ser mayor al total por aquella población que tiene derecho a este servicio en más de una institución de salud.

\footnotetext{
${ }^{40}$ Esta variable permite conocer los cambios y avances en materia de educación; mediante ella se puede tener una idea clara del grado promedio de escolaridad alcanzado por la población en su conjunto (INEGI, 2010: 65).

${ }^{41}$ Este porcentaje incluye a la población de la categoría No especificado.
} 
De la población que tiene acceso a algún tipo de servicio de salud, $75.30 \%$ se encuentra afiliada al IMSS, $7.76 \%$ al ISSSTE, $7.21 \%$ al Seguro Popular, $4.43 \%$ recibe servicios de salud de otra institución, $2.46 \%$ de una institución privada, $2.05 \%$ del ISSSTE estatal y $0.83 \%$ tiene acceso a instituciones como Pemex, Defensa o la Marina.

Estos datos son importantes debido a que la salud es un factor indispensable para garantizar el bienestar de las personas. El tener acceso a servicios de salud disminuye la vulnerabilidad de los individuos y de sus familias ante el embate de las enfermedades, al tiempo que facilita el aprovechamiento de una gama de servicios de salud de corte preventivo, los cuales inciden positivamente sobre la calidad de vida de las personas (CONAPO, 2002: 13).

Por lo cual resulta preocupante con un número significativo de la población de este municipio no tenga acceso a servicios de salud.

\subsubsection{Hogares}

INEGI define al hogar como el núcleo de residentes de la vivienda con independencia de sus vínculos de parentesco. De acuerdo con este Instituto, los hogares se clasifican en dos tipos:

1. Hogares familiares: divididos a su vez y de acuerdo a sus características en hogares nucleares, ampliados y compuestos.

2. Hogares no familiares: refieren a aquellos hogares unipersonales y de corresidentes.

Identificar a los núcleos familiares que viven bajo el mismo techo es de suma importancia, ya que conocer el tipo de hogares que residen en determinado espacio y su relación con otras variables demográficas, sociales y económicas 
permite conocer la situación de rezago o vulnerabilidad social que guardan algunas familias mexicanas (INEGI, 2011: 125), así como atender a las necesidades y demandas de la población, que como ya mencionábamos anteriormente, se definen a partir de las características demográficas de la población.

En Cuautitlán, $98.06 \%$ de la población habita en hogares familiares y sólo $1.94 \%$ corresponden a la categoría de no familiares. ${ }^{42}$ De los primeros, $69.8 \%$ habitan en hogares nucleares, es decir, están conformados por el jefe (a) de familia y su cónyuge; el jefe (a) y los hijos; o el jefe (a), cónyuge e hijos (INEGI, 2010).

Cuadro 6. Porcentajes de población en hogares censales, según tipo y clase de hogar censal.

\begin{tabular}{|c|c|c|c|c|c|c|c|}
\hline \multirow{3}{*}{$\begin{array}{c}\text { Población en } \\
\text { hogares censales }\end{array}$} & \multicolumn{7}{|c|}{ Tipo y clase de hogar censal } \\
\hline & \multicolumn{4}{|c|}{ Familiar } & \multicolumn{3}{|c|}{ No familiar } \\
\hline & Total & $\%$ Nuclear & $\%$ Ampliado & $\begin{array}{c}\% \\
\text { Compuesto }\end{array}$ & Total & $\begin{array}{c}\% \\
\text { Unipersonal } \\
\end{array}$ & $\begin{array}{c}\% \mathrm{De} \\
\text { corresidentes }\end{array}$ \\
\hline 136,532 & 133,887 & 69.81 & 27.61 & 1.01 & 2,654 & 88.02 & 7.65 \\
\hline
\end{tabular}

Elaboración propia con base en INEGI, Censo de Población y Vivienda, 2010.

$27 \%$ de las personas que habitan en hogares familiares corresponden a la categoría de hogares ampliados, formados por un hogar nuclear y al menos otro pariente. Mientras que solamente $1.01 \%$ de la población del municipio habita en hogares de tipo compuesto; de acuerdo con INEGI, los hogares compuestos están formados por un hogar nuclear o ampliado y al menos un integrante sin parentesco.

\footnotetext{
${ }^{42}$ Estos datos corresponden a la población del municipio de Cuautitlán que reside en hogares censales, entendidos como aquellas unidades formadas por una o más personas, vinculadas o no por lazos de parentesco, que residen habitualmente en la misma vivienda particular (INEGI, Glosario del Censo de Población y Vivienda, 2010).
} 
Por otro lado, encontramos que de las 2,654 personas que habitan en hogares censales no familiares, $88.02 \%$ residen en hogares unipersonales y $7.65 \%$ en hogares de corresidentes.

Cuando hablamos del tema de vivienda estos datos son esenciales, pues permiten conocer qué tipo de vivienda requiere la población de acuerdo al número de personas que habitan ella y las características de las familias.

\subsubsection{Actividades económicas de la población}

El empleo es quizás una de las variables más relevantes cuando se trata de describir las características de determinada población, ya que la posibilidad de obtener un ingreso repercute de manera directa en las condiciones de acceso a satisfactores básicos como alimentos, luz, agua, vivienda, vestido, etc.

En el caso del municipio de estudio, encontramos que poco menos de la mitad de la población total (42.69\%) es económicamente no activa. Siendo las mujeres con $60.40 \%$, las que presentan el mayor porcentaje en este rubro, mientras que sólo $24.09 \%$ de los hombres no está vinculado a alguna actividad económica.

Cuadro 7. Población de 12 años y más según condición de actividad económica y sexo

\begin{tabular}{|c|c|c|c|c|c|c|c|}
\hline \multirow{2}{*}{\multicolumn{2}{|c|}{ Población de 12 años y más }} & \multicolumn{6}{|c|}{ Condición de actividad económica } \\
\hline & & \multicolumn{4}{|c|}{ Población económicamente activa } & \multirow{2}{*}{$\begin{array}{c}\text { Población no } \\
\text { económicamente active }\end{array}$} & \multirow{2}{*}{$\begin{array}{c}\text { \% Población no } \\
\text { económicamente activa }\end{array}$} \\
\hline & & Total & \%Total & Ocupada & Desocupada & & \\
\hline Total & 105,088 & 58,806 & 55.96 & 56,539 & 2,267 & 44,864 & 42.69 \\
\hline Hombres & 51,247 & 37,742 & 64.18 & 36,088 & 1,654 & 12,345 & 24.09 \\
\hline Mujeres & 53,841 & 21,064 & 35.82 & 20,451 & 613 & 32,519 & 60.40 \\
\hline
\end{tabular}

Nota. No se incluye la variable No especificado. Elaboración propia con base en INEGI, Censo de Población y Vivienda, 2010. 
Por otro lado, observamos que $55.96 \%$ de la población total es económicamente activa, es decir, se trata de personas de 12 y más años de edad que estuvieron vinculadas a alguna actividad económica o que buscaron empleo en la semana de referencia (INEGI, glosario 2010). De estos, 64.18\% son hombres y $35.82 \%$ son mujeres.

\subsection{Condiciones y características de las viviendas}

\subsubsection{Número y tipos de vivienda}

Según datos de INEGI, en 1995 el número de viviendas particulares habitadas en el municipio de Cuautitlán era de 12,451; para el año 2000 había 3,626 viviendas más que en 1995.

Los incrementos más importantes se registraron entre el año 2000 y 2005, periodo en el que número de viviendas pasó de 16,077 a 27,261, es decir, hubo un incremento porcentual de $41.03 \%$ viviendas particulares habitadas.

Cuadro 8. Total de viviendas particulares habitadas e incremento porcentual de 1995 a 2010, municipio de Cuautitlán

\begin{tabular}{|c|c|c|c|c|c|c|c|c|c|}
\hline \multicolumn{1}{|c|}{ Número de viviendas particulares habitadas } \\
\hline 1995 & $\mathbf{2 0 0 0}$ & $\begin{array}{c}\text { Incremento } \\
\mathbf{1 9 9 5 - 2 0 0 0}\end{array}$ & $\begin{array}{c}\text { Incremento } \\
\text { porcentual }\end{array}$ & $\mathbf{2 0 0 5}$ & $\begin{array}{c}\text { Incremento } \\
\mathbf{2 0 0 0 - 2 0 0 5}\end{array}$ & $\begin{array}{c}\text { Incremento } \\
\text { porcentual }\end{array}$ & $\mathbf{2 0 1 0}$ & $\begin{array}{c}\text { Incremento } \\
\mathbf{2 0 0 5 - 2 0 1 0}\end{array}$ & $\begin{array}{c}\text { Incremento } \\
\text { porcentual }\end{array}$ \\
\hline 12,451 & 16,077 & 3,626 & 22.55 & 27,261 & 11,184 & 41.03 & 36,886 & 9,625 & 26.09 \\
\hline
\end{tabular}

Elaboración propia con base en INEGI, Censos y Conteos de Población y Vivienda, 1995 a 2010.

Estos datos son consistentes con el número de Conjuntos Urbanos que fueron autorizados durante ese periodo, lo cual, da cuenta del impacto que 
tuvieron los cambios en las políticas de vivienda en este territorio. De acuerdo con Datos de la Secretaría de Desarrollo Urbano y Metropolitano del Estado de México, ${ }^{43}$ entre 1999 y el año 2015 se autorizaron para este municipio 18 Conjuntos Urbanos de distintas características y número de viviendas (véase cuadro 10 disponible en los anexos). En su mayoría se trata de Conjuntos Urbanos de interés social con un promedio de 1,577 viviendas.

Actualmente, Cuautitlán es el vigésimo tercer municipio con mayor número de viviendas particulares en el Estado de México. Cuenta con un parque habitacional de 51,339 viviendas, de las cuales 36,886 corresponden a la categoría de viviendas particulares habitadas, ${ }^{44} 11,406$ a la de viviendas deshabitadas (construidas y disponibles para ser habitadas pero que no cuentan con habitantes habituales al momento del censo) y 3,047 de uso temporal.

En el año 2010, ocupó la posición número 17 (después de Ecatepec, Tecámac, Zumpango, Ixtapaluca, Huehuetoca, etc.) en la lista de los municipios del Estado de México con mayor número de viviendas deshabitadas. Es decir, de las 538,220 viviendas deshabitadas con las que cuenta el estado, $2.12 \%$ se ubican en este municipio.

De acuerdo con el diagnóstico "Estado actual de la vivienda en México 2014" realizado por el Centro de Investigación y Documentación de la Casa (Cidoc), México presentó una tasa de $14.2 \%$ de viviendas deshabitadas durante el año en mención, es decir, 4 puntos porcentuales más que el promedio internacional.

\footnotetext{
${ }^{43}$ Secretaría de Desarrollo Urbano y Metropolitano del Estado de México, Autorizaciones de Conjuntos Urbanos, disponible en: http://sedur.edomex.gob.mx/autorizaciones (Consultado el: 22 de enero de 2017).

44 El Instituto Nacional de Geografía y Estadística (Glosario, 2010) define a las viviendas particulares habitadas como aquellas viviendas que en el momento del levantamiento censal tiene residentes habituales que forman hogares. Incluye también cualquier recinto, local, refugio, instalación móvil o improvisada que estén habitados.
} 
Aunque el origen de este fenómeno es multicausal, diversos autores coinciden en señalar a la ubicación de los desarrollos habitacionales, la carencia de equipamiento, el tamaño reducido de las viviendas y la inseguridad como los principales motivadores de abandono de la vivienda, siendo la localización del desarrollo habitacional el factor que más incrementa la probabilidad de que una familia abandone su vivienda, ya que la lejanía de los centros de trabajo o de las escuelas aumenta el costo del transporte y disminuye el ingreso disponible para el pago de hipoteca (Cideco, 2014: 58).

Cuadro 9. Porcentajes de viviendas particulares según condición de habitación, respecto al total del Estado de México

\begin{tabular}{|c|c|c|c|c|c|}
\hline \multirow{2}{*}{ Municipio } & \multirow{2}{*}{$\begin{array}{c}\text { Viviendas } \\
\text { particulares }\end{array}$} & \multicolumn{4}{|c|}{ Condición de habitación } \\
\hline & & Habitadas & $\%$ Habitadas & Deshabitadas & $\%$ Deshabitadas \\
\hline Estado de México & $4,494,751$ & $3,749,106$ & 100 & 538,220 & 100 \\
\hline Ecatepec de Morelos & 473,753 & 419,087 & 11.18 & 41,286 & 7.67 \\
\hline Tecámac & 152,715 & 97,147 & 2.59 & 39,028 & 7.25 \\
\hline Zumpango & 73,918 & 37,645 & 1.00 & 29,345 & 5.45 \\
\hline Ixtapaluca & 156,883 & 118,687 & 3.17 & 29,040 & 5.40 \\
\hline Toluca & 238,021 & 199,789 & 5.33 & 28,693 & 5.33 \\
\hline Huehuetoca & 52,841 & 25,187 & 0.67 & 23,612 & 4.39 \\
\hline Tultitlán & 151,357 & 125,151 & 3.34 & 20,567 & 3.82 \\
\hline Chalco & 99,541 & 74,761 & 1.99 & 20,297 & 3.77 \\
\hline Cuautitlán Izcalli & 163,472 & 135,004 & 3.60 & 19,958 & 3.71 \\
\hline Coacalco de Berriozábal & 94,832 & 75,055 & 2.00 & 15,607 & 2.90 \\
\hline Nezahualcóyotl & 303,248 & 285,027 & 7.60 & 14,039 & 2.61 \\
\hline Naucalpan de Juárez & 237,930 & 219,286 & 5.85 & 13,707 & 2.55 \\
\hline Tlalnepantla de Baz & 194,375 & 177,298 & 4.73 & 12,393 & 2.30 \\
\hline Chimalhuacán & 162,705 & 147,761 & 3.94 & 12,329 & 2.29 \\
\hline Chicoloapan & 60,956 & 44,659 & 1.19 & 12,214 & 2.27 \\
\hline Nicolás Romero & 107,538 & 91,355 & 2.44 & 12,068 & 2.24 \\
\hline Cuautitlán & 51,339 & 36,886 & 0.98 & 11,406 & 2.12 \\
\hline Atizapán de Zaragoza & 143,563 & 129,300 & 3.45 & 10,749 & 2.00 \\
\hline
\end{tabular}

Elaboración propia con base en INEGI, Censo de Población y Vivienda, 2010.

El emplazamiento cada vez más lejano de los conjuntos urbanos ha dado lugar a asentamientos de pobres excluidos, el confinamiento de población en 
estas áreas, la segregación y separación de la metrópoli (Esquivel y Capron; 2016: 28).

El deterioro, la inseguridad y el olvido de los grandes conjuntos urbanos, han propiciado inseguridad, descuido de sus espacios públicos, grafiti, la paulatina desocupación de viviendas y el abandono de estos espacios periféricos. Además en las zonas en donde se han asentado, generalmente caracterizadas por la presencia de actividades rurales, han generado dinámicas metropolitanas conflictivas (Esquivel y Capron; 2016: 28).

Conocer estos datos es de vital importancia debido a que "lo que históricamente se ha denominado 'problema de la vivienda' se concreta en la actualidad en la existencia de hogares que no alcanzan la renta necesaria para poder satisfacer por sí mismos la necesidad básica de alojamiento" (Vinuesa, 2011: 8). El número de viviendas desocupadas puede ser valorado como la expresión de un fenómeno cargado de grandes connotaciones: a nivel económico hablamos de la existencia de un patrimonio de valor elevado que no produce rentabilidad alguna; en términos sociales, se trata de una problemática que favorece el deterioro y el uso inadecuado de los espacios residenciales (Vinuesa, 2011).

Desde el punto de vista urbanístico y territorial, es importante recordar que el suelo es un bien escaso y que un exceso de viviendas vacías da lugar a un funcionamiento ineficiente del espacio urbano, ya que

...el uso de espacio urbano, del que la vivienda no es más que una porción, debe estar al servicio del conjunto de la sociedad, prevaleciendo siempre los intereses colectivos sobre los privados. Además, desde criterios de sostenibilidad hay que recordar que el territorio es un bien básico y limitado y que los desarrollos residenciales por encima de las necesidades de alojamiento pueden estar suponiendo 
consumos excesivos de territorio, en detrimento del paisaje y de otros posibles usos no residenciales (Vinuesa, 2011: 9).

\subsubsection{Promedio de ocupantes por vivienda}

En el año 2010, el promedio de ocupantes por vivienda en el municipio de Cuautitlán era de 3.78 y solamente $2.14 \%$ del total de las viviendas contaban con más de 2.5 ocupantes por cuarto, es decir, presentaba condiciones de hacinamiento. ${ }^{45}$

Pese a que la presencia de viviendas con hacinamiento en el municipio es considerablemente baja, resulta de vital importancia conocer estas cifras debido a que son indicadores de la carencia de espacios de espacios dentro de la vivienda, o bien, de la sobreocupación de personas en la vivienda. Puede también ser interpretado como un problema de espacio o como evidencia de la existencia de "hogares ocultos". Los altos niveles de ocupación dan lugar también, a otro tipo de problemáticas relacionadas con la higiene, la sanidad y la falta de privacidad (Spicker, Alvarez y Gordon, 2009: 152).

\subsubsection{Bienes y servicios}

La carencia de bienes básicos dentro de la vivienda reduce el nivel de bienestar de las familias ya que constituye un límite importante para el desarrollo de las actividades domésticas y familiares de quienes la habitan (CONAPO, 2002: 12).

En el caso de Cuautitlán, encontramos que el nivel de consolidación de los servicios es bastante alto pues es mínimo el porcentaje de viviendas que carecen

45 De acuerdo con la Organización Mundial de la Salud, se considera que existe hacinamiento dentro de una vivienda cuando residen en ella más de 2.5 ocupantes por cuarto. 
de los servicios indispensables. De las $33,886^{46}$ viviendas particulares habitadas con las que cuenta el municipio $98.36 \%$ dispone de excusado y drenaje; $98.75 \%$ cuenta con agua entubada y $99.70 \%$ cuenta con servicios de energía eléctrica. De éstas, solamente 329 viviendas tiene piso de tierra.

La posesión de agua entubada, drenaje, energía eléctrica y pisos firmes son para el Consejo Nacional de Población los indicadores económicos relevantes cuando se habla del nivel de marginación de determinada comunidad. La carencia de agua entubada es perjudicial para la salud, debido a que potencia la presencia de enfermedades gastrointestinales, de la piel y respiratorias, a la vez que dificulta las labores domésticas. Por otra parte, la ausencia de drenaje y servicio sanitario repercute de manera importante sobre la salud de las personas, ya que no sólo favorece el contagio de diversas enfermedades, sino que también, se afecta la calidad de vida de las familias (CONAPO, 2002: 13).

La falta de energía eléctrica en la vivienda limita el uso de bienes y servicios tecnológicos que permiten la preparación y conservación de alimentos, así como el acceso a sistemas de información, comunicación $y$ entretenimiento que repercuten en la calidad de vida. Asimismo, supone el uso de fuentes de energía que además de elevar los costos afectan negativamente al medio ambiente y la salud de los ocupantes. La presencia de piso de tierra se relaciona directamente con la salubridad de las viviendas y su vulnerabilidad ante enfermedades principalmente gastrointestinales; también influye en la confortabilidad, por ello se considera una limitante para el desarrollo integral de las familias y las comunidades (CONAPO, 2002: 13).

\footnotetext{
${ }^{46}$ Los porcentajes se calcularon considerando 36,056 viviendas particulares como el total ya que los datos disponibles excluyen viviendas móviles, refugios y locales no construidos para habitación debido a que no se captaron. Además, se excluye a aquellas viviendas sin información de ocupantes.
} 
En lo que respecta a los bienes y tecnologías de la información y de la comunicación encontramos que $6.5 \%$ de las familias carecen de refrigerador, $50 \%$ no poseen automóvil, $8.9 \%$ no cuentan con radio, $0.9 \%$ no poseen televisor, $54.80 \%$ no cuenta con computadora, $39.77 \%$ no tiene instalada una línea de teléfono fija; $17.09 \%$ no cuenta con teléfono celular y $70.9 \%$ no tiene acceso a internet dentro de la vivienda. Esta última cifra es de llamar la atención ya que en los últimos años, el internet se ha convertido en un bien elemental para el desarrollo de las actividades cotidianas, no sólo porque permite el acceso diferentes tipos de información y entretenimiento, sino también, porque es esencial para el funcionamiento de un número importante de aparatos tecnológicos.

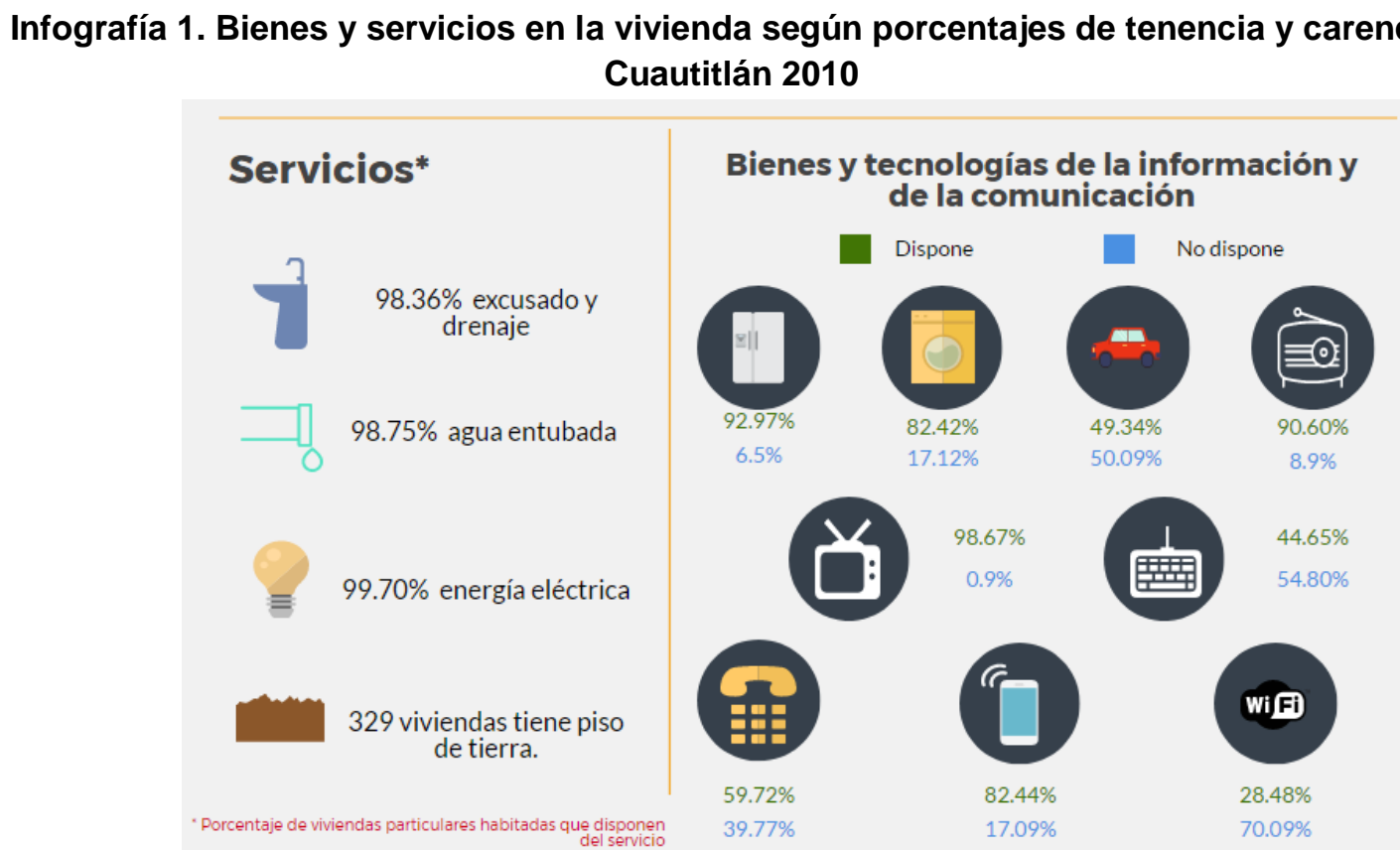

Elaboración propia con base en INEGI. Censo de Población y Vivienda 2010. Infografía realizada mediante la aplicación Piktochart.

Por otra parte, la carencia de refrigerador reduce significativamente la posibilidad de conservar los alimentos en buen estado durante más tiempo, lo que 
repercute en la alimentación y salud de las familias y aumenta el gasto destinado a la adquisición de alimentos.

\subsection{El Conjunto Urbano Rancho Santa Elena}

En este apartado se presentan los resultados del trabajo de observación realizado como parte de esta investigación. Por un lado, se exponen las principales características del conjunto urbano tales como su estructura organizativa, principales accesos, uso de suelo predominante, transporte disponible y vías de comunicación. Y por otro, se habla de la existencia del equipamiento urbano, analizando su estado de conservación y contrastando la infraestructura disponible con los acuerdos de autorización publicados en la Gaceta del Gobierno del Estado de México el 10 de agosto de 1999.47

\subsubsection{Inserción del conjunto en el contexto urbano y estructura organizativa}

El conjunto urbano Rancho Santa Elena se ubica en la parte noroeste del municipio de Cuautitlán, en la periferia de la cabecera municipal y en los límites del municipio de Tultepec. Fue autorizado en 1999 (año en que inicia el boom habitacional del Estado de México) durante el mandato del Gobernador César Camacho Quiroz (1995-1999); el desarrollo y construcción del conjunto habitacional corrió a cargo de la empresa Promotora Hogares Ideales S.A. de C.V., hoy conocida bajo el nombre de GEO Hogares Ideales S.A. de C.V. Cabe

\footnotetext{
${ }^{47}$ Disponible

en: http://www.google.com.mx/url?sa=t\&rct=j\&q=\&esrc=s\&source=web\&cd=2\&cad=rja\&uact=8\&ved=0 ahUKEwj1ldCXpZvUAhUIsVQKHVI9C6MQFgguMAE\&url=http\%3A\%2F\%2Flegislacion.edomex.go b. $\mathrm{mx} \% 2 \mathrm{Fsites} \% 2 \mathrm{Flegislacion}$.edomex.gob.mx\%2Ffiles\%2Ffiles\%2Fpdf\%2Fgct\%2F1999\%2Fago10 2.pdf\&usg=AFQjCNE0w6Tke-uATO8mTqxSeqybTR6jfg (Consultado el 20 de febrero de 2017).
} 
mencionar que dicha desarrolladora fue hasta la crisis del año $2013,{ }^{48}$ la constructora de vivienda social más grande del país.

\section{Plano 2. Ubicación del Conjunto Urbano Rancho Santa Elena}

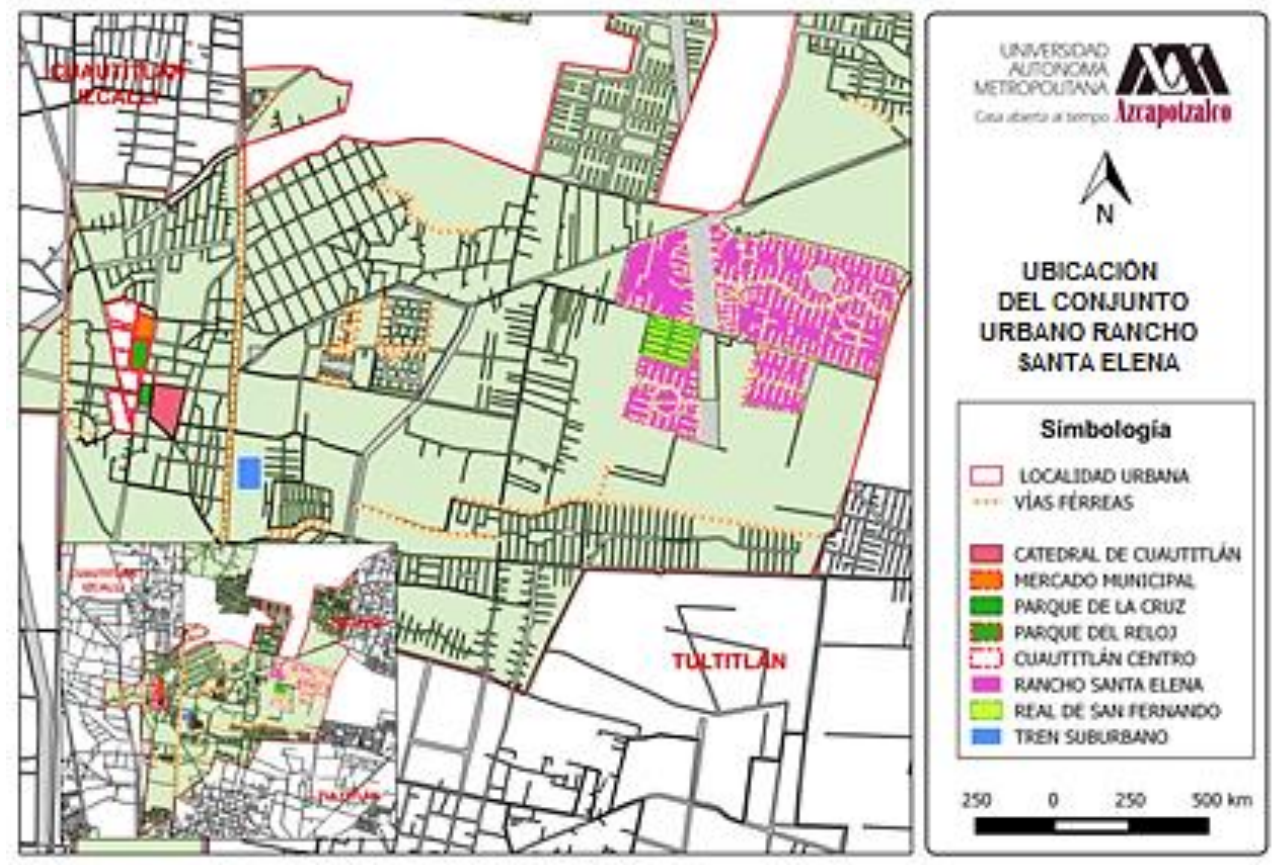

Elaboración propia con base en INEGI Cartografía Geoestadística Urbana 2010

48 Durante el año 2013 la Secretaría de Desarrollo Agrario, Territorial y Urbano (SEDATU) reportó una caída del $9.7 \%$ en el sector de la construcción de viviendas, causada principalmente por las desarrolladoras URBI, GEO y Homex (García y López: 2014: 46). José Humbertus Pérez Espinoza (presidente y representante legal del Frente Mexiquense en Defensa para una Vivienda Digna (FMDVD) declaró al periódico La Jornada en mayo del 2013 que la crisis que vive ese sector en México tiene su origen en la sobrevaluación del valor de las viviendas que se vendieron entre 2001 y 2012... señaló que las seis principales desarrolladoras de vivienda, HOMEX, GEO, URBI, ARA, SARE y HOGARB, cotizan en el Índice Habita de la Bolsa Mexicana de Valores (BMV) y sobrevaluaron las viviendas para lograr un crecimiento permanente de sus ventas, mantener sus utilidades y el precio de sus acciones en la BMV durante los gobiernos de Vicente Fox y Felipe Calderón. Mencionó también que a diferencia de los gobiernos de Estados Unidos y de España, que durante la crisis hipotecaria frenaron operaciones para construcción y venta de nuevas viviendas, el gobierno mexicano continúo financiando la construcción y venta de vivienda nueva con recursos de la Sociedad Hipotecaria Federal para mantener indicadores de las viviendas sobrevaluadas de las seis principales desarrolladoras en la BMV. Artículo completo disponible en: http://www.jornada.unam.mx/2013/05/06/sociedad/041n1soc (Consultado el 28 de febrero de 2017). 
Santa Elena es uno de los Conjuntos Urbanos más grandes del municipio (en cuanto a tamaño y número de viviendas), y forma parte de los primeros tres autorizados bajo la modalidad de Conjunto Urbano (Rancho San Blas y Paseos de Cuautitlán son los otros conjuntos autorizados durante el mismo periodo). Está integrado por 6,119 viviendas (que corresponden al $11.91 \%$ del total de las viviendas con las que cuenta el municipio) consturídas en una superficie de terrerno de $867,821.49 \mathrm{~m}^{2}$ y distribuido mediante un total de 488 lotes y 41 manzanas.

Este conjunto se ubica a 3.7 kilómetros de la cabecera municipal y a 12 minutos del Tren Suburbano (39 minutos a pie); colinda con el pueblo conurbado 49 de San Mateo Ixtacalco; con los conjuntos habitacionales Paseos de Tultepec II, Real de San Fernando y Ángel de Luz; y con dos centros comerciales: Sam's Club Santa Elena y Plaza Centella. ${ }^{50}$

Cabe resaltar que los últimos dos conjuntos urbanos mencionados en el párrafo anterior, fueron construídos en lotes que anteriormente pertenecían a Santa Elena y dan cuenta del tipo de urbanización insular suscitada -en distintas partes del Estado de México- a partir de la edificación de conjuntos urbanos; y que se define por la manera aislada y contrastante en la que éstos se proyectan en el territorio (Esquivel, 2011:22).

\footnotetext{
49 De acuerdo a la definición de Connolly (2005: 16), los pueblos conurbados son un tipo de poblamiento que refiere a pueblos menores, ranchos, barrios y territorios que se urbanizaron alrededor de las cabeceras y villas después de 1929, y que hoy se encuentran absorbidos por la expansión de las áreas centrales de la ciudad. Se trata de espacios heterogéneos que se desarrollaron en su mayoría de forma irregular (sin apego a la normatividad vigente), progresiva e independiente a la urbanización de la ciudad.

${ }^{50}$ Desarrollada en 2011 bajo el concepto de "Centro Comunitario" por el Consorcio ARA que de acuerdo con datos del periódico EL ECONOMISTA (Huerta, 2016), es una de las cuatro desarrolladoras de vivienda que crecieron durante los pasados sexenios panistas. Véase: Cimientos fuertes: Liderazgo y crecimiento, INFORME ANUAL Y DE SUSTENTABILIDAD 2014, Consorcio ARA, página $23 . \quad$ Disponible en: http://www.consorcioara.com.mx/sites/default/files/archive/reporte_anual_2014_0.pdf (Consultado el 21 de junio de 2017).
} 
En este caso, hablamos de espacios que no sólo irrumpen en los lugares tradicionales del municipio, sino que también, rompen con la trama del conjunto Santa Elena al estar inmersos dentro de otro conjunto urbano de mayores dimensiones, separados por bardas perimetrales que los aíslan de su entorno, generando un territorio municipal fragmentado y desarticulado (ibid).

El conjunto Ángel de Luz, es en sí mismo, un claro ejemplo de la escasa planeación de la que son objeto los conjuntos urbanos en el Estado de México, ya que, pese a que fue edificado con el objetivo de beneficiar a personas en condiciones de vulnerabilidad, no cuenta con las características necesarias para por ejemplo, brindar una vivienda digna a personas con discapacidad.

\section{Imagen 3. Vista de sátelite del conjunto urbano Ángel de Luz}

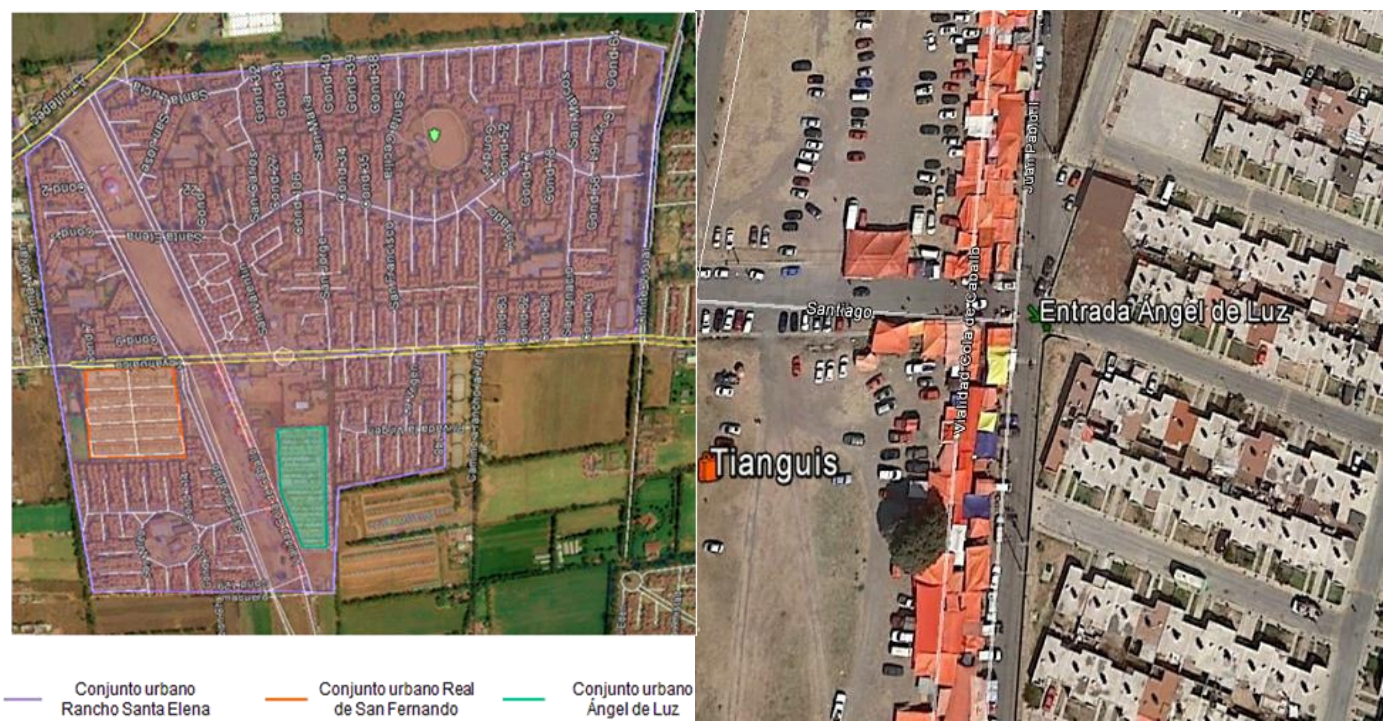

Fuente: vista de sátelite de Google Earth, polígonos de elaboración propia.

En entrevista con la profesora Miriam Guadalupe Torres Díaz, habitante de este conjunto y Directora del Centro de Capacitación e Integración Laboral para 
Personas con Capacidades Diferentes, ubicado en el municipio de Cuautitlán, señaló que:

las viviendas fueron entregadas por parte de un proyecto federal de vivienda popular a bajo costo, para familias en condiciones de vulerabilidad, es decir, personas con discapacidad, viudas de militares y polícias en cumplimiento de su deber y mujeres víctimas de violencia. Se trató de un proyecto en el que participaron SEDESOL, Televisa, Monte de Piedad y Fundación Teletón; y en el que nos entregaron la vivienda por un costo de 10,600 pesos. La particpación del municipio consitió en otorgar un subsidio al pago del impuesto predial y de traslado de dominio, sin embargo, son viviendas que no cuentan con ningún tipo de adecuación para las personas con discapacidad, la única ventaja es que son de fácil acceso porque son de un piso, pero no cuentan con rampas u otra cosa.

Situación que pudo ser contrastada en los recorridos de campo realizados, ya que como se observa en la imagen 3, el conjunto Ángel de Luz se encuentra en los límites del conjunto Santa Elena y no cuenta con rampas para discapcitados o accesos que faciliten el uso de sillas ruedas; incluso, la entrada principal del conjunto es obstruída los fines de semana que se instala el tianguis, dificultando aún más, la movilidad de quienes ahí habitan.

\subsubsection{Modificaciones a las viviendas}

En los recorridos de campo realizados como parte del trabajo de investigación, se observó que más de la mitad de las viviendas que integran Santa Elena han sufrido algún tipo de modificación.

Dichas transformaciones van desde alteraciones simples como la instalación de protecciones en puertas y ventas, cambios en el color de la pintura, 
colocación de cercas y portones en los espacios de estacionamiento (fotografía 1); hasta cambios drásticos que incluyen ampliaciones o modificaciones a las viviendas que en la mayoría de los casos, rebasan las superficies originales expandiéndose hacia las áreas destinadas para el estacionamiento de automóviles o más pisos de los edificados inicialmente, tal y como se observa en las fotografías 2 y 3 , lo cual pone en el patrimonio y la inversión de las familias.

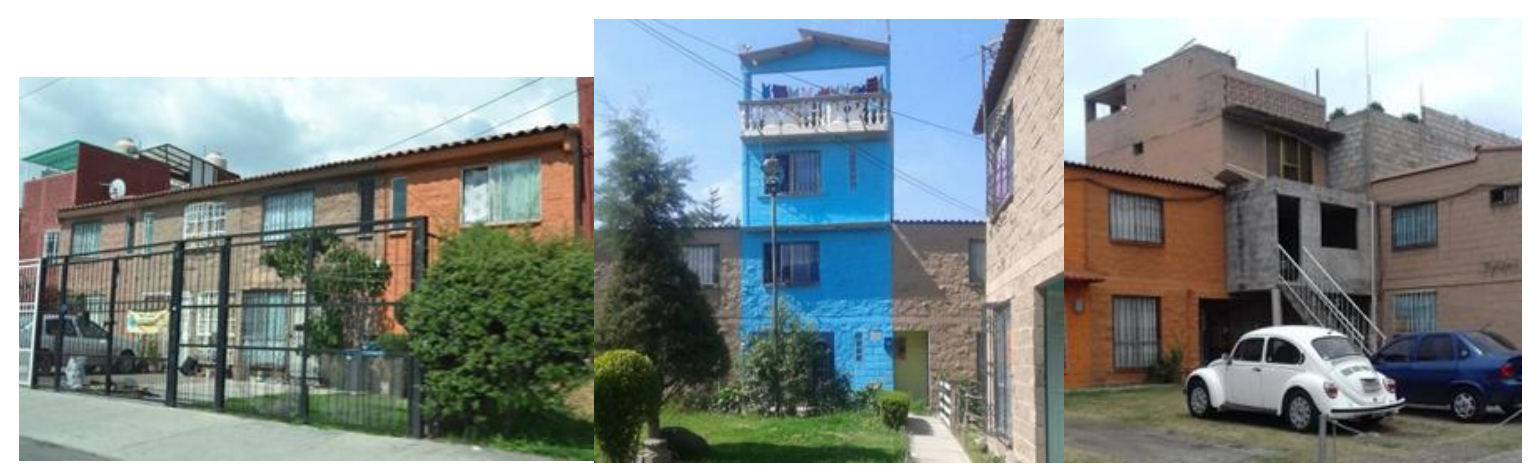

Fotografías 1, 2 y 3. Modificaciones realizadas a las viviendas.

Las ampliaciones suelen ser destinadas para su uso como recámaras, extensiones de la sala-comedor (o alguna otra área de la casa como la cocina y el patio de servicio), terrazas, áreas para el tendido de ropa o bien, como espacios comerciales.

Entre los negocios instalados dentro de la vivienda, destacan las carnicerías, jardines de niños, puestos de comida, gimnasios, tiendas de abarrotes, tiendas de ropa, farmacias, e incluso veterinarias. En la fotografía número 6 , se muestra uno de los negocios más grandes del conjunto habitacional, se trata de un gimnasio y una paletería que fueron construidas a partir de un conjunto de casas que abarcan la esquina de la calle San Valentín; cabe resaltar que las ampliaciones destinadas para negocios se ubican en su mayoría sobre 
avenidas principales, ya que su localización permite que un mayor número de personas tengan acceso a los servicios que ofrecen (véase plano 3 ).

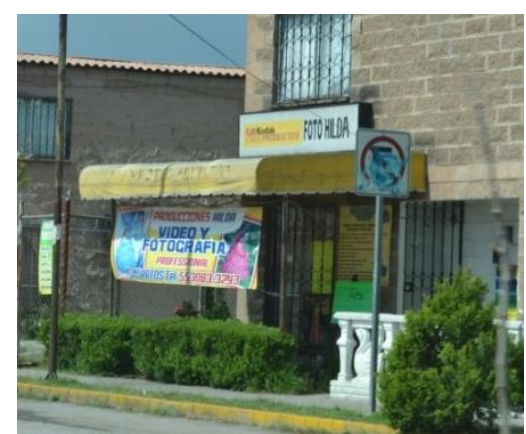

Fotografía 4. Negocio de vídeo y fotografía

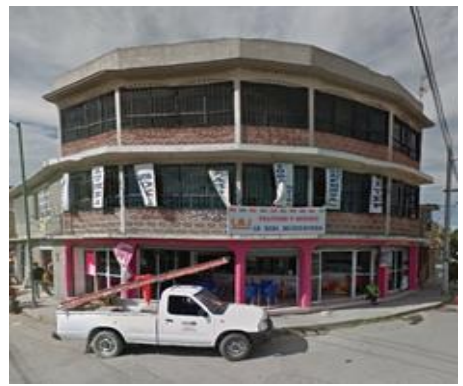

Fotografía 6. Peletería y gimnasio ubicados en sobre la calle San Valentín (fuente Google Maps).

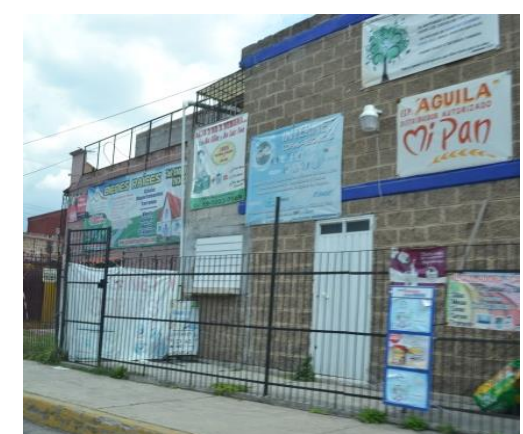

Fotografía 5. Negocios ubicados sobre la Avenida Santa Elena

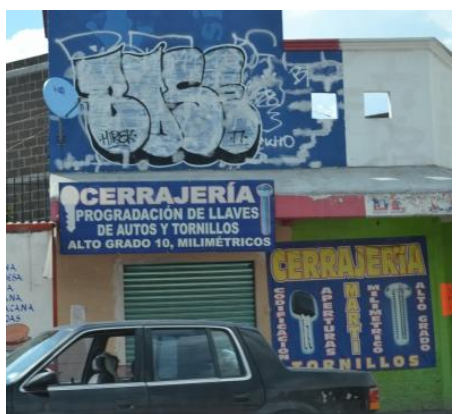

Fotografía 7. Cerrajería ubicada sobre la calle Teyahualco.

Esta situación es resultado de que durante casi una década, los habitantes de este conjunto urbano tuvieron que encontrar formas para abastecerse de alimentos y cubrir sus necesidades básicas, ya que los primeros centros comerciales cercanos a este conjunto, se construyeron hasta principios de 2008 aproximadamente, dejando a los habitantes con escasas posibilidades para satisfacer las necesidades de sus familias, especialmente, para las mujeres que son quienes normalmente se encargan de las actividades domésticas. 
Aunque en los acuerdos de autorización del conjunto urbano se establece la obligación de equipar a Santa Elena con un mercado público y locales comerciales (fotografías 8 y 9) -y de hecho se cuenta con este tipo de equipamiento-; se trata de acuerdo con los testimonios de los habitantes, de espacios que durante sus primeros años de funcionamiento, ofrecieron productos a precios excesivos, lo que dio lugar al surgimiento de pequeños negocios dentro de las viviendas (o en extensiones de ellas) que ofrecían productos y servicios a costos más accesibles.

Las compras diarias, pues lo de verdura y eso en el tianguis del domingo; lo que se compra en el centro comercial pues allá en Cuautitlán, en Wal-Mart, en Aurrera o allá en Cuauti... antes de que estuvieran los centros comerciales íbamos al Aurrera que está ahí en la entrada de Cuauti y pues juf!, está lejísimos pero ahí estaba más fácil llegar antes, ahora con tantas cosas no se puede; pero íbamos ahí porque a mi esposo le daban vales y era una vez al mes. Las verduras en el tianguis porque en los de por aquí está muy caro, quieren que les pague la renta yo creo [se ríe]; antes porque no había más opciones y era la única opción, pero como ahora ya hay más opciones uno le busca... por ejemplo, para darle de comer a estos [a sus perros] le compraba el pollo a una amiga allá en los locales y ahora con estas dos, como que comencé a resentir y dije no, voy a gastar más; nos recomendaron un lugar en Tultepec, entonces vamos hasta allá, donde nos sale más económico. Ahorita ya hay más opciones donde buscarle, pero cuando llegamos estaba más difícil, ahorita ya está más accesible, aunque de todos modos yo he ido al Distrito [Ciudad de México] y está más barato, pero aun así no me iría a vivir para allá porque está muy feo, no me gusta (Señora Aurora, 16 años residiendo en Santa Elena). 


\subsubsection{Uso de suelo predominante}

De acuerdo con lo establecido en la Gaceta de Gobierno № 29 del Estado de México, originalmente se autorizó la construcción del Conjunto Urbano Rancho Santa Elena en 488 lotes con uso de suelo habitacional y 8 obras de equipamiento que incluyen la construcción de dos locales comerciales que requirieron de previa autorización por parte de la Secretaría de Desarrollo Urbano y Obras Públicas (imagen 2).

Dichos locales se encuentran en la posterior del conjunto, por lo que no representan una opción para aquellas familias y personas que habitan en las áreas contiguas a la entrada principal de Santa Elena. Según datos de 2014 del Directorio Estadístico Nacional de Unidades Económicas (DENUE) del INEGI, en Santa Elena se ubican un total 189 unidades económicas que incluyen: comercio al por mayor y al por menor; servicios de alojamiento temporal y de preparación de alimentos y bebidas; y otros servicios excepto actividades gubernamentales.

Imagen 2. Artículo décimo sexto del ACUERDO: Por el cual se autoriza el conjunto urbano de interés social denominado "Santa Elena", ubicado en el Municipio de Cuautitlán, Estado de México.

En los lotes del conjunto urbano "SANTA ELENA", sólo podrán llevarse a cabo las construcciones relativas a los usos habitacionales que se autorizan, no siendo por tanto necesario tramitar la obtención de las licencias estatales de uso del suelo para cada uno de ellos, y no causándose el cobro de derechos de conformidad con lo establecido en el artículo 94 fracción IV del Código Financiero del Estado de México y Municipios. Para el aprovechamiento de los lotes comerciales y de servicios del conjunto urbano, deberán obtenerse previamente la licencia estatal de uso del suelo, la municipal de construcción y las demás licencias y autorizaciones que correspondan.

Fuente: Gaceta $N^{\circ} 29$ del Estado de México con fecha 10 de agosto de 1999. Disponible en la Dirección de Legalización y del Periódico Oficial "Gaceta del Gobierno". 
Tal y como se pudo constatar en los recorridos de campo llevados a cabo como parte de este trabajo, se han instalado negocios especialmente en las avenidas principales y en lugares estratégicos del conjunto como glorietas, escuelas y paradas de transporte público. Con esto, se ha ido cambiando el uso de suelo habitacional original a un uso de suelo mixto, en un número significativo de viviendas; todo con el objetivo de satisfacer las necesidades de consumo y empleo de las familias, ya que muchos de estos negocios representan una opción factible de empleo.

Como todos los lugares, al principio el conjunto era bonito, pues las casas estaban nuevas, nadie había hecho cambios e incluso los primeros años todavía había muchas casas vacías. Lo malo es que no había nada, ni tiendas, ni escuelas... siempre teníamos que ir al centro de Cuautitlán, al Aurrerá o a otro lugar a comprar; cuando iba a visitar a mi papá aprovechaba para traerme fruta o algunas cosas del tianguis porque aquí no había nada (Señora Rebeca, 16 años residiendo en Santa Elena).

Plano 3. Usos de suelo Conjunto Urbano Rancho Santa Elena 2016.

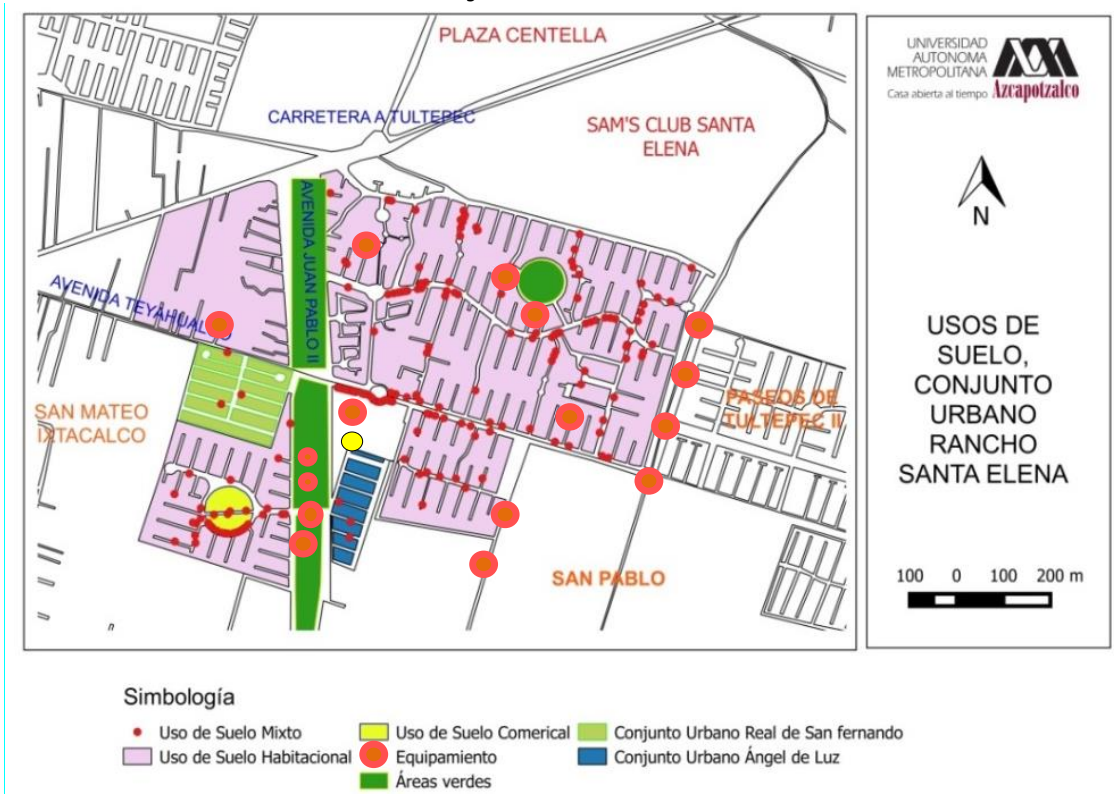

Fuente: Elaboración propia con base en los recorridos de campo realizados y con datos del DENUE, INEGI 2014. 
[...] los de las combis y los camiones que entran a surtir las tiendas no estaban, sólo venía el del gas, el del pan y un señor que entra en moto a vender tortillas. Entonces no había mucho tráfico, no había mucho ruido... ahora hay muchas tiendas, porque hacian falta, hacian falta para la gente y las necesidades de la casa, porque si despedían a alguien estaba en chino encontrar trabajo, ¿entonces qué les quedaba?, pues poner un negocio aunque no estaba permitido, porque si no podían pagar sus casas el INFONAVIT sólo les perdonaba un año y ya después de eso te cobra hasta la risa, había que buscarle no había de otra... a la vez nos benefició porque antes no encontrabas dónde comprar a las 7 u 8 de la noche, ya sabías que si se te pasaba el del pan pues te quedabas sin pan y si se te pasaba el del gas pues valía gorro, ite quedaste sin gas!, ya sabía uno más o menos. Ahora, ya pues si está cerrada una tienda vas aquí o vas a allá a ver si está abierta y antes no, o sea no podías mandar a tu hijo a las 7 de la noche a la entrada porque estaba muy solo... (Señora Aurora, 16 años residiendo en Santa Elena).

Anteriormente yo trabajaba en la tienda de allá [señala una tienda de abarrotes que se encuentra cruzando la calle dónde se encuentra su casa] y allá esa tienda se cerraba a las 12 - 1... mi hija trabajaba en el puesto de papas y actualmente yo casi no estoy en casa, porque a veces ayudo en un negocio de lavandería que se ha convertido en mi segunda casa (Señora Maribel, 8 años residiendo en Santa Elena).

\subsubsection{Accesos, transporte y vías de comunicación}

La movilidad es un asunto prioritario a atender en las agendas gubernamentales de la región de América Latina y el Caribe, ya que el acelerado crecimiento de las ciudades ha dado lugar a dinámicas de movilidad deficientes que deterioran la calidad de vida de la población. De acuerdo con la ONU, la región está lejos de contar con sistemas de movilidad eficientes que permitan a la población acceder a 
servicios, oportunidades laborales, educativas y que favorezcan el disfrute pleno de la ciudad; esto se debe en gran medida a que su dinámica de movilidad está definida por dos rasgos contrastantes: 1) la importancia del transporte público, los viajes a pie y en bicicleta; y 2) el aumento de la motorización y la congestión. Lo cual, se traduce en tiempos largos de traslado y altos costos económicos que impactan en el presupuesto de las familias (ONU-Hábitat, 2014: 6).

Por lo que actualmente, la falta de integración del transporte con la planeación urbana, sin prever cualidades para la conectividad ha sido la causa principal del modelo desarticulado de movilidad que predomina en las ciudades mexicanas, así como las pérdidas que esta situación genera por las externalidades negativas que origina, como son: descenso en la productividad económica, impacto en la salud de los habitantes y en la calidad de vida, y el deterioro ambiental (ONU-Hábitat, 2014: 6).

Este escenario es también visible a escalas menores, puesto que la falta de articulación y la escasa planeación de los sistemas de movilidad, así como la falta de accesibilidad, son problemáticas que están presentes en los conjuntos urbanos del Estado de México.

Como se mencionó anteriormente, el sistema de transporte de las ciudades está compuesto por elementos físicos que favorecer la movilidad de los diferentes medios de transporte; pero para que un gobierno se capaz de facilitar y asegurar a todos sus habitantes el acceso a este sistema, debe garantizar que su diseño y gestión son adecuados (IGLUS, EPFL, 2015). Por ello es indispensable contar con información relacionada con la movilidad y la accesibilidad de los distintos espacios de los que se compone una ciudad para determinar si el lugar ofrece a los habitantes la posibilidad de acceder a los servicios e infraestructura disponibles en las urbes. 
En el Conjunto Urbano Rancho Santa Elena se pudo identificar tres tipos vialidades:

\section{a) Avenidas o ejes estructurantes}

De acuerdo con Delgado (2013), son las vialidades que conectan a determinado espacio con su entorno. En Santa Elena se reconoce la Carretera a Tultepec sobre la que se ubica la entrada principal y que enlaza al conjunto con los municipios de Cuautitlán y Tultepec. Las avenidas San Fernando, Juan Pablo II, Teyahualco y Santa Elena que atraviesan al conjunto; y la avenida Camino a la Antigua que conecta la parte posterior de Santa Elena con el Conjunto Paseos de Tultepec II, el Circuito Exterior Mexiquense y el Pueblo de San Mateo Ixtacalco.

Plano 4. Restricciones de los accesos y calles del Conjunto Urbano Rancho Santa Elena.

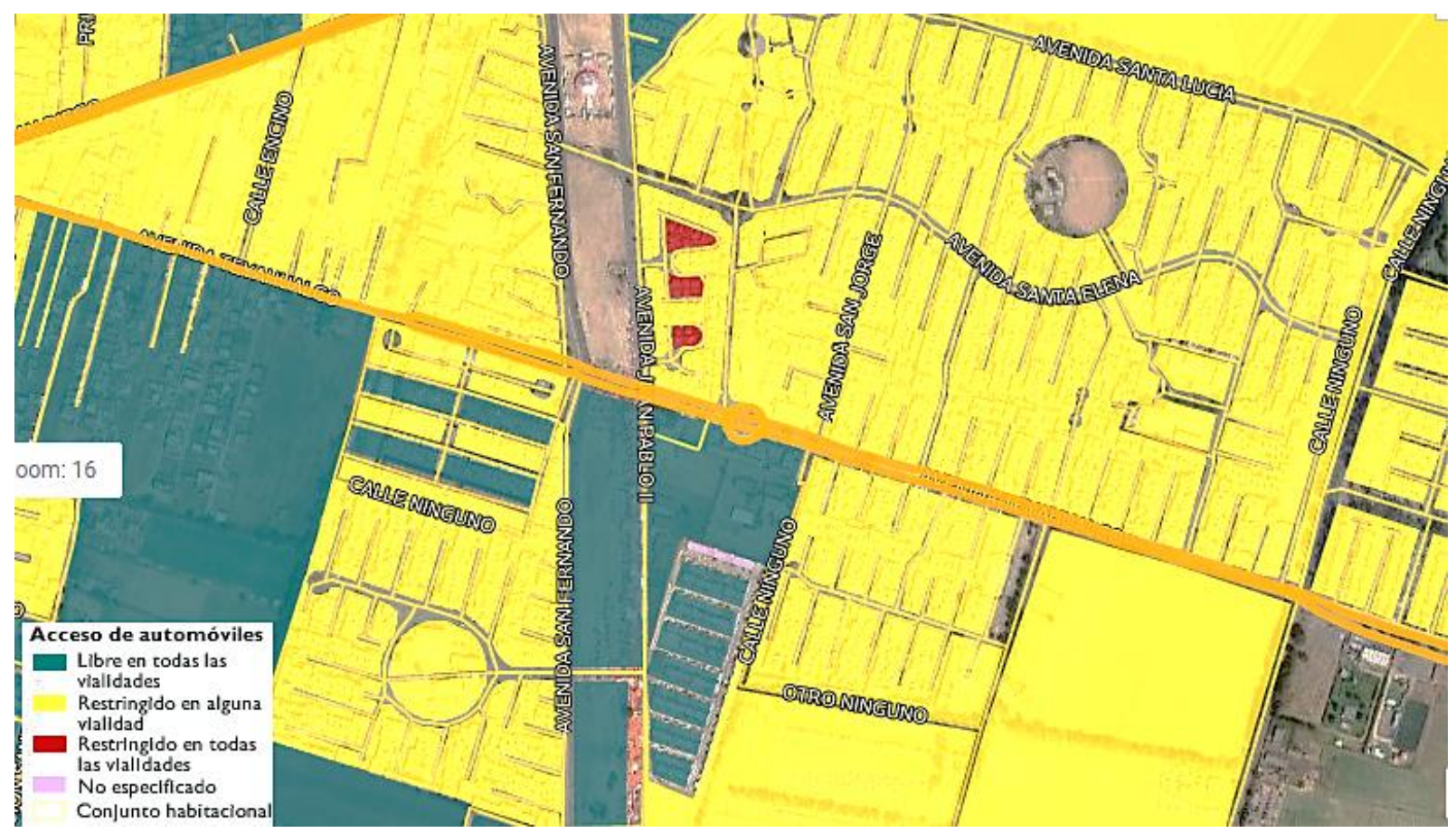

Fuente. INEGI, Inventario Nacional de Viviendas, 2016. 


\section{b) Calles}

Las calles o ejes barriales que permiten la movilidad dentro del conjunto se caracterizan por ser calles cerradas rodeadas de viviendas que actúan como una especie de pasillo por el que las familias tienen acceso a su casa (fotografías 10 y 11), pero que lejos de conectar al conjunto, separan a las viviendas, incluso cuando se encuentran dentro de la misma manzana.

Fotografías 10 y 11. Vista de las calles Condominio 31 y Condominio 65

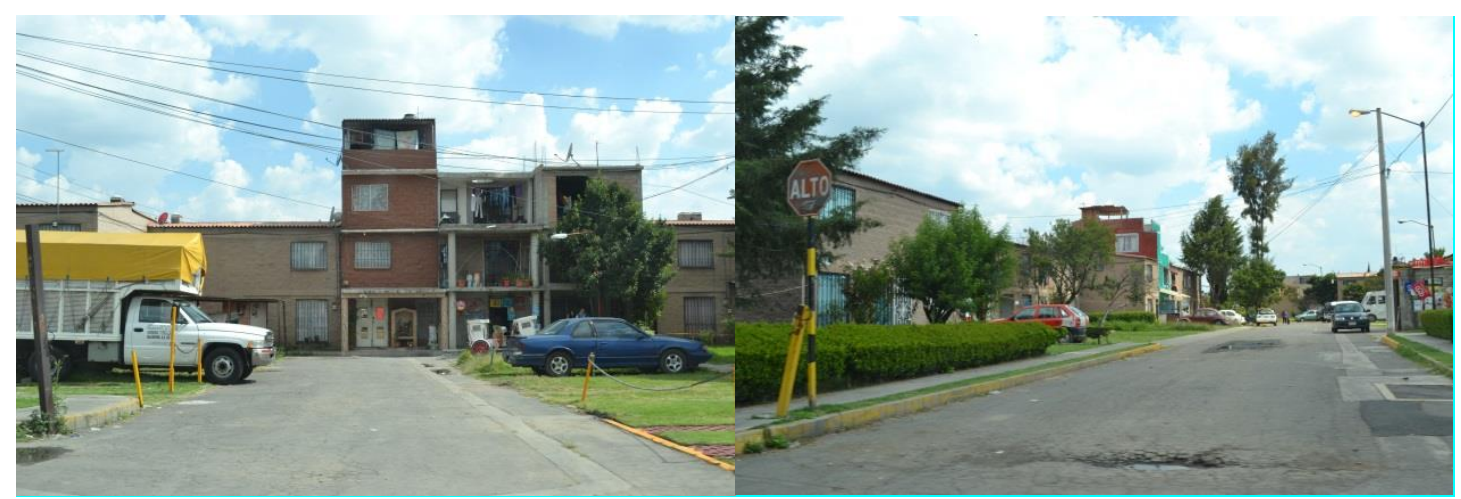

Casi todas las calles de Santa Elena se encuentran cerradas por una reja o zaguán que corta la circulación para los automovilistas o peatones que no habitan dentro de la calle delimitada (fotografías 12 y13).

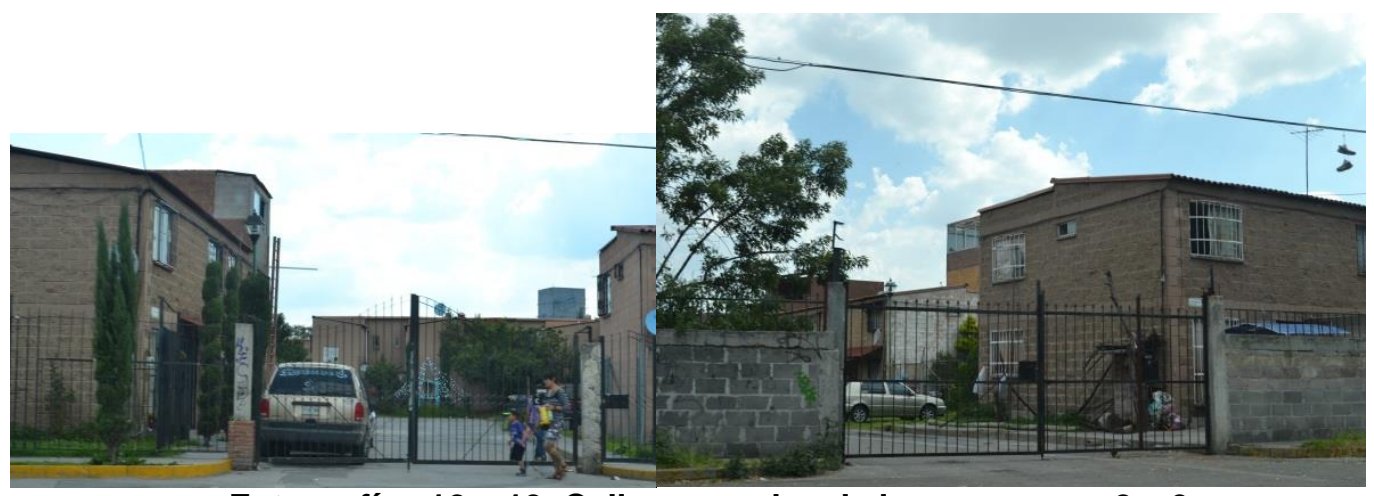

Fotografías 12 y 13. Calles cerradas de las manzanas 2 y 3. 
En las fotografías 14, 15, 16 y 17 se puede observar que la gran mayoría de los habitantes optó por colocar, rejas, cercas, protecciones o zaguanes para cerrar o delimitar su casa, en beneficio de su privacidad y seguridad, pues el testimonio de la población, los asaltos, el vandalismo y las peleas, son temas recurrentes dentro del conjunto y sus alrededores. Aunque también, estos espacios son utilizados como extensiones de la casa como tendederos, bodegas o áreas comerciales.

Además de que son pocas las calles que -como se muestra en el plano $4^{51}$. cuentan con accesos para sillas de ruedas, carriolas o algún otro tipo de aparato que facilite la movilidad de las personas con discapacidad, adultos mayores o mujeres con bebés. Situación que puede contribuir al aislamiento de estos grupos y afectar su calidad de vida.

Plano 5. Disponibilidad de rampa silla de ruedas, Santa Elena, 2016.

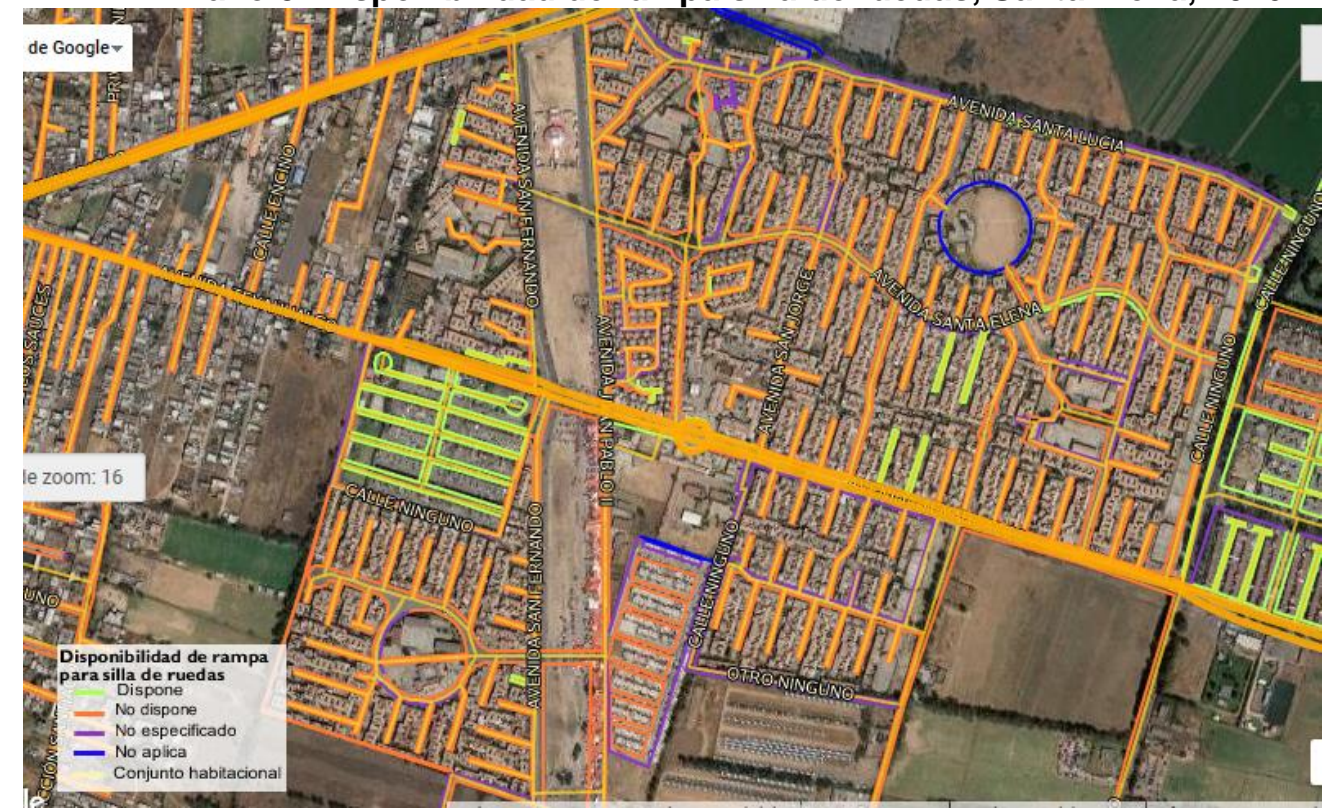

Fuente. INEGI, Inventario Nacional de Viviendas, 2016.

\footnotetext{
${ }^{51}$ Cabe mencionar que el área que se encuentra marcada con verde en el plano, es decir, la que cuenta el mayor número de accesos para sillas de ruedas, corresponde al Conjunto Urbano San Fernando que fue construido ex profeso para personas con discapacidad. En el resto de Santa Elena son escasas las calles que cuentan con este tipo de equipamiento.
} 
Y así es, porque ya ha habido chamacos de aquí mismo del fraccionamiento que ya han matado... cada quien sabe a lo que le da prioridad en la vida ¿verdad? Pero yo les decía, el que trabaje la mamá o el papá a la larga va a traer consecuencias, lo malo fue que se me adelantaron varios años porque yo decía 20... todavía no llevamos 16 y ya hay problemas de que asaltan, de que andan en las motos y todo ocasionado por la misma gente (Señora Aurora, 16 años residiendo en Santa Elena).

A mí las casas se me hacen muy pequeñas... para empezar la sociedad no la puedes cambiar, vienen con su cultura y su educación, tienes que adaptarte a veces a las cosas, de ahí en fuera ya está muy feo, aquí Santa Elena ya está feo, a como estaba recién que yo ya llegue ya está horrible, ya hasta se nota la violencia, los asaltos... acaban de matar hace 20 días a un muchacho allá adelante, asaltaron aquí, han asaltado los locales, o sea ya se detonó, ¿por qué? porque aquí es puerta abierta para todos los de Tultepec, los de la Antigua, los de Cebadales... esto ya se ha hecho feo, nosotros pensamos vender en un futuro, nada más que salga mi hija de la preparatoria (Señora Maribel, 8 años residiendo en Santa Elena).

[...] no sé qué ha pasado pero ha habido asaltos aquí afuera, nosotros nunca nos enterábamos... apenas ahorita que vinieron ajustarle cuentas a alguien que yo creo se había metido mal, también anduvo mucho el ejército entonces de repente entran cuando hay algo así; entonces, como que ya no es la misma confianza, por ejemplo ese día del asalto fue a la hora que venían los niños de la escuela, entonces empezaron los balazos y pues ellos llegaron corriendo, entonces dices tú ¿dónde está la seguridad? Un balazo les da a los niños, y dices tú, paga quien no debe de pagar y como yo siempre he dicho creo que tenemos muchas cosas por hacer como para que nos pase otra más. No te creas día a día así piensa uno (Señora Mónica, 16 años residiendo en Santa Elena). 
Estas dificultades son atribuibles al tamaño del conjunto y a su diseño deficiente, ya que algunos espacios quedaron prácticamente aislados del entorno o separados por las dos grandes avenidas que atraviesan al conjunto y que obligan a la población a realizar grandes recorridos a pie o en automóvil para llegar a los espacios en donde se ubican las escuelas, los comercios y el transporte.

Fotografías 14, 15, 16 y 17. Rejas colocadas en los frentes de las viviendas
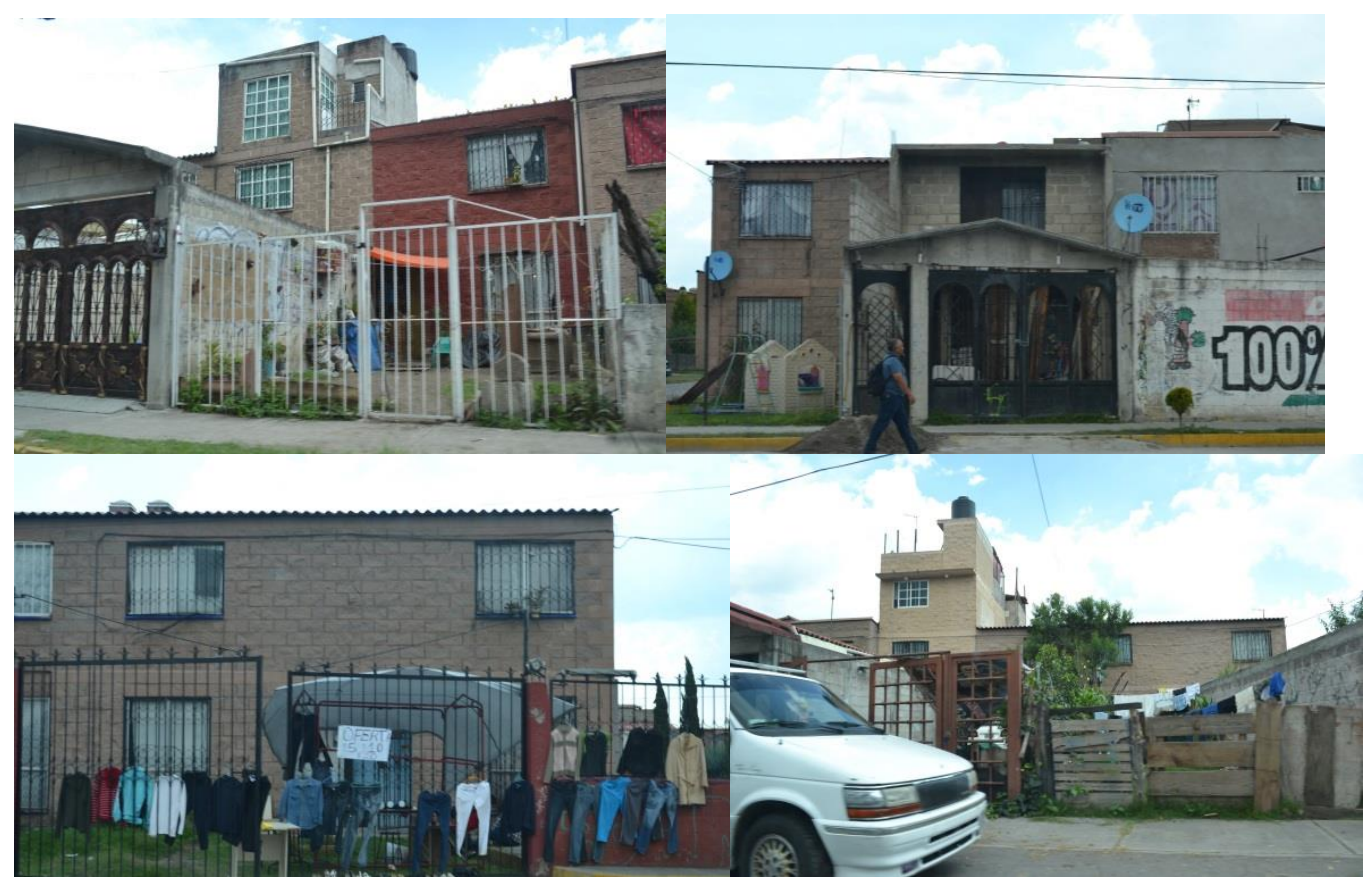

\section{c) Andadores}

En el plano número 3 se puede observar una suerte de pasillos o andadores con forma de "laberinto" que funcionan como conexión peatonal dentro de la misma manzana. Éstos se caracterizan por ser espacios estrechos y poco iluminados, rodeados por edificaciones que dan lugar a una nula relación espacial entre viviendas de la misma calle o manzana, lo cual, se convierte en una barrera que 
dificulta la vida cotidiana de sus habitantes, tal y como señala la señora Ofelia de 82 años de edad:

En el Distrito todo era diferente porque allá todo encuentras, yo incluso me perdí aquí [en el conjunto habitacional] cuando llegué porque había un local en la salida por donde está el arco, entonces dije: -ahorita vengo, al fin que nada más es la salida. Y fui a buscar jamón de pavo... la cosa es que ya en lugar de regresarme por donde me fui, quién sabe por dónde me fui a meter y fui a salir hasta por allá atrás del conjunto, entonces me vio una señora que por cierto hasta la fecha me dice abuelita y me dice: -¿qué le pasa señora, está bien? Y le dije: -¡No sé señora ando perdida, no sé dónde ando, lo único que me ayudaba era una colcha vieja que tenía yo de cortina! Y me dice la señora: espérenos ahorita la llevamos, siéntense. Pues me veía yo desesperada, me sacó un vasito de agua y ya que estaba tranquila me dijo: -véngase, nos vamos despacito y dónde sea usted ya nos dice. Y le contesté: -es que de verdad no sé, nada más dije ¡Madre santísima ilumíname porque no sé!... Nos fuimos caminando hasta que vi mi cortina vieja y dije isí, aquí es!- Me apuntó ella en un papelito mi dirección y me dijo -cuando salga así solita dígale a los del bicitaxi que la lleven porque ellos ya conocen Santa Elena. Total, hasta hace poco tire el papel... en muchos años lo que nunca me pasó en el Distrito me vino a pasar aquí, porque son muchas casas y luego todas iguales.

\section{d) Transporte y accesibilidad}

Santa Elena cuenta con 5 accesos, dos ubicados en las partes frontal y posterior del conjunto habitacional; otro en límite con el Pueblo de San Mateo Ixtacalco sobre la avenida Teyahualco y dos más en los límites de la Avenida San Fernando y la Avenida Juan Pablo II que conectan con el Conjunto Urbano Rancho San Blas. 
En la fotografía 17 podemos observar la parte de una barda que fue abierta por los propios habitantes del conjunto, para evitar recorrer el trayecto hasta el acceso ubicado sobre avenida Teyahualco y donde se ubica una base de transporte público.

En lo que respecta al transporte, el conjunto cuenta con una base de "combis" instalada en la parte posterior del fraccionamiento, frente al conjunto Ángel de Luz; una base de taxis ubicada sobre la Avenida Juan Pablo II esquina con Avenida Santa Elena; dos sitios de taxi ubicados sobre la Carretera a Tultepec y una parada de transporte público ubicada frente a la entrada principal. Asimismo, cuenta con un servicio de "bici taxis" que opera desde los locales comerciales hasta las viviendas.

\section{Fotografía 17. Barda abierta por los habitantes que colinda con Avenida la Antigua}

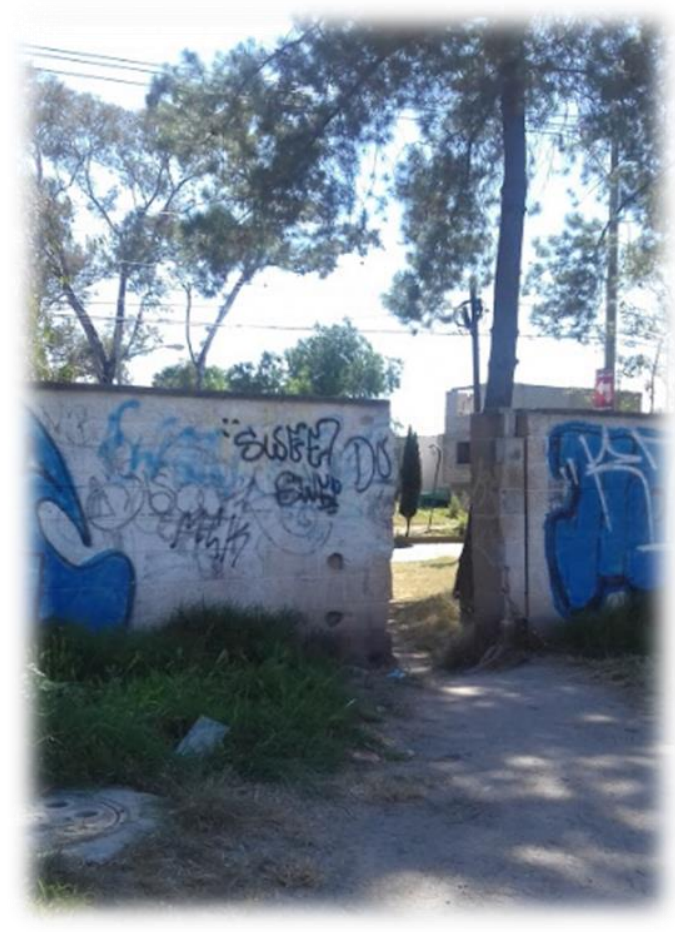

Algo que es de llamar la atención, es que en Santa Elena existe un número importante de barreras físicas y sociales que atentan contra posibilidad de transitar de manera libre y segura dentro del conjunto habitacional. Las barreras físicas se 100 
asocian a la escasez de rampas para sillas de ruedas o carriolas, autos mal estacionados en calles y avenidas que impiden el libre tránsito, banquetas rotas o en mal estado, baches y grandes cantidades de basura en las calles (fotografías $18,19,20$ y 21$)$.

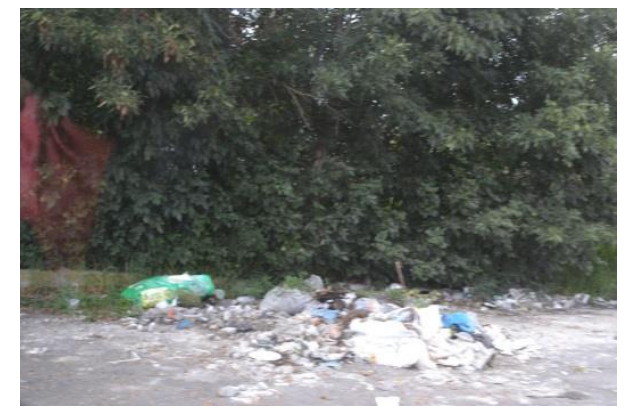

Fotografía 18. Basura ubicada en Avenida Santa Lucía

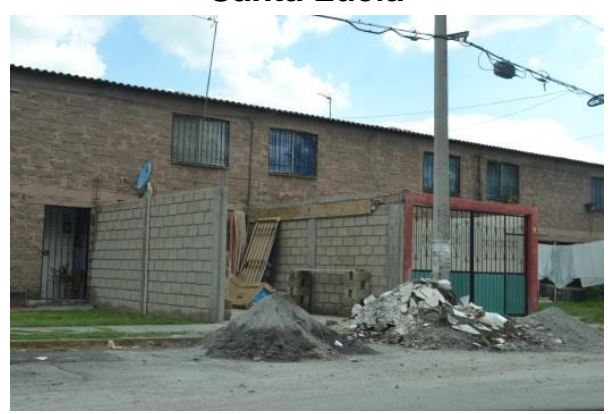

Fotografía 20. Desechos de construcción ubicados sobre Avenida Santa Lucía

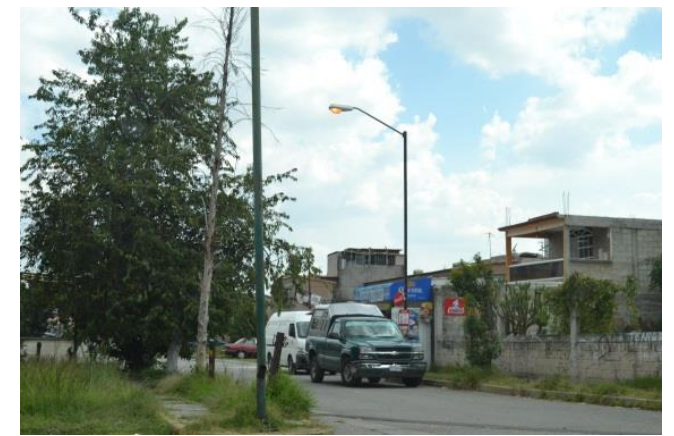

Fotografía 19. Autos estacionados sobre Avenida San José

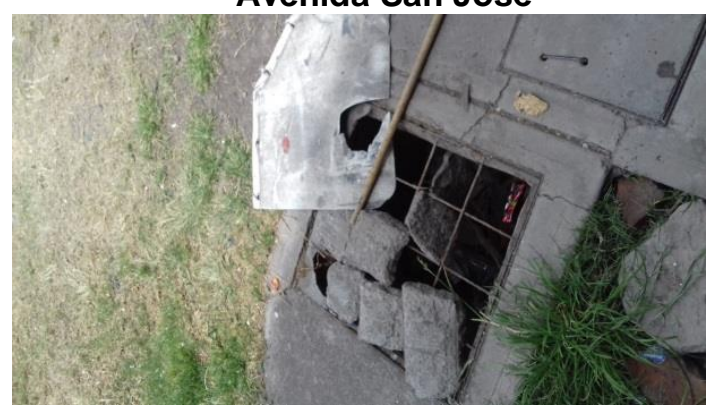

Fotografía 21. Coladera y parte de banqueta rotas ubicadas en la calle Condominio 52

Las barreras sociales corresponden a los límites que establecen los habitantes en su andar cotidiano y los lugares por los que evitan transitar ya que son considerados como peligrosos:

Los parques ni existen porque vete a ver los parques... el de acá lo tenía un maestro que daba clases de pentatlón, maratón o algo así y nadie lo quiso apoyar para arreglar, el pobre maestro, con los alumnos y con su 
dinero y las cuotas medio arregló pero está horrible. En las canchas están todos los marihuanos que van ¿tú crees que yo voy a dejar ir a mis hijos o a mis hijas? ¿Qué otro parque aquí te dicen que hay? ¡No hay! Seguimos esperando un deportivo que supuestamente iba a haber, ya hasta me casé y todavía no está (Señora Aurora, 16 años residiendo en Santa Elena).

\subsubsection{Equipamiento y estado de conservación}

Aunque al interior el conjunto cuenta con instalaciones para equipamiento deportivo, de salud y comercial (un mercado, una clínica de salud municipal y una alberca municipal), este conjunto sigue siendo dependiente del exterior, es decir, de la cabecera municipal y del resto de la ciudad en donde se encuentran las principales fuentes de empleo. Esto da cuenta que la figura de Conjunto Urbano lejos de promover la autosuficiencia de estos espacios, ha generado una gran dependencia de los entornos inmediatos.

Es importante mencionar que Santa Elena limita con uno de los asentamientos más antiguos del municipio: el pueblo de San Mateo Iztacalco, el cual se caracteriza por sus arraigadas costumbres, tradiciones y modos de vida distintos a los que llevan los habitantes de los Conjuntos Urbanos, lo que en ocasiones puede llegar a generar conflictos derivados de las distintas formas de apropiación de los espacios. Este problema es recurrente entre los mismos vecinos del conjunto habitacional tal como evidencia el testimonio de una de sus habitantes:

Cuando nosotros llegamos, las personas del pueblito de al lado del fraccionamiento no nos querían, pero de algún modo se beneficiaron porque ya tienen pavimento y sus casas bien pintadas y todo; de algún modo les sirvió que llegáramos, destruimos el sembradío... bueno nosotros no, a nosotros nos vendieron, ahora sí que el que se benefició 
fue el dueño del sembradío, entonces yo no viene a hacer mi casa, a mí me la vendieron, tampoco era mi culpa, yo nada más acepté lo que ya estaba pero ¿qué se hace? (Señora Aurora, 16 años residiendo en Santa Elena).

Otro problema que aqueja no solo a los habitantes de Rancho Santa Elena sino también a otros cercanos a éste, es la carencia de servicios y el desinterés de las autoridades municipales para gestionar estos espacios; lo que ha llevado a que en constantes ocasiones, su población se manifieste en las calles exigiendo la resolución a los problemas que los aquejan, relacionados entre otras cosas con la inseguridad y los cortes constantes al suministro de agua, así como a las fuertes inundaciones que sufren durante la temporada de lluvia.

GEO se deshizo de nosotros... tuvimos que ir a pararnos ahí, a travesar la carretera para no dejar pasar carros, ni dejar entrar al fraccionamiento para que nos hicieran caso. Eso fue como al medio año de que llegamos porque no fue lo que nos habían prometido en el contrato y tuvimos que andar aquí haciendo borlote ${ }^{52}$ para que nos hicieran caso... Ya después tuvieron que mandar a alguien del Ayuntamiento porque nos fuimos atravesar y jahí iba yo!, eso sólo fue un ratito porque luego, luego nos hicieron caso porque paramos la avenida y no les convenía... eso fue por el agua y con el comandante fue porque se inundó aquí atrás y en una noche hubieron [sic] tres muertos en el fraccionamiento, pero en la televisión nada más salió uno para variar, pero en realidad fueron tres (Señora Aurora, 16 años residiendo en Santa Elena).

A esto se suma que desde el año 2002, este conjunto enfrenta un problema administrativo importante, ya que ni el gobierno municipal, ni sus habitantes tienen claro a qué municipio pertenece. Esto resulta alarmante, no sólo porque pone en

\footnotetext{
52 Palabra coloquial mexicana que se utiliza para referirse a una situación escandalosa o en la que predomina el alboroto. Fuente. http://www.oxforddictionaries.com/definition/spanish/borlote (Consultado el: 11 de mayo de 2016).
} 
duda los mecanismos bajo los cuales son autorizados los Conjuntos Urbanos, sino también, porque genera sentimientos de incertidumbre en la población residente.

En el año 2012 los residentes declararon al periódico El Universal:

Tenemos cerca de 12 años peleando nuestro territorio, que nos definan de dónde somos, de Cuautitlán o de Tultepec, porque es muy problemático para nosotros, hay cosas que nos exigen en Cuautitlán y cosas que no nos resuelven, porque no somos ni de aquí ni de allá... Hay mucha delincuencia, el problema de las calles que están muy mal, la luz luego se va, el agua, son varias cosas, que no se resuelven porque no se sabe a dónde pertenecemos (Barrera, 2012).

Los problemas que aquejan a los habitantes Santa Elena, las evidentes transformaciones realizadas a las viviendas y al conjunto, observadas durante los recorridos de campo, así como de las características que en general comparten los Conjuntos Urbanos construidos en el Estado de México, nos invitan a reflexionar sobre el grado de satisfacción residencial que experimentan las personas que habitan estos espacios. Para esta investigación interesa de manera especial, conocer la evaluación de las mujeres amas de casa que residen en este conjunto, pues por el tipo de actividades domésticas que ellas realizan en su andar cotidiano, son las que generalmente, pasan más tiempo y hacen mayor uso de estos espacios.

Como se señaló anteriormente, el estudio de la satisfacción residencial permite entender la percepción y la valoración que los beneficiarios de la vivienda le asignan a los atributos y propiedades de ésta y de los conjuntos habitacionales que conforman. De ahí que este trabajo busque conocer el grado de satisfacción residencial de las mujeres amas de casa que habitan en el Conjunto Urbano Rancho Santa Elena, buscando identificar elementos que contribuyan a mejorar la política habitacional actual. 
Debemos recordar que la percepción que se tiene sobre el espacio habitable y sobre la calidad de la vivienda depende en buena parte de la estructura de relaciones sociales que se establecen en el espacio. Por ello, reconocemos que las opiniones de las mujeres no son universales, ni permanentes; por lo que no existe una sola percepción sobre la calidad del espacio, ni siquiera en aquellos espacios físicamente iguales, como es el caso de las viviendas de interés social (Haramoto, 2002: 20).

\subsection{6 ¿Quiénes habitan en Santa Elena?}

De acuerdo con los resultados por AGEB y manzana urbana del Censo de Población y vivienda 2010, en Santa Elena residen un total de 16,299 personas, es decir, $11.63 \%$ de la población total del municipio. De éstas, $49.15 \%$ son hombres y $50.83 \%$ son mujeres; se trata de una población mayoritariamente joven ya que $67.15 \%$ de la población tenía durante el año en mención entre 15 y 64 años de edad; $31.44 \%$ se ubicaba en el grupo de 0 a 14 años y solamente $1.40 \%$ de la población corresponde a adultos mayores de 65 años y más. ${ }^{53}$

En lo que respecta al número de hogares que habitan en este conjunto, se encontró que de los 4,178 hogares que residen en Santa Elena, 19.53\% son encabezados por una mujer, es decir, en este conjunto habitan $3.3 \%$ de los hogares con Jefatura Femenina del municipio de Cuautitlán.

Aunque no se cuenta con datos a nivel AGEB que permitan establecer las condiciones y características de los hogares liderados por mujeres en este conjunto, es importante al menos conocer el número que de hogares de este tipo que residen en este espacio, ya que el tema de los hogares con Jefatura Femenina ha sido recientemente uno de los más controversiales en los estudios

53 Se consideró a 16, 131 personas como el total de la población ya que no se cuenta con información a nivel AGEB de los indicadores que cuentan con menos de 3 unidades. 
de las familias contemporáneas, debido al considerable aumento de este tipo de hogares y a su estado de pobreza y vulnerabilidad. ${ }^{54}$

\section{a) Características educativas}

Si hablamos de las características educativas de los residenres de Santa Elena, encontramos que el promedio general de escolaridad de los habitantes de 15 años y más, es de 8.74 años, es decir 1.64 años menos que el promedio municipal. Sin embargo, al observar los datos a nivel manzana urbana, encontramos que en algunos casos este promedio supera la media municipal alcanzando 13.35 años de estudio. Incluso, el nivel de analfabetismo en este conjunto es mínimo ya que solamente 66 personas $^{55}$ de las 16,299 que habitan en Santa Elena no sabe leer ni escribir.

\section{b) Características económicas y derechohabiencia a servicios de salud}

La posibilidad de contar con un trabajo formal, está relacionada de manera directa con la condición de derechohabiencia, el acceso a servicios básicos y el ingreso la población, todos ellos indicadores de la calidad de vida. Razón por la cual es importante contar con datos que nos permitan conocer las características de la población en determinado espacio.

\footnotetext{
${ }^{54}$ García y de Oliveira (2005: 29) señalan que el surgimiento de estos hogares puede ser atribuido a un aumento en la esperanza de vida femenina y al menor número de uniones posteriores de las viudas. Sin embargo, diversas investigaciones sugieren que el incremento de estos hogares responde a factores económicos, culturales y subjetivos entre los que destacan: el aumento en la escolaridad, una mayor participación laboral de las mujeres, el incremento de las separaciones y divorcios, los abandonos masculinos y los embarazos en mujeres cada vez más jóvenes.

55 Estos datos son aproximados debido a que el principio de confidencialidad que establece el INEGI impide conocer datos de los indicadores con menos de tres unidades registradas.
} 
En el caso de Santa Elena se encontró que durante el año 2010, 6,755 personas eran económicamente activos y 5,542 económicamente eran inactivos, lo que quiere decir que durante la semana de referencia del censo no buscaron trabajo, ni realizaron actividades económicas. $73.36 \%$ de los residentes tenían acceso a servicios médicos en alguna institución pública o privada y aproximadamente $25.52 \%$ no contaban con acceso algún tipo de servicio de salud.

Infografía 3. Características de la población y de las viviendas, Conjunto Urbano Santa Elena 2010

\section{Características de la Población}
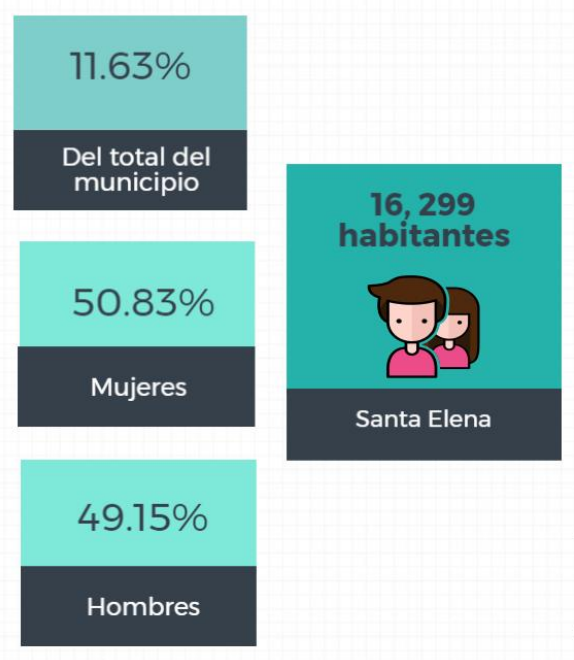

(4) $31.44 \%$

0-14 años

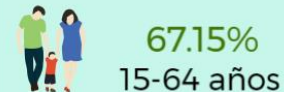

$1.40 \%$ 65 y más

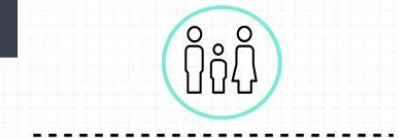

4, 178 hogares

(4) $\begin{gathered}19.53 \% \\ \text { encabezados por } \\ \text { mujeres }\end{gathered}$
$73.36 \%$ con acceso a servicios de

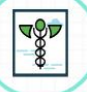
salud

$25.52 \%$ sin acceso a servicios de salud

Grado promedio de escolaridad:
8.74 años

66 personas analfabetas

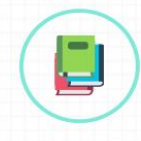

6,755 personas económicamente activas

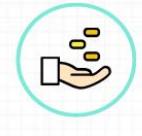

5,542 personas económicamente no activas

\section{Caracterísitcas de las viviendas}

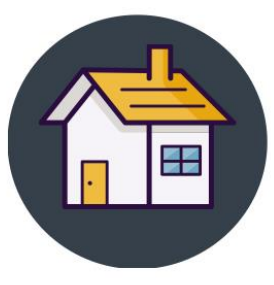

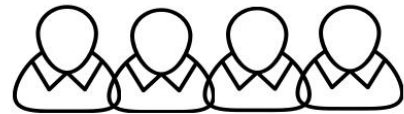

Promedio de habitantes por vivienda:

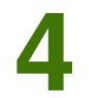

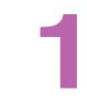

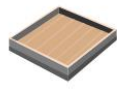

Habitante por cuarto

Fuente: Datos por AGEB y manzana urbana, Censo de Población y Vivienda 2010. Infografía realizada mediante la aplicación Piktochart. 


\section{c) Características de las viviendas}

Aproximadamente 1,655 de las 6,119 viviendas con las que cuenta Santa Elena ${ }^{56}$ se encuentra deshabitadas, es decir, no tienen residentes habituales, no son de uso temporal y no son utilizadas para fines económicos.

Aunque el promedio de habitantes en este conjunto es de 4 personas por vivienda (similar al promedio municipal) y un habitante por cuarto, se encontró durante las entrevistas a profundidad y la aplicación de los cuestionarios, que existen casos particulares donde habitan hasta 10 personas en una misma vivienda; lo cual impone una serie de dificultades a las familias que habitan bajo esta condición, tal y como señala la señora Mónica de 47 años de edad, quien vive con sus hijos, nueras y nietos:

Cada quién nos organizamos por decir ... mi nuera un día trapea, yo hago de comer, mi hija hace allá arriba; cada quien se encarga de lo suyo: de su recámara, de su ropa, de sus hijos, de su marido... igual yo me encargo más del bebé porque él siempre ha estado conmigo [señala a su nieto que la acompaña durante la entrevista], entonces yo me encargo más de él... termino lo que me toca por decir, la comida, y eso y ya me estoy con él. O sea nos organizamos, al otro día mi hija trapea, la otra hace de comer y así estamos... mi hija se encarga por decir de su escuela de ellos [de los niños] de todo lo que es de ellos y yo me encargo nada más de darles de comer y eso.

Es complicado porque mi nieto está enfermo, tiene discapacidad y cuando tenemos citas con el niño y tenemos que ir algún lado como antier que fuimos a sacar una cita a Plaza Aragón, porque de Coacalco nos mandaron hasta allá... a veces sí se nos complica porque tenemos que ir y regresar y dejar a los niños y entonces sí a veces si se nos

\footnotetext{
${ }^{56}$ Estos datos son aproximados ya que no se cuenta con información precisa de las viviendas a esta escala territorial. Los números que aquí se señalan, incluyen datos de los conjuntos Ángel de Luz y San Fernando y provienen de la herramienta del INEGI Espacio y Datos de México.
} 
Mujer y satisfacción residencial. La mirada de quienes habitan en el Conjunto Urbano Rancho Santa Elena. Cuautitlán, Estado de México.

complica un poquito. Incluso para dormir porque como quiera que sea mi hija tiene su recámara arriba, mi nuera acá adentro y nosotros nos quedamos en la sala mientras nos acomodamos.

Esta información ofrece un panorama general de la población y las características de las viviendas del Conjunto Urbano Rancho Santa Elena; lo cual permite contextualizar los resultados de los 50 cuestionarios aplicados que se exponen en el siguiente capítulo de este trabajo. 


\section{CAPÍTULO 4. VIVIENDA Y SATISFACCIÓN RESIDENCIAL, LA MIRADA DE QUIENES HABITAN EN EL CONJUNTO URBANO RANCHO SANTA ELENA}

Este capítulo tiene como objetivo presentar los resultados del trabajo de campo, el cual consistió en la aplicación de una encuesta con 50 cuestionarios y 5 entrevistas en profundidad a mujeres amas de casa de entre 24 y 72 años de edad que habitan en el Conjunto Urbano Rancho Santa Elena.

\subsection{Datos generales de la población encuestada}

Este apartado tiene como objetivo exponer algunos datos generales sobre la población encuestada que permiten contextualizar los resultados de la Encuesta de Satisfacción Residencial que se presentan en los apartados siguientes.

Es importante recordar que esta investigación se basa en la opinión de 50 mujeres amas de casa, que habitan en el Conjunto Urbano Rancho Santa Elena y que, al momento de la aplicación de la encuesta, tenían por lo menos un año de vivir en el conjunto. Se trata de mujeres con una media de 45 años de edad, cuyas actividades principales son los quehaceres del hogar y el cuidado de los hijos.

De acuerdo con los resultados de la Encuesta de Satisfacción Residencial para el Conjunto Urbano Rancho Santa Elena 2016 (Gráfica 2), 32\% de la población llegó a vivir al conjunto en el año 2000, es decir, inmediatamente después de que finalizaron los trabajos de construcción; mientras que $22 \%$ ocupó su vivienda un año después (2001); 10\% llegaron al conjunto en el año 2002 y el resto de las encuestadas lo hizo en los años subsecuentes.

Lo anterior quiere decir, que la mayoría de las encuestadas tiene un promedio de 15 años viviendo en Santa Elena, por lo que han sido testigos de las transformaciones que ha sufrido el conjunto y su entorno, durante los últimos años. 
Mujer y satisfacción residencial. La mirada de quienes habitan en el Conjunto Urbano Rancho Santa Elena. Cuautitlán, Estado de México.

Gráfica 2. Porcentaje de población según año en que llegó a vivir al Conjunto Urbano Rancho Santa Elena

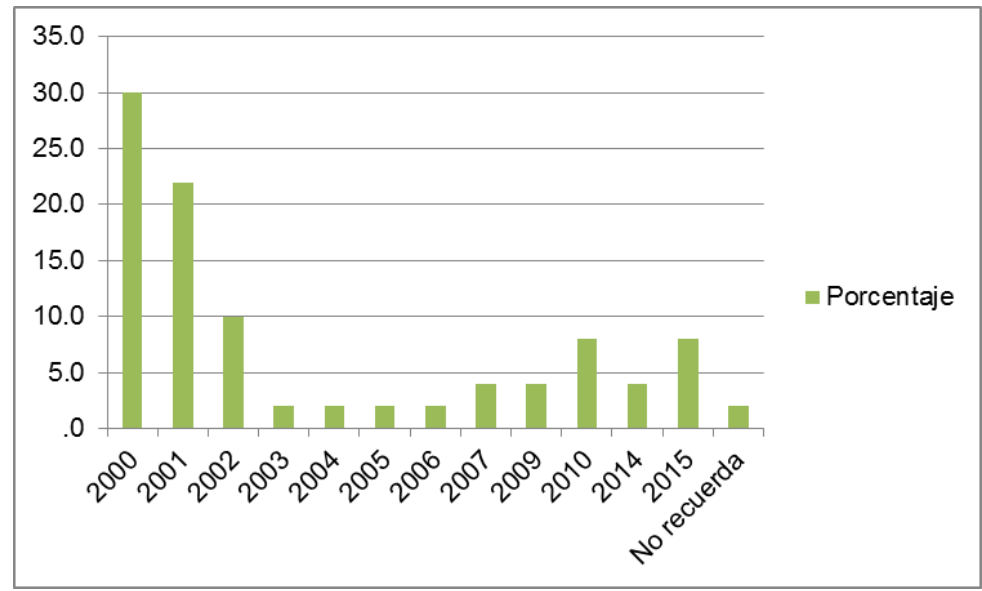

Elaboración propia con base en los resultados de la Encuesta de Satisfacción Residencial para el Conjunto Urbano Rancho Santa Elena 2016.

En cuanto a la forma de adquisición de la vivienda, se encontró que $76 \%$ de las mujeres reportaron haber adquirido su vivienda mediante un crédito hipotecario asignado a su cónyuge por el INFONAVIT; 10\% obtuvo su vivienda mediante una institución bancaria, $8 \%$ renta la vivienda, $2 \%$ la adquirió con sus ahorros y $4 \%$ la pidió prestada a algún familiar o amigo.

Gráfica 3. Porcentajes de población según modo de adquisición de la vivienda

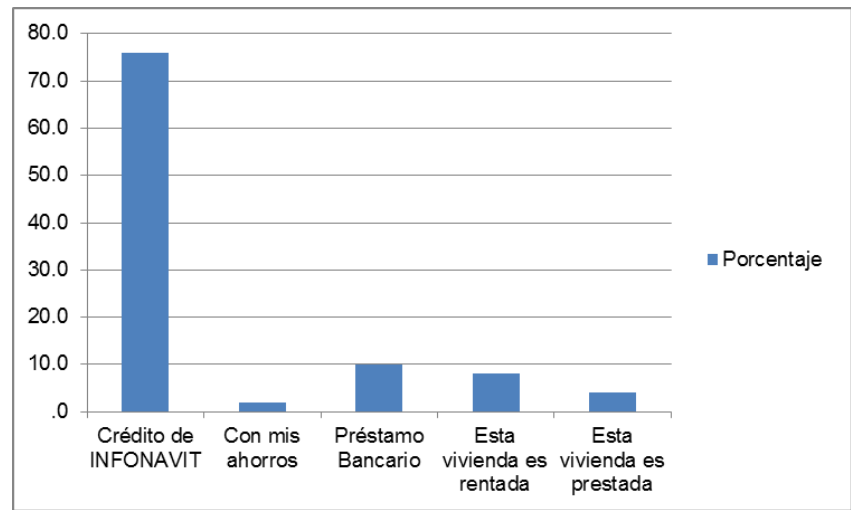

Elaboración propia con base en los resultados de la Encuesta de Satisfacción Residencial para el Conjunto Urbano Rancho Santa Elena 2016. 
Al analizar los datos acerca del lugar de procedencia de las encuestadas encontramos que $68 \%$ provenía de municipios contiguos o cercanos, $22 \%$ vivía dentro del mismo municipio y solamente 10\% habitaba en alguna delegación de la Ciudad de México. Esto es importante porque muchas veces se piensa que los habitantes de estos conjuntos provienen de la Ciudad de México y que al no encontrar vivienda accesible en esa entidad, tienen que salir a los municipios metropolitanos.

Gráfica 4. Porcentajes de población según lugar de procedencia

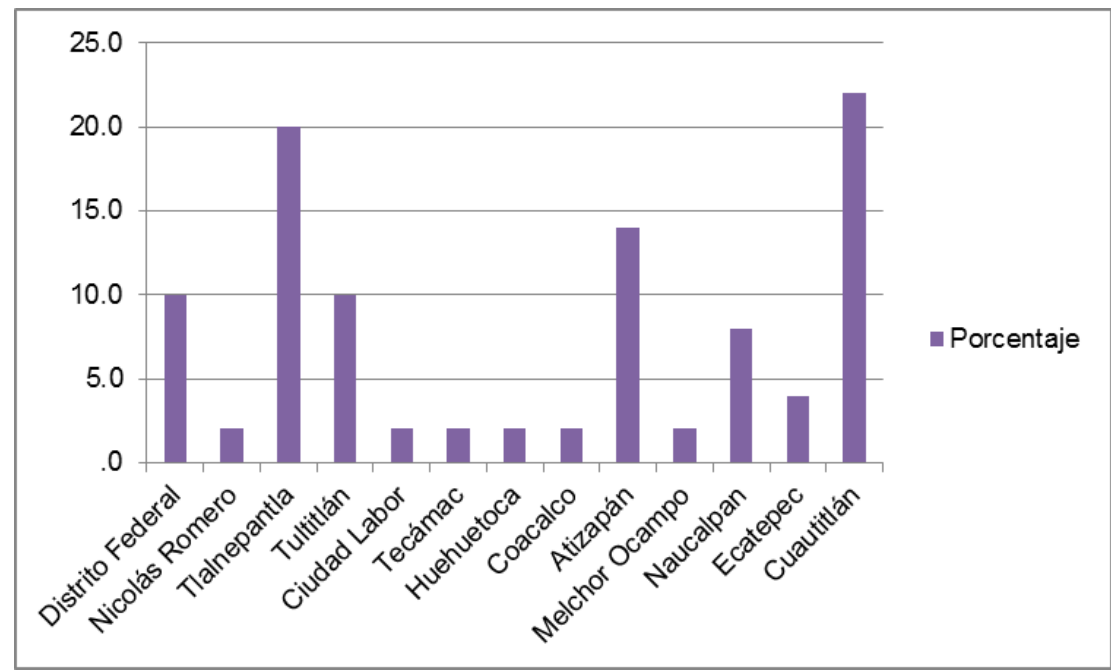

Elaboración propia con base en los resultados de la Encuesta de Satisfacción Residencial para el Conjunto Urbano Rancho Santa Elena 2016.

\subsection{Situación de la vivienda anterior}

Cuando hablamos de evaluar el grado de satisfacción que los usuarios de un conjunto habitacional tienen con su vivienda, resulta relevante indagar acerca de la situación habitacional anterior. Estos datos permiten conocer los fundamentos que sustentan la opinión de los usuarios y las bases sobre las cuales se forma su percepción acerca del nuevo lugar de residencia. 
En relación al tema de la tenencia de la vivienda anterior, los resultados indican que $46 \%$ de las familias de las encuestadas eran arrendatarias, $40 \%$ familiares 0 amigos del propietario, $2 \%$ habitaban una vivienda prestada y solamente $12 \%$ eran propietarios. La importancia estos datos radica en las expectativas que se generan y con el nivel de satisfacción o desilusión que se produce al encontrarse con la realidad de la vivienda recibida. Se ha señalado que la propiedad es un factor que influye en el grado de satisfacción que tiene las personas con su vivienda y que las lleva a superar los otros problemas derivados de la ubicación, el tamaño y los materiales con que ésta está construida.

Así, aunque más adelante se analiza este aspecto con detalle, es importante mencionar que aunado a las comparaciones que se puedan realizar entre la vivienda anterior y la situación habitacional actual; hemos encontrado que la situación personal y los factores que motivan el deseo de cambiar de residencia, son elementos clave en la definición del grado de satisfacción con la vivienda.

Infografía 2. Datos sobre la tenencia de la vivienda anterior y tipo de vivienda

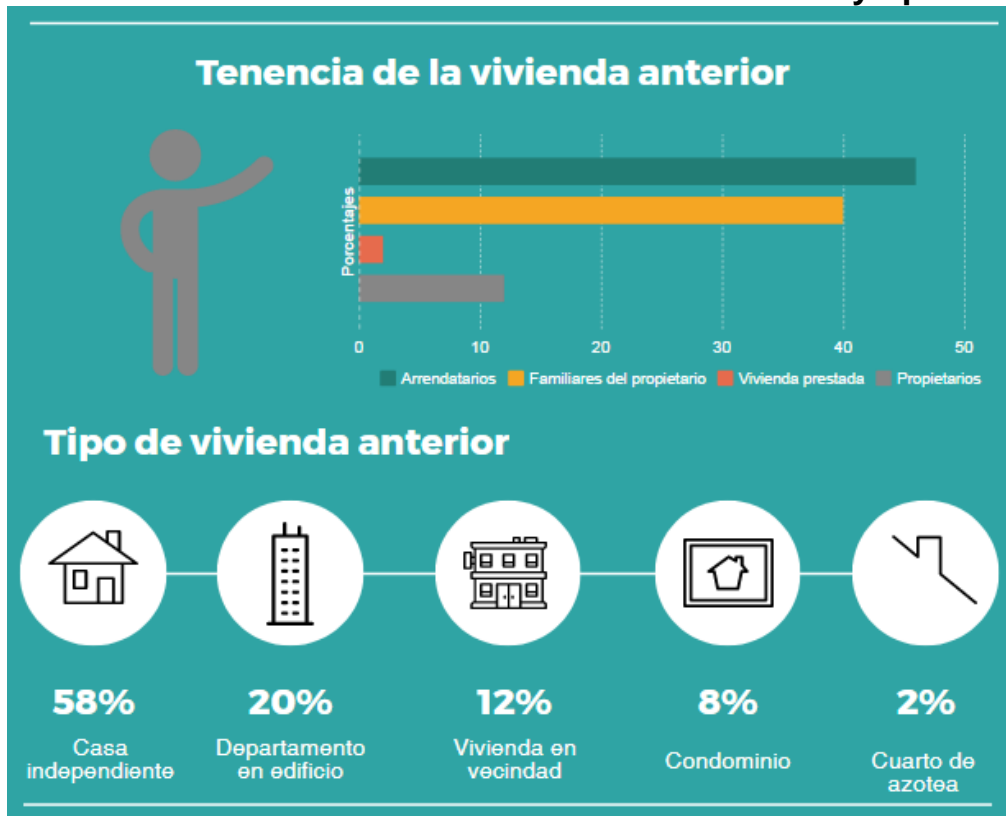

Elaboración propia con base en los resultados de la Encuesta de Satisfacción Residencial para el Conjunto Urbano Rancho Santa Elena 2016. Infografía realizada mediante la aplicación Piktochart. 
En lo que respecta a la clase de vivienda anterior, los resultados de la encuesta revelan que $58 \%$ de la población residía en casa independiente, $20 \%$ en un departamento en edificio, $12 \%$ en vivienda en vecindad, $8 \%$ en casa en condominio y $2 \%$ en un cuarto de azotea. Estos datos reflejan cambios importantes en los modos de vida de las encuestadas y sus familias, ya que más de la mitad de los encuestados (al vivir en casa independiente), no había tenido la experiencia de compartir los espacios o áreas comunes que son características de los Conjuntos Urbanos, lo que puede desencadenar una serie de problemáticas relacionadas con la imposibilidad de comunicarse y ponerse de acuerdo con los vecinos para dar mantenimiento a las zonas que rodean a la vivienda y en consecuencia el surgimiento de conflictos derivados de la convivencia cotidiana.

Tal como señaló en entrevista la señora Aurora de 46 años de edad:

El conjunto ha cambiado mucho, pero no para bien sino para mal. Yo lo recuerdo así como tipo de los que salen en la tele de esos bien bonitos, todo bien limpio, en las calles no había basura y las calles no estaban así de desechas... ¡Estaba todo re-bonito! Pero obvio estaba todo nuevo y había poca gente, la mayoría eran niños que no iban a la escuela, los que estábamos al principio... Y de ahí todo empezó para atrás y para atrás.

\subsubsection{Evaluación de la vivienda anterior}

Sobre la satisfacción con la vivienda anterior, encontramos que $48 \%$ de las encuestadas considera que su antigua casa les permitía llevar una vida familiar Muy satisfactoria, $10 \%$ señaló que se sentía satisfecha con este rubro, $28 \%$ que su vida familiar en la vivienda anterior era poco satisfactoria y $14 \%$ dijo sentirse nada satisfecho. 
Gráfica 5. Resultados a la pregunta ¿Considera que su vivienda anterior le permitía llevar una vida de familia satisfactoria?

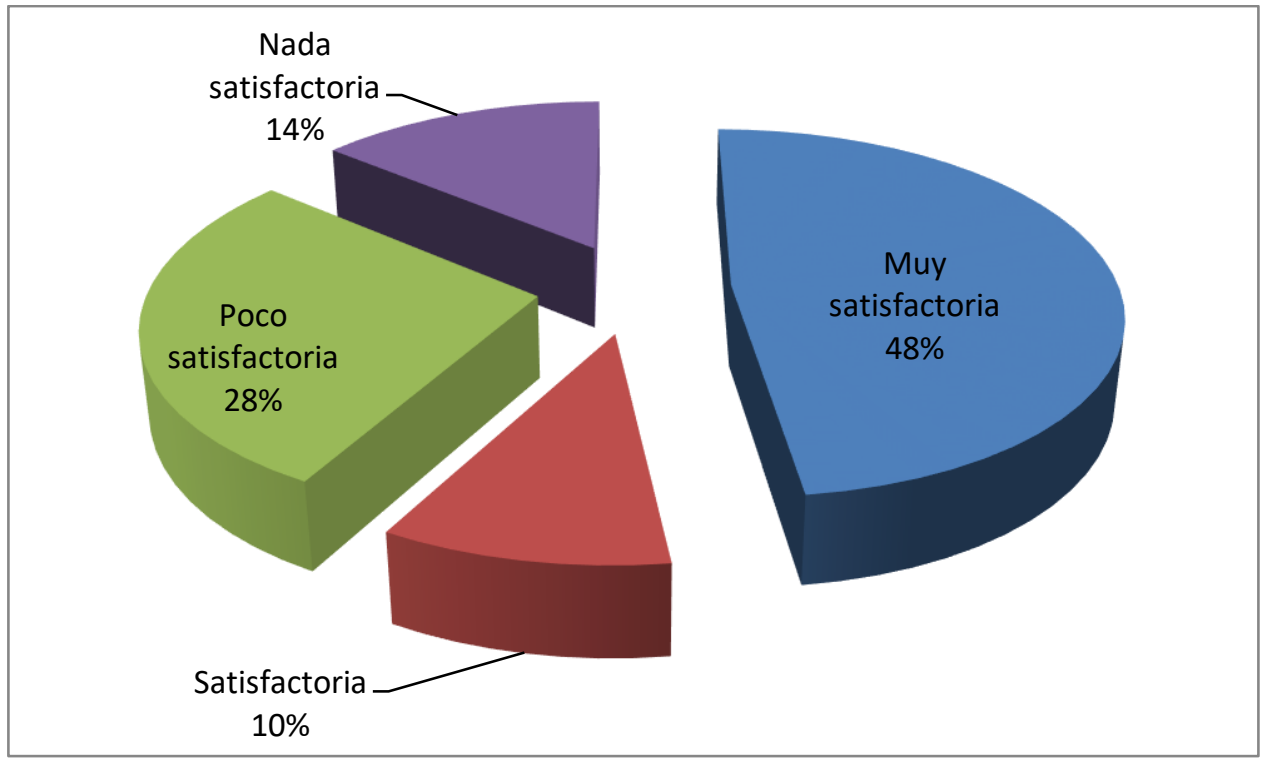

Elaboración propia con base en los resultados de la Encuesta de Satisfacción Residencial para el Conjunto Urbano Rancho Santa Elena 2016.

En este ámbito, los resultados de la encuesta demuestran que el tipo de solución habitacional no es una variable que determine el nivel de satisfacción de las familias con su vivienda ya que $5.71 \%$ de los que se sentían nada satisfechos habitaban en un casa de tipo independiente, lo cual supone que cuentan con mayores comodidades pues generalmente se trata de viviendas que pueden ser adaptadas y modificadas de acuerdo a las necesidades de sus habitantes, ya que no comparten pared, techo o piso con otra vivienda, y cuentan con acceso independiente desde la calle, camino o campo (Glosario INEGI: 2010).

En lo que respecta a la satisfacción con la vivienda anterior, encontramos que $48 \%$ de las encuestadas considera que su antigua casa les permitía llevar una vida familiar Muy satisfactoria; $10 \%$ señaló que se sentía Satisfecha con este rubro; $28 \%$ indicó que su vida familiar en la vivienda anterior era Poco satisfactoria y $14 \%$ se ubicó en la categoría de Nada satisfactoria. De quienes dijeron llevar una vida familiar Muy satisfactoria antes de mudarse a Santa Elena 70.84\% 
residía en una vivienda de tipo independiente; $20.84 \%$ en departamento en edificio, $4.16 \%$ en vivienda en vecindad y $4.16 \%$ en vivienda en condominio.

Pese a que un porcentaje importante de la población que residía en casa independiente mencionó sentirse Muy satisfecha o Satisfecha con su vivienda anterior, es interesante notar que $31 \%$ de estos señaló sentirse Poco o Nada satisfecho con la solución habitacional anterior; por lo que ante estos datos vale la pena matizar lo siguiente:

Aunque tradicionalmente la gran mayoría de las familias mexicanas ha recurrido a formar parte de un tipo de urbanización popular asentada en terrenos irregulares debido a las ventajas que ésta ofrece -el acceso a suelo barato, la posibilidad de modificar y construir de acuerdo a sus necesidades y posibilidades económicas- es cierto también, que existen otros factores que pueden llevar a los residentes a sentirse insatisfechos con este tipo de solución habitacional y que están más relacionados con las dinámicas familiares que se desarrollan en el interior de estos espacios, el entorno social y las aspiraciones individuales, que con las características físicas de la vivienda en sí.

Al profundizar con las entrevistadas respecto a este tema, se encontró que la insatisfacción que sentían por su vivienda anterior se asocia a problemáticas derivadas de la vida familiar, ya que suele ocurrir que los individuos se mudan de casa de sus padres con el objetivo de independizarse, formar una familia, mejorar sus condiciones de vida o por circunstancias que los orillaron a mudarse, tal y como expresan las entrevistadas en sus testimonios:

Yo me vine a vivir para acá porque era conserje de un edificio y llegó el momento en que me cansé y que ya no podía y dejé el trabajo, me liquidaron y todo. Entonces yo tuve que pensar en qué rumbo iba a agarrar y mi hija la que falleció, que en paz descanse porque murió de cáncer... ella me dijo mamá ahí está la casa si quieres vete para allá, pero yo ni conocía este lugar (se ríe) y ya me trajo y me dijo -mira mamá 
esta es la casa, nosotros no nos vamos a venir a vivir aquí- pero en ese entonces creo que les metieron la casa a fuerza en el trabajo y aquí estoy, aquí me tocó vivir... (Señora Ofelia, 16 años residiendo en Santa Elena).

Me gustaba mucho mi casa, pero como soltera... porque para ese entonces cubría lo que yo necesitaba, nada más que ya casada y con un hijo ya no fue... no es que no fuera suficiente aunque mi mamá me dice que me quedó chica la casa no era eso, sino que yo no iba a poder lograr lo que yo quería para mi hijo estando ahí, porque al ser familiares estaban mis hermanos y mi mamá, mi papa ya no porque él se murió en febrero y yo me casé en junio, entonces mi hijo ya no lo conoció. Pero lo que yo quería para mi hijo mi mamá no me lo iba a permitir, o sea de mi casa a mí no me interesa el valor económico, yo lo quería para vivir y punto (Señora Aurora, 16 años residiendo en Santa Elena).

De mi vivienda anterior, no me gustaba nada porque era un vínculo social ya muy pesado, drogadicción, violencia, bandas... Tomé la decisión de venir a venir acá para darles otro tipo de vida social a mis hijos, tengo dos chicos jóvenes de 18 y de 17 y la pequeña de 7 años; como yo crecí, yo sabía lo que era vivir en ese vínculo de amistades o de sociedad, yo no quería eso para mis hijos (Señora Maribel, 8 años residiendo en Santa Elena).

La casa era de mis suegros... entonces éramos varios, por eso ya también él [su esposo] hizo por comprar esta vivienda, para que nosotros estuviéramos mejor. Al principio nos gustaba porque por lo menos ya no éramos tantos en la misma casa, pero pues a lo mejor 
Mujer y satisfacción residencial. La mirada de quienes habitan en el Conjunto Urbano Rancho Santa Elena. Cuautitlán, Estado de México.

ahorita si te pesa un poco porque nosotros con otro cuarto pues si la haríamos un poquito más; pero pues no tenemos lo económicamente necesario para poder hacer todo eso... (Señora Mónica, 16 años residiendo en Santa Elena).

Antes de vivir aquí, vivíamos en Tlalnepantla en casa de mis papás... era un poco incómodo porque éramos 4 personas viviendo en un cuarto que tiene mi papá en su casa y aunque pues es un cuarto grande y teníamos cocina y baño independientes a la casa de mi papá pues no dejaba de ser un cuarto. El techo era de lámina y cuando hacía calor parecía sauna, todo el calor se encerraba y pues si llovía era muy escandaloso, teníamos que subirle a la tele para escuchar porque con la lámina hacía mucho ruido. [...] nos venimos a vivir para acá, gracias a mi mamá porque antes de fallecer me dejó un dinerito y me hizo prometerle que lo iba a utilizar para salirme de ahí... yo ya sabía que en cuanto mi mamá muriera los pelitos con mis hermanas iban a ser más graves y mi papá siempre tuvo un carácter horrible, así que un día un amigo de mi esposo que vivía en Melchor Ocampo le dijo que viviéramos a ver las casas y pues no estaban tan mal, todavía estaban terminando de construir y sólo vimos la maqueta que nos enseñó GEO, años después nos daríamos cuenta de que el fraccionamiento no era como lo habían prometido, pero pues ya qué podemos hacer ya estamos aquí.

(Señora Rebeca, 16 años residiendo en Santa Elena)

De estos testimonios, se puede rescatar que cuando se profundiza en los aspectos cualitativos que llevan a una persona a sentirse insatisfecha con su espacio habitacional, es posible entender que el grado de satisfacción o insatisfacción habitacional no solamente se basa en un análisis cuantitativo de las características físicas de la vivienda, sino que además, involucra sentimientos, 
aspiraciones y experiencias que son rememoradas por los usuarios a la hora de evaluar o calificar el espacio residencial.

\subsection{Características de la vivienda actual}

Como se explicaba en los capítulos anteriores, la valoración que los usuarios realizan a su vivienda actual es uno de los indicadores más relevantes de la satisfacción residencial debido al significado que la vivienda adquiere en el desarrollo de las familias (Haramoto, 2002: 39). Y además, porque como señala Pedrotti (2012: 179) una valoración favorable de la vivienda actual redundaría en un avance positivo en su trayectoria habitacional.

Fotografías 22 y 23. Vista de las fachadas de Santa Elena

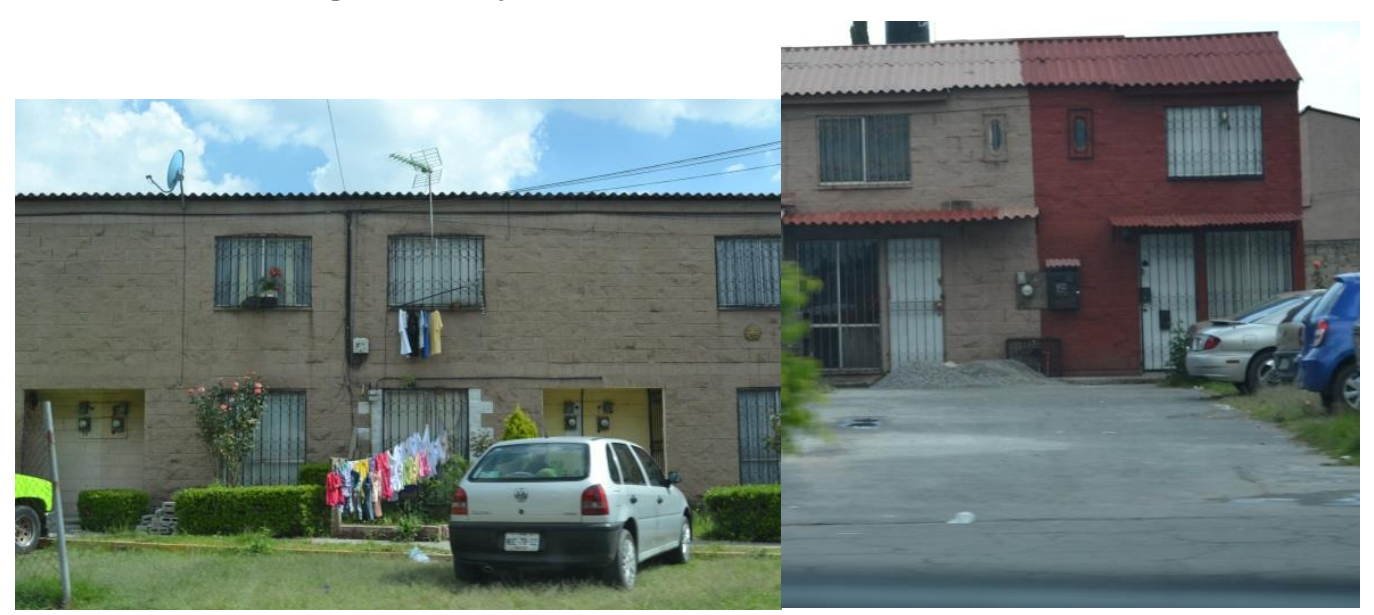

De acuerdo con información proporcionada por los encuestados, Santa Elena cuenta con dos prototipos de vivienda: el primero, tiene un baño y dos dormitorios; y el segundo, dispone de dos recámaras y dos baños. Los tipos de vivienda se pueden distinguir fácilmente gracias a la ubicación de las puertas de las casas, pues tal y como se muestra en la fotografía 22 las casas que de un baño, se caracterizan porque en ellas las puerta por la que se accede a la vivienda 
se encuentra frente a la puerta de la casa contigua. Mientras que en las casas de dos baños, la puerta se ubica en la parte frontal de la construcción y con vista a la calle (fotografía 23).

Ambos tipos de vivienda tienen una superficie de 63 metros cuadrados, siendo la distribución de los espacios la variante principal, de acuerdo al número de baños y dormitorios.

En lo que respecta a los resultados de la encuesta realizada, se encontró que $86 \%$ de las familias residen en una vivienda de un solo baño y dos dormitorios y el $14 \%$ restante cuenta con un solo baño. Únicamente $8 \%$ de los encuestados señaló contar con 3 dormitorios, esto gracias a las ampliaciones y modificaciones que han realizado en su vivienda con el fin de adaptarlas a sus necesidades; cabe mencionar aquí que el $20 \%$ de los encuestados ha realizado algún tipo de ampliación en su vivienda; siendo los dormitorios y la cocina los espacios mayormente modificados por los habitantes.

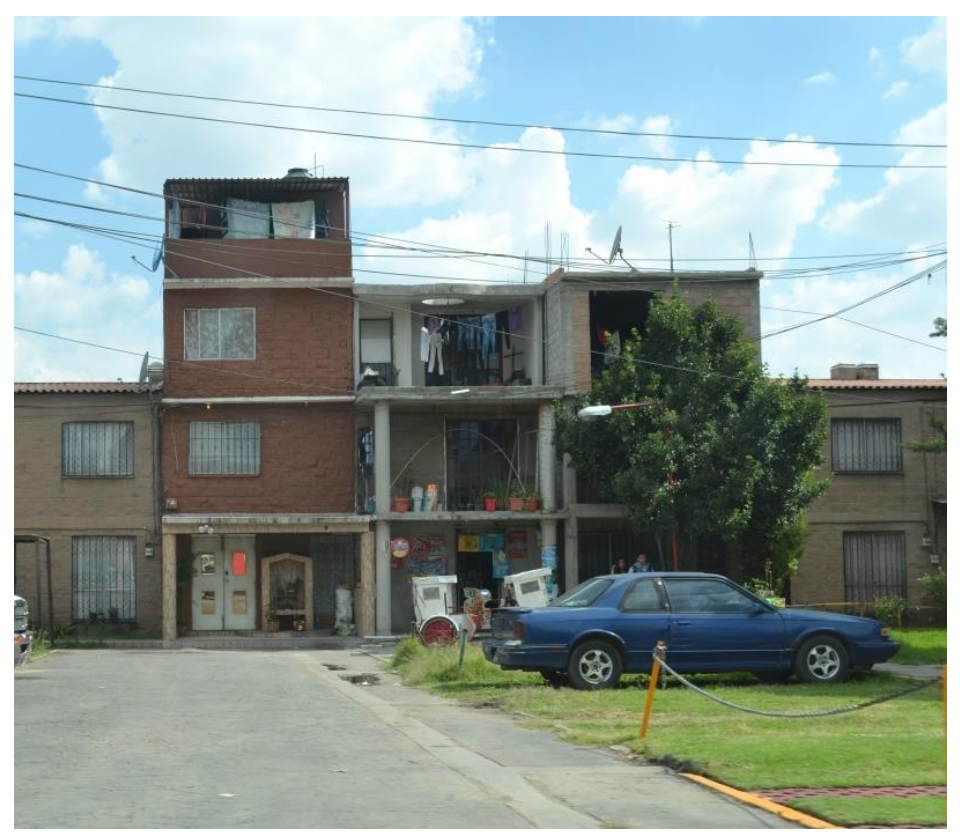

Fotografía 23.

Ampliaciones de las viviendas para su uso como dormitorios o áreas de lavado. 
En la fotografía 23 se muestran tres viviendas en las que fueron construidos pisos adicionales ( 2 pisos en la primer casa de la izquierda y 1 piso en las dos casas siguientes) y que son utilizados como recámaras o espacios para secar ropa, pues los residentes de Santa Elena consideran que el espacio destinado para estos fines en el diseño original, es insuficiente.

Cuadro 12. Número de baños y dormitorios, según porcentaje de encuestados.

\begin{tabular}{|c|c|c|c|}
\hline Número de baños & Porcentaje & $\begin{array}{c}\text { Número de } \\
\text { dormitorios }\end{array}$ & Porcentaje \\
\hline 1 & $86.0 \%$ & 1 & $14.0 \%$ \\
\hline 2 & $14.0 \%$ & 2 & $78.0 \%$ \\
\hline 3 & $0.00 \%$ & 3 & $8.0 \%$ \\
\hline
\end{tabular}

Elaboración propia con base en los resultados de la Encuesta de Satisfacción Residencial para el Conjunto Urbano Rancho Santa Elena 2016.

\subsubsection{Actividades difíciles de realizar dentro de la vivienda}

Según los resultados de la encuesta, las actividades que son más difíciles de realizar para los habitantes de este conjunto debido a las características de las viviendas son: realizar fiestas y reuniones, poner un negocio o taller, trabajar, realizar ejercicio, estacionar su auto y escuchar música.

Gráfica 6. Actividades que son difíciles de realizar en la vivienda según porcentaje

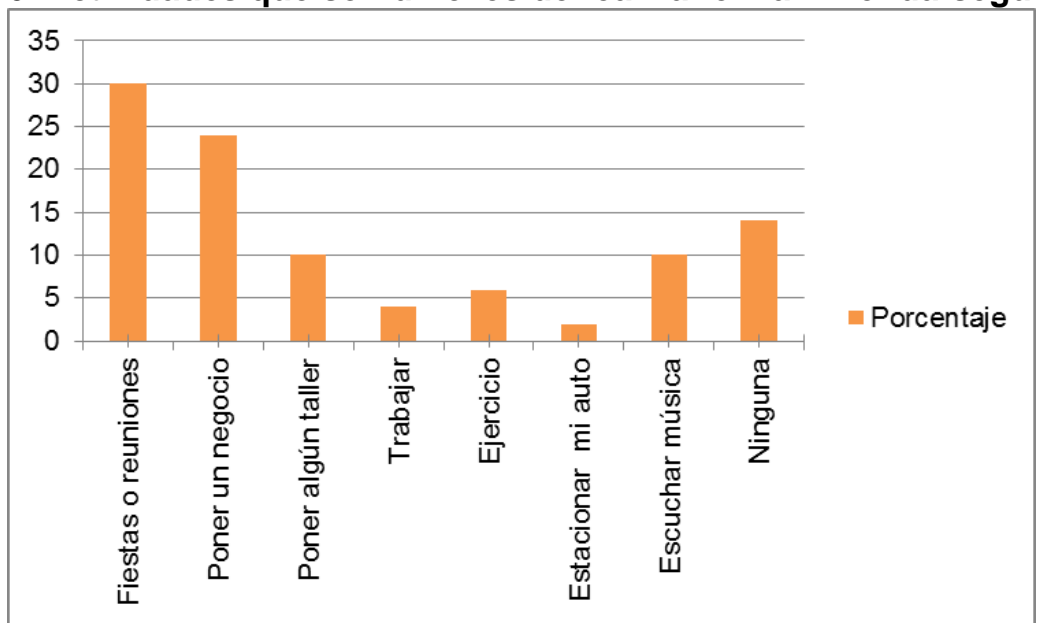

Elaboración propia con base en los resultados de la Encuesta de Satisfacción Residencial para el Conjunto Urbano Rancho Santa Elena 2016. 
Siendo realizar fiestas y reuniones (30\%), poner un negocio o taller (34\%) y escuchar música (10\%) las tres opciones que los encuestados escogieron como las más difíciles de realizar.

\subsubsection{Evaluación de la vivienda actual}

Al preguntar a las entrevistadas sobre el motivo por el que eligieron su vivienda, resulta sorprendente conocer que solamente $6 \%$ la eligió porque le gusta la vivienda o el conjunto; $31 \%$ dijo haberla escogido por que la adquirieron a un precio accesible, $27 \%$ porque la institución otorgante del crédito se las asignó en dicho lugar y $20 \%$ porque está cerca del trabajo de su esposo o la escuela de sus hijos.

Gráfica 7. Motivo por el que eligió la vivienda

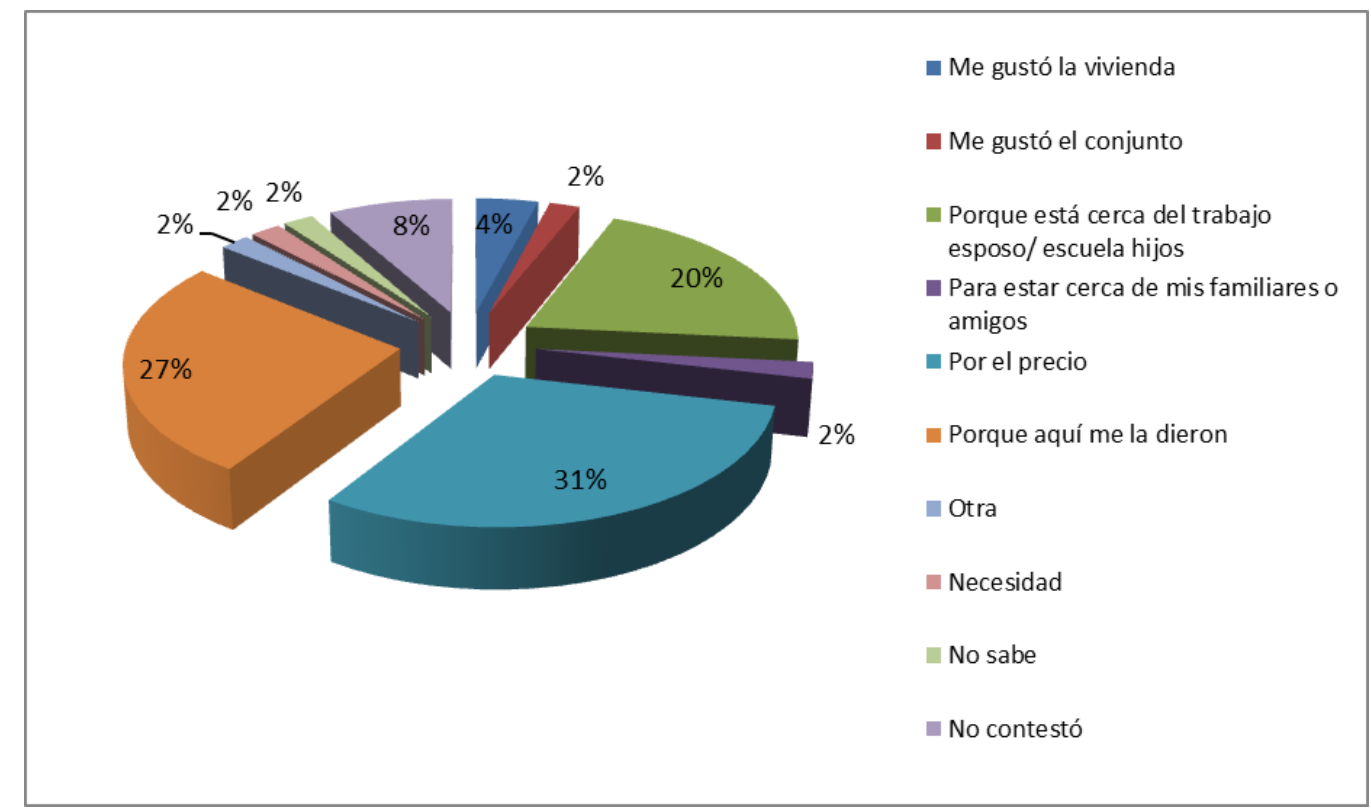

Elaboración propia con base en los resultados de la Encuesta de Satisfacción Residencial para el Conjunto Urbano Rancho Santa Elena 2016. 
Esto habla de que en realidad, pocas veces las familias tienen la oportunidad de escoger una vivienda que acorde a sus gustos o necesidades, sino que más bien, escogen de acuerdo a lo que les alcanza y en base a la escasa oferta del mercado inmobiliario para las familias con menores recursos; situación que se compensa para los usuarios con la realización del sueño de ser propietarios de su vivienda y se refleja en las respuestas que otorgan los usuarios al cuestionarlos sobre los aspectos que más les agradan de su casa actual.

Ya que 33.3\% eligió la opción "Que es propia" como el elemento que más les gusta de su vivienda, seguido de "Estoy tranquila y cómoda" con $22.2 \%$ y "La ubicación" con $20 \%$.

Grafica 8. Respuestas a la pregunta ¿Qué es lo que más les gusta de su vivienda?, según porcentaje.

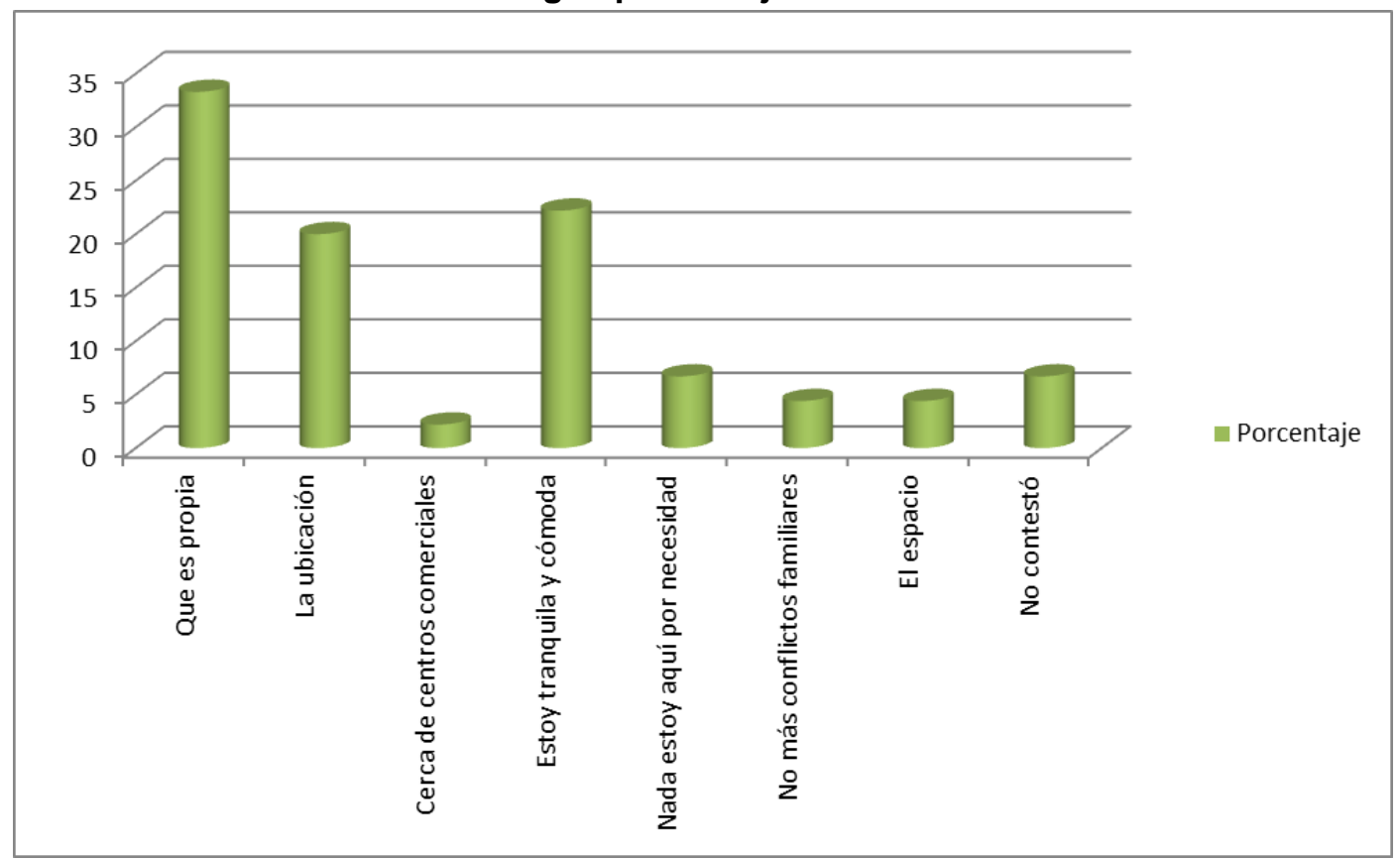

Elaboración propia con base en los resultados de la Encuesta de Satisfacción Residencial para el Conjunto Urbano Rancho Santa Elena 2016. 
En relación a lo que menos les agrada de su casa actual, encontramos que la inseguridad (38.1\%) y los vecinos $(26.2 \%)$ son los factores a los que mayormente se refieren las encuestadas. Incluso, es algo que destaca en los testimonios obtenidos mediante las entrevistas en profundidad, tal y como se puede leer en los siguientes testimonios:

Al principio estaba feliz con mi casa, aún lo tengo mucho cariño no sólo porque fue como un regalo de mi mamá, sino por el trabajo que nos costó hacernos de ella. Incluso ya andamos viendo si nos cambiamos porque los problemas con los vecinos muchos y el ambiente es horrible, hay mucha inseguridad y todo... lo único que me frena un poco es el cariño que le tengo a mi casa, pero aun así nos vamos a ir en cuento podamos... cuando la gente no quiere cooperar pues es obvio que el conjunto se va a ir deteriorando, sólo vete a dar una vuelta a los parques y ya están todos grafiteados, las bancas rotas, con basura, ya ni siquiera se puede ir a pasear ahí porque es donde se juntas los borrachos y los drogadictos, ya en la noche hasta da miedo pasar por ahí.

(Señora Rebeca, 16 años residiendo en Santa Elena)

Siempre ha sido inseguro, porque cuando recién llegué encontraban casas llenas de cosas que se robaban, habían muchos asaltos... que ahora dicen que sí los hay un poco menos pero es que la policía si entra sólo atrás de la malla pero para cobrar lo que roban los rateros, no hay vigilancia... recién llegada si había pero ya no, se acabó todo. Aquí por cierto le dicen el "Santa Elena sin ley" porque por ejemplo pasa algo y no hay nadie a quién recurrir, no hay un policía y el municipio no hace nada.

(Señora Aurora, 16 años residiendo en Santa Elena) 
Si se observa los resultados de la gráfica 9 , se puede notar que las encuestadas otorgan una valoración más negativa a aspectos subjetivos del espacio residencial como la sensación de inseguridad y las relaciones vecinales; que a aspectos objetivos propios de la vivienda tales como: la distribución (7.1\%), número (2.4\%) o la calidad de las viviendas (4.8\%).

Esto nos lleva a confirmar lo ya antes dicho por autores como Amérigo y Haramoto, sobre la importancia de considerar aspectos que van más allá de la mera valoración de la vivienda.

Gráfica 9. Respuestas a la pregunta ¿Qué es lo que menos le gusta de su vivienda?, según porcentaje.

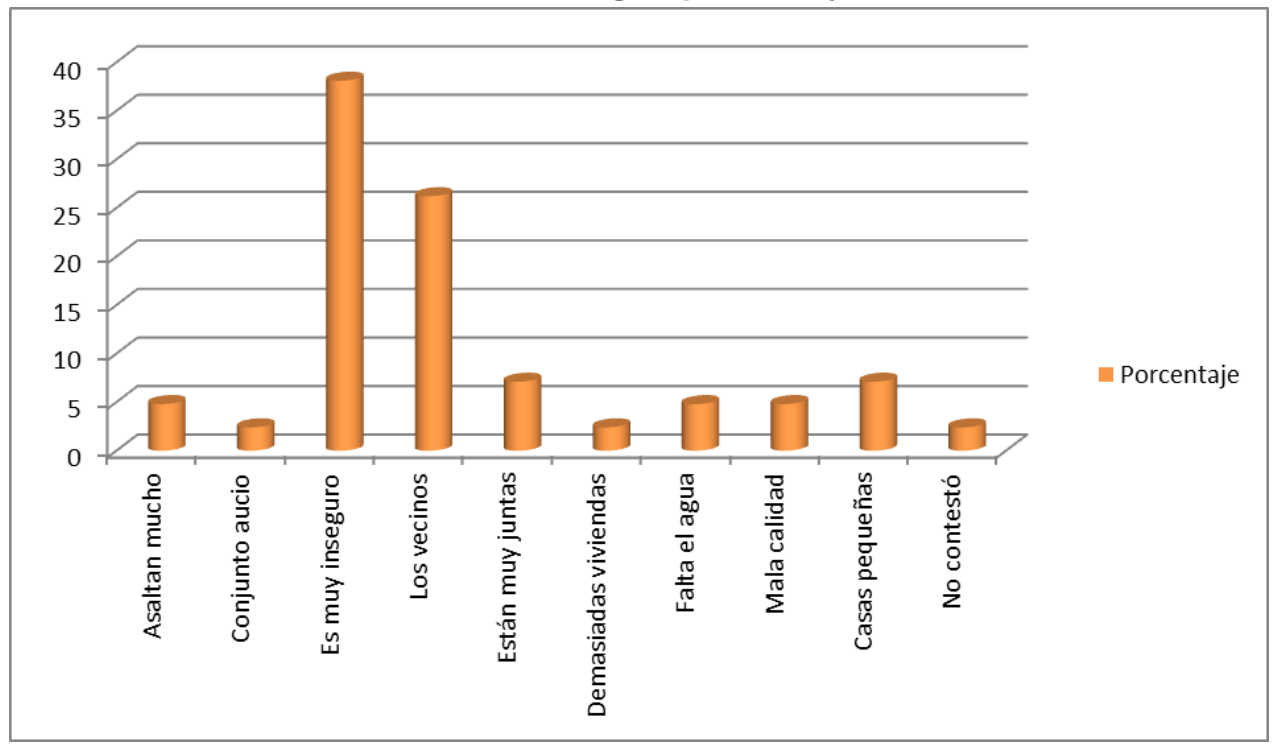

Elaboración propia con base en los resultados de la Encuesta de Satisfacción Residencial para el Conjunto Urbano Rancho Santa Elena 2016.

\subsubsection{Calificación de los espacios que componen la vivienda}

Con el objetivo de medir la satisfacción con la vivienda, se solicitó a las encuestadas evaluar con una calificación de 1 a 6 los siguientes aspectos de su vivienda: dormitorios, comedor, cocina, tamaño del baño, patio, lavadero, 125 
artefactos del baño, muros, ventanas, puertas, tabiques, iluminación, ventilación, ubicación de las áreas de la vivienda y tamaño de la vivienda.

Para ello se construyó un Índice de Satisfacción Residencial basado en la metodología propuesta por el INVI chileno que consiste en sacar un promedio simple de los aspectos evaluados y clasificarlos en cuatro categorías según el puntaje obtenido: de 1 a 2.1 malo, de 2.2 a 3.3 insuficiente, de 3.4 a 4.6 suficiente y de 4.7 a 6 bueno.

Gráfica 10. Promedio de evaluación de diferentes aspectos de la vivienda

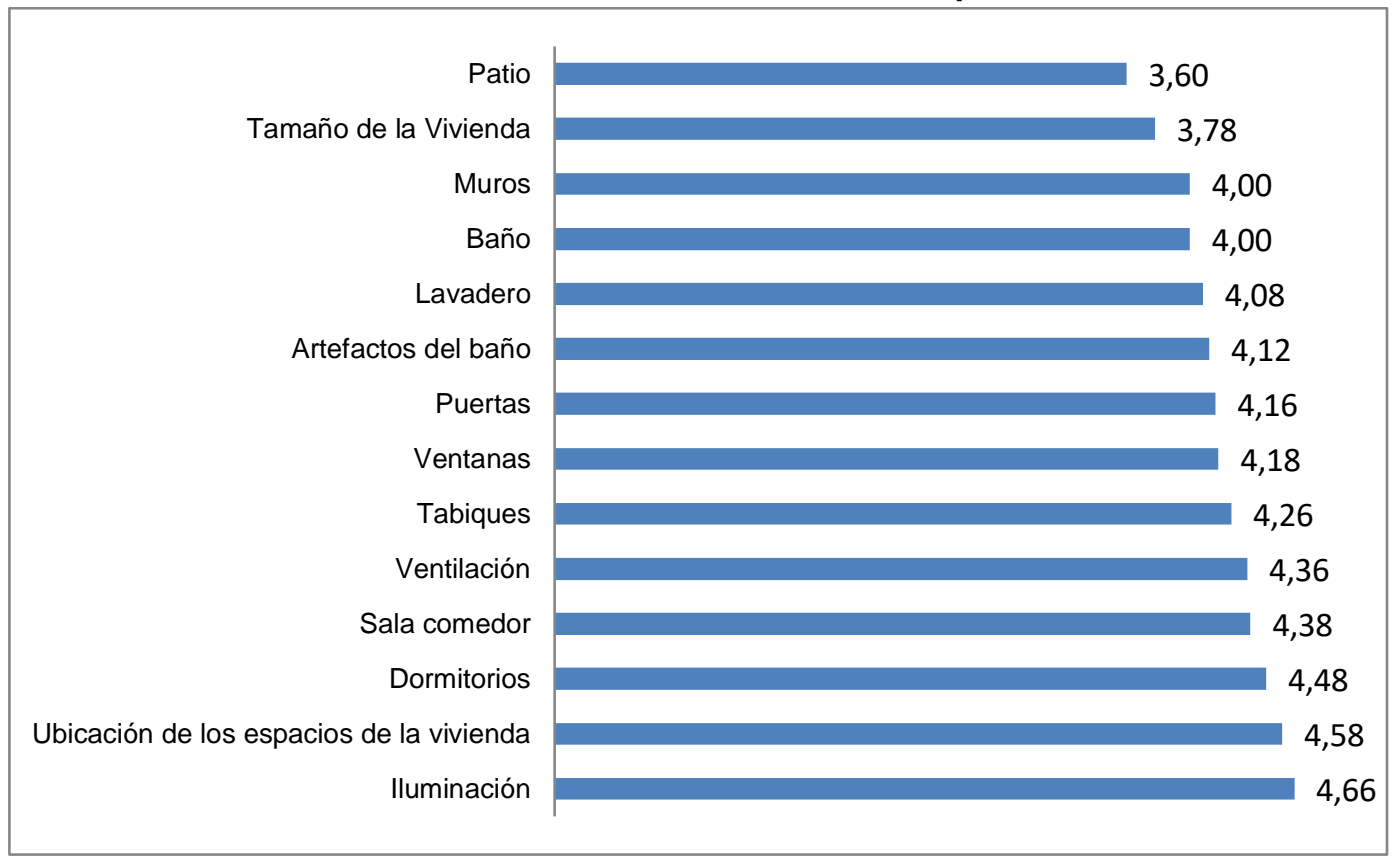

Elaboración propia con base en los resultados de la Encuesta de Satisfacción Residencial para el Conjunto Urbano Rancho Santa Elena 2016.

La evaluación de los habitantes de Santa Elena mostró que los aspectos de las viviendas mejor evaluados fueron la iluminación (4.66) y la ubicación de los espacios de la vivienda, es decir la distribución (4.58); mientras que los peor evaluados por las usuarias fueron el tamaño de la vivienda (3.78) y el patio (3.60). 


\subsubsection{Problemas con la vivienda y cambios a realizar}

Al cuestionar a las encuestadas sobre el tipo de cambios que realizaran a sus viviendas se hace evidente que éstas realizan observaciones más relacionadas con el diseño de la vivienda que con el aspecto constructivo (el tipo de materiales, las instalaciones y terminaciones de la vivienda); ya que $72 \%$ mencionó que ampliar su vivienda sería sin duda, una de las modificaciones principales que harían si tuviesen la oportunidad de hacerlo.

\section{Gráfica 11. Cambios que desearía realizar a la vivienda según porcentaje}

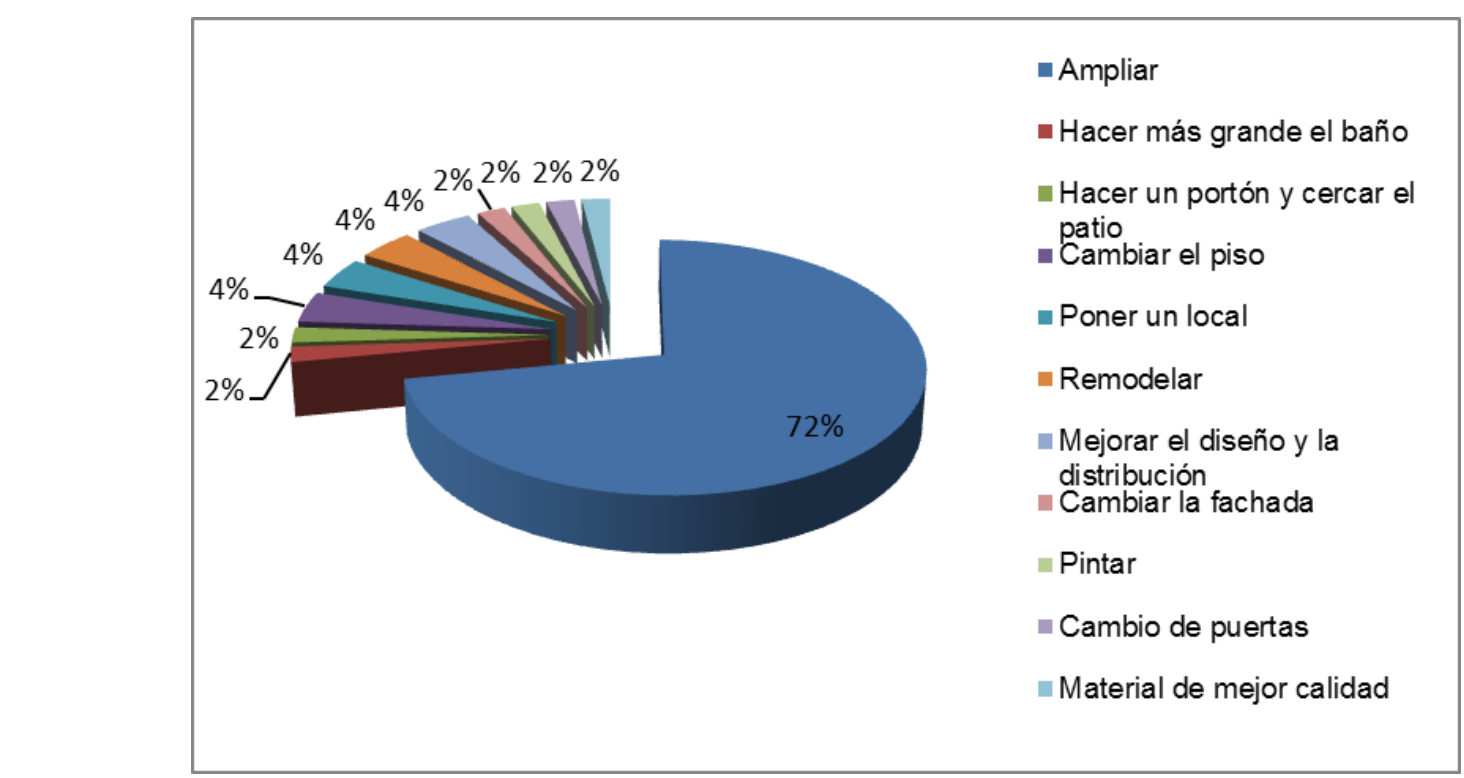

Elaboración propia con base en los resultados de la Encuesta de Satisfacción Residencial para el Conjunto Urbano Rancho Santa Elena 2016.

Además de los inconvenientes en el diseño de la vivienda, las usuarias lograron identificar otro tipo de problemáticas relacionados con los aspectos constructivos de su casa, pues $50 \%$ de las encuestadas mencionó haber tenido problemas de goteras al poco tiempo de haber recibido su vivienda; $51 \%$ señaló que su vivienda presentó problemas asociados a los materiales de construcción; $39 \%$ con las tuberías; $76 \%$ con la acústica de la casa (es decir, el aislamiento de las paredes es bastante malo ya que se logra escuchar el ruido de los vecinos); 
65.3\% dijo tener problemas de aislación térmica -sienten mucho calor o mucho frío dependiendo del clima-; $41.7 \%$ señaló que la iluminación de sus viviendas es deficiente; $45.8 \%$ señaló que la ventilación es mala ya que se guardan los olores; $27.1 \%$ tuvo problemas eléctricos y para el $59.2 \%$ de las encuestadas el tamaño reducido de los dormitorios representa un problema considerable.

Estos datos reflejan la poca importancia que los programas de vivienda han otorgado al diseño y construcción de las soluciones habitacionales, lo cual incide en el grado de Satisfacción de los usuarios con su vivienda y evidentemente, en la evaluación que realizan su ambiente residencial.

\subsection{5 índice de Satisfacción con la vivienda actual}

En general, los resultados de la encuesta permiten concluir que el Índice de Satisfacción con la vivienda es malo, pues el promedio de calificación en este rubro es de 2.12. Situación que se confirma al observar los resultados arrojados a la pregunta $¿ E n$ general qué tan satisfecho se siente con su vivienda? Como se observa en el Cuadro 13, 46\% de las encuestadas dijo sentirse Poco satisfecha con su vivienda, $22 \%$ Nada satisfecha y solamente $32 \%$ señaló sentirse Muy Satisfecho con la vivienda.

Cuadro 13. Respuestas a la pregunta ¿En general qué tan satisfecho se siente con su vivienda?, según porcentaje.

\begin{tabular}{|c|c|}
\hline Nivel de Satisfacción & Porcentaje \\
\hline Muy satisfecho & $32.0 \%$ \\
\hline Poco satisfecho & $46.0 \%$ \\
\hline Nada Satisfecho & $22.0 \%$ \\
\hline Total & $\mathbf{1 0 0 . 0 0 \%}$ \\
\hline
\end{tabular}

Elaboración propia con base en los resultados de la Encuesta de Satisfacción Residencial para el Conjunto Urbano Rancho Santa Elena 2016. 


\subsection{Percepción del entorno, relaciones vecinales}

De acuerdo con Haramoto (2002: 53), cuando hablamos de la Satisfacción Residencial es fundamental analizar la valoración que los habitantes realizan sobre el entorno inmediato a la vivienda, pues este aspecto refiere a los espacios inmediatos a la vivienda que son compartidos por los residentes y que permite o facilita su interacción. Ya que de acuerdo con este autor, el nivel y la calidad de las relaciones vecinales contribuirá a que estos perciban positivamente o no, las configuraciones físicos-espaciales facilitando la identidad de lugar. Por ejemplo, si la percepción de dichas interrelaciones es positiva, es altamente probable que el sistema social tienda a generar entornos inmediatos de mejor calidad, fortaleciendo los sentimientos de identidad y pertenencia.

Al respecto $52 \%$ de las encuestadas señaló que en este conjunto no se puede convivir bien con sus vecinos debido a que son conflictivos y a que existen "demasiados chismes".

Gráfica 12. Motivos por los que no puede convivir bien con sus vecinos

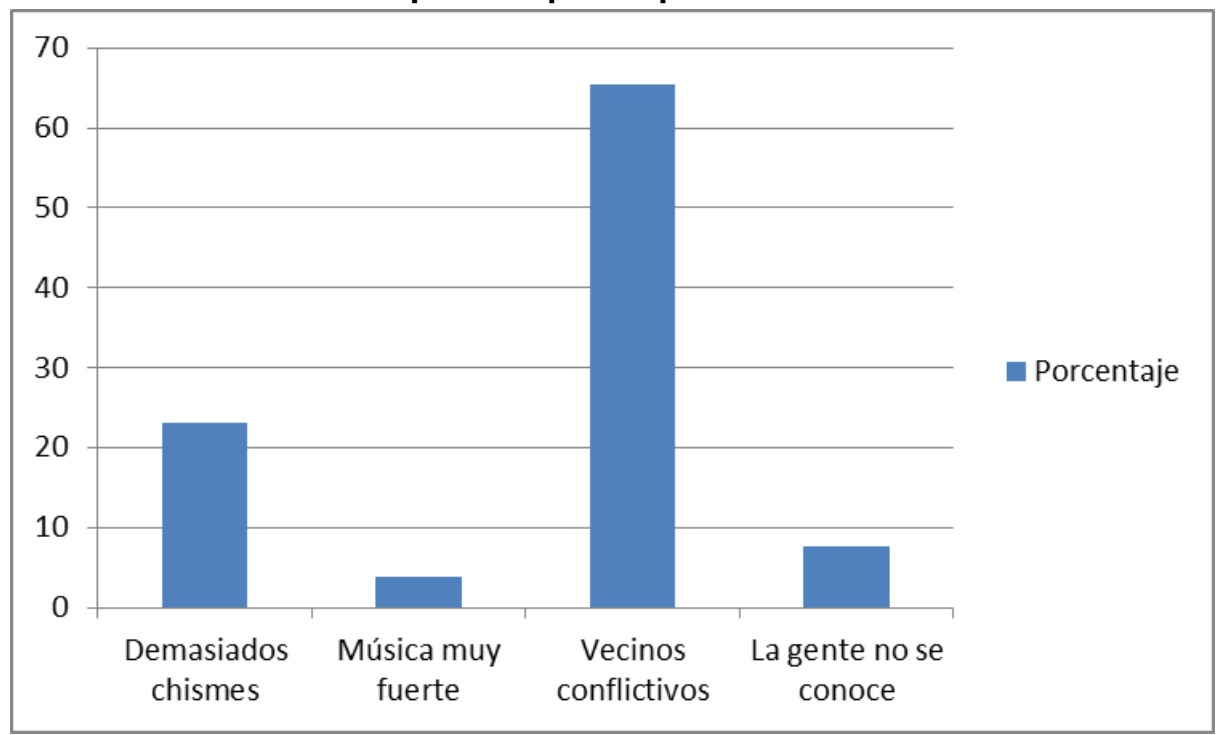

Elaboración propia con base en los resultados de la Encuesta de Satisfacción Residencial para el Conjunto Urbano Rancho Santa Elena 2016. 


\subsection{Percepción del conjunto habitacional}

La valoración de los habitantes sobre el conjunto habitacional es en general mala, ya que el Índice de Satisfacción con el conjunto es de 2.46. Al preguntar a las encuestadas ¿Qué tan satisfecha se siente de vivir en este conjunto habitacional? $62 \%$ señaló sentirse Poco Satisfecha; $2 \%$ Nada satisfecha, $16 \%$ Satisfecha y $20 \%$ Muy satisfecha.

Estos datos se relacionan también con el orgullo que los habitantes sienten o no, de vivir en este Conjunto Urbano ya que $44 \%$ dijo sentirse Algo orgullosa de vivir en Santa Elena; 30\% Poco orgullosa; 10\% Nada orgullosa y solamente 16\% mencionó que se sentía Muy orgullosa de vivir aquí. Según la variable año en que llegó a vivir en el Conjunto Urbano, el orgullo disminuye cuando se lleva más de 10 años residiendo en este lugar e incrementa ligeramente cuando las encuestadas han vivido menos de 7 años en el conjunto, es decir, éstas últimas dijeron sentirse Algo orgullosas de vivir en el Conjunto Urbano Santa Elena.

Por otro lado, se pidió a las encuestadas calificar 5 aspectos relevantes del conjunto (o barrio según la metodología de Haramoto): tranquilidad, seguridad, privacidad, belleza y limpieza. Al respecto se halló que la seguridad y la limpieza del conjunto son los peores evaluados (con un promedio de 2.38 y 2.78 respectivamente); mientras que aspectos como la tranquilidad (3.38) y la privacidad (3.34) fueron calificados por las usuarias como suficientes.

Tanto los testimonios de las entrevistadas como los resultados de las encuestas apuntan a concluir que las habitantes de Santa Elena reconocen que con el paso de los años, los ambientes físico y social se han deteriorado:

El conjunto habitacional ha cambiado muchísimo porque de alguna manera pues antes se veía pues limpio, más tranquilo, ahorita ha 
cambiado también porque pues no sé qué ha pasado pero ha habido asaltos aquí afuera, nosotros nunca nos enterábamos apenas ahorita que vinieron ajustarle cuentas a alguien que yo creo se había metido mal, también anduvo mucho el ejército entonces de repente entran cuando hay algo así, entonces, como que ya no es la misma confianza.

(Señora Mónica, 16 años residiendo en Santa Elena)

El conjunto ha cambiado mucho, pero no para bien sino para mal. Yo lo recuerdo así como tipo de los que salen en la tele de esos bien bonitos, todo bien limpio, en las calles no había basura y las calles no estaban así de desechas... jestaba todo re-bonito! Pero obvio estaba todo nuevo y había poca gente, la mayoría eran niños que no iban a la escuela, los que estábamos al principio... cuando termina el ciclo escolar y va empezar el otro que llegan los de la primaria, ahí fue donde se empezó a poner todo feo jluego, luego se notó el cambio! Y de ahí todo empezó para atrás y para atrás. Por ejemplo, descompusieron los juegos que había, donde están los tanques pusieron columpios, resbaladillas y fue lo primero que se acabó la gente; después fue la basura por todo lados... empezaron a modificar las fachadas y de ahí se empezó a descomponer. $Y$ son los mismos vecinos, la misma gente... o sea hay gente que va y viene como en todos los lugares, pero ahora sí que la base, digamos que los de casa propia que no tenemos o que no nos queremos ir siempre aquí seguimos.

El problema... llegamos con los niños chiquitos, ahorita ya no están chiquitos y ya de ahí pues cada quien ha educado a sus hijos como ha creído y eso es parte del problema. Porque yo le decía a mi esposo cuando estaban los niños chiquitos... jen un futuro eso va a ser un problema!, pero yo me imaginaba no sé en unos veinte años no tan rápido jeh!, [pone cara de sorpresa]. Porque la mayoría vienen chiquitos y trabaja el papá o la mamá... y todos esos niños casi siempre o los llevan a la escuela y ahí los dejan... o va la abuelita, o la tía, o la amiga y los dejan solos todo el día hasta que llega el papá o la mamá y todo 
eso va a ser un problema. Y así es eh, porque ya ha habido chamacos de aquí mismo del fraccionamiento que ya han matado... cada quien sabe a lo que le da prioridad en la vida ¿verdad? Pero yo les decía, el que trabaje la mamá o el papá a la larga va a traer consecuencias, lo malo fue que se me adelantaron varios años porque yo decía $20 .$. todavía no llevamos 16 y ya hay problemas de que asaltan, de que andan en las motos y todo ocasionado por la misma gente.

(Señora Aurora, 16 años residiendo en Santa Elena)

\subsubsection{Evaluación del Conjunto Urbano}

Para conocer la evaluación que las encuestadas realizan al Conjunto Urbano, se solicitó calificar en una escala del 1 al 6 (en donde 1 es Muy malo y 6 Excelente) 16 aspectos del conjunto habitacional.

\section{Gráfica 13. Evaluación de aspectos del Conjunto Urbano}

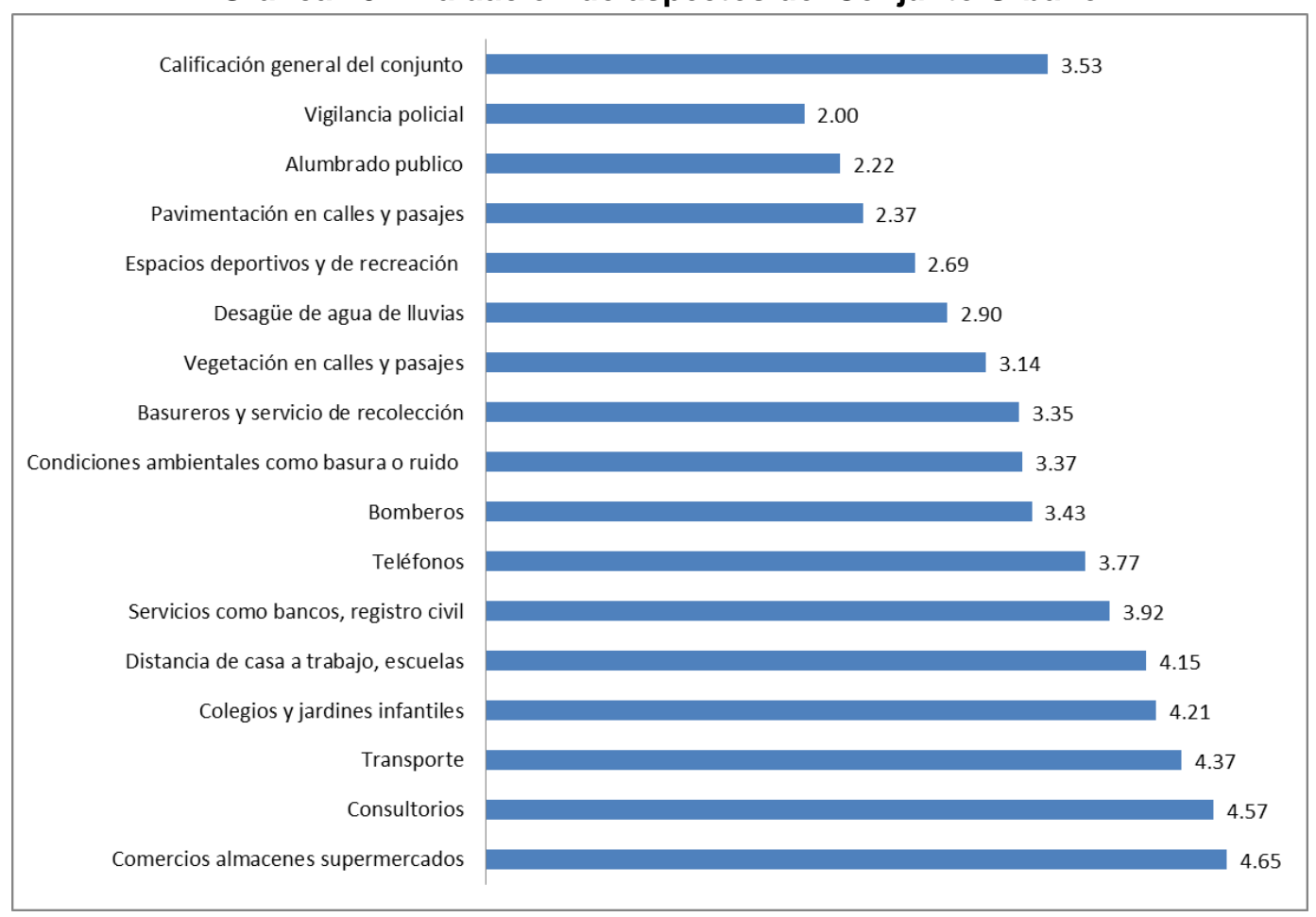

Elaboración propia con base en los resultados de la Encuesta de Satisfacción Residencial para el Conjunto Urbano Rancho Santa Elena 2016. 
En la gráfica 13 se puede ver que los rubros peor evaluados son aquellos que se relacionan con los servicios que debe -por Ley- brindar el municipio: como vigilancia policial (2.0), alumbrado público (2.22) y pavimentación de calles y pasajes (2.37). Siendo la disponibilidad de almacenes, comercios 0 supermercados (4.65); la cercanía con consultorios (4.57), el transporte (4.37) y los colegios y jardines infantiles (4.21) los mejor evaluados por los residentes.

\subsubsection{Actividades difíciles de realizar}

En cuanto a las actividades que son difíciles de realizar debido a la ubicación de la vivienda y del Conjunto Urbano, las encuestadas mencionaron que tanto para ellas como para sus familias, resulta complicado: hacer ejercicio (24\%), participar en actividades recreativas (16\%) e ir al parque con sus hijos (18\%),

Gráfica 14. Actividades difíciles de realizar

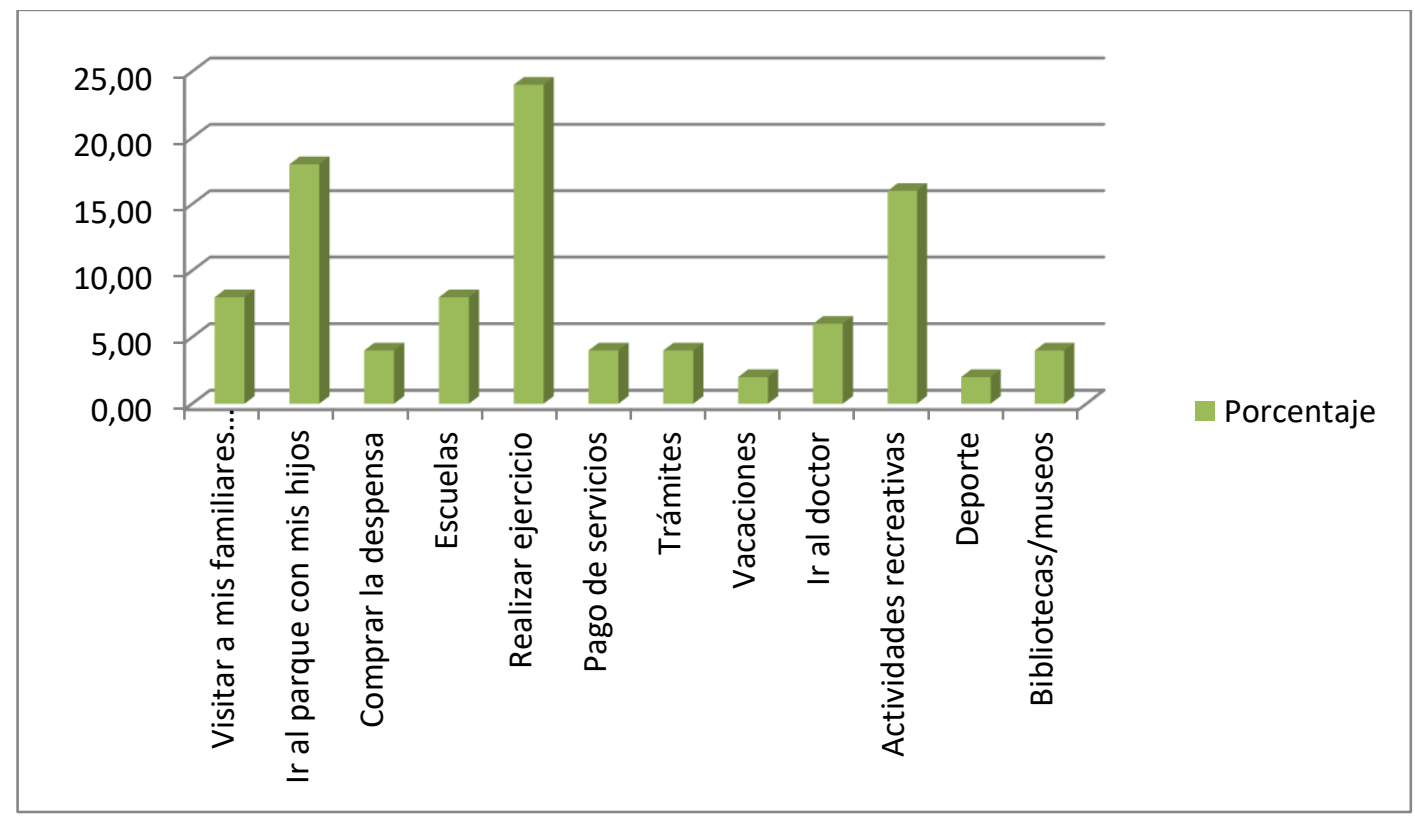

Elaboración propia con base en los resultados de la Encuesta de Satisfacción Residencial para el Conjunto Urbano Rancho Santa Elena 2016. 


\subsection{Administración y organización de los bienes de la comunidad}

Aunque la vivienda tiene connotaciones sociales como las señaladas anteriormente, también puede ser vista como una mercancía que requiere de una importante inversión económica, no sólo para adquirirla sino también para su mantenimiento y cuidado (Labastida, 2010: 1). De tal forma que para el sostenimiento de los conjuntos habitacionales, se requiere de la existencia de cierto grado de organización vecinal.

Cuando hablamos de Satisfacción Residencial, la comunidad es uno de los elementos más relevantes, ya que es en este macrosistema donde se correlacionan los componentes o atributos del barrio y la percepción que tienen los habitantes sobre su conjunto habitacional (Haramoto, 2002: 69).

De acuerdo con Haramoto (2002) la comunidad aparece cuando los habitantes son capaces de superar las relaciones de simpatía que se dan entre grupos de vecinos y empiezan a asumir roles y compromisos que tienen como efecto, el mejoramiento de las condiciones del conjunto habitacional. No obstante, investigaciones como la realizada por Esquivel (2009), dan cuenta de lo complicado que resulta para los habitantes de los conjuntos habitacionales -en México-, organizarse para llevar a cabo tareas de mantenimiento y conservación de las áreas que los vecinos comparten en este tipo de soluciones habitacionales.

Ante la inexistencia de una instancia oficial que se encargue de la administración de los conjuntos, los conflictos entre vecinos se hacen presentes. Problemas en torno al uso y mantenimiento de los espacios comunes, los derechos y obligaciones de los habitantes, las prácticas, los intereses privados, la invasión de los espacios colectivos, el desinterés de los vecinos y la costumbre de vivir en tales condiciones son frecuentes en este tipo de conjuntos habitacionales (Esquivel, 2009). 
A esto, se suma el desconocimiento de la Ley Condominal y la ausencia de una figura gubernamental o autoridad ${ }^{57}$, que se encargue de sancionar a quienes incumplen este tipo de ordenanzas. En el caso de Santa Elena, 66\% de las encuestadas declaró conocer poco o nada de la Ley Condominal, es decir, saben que ésta Ley existe, pero ignoran su contenido.

Al cuestionar a las amas de casa sobre la organización vecinal dentro del Conjunto Urbano Santa Elena, $68 \%$ mencionó que en su manzana o calle, no se llevan a cabo labores de mantenimiento ya que los vecinos no se llevan bien o se niegan a pagar las cuotas que se establecen para los gastos comunes, además, de que los vecinos no están dispuestos a asumir la responsabilidad que conlleva el ocupar el cargo de administrador; ya sea por los conflictos que se generan, por falta de tiempo o por lo engorroso que resulta tener que cobrar a sus vecinos.

Los vecinos ya no nos ponemos de acuerdo, inicialmente mi esposo era el tesorero, se daba una cooperación de treinta pesos al mes o a la semana, no me acuerdo, pero eran treinta pesos por casa; ese dinero era para comprar herramienta para darle mantenimiento al fraccionamiento, para cortar el pasto, para barrer, hacer la capilla... pero ipuros sueños!, inicialmente uno si cooperaron y otros no, el inconveniente es que si mi vecino me cae mal a él no le cortaron el pasto o se lo cortaron mal, ese fue uno de los problemas... y que compran la herramienta y yo la tenía aquí entonces venían y me pedían las tijeras o la herramienta, se las prestaba porque es del condominio pero el problema era que no les pedía un comprobante o que me firmaran algo; entonces yo la presto y después ya

${ }^{57}$ En los artículos 45 y 46 de la Ley que Regula el Régimen de Propiedad en Condominio en el Estado De México (2002), se establece que de manera semestral, los ayuntamientos por conducto de las dependencias competentes, realizarán campañas tendientes a la promoción de la cultura condominal, en las que deberán realizar charlas, conferencias y entrega de material que contenga los derechos y obligaciones de condóminos y residentes, así como las vías y procedimientos a seguir en caso de controversias. El Síndico Municipal, será competente para desahogar los procedimientos arbitrales para resolver controversias en materia de propiedad en condominio... Sin embargo, de acuerdo con las declaraciones de los vecinos, éstas tareas son a veces omitidas por los funcionarios municipales, es decir, no se llevan a cabo o no se les da seguimiento. 
no me la regresaron y después querían que mi esposo la pagara. Yo decía cómo la va a pagar si el vecino la tiene, entonces que el vecino la regrese... total que al final hicieron una junta que porque mi esposo se estaba quedando con el dinero y yo le dije a mi esposo: jentrega todo!, porque yo no quiero que el día de mañana mi hijo salga a la calle y alguien le diga que su papá o su mamá se quedó con dinero, el día de mañana alguien va a decir tu papá es un ratero y yo no quiero eso. Entonces el entrega el dinero, entrega la herramienta que había, entrega cuentas y dicen que no que les faltaba dinero; a la siguiente persona que se 10 entregó les metió recibo de teléfono y taxis porque decía que para ir a comprar herramienta se necesitaba pasaje, entonces él les metió el recibo de los taxis y teléfono.

$Y$ iqué bueno!, me da muchísimo gusto porque a mi esposo lo acusaron de algo que no era y en ese entonces mi hijo estaba chiquito $y$ como le dije, me quedaba sin dinero y aunque tenía el dinero del condominio, yo no tocaba ni 5 centavos... así no tuviera ni qué darle a mi hijo... porque le decía a mi esposo: si alguien vienen a pedirte el dinero nada más por fastidiar o calarte, con que tú les digas espéreme 10020 minutos... iya valiste!, van a decir que te lo gastaste... entonces ese dinero no existe aquí en la casa y entonces cuando dijeron que se robó el dinero, me enojé... sí me enojé y después ya no quería darles cooperación; que al final si la di y por eso se hizo la barda de atrás que se está cayendo y se hizo la capilla y se le estuvo dando mantenimiento.

Entonces la siguiente persona ya no les gustó porque les metía recibos que mi esposo no les cobraba, o sea nosotros íbamos a Cuautitlán a comprar y mi esposo no les decía gasté tanto en pasaje ¡no, nunca metió un papel así! Entonces la otra señora ya no les gustó y le quitaron el dinero y el poder... se lo dieron a otra [vecina] y ella intentó hacerlo forzoso, sino iba a multar al que no diera la cooperación [se ríe] pero pues cómo le iba a hacer, o sea sino les pago la cooperación, menos la multa. Así han sido 
tres administradores y ya no se puede, ya nadie se avienta, ni quiere (Señora Aurora, 16 años residiendo en Santa Elena).

Por esta razón, es que la gran mayoría de los habitantes que sí se organizan (32\%) para dar mantenimiento a las áreas comunes que rodean a su vivienda han elegido las juntas vecinales como la mejor herramienta para ponerse de acuerdo y organizarse con sus vecinos.

Cabe mencionar, que la distribución y el diseño del conjunto constituyen para el caso de Santa Elena, una barrera que limita y en algunos casos impide, la organización entre los vecinos, ya sea porque éstos no se conocen o porque de acuerdo a los testimonios de las entrevistadas, se han construido barreras sociales entorno a la ubicación de las viviendas. Es decir, la gente "no se junta" o se relaciona con aquellas familias que consideran inferiores o distintas a ellos; porque tienen estilos de vida distintos (costumbres, tradiciones, formas de vestir, hablar y conducirse) o por rencillas que los llevaron a no hablarse, ni querer relacionarse entre sí.

Hay casas más pequeñas, de sólo un baño, cuando nosotros compramos podíamos elegir entre la más chica y ésta que supuestamente es la más grande... las que un cacho de terreno como extra no sé si sólo son de INFONAVIT o también fue el banco el que dio los préstamos por eso tienen ese terreno porque se los vendieron a parte de la casa. Ellos son como los ricos de aquí, de hecho nos ven feo como si fuéramos los pobres, cuando pasa uno por ahí que tenemos que ir a los locales o así, se nos quedan viendo feo, como diciendo estos vienen del barrio pobre... yo sea todo es Santa Elena. De hecho del otro lado también es Santa Elena, sólo que ahí pusieron el fraccionamiento San Fernando y están también ahí las otras casitas que regaló el gobierno, que son de esas que pasan en la televisión de hecho vino la primera dama... "la Gaviota" pero de hecho ella ni siquiera se paró aquí, vino el helicóptero y la dejo por atrás y no quiso salir a la gente, al fin que ni la queríamos ver [se ríe] pero digo, de por sí ya 
éramos muchos, ahora vamos a ser más. Pero la gente que vive en esas casitas la mayoría es gente con niños discapacitados, no sé cómo se las dieron pero son donadas; este fraccionamiento es muy grande.

Cuando llegaron los de San Fernando nadie nos preguntó, ahora sí que marcaron su perímetro, pusieron su barda y listo; nadie se opuso o alegó, el único pleito que hubo fue por la escuela, unos querían primaria, otros secundaria y pues terminó en kínder por el DIF. Como mi hijo ya estaba en la secundaria pues yo ni me metí; yo no conozco a nadie de San Fernando porque ese está cerrado y hasta policía tienen. (Señora Aurora, 16 años residiendo en Santa Elena).

De esta manera, las posibilidades de mantener en buen estado el conjunto habitacional, disminuyen cuando no existe una buena relación entre los vecinos y cuando se perciben importantes desventajas sobre el espacio en el que vive, pues son elementos que desincentivan la participación. A esto se le suma una práctica conocida como "el problema del polizón o free rider" que refiere a la conducta de uno o más individuos que aunque no participan con el pago de la cuota de mantenimiento o que no se involucran en las actividades que permiten mantener el conjunto en buen estado (como la poda de árboles y jardines, la limpieza de las áreas comunes, etc.), reciben los mismos beneficios que quienes sí colaboraron, por lo que se expande la falsa idea de que no es necesario participar porque a final de cuentas otros van hacerlo.

Es por ello, que la forma de hábitat que implican los conjuntos habitacionales implica asumir que se vive bajo una forma jurídica de propiedad en condominio que supone no sólo la propiedad privada de la vivienda sino que ésta va a acompañada de la propiedad colectiva de las áreas comunes. Lo que a su vez debe de ir acompañado de un reconocimiento de los derechos y responsabilidades para el cuidado y mantenimiento del espacio que pertenece a 
todos. De manera en que se entienda que la vida en colectividad debe estar acompañada de comportamientos y actitudes personales que impliquen el reconocimiento de que se está dentro de una comunidad y que existen por tanto, reglas que deben ser respetadas pues están encaminadas a lograr el bien común (Esquivel; 2002).

\subsection{Relación con instituciones}

Al cuestionar a las amas de casa si sienten que el gobierno municipal se preocupa por los problemas del Conjunto Urbano, $86 \%$ señaló que el municipio no se interesa en lo absoluto por su conjunto habitacional; $12 \%$ señaló que esta autoridad se preocupa en ocasiones por lo que ocurre en este espacio y $2 \%$ mencionó que las autoridades municipales muestran poco interés en los intereses y conflictos del lugar. Además, 92\% indicó que una vez que una vez recibida la vivienda, no perciben que exista una instancia -en este caso el municipio- donde plantear o resolver sus problemáticas.

La deficiente relación con las autoridades municipales, es para los habitantes de Santa Elena una de las cuestiones que más les preocupa y que más genera descontento, ya que desde el año 2000 - a 1 año de la construcción del conjunto- los habitantes se enfrentan a un problema administrativo importante, que se deriva del hecho de que ni el gobierno municipal, ni sus habitantes, tienen claro a qué municipio pertenece. Esto resulta alarmante, no sólo porque pone en duda los mecanismos bajo los cuales son autorizados los Conjuntos Urbanos, sino también, porque se convierte en un impedimento para la generación de sentimientos de identidad y pertenencia que juegan un papel importante en la vida cotidiana de los habitantes. 
Esto ha generado que las autoridades municipales, se muestren indiferentes a los conflictos y necesidades de la población, lo que ha orillado a los habitantes a manifestarse en diversas ocasiones -mediante protestas y el cierre de calles- para exigir la resolución de problemas que los aquejan; relacionados principalmente, con la inseguridad, los cortes constantes al suministro de agua, así como con las fuertes inundaciones que sufren durante la temporada de lluvia. Ante esta situación, de acuerdo con los testimonios de las entrevistadas, la respuesta de los trabajadores del municipio es que el conjunto pertenece al municipio de Tultepec y que es ahí donde deben solicitar los servicios.

[...] no sé si en Cuautitlán no tengan ese problema pero nosotros empezamos a notar que nos faltaba el agua cuando pusieron el fraccionamiento de aquí cerca el de Haciendas de Cuautitlán, no sé si tenga que ver que de la misma agua que nos distribuían ahora también les distribuyen a ellos y también todos los del Dorado y la Antigua [conjuntos urbanos cercanos a Rancho Santa Elena] no sé si también a ellos, pero... ¿Cómo peleamos eso no? Con el gobierno que está ahorita pues no les entiendo o sea, yo no hallo quién dirige o cómo está y eso que aquí anduvieron todos los candidatos y yo les dije... pero uno me dijo -pues usted vaya y me reclama- $y$ que le contesto mire mejor no me provoque porque si voy y si lo busco [se ríe] pero la verdad ya no sé si ganó porque además era de Tultepec y de hecho si le dije: usted qué hace aquí si nosotros somos de Cuautitlán, por qué viene a ofrecer algo que no nos va a dar... y a la de Cuautitlán [la candidata a presidenta municipal] le dije por qué no va a Santa Elena y arregla el problema de Santa Elena porque han llegado los de Tultepec a ofrecernos cosas y ustedes no se aparecen pero pues tampoco vino y es meterse en broncas.

Después de que nos paramos en la carretera ya no volvimos a tener problemas graves, eso sí los de Geo jamás se aparecieron, sólo mandaron a sus representantes y las fallas que estábamos reportando de las casas si las vinieron a componer... una de esas fallas era que este baño [señala 
una pequeña puerta que se encuentra a un costado del comedor] no tenía la puerta, ni los accesorios... o sea tenía el puro hueco y eso no estaba así en lo que ellos nos prometieron, entonces tuvieron que hacerlo, pero en todas las casas.

\subsection{Gastos en la vivienda}

El ingreso monetario es uno de los aspectos que más preocupa a las familias, ya que éste no sólo determina su capacidad para adquirir bienes y servicios básicos; sino que también se relaciona con la posibilidad de acceder a servicios educativos, de salud o entretenimiento, que son esenciales para el desarrollo de su vida cotidiana (CONAPO, 2002). La proporción de los ingresos que las familias destinan al pago de la hipoteca o renta de la vivienda, es un aspecto que influye importantemente sobre la percepción o el nivel de satisfacción con el ambiente residencial; ya que cuando se juntan los gastos básicos de la vivienda, con el pago de la hipoteca y los gastos que surgen de situaciones particulares de las familias (como enfermedades, discapacidades, necesidades especiales, etc.), surge la duda acerca de la decisión de mudarse o adquirir el compromiso de comprar una vivienda nueva.

Es complicado porque mi nieto está enfermo, tiene discapacidad y cuando tenemos citas con el niño, tenemos que ir algún lado, como antier que fuimos a sacar un acita a plaza Aragón, porque de Coacalco nos mandaron hasta allá, entonces pues no sabíamos, a veces si se nos complica porque tenemos que ir y regresar y dejarle a ella y los niños y entonces si a veces si se nos complica un poquito. Incluso para dormir porque como quiera que sea mi hija tiene su recamara arriba, mi nuera acá adentro y nosotros nos quedamos en la sala mientras, nos acomodamos.

El conjunto habitacional ha cambiado muchísimo porque de alguna manera pues antes se veía pues limpio, más tranquilo, ahorita ha cambiado 
también porque pues no sé qué ha pasado pero ha habido asaltos aquí afuera, nosotros nunca nos enterábamos, hasta apenas ahorita que vinieron ajustarle cuentas a alguien que yo creo se había metido mal, también anduvo mucho el ejército entonces de repente entran cuando hay algo así, entonces, como que ya no es la misma confianza. Por ejemplo ese día del asalto fue la hora que venían los niños de la escuela, entonces empezaron los balazos y pues ellos llegaron corriendo, entonces dices tú, ¿Dónde está la seguridad? Un balazo les da a los niños, y dices tú paga quien no debe de pagar y como yo siempre he dicho... creo que tenemos muchas cosas por hacer como para que nos pase otra más ¿no? No te creas día a día así piensa uno (Señora Mónica, 16 años residiendo en Santa Elena).

Gráfica 15. Proporción de los ingresos que destinan al pago de la hipoteca o de la renta de la vivienda

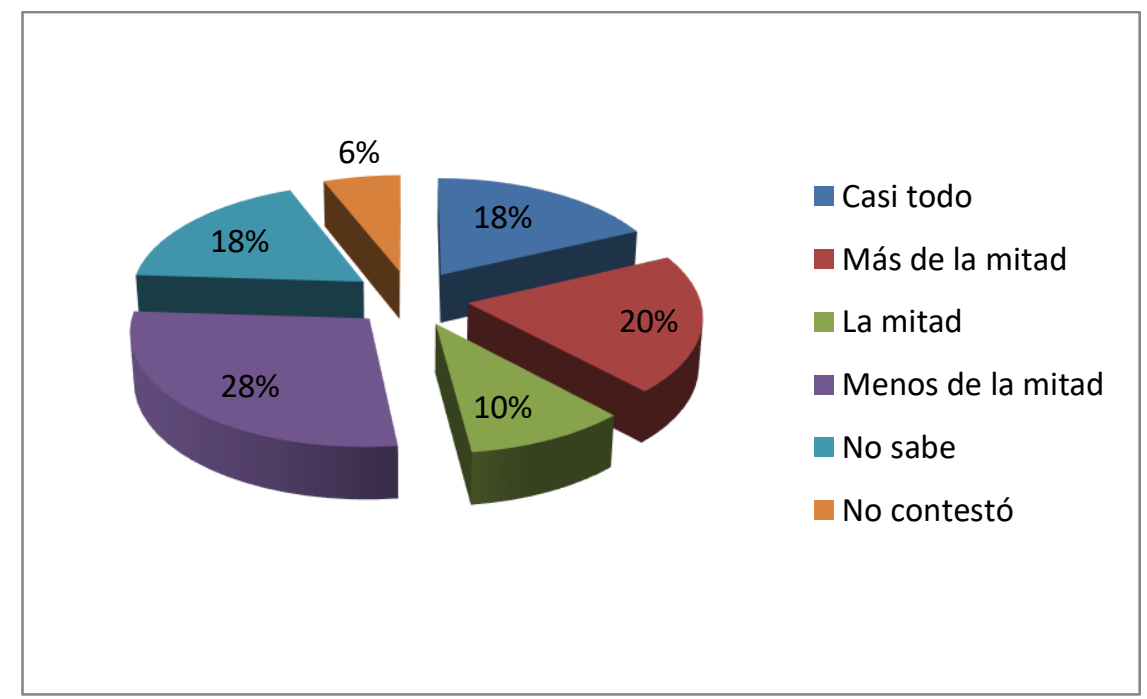

Elaboración propia con base en los resultados de la Encuesta de Satisfacción Residencial para el Conjunto Urbano Rancho Santa Elena 2016.

Al cuestionar a las amas de casa de Santa Elena sobre la proporción de los ingresos que destinan al pago de la hipoteca o la renta de su vivienda, 20\% respondió que gastan más de la mitad de los ingresos familiares en el pago de 
este rubro, $18 \%$ señaló que destinan casi todo su ingreso, $28 \%$ gasta menos de la mitad, $10 \%$ destina la mitad de su ingreso, 18\% desconoce cómo se distribuyen los ingresos de su familia y $6 \%$ no contestó a esta pregunta.

Por otra parte, $47.8 \%$ de las encuestadas considera que el dinero que destinan al pago de la vivienda es adecuado, $43.5 \%$ piensa que el pago que realizan no es justo o adecuado en relación a la vivienda que tienen y a los beneficios que perciben de ella, $4.4 \%$ señala no estar segura y $4.3 \%$ no contestó a esta pregunta. Los resultados obtenidos en este rubro son relevantes ya que influyen sobre la percepción que los habitantes tienen sobre este tipo de solución habitacional; en las entrevistas a profundidad que fueron realizadas para propósitos de esta investigación, se pudo notar que aquellas personas que consideran "todo un triunfo" el haber adquirido una vivienda propia, se encuentran más satisfechas con su vivienda, aunque esto no significa que estén conformes con los demás elementos que componen el ambiente residencial (los vecinos y el conjunto urbano en general), es decir, valoran los beneficios que les proporciona el hecho de tener una casa, como la privacidad, el poder vivir lejos de sus papás u otros parientes o el poder consumar el sueño de tener una vivienda propia; tal y como reflejan los siguientes testimonios:

Nos venimos para acá porque yo ya no quería vivir con mis suegros, y cuando a él le dieron la casa que él trabajaba en Ford, y lo bueno que la adquirió antes de que lo corrieran pues yo por eso dije pues si es un buen lugar para mis hijos, de hecho me la habían dado en Tecámac pero yo dije no pues voy a estar muy lejos, después qué hago ¿no? Y aquí me la dieron $y$ yo dije pues es un buen lugar para mis hijos pero pues luego no piensas más adelante ¿no? Piensas en la estabilidad del momento pero si pensar que a lo mejor pues se iba a casar pronto mi hija, mi hijo después, y pues sin pensar que a lo mejor, o sea no reniegas del bebé al contrario es una bendición lo que tenemos, pero no cuentas con que pudiera pasar e implicando todo lo que, todo lo que hemos visto y todo lo que hemos 
pasado con él, o sea no, no piensas que pudiera pasar ¿no?, entonces pues si son, son cositas que te van pues deteniendo pero pues al mismo tiempo, pues echándole porque pues no nos queda de otra (Señora Mónica, 16 años residiendo en Santa Elena).

Tuve que pedirle dinero prestado a una de mis hermanas para poder completar lo que faltaba, después como mi esposo no tenía crédito INFONAVIT tuvimos que ir al banco y pedir un crédito hipotecario, afortunadamente ya terminamos de pagar, pero los primeros años nos las vimos negras porque teníamos que dividir los gastos entre el crédito, la comida, la luz, el agua y todo eso. Había veces que no teníamos nada para comer. Al principio estaba feliz con mi casa, aún le tengo mucho cariño no sólo porque fue como un regalo de mi mamá, sino por el trabajo que nos costó hacernos de ella. Incluso ya andamos viendo si nos cambiamos porque los problemas con los vecinos muchos y el ambiente es horrible, hay mucha inseguridad y todo... lo único que me frena un poco es el cariño que le tengo a mi casa, pero aun así nos vamos a ir en cuanto podamos.

Como todos los lugares al principio el conjunto era bonito, pues las casas estaban nuevas, nadie había hecho cambios e incluso los primeros años todavía había muchas casas vacías. Lo malo es que no había nada, ni tiendas, ni escuelas... siempre teníamos que ir al centro de Cuautitlán, al Aurrera o a otro lugar a comprar; cuando iba a visitar a mi papá aprovechaba para traerme fruta o algunas cosas del tianguis porque aquí no había nada.

Con el tiempo pues usted lo puede ver... el conjunto está cada vez más feo, la gente pone rejas o hasta se hecha tres pisos de ampliación, cambia los colores de las casas, que por cierto ique colores tan feos escogen!, todo eso. Como hay mucha gente que no quiere vivir aquí porque les queda lejos el trabajo o las escuelas, ponen sus casas en renta y eso ha ocasionado que venga mucha gente desconocida que como no son sus 
casas pues no les importa respetar a los vecinos, romper o maltratar (Señora Rebeca, 16 años residiendo en Santa Elena).

Al preguntar a las amas de casa sobre si al mudarse a Santa Elena, aumentaron los gastos básicos de su vivienda, 84\% mencionó que efectivamente, hubo un incremento en sus gastos en relación al pago de agua, luz y transporte. Este elemento es importante, ya que constituye un choque entre las expectativas que tenían las familias antes de cambiarse de casa y la realidad a la que se enfrentan al llegar al Conjunto Urbano.

Al cruzar estos resultados con la variable ¿Qué tan satisfecho se siente con su vivienda?, observamos que existe una relación entre el incremento de los pagos de los servicios básicos y el nivel de insatisfacción con la vivienda, tal y como se observa en las gráficas siguientes:

Gráfica 16. Aumento de los gastos básicos de la vivienda: agua, luz y transporte
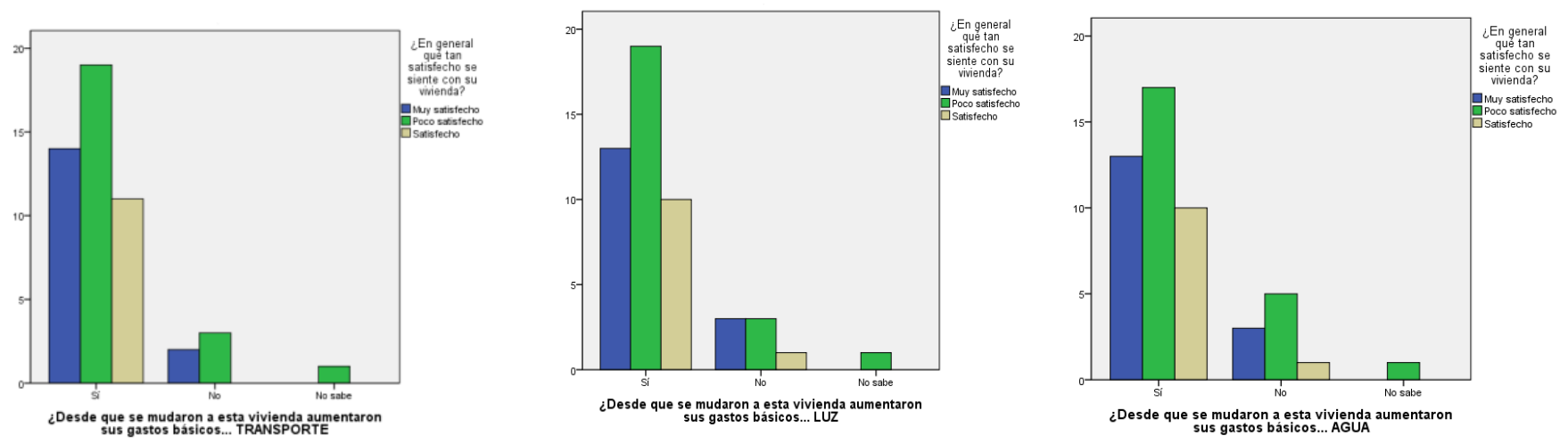

Elaboración propia Elaboración propia con base en los resultados de la Encuesta de Satisfacción Residencial para el Conjunto Urbano Rancho Santa Elena 2016

\subsubsection{Deseo de quedarse o mudarse}

Evidentemente, los resultados expuestos en los apartados anteriores influyen sobre los deseos de los habitantes de permanecer o mudarse del Conjunto 
Urbano. No obstante, vale la pena realizar algunos matices sobre los resultados obtenidos: más de la mitad de las encuestadas (60\%) manifestó su deseo de mudarse de su vivienda actual, 38\% señaló que no tiene intenciones de mudarse y $2 \%$ no contestó a la pregunta.

Al cruzar estos datos con la variable año en que llegó a vivir al Conjunto Urbano, encontramos que más de la mitad de las personas que llegaron al conjunto hace más de 13 años (entre el 2000-2004), se mudaría si tuviera la oportunidad de hacerlo y solamente $39.4 \%$ se quedaría.

De las personas que llegaron a vivir a Santa Elena entre 2005 y 2009, $57.2 \%$ tiene deseos de mudarse, $28.6 \%$ permanecería en su lugar de residencia actual y $14.2 \%$ no respondió a la pregunta. De quienes llegaron al conjunto entre el 2015 y el 2016, 100\% manifestó que tiene deseos de mudarse.

Por otra parte, $60 \%$ de los que llegaron a vivir entre 2010 y 2014 señaló que sí se quedaría en el conjunto y $40 \%$ que se mudaría; aunque se puede pensar que los resultados en este periodo son distintos debido a los beneficios que los habitantes encontraron a su llegada -pues en ese periodo se construyeron los dos centros comerciales que colindan con Santa Elena, y el Tren Suburbano tenía un año de funcionar de manera regular-, al contrastar estos datos con el grado de satisfacción general con el conjunto, encontramos que los que se mudaron a Santa Elena durante este periodo, mencionaron sentirse poco satisfechos de vivir en el conjunto, por lo que la decisión de permanecer en este lugar está condicionada por otros factores como la falta de recursos económicos u otro tipo de situaciones personales que obligan a las familias a quedarse en su lugar de residencia actual porque no les queda de otra:

Piensas en la estabilidad del momento... pero no cuentas con qué pudiera pasar y todo lo que implica lo que hemos visto y todo lo que hemos pasado, o sea no, no piensas en qué pudiera pasar ¿no?, entonces, pues si 
son cositas que te van deteniendo, pero pues echándole ganas al mismo tiempo porque pues no nos queda de otra (Señora Mónica, 16 años residiendo en Santa Elena).

Lo anterior, da cuenta de que el tiempo de residencia no es una variable que influye en los deseos de permanecer en el conjunto urbano; a diferencia de lo que se planteaba en la hipótesis que orientó este trabajo de investigación ${ }^{58}$, los resultados indican que sin importar el tiempo que las encuestadas y sus familias llevan residiendo en este Conjunto Urbano, existe una sensación de inconformidad generalizada que se deriva de los conflictos o problemas que las familias perciben en su ambiente residencial.

\subsection{Satisfacción general}

Para finalizar la encuesta de satisfacción residencial que fue aplicada a las amas de casa del Conjunto Urbano Rancho Santa Elena, se solicitó a las encuestadas que consideraran todos los aspectos planteados en los párrafos anteriores para evaluar su nivel de satisfacción con el ambiente residencial - tomando en cuenta los tres elementos que lo componen: la vivienda, las relaciones vecinales y el conjunto urbano-.

Al respecto, se encontró que el promedio de la nota general asignado es de 3.53, es decir, suficiente; no obstante, al desglosar los resultados encontramos que $6.1 \%$ evaluaron al conjunto urbano como muy malo, $12.2 \%$ como malo, $28.6 \%$ señaló que el conjunto urbano cumple mínimamente, $28.6 \%$ mencionó que es más que suficiente y $24.5 \%$ lo calificó como bueno.

\footnotetext{
${ }^{58}$ A mayor tiempo de habitar en Santa Elena, menor es el deseo de permanecer aquí y menor es el grado de satisfacción con el conjunto habitacional.
} 
Lo anterior, no coincide con los resultados obtenidos al cuestionar a las amas de casa, sobre qué tan satisfechas se sienten de vivir en el Conjunto Urbano Santa Elena, ya que aunque más de la mitad de ellas respondió que el conjunto cumple de manera mínima o suficiente con sus necesidades y las de sus familias, $2 \%$ mencionó sentirse nada satisfecha con el conjunto habitacional; $62 \%$ declaró sentirse poco satisfecha, $16 \%$ satisfechas y $20 \%$ dijo estar muy satisfecha con el hecho de vivir en Santa Elena.

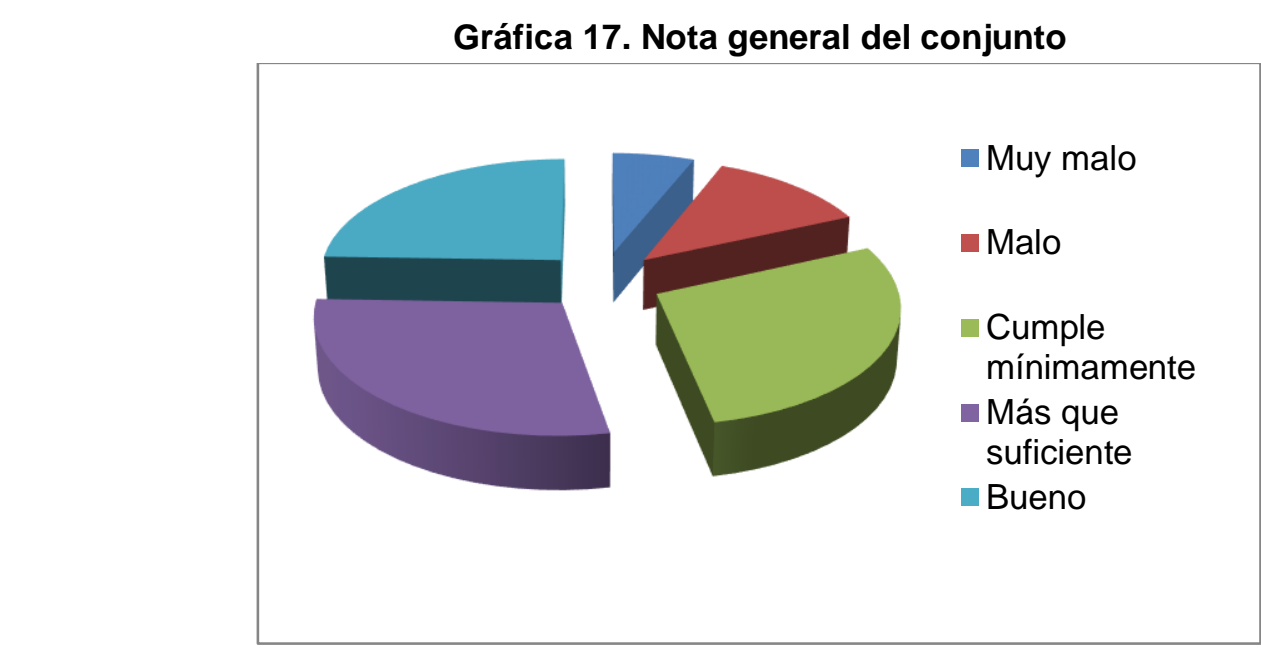

Elaboración propia con base en los resultados de la Encuesta de Satisfacción Residencial para el Conjunto Urbano Rancho Santa Elena 2016

De las mujeres que llegaron a vivir al conjunto entre el año 2000 y 2004, $54.5 \%$ dijo sentirse poco satisfecha con el hecho de vivir en Santa Elena, 3\% dijo estar nada satisfecha, $21.2 \%$ muy satisfecha y 21.3 satisfecha; $66.7 \%$ de las mujeres que llegaron al conjunto entre el año 2005 y 2009 mencionó que se sentía poco satisfecha, mientras que $33.3 \%$ dijo sentirse muy satisfecha.

83.3\% de las encuestadas que se mudaron a este espacio entre el año 2010 y el año 2014 se sentía poco satisfecha de residir en este conjunto, mientras que $16.7 \%$ estaba muy satisfecha con este aspecto. Finalmente, $75 \%$ de las mujeres que llegaron a Santa Elena entre el año 2015 y 2016 indicó que se sentía 
Mujer y satisfacción residencial. La mirada de quienes habitan en el Conjunto Urbano Rancho Santa Elena. Cuautitlán, Estado de México.

poco satisfecha de vivir aquí, mientras que el $25 \%$ restante dijo sentirse satisfecha con este rubro.

Los datos anteriores demuestran nuevamente, que el tiempo de residencia en el conjunto, no tiene tanto peso sobre la evaluación que las mujeres realizan su ambiente residencial, sino que más bien, su perspectiva se define a partir de los beneficios y las dificultades que los habitantes perciben. 


\section{CONCLUSIONES Y PROPUESTAS}

La vivienda es un elemento que posee atributos relevantes para el desarrollo de las sociedades actuales. Dado que responde a las necesidades básicas de abrigo y protección del hombre, se enmarca dentro de un contexto socio-físico mayor que incluye a la cultura, la economía, la política y el desarrollo físico- ambiental.

En este espacio se intercambian y reproducen gesticulaciones, elementos culturales, de comportamiento y supervivencia que fortalecen el sentimiento de pertenencia, permiten el dominio del sentido común y la interiorización de nociones prácticas que son útiles en distintos y numerosos ámbitos de la vida cotidiana (Pérez, 1999: 4).

No obstante, en las últimas décadas hemos sido testigos de una serie de cambios que trajeron consigo un aumento del déficit habitacional, haciendo que cada vez sea más complicado para los gobiernos, dotar a la población de una vivienda adecuada; especialmente en las ciudades, donde la alta concentración de personas se conjuga con los altos déficits en la cobertura y calidad de infraestructura y servicios. Problemas que se agravan debido a la incapacidad de los gobiernos locales para gestionar estos espacios ${ }^{59}$.

De acuerdo con el Banco Interamericano de Desarrollo (BID) ${ }^{60}$, en América Latina y el Caribe los altos déficits de vivienda se relacionan mayormente con los altos costos de las viviendas y la falta de acceso a créditos hipotecarios.

En el caso de México, el problema de la vivienda se asocia a los cambios sociodemográficos experimentados entre 1940 y 1980, que estuvieron acompañados de transformaciones importantes en los patrones de urbanización, relacionados con la expansión de la ciudad y los flujos migratorios provenientes del campo. Así como a los cambios suscitados en torno a la política de vivienda,

\footnotetext{
${ }^{59}$ Banco Interamericano de Desarrollo

60 lbíd.
} 
que hasta finales de los años ochenta había contado con la participación directa del Estado y que a principios de los años noventa, dio un giro impulsado por las políticas neoliberales que requerían fomentar la rentabilidad de las inversiones en materia de vivienda.

Las reglas impuestas por los organismos internacionales obligaron al Estado mexicano a abandonar su papel interventor en la producción, financiamiento y mantenimiento de las viviendas para crear condiciones que mejoraran la eficacia del mercado (Esquivel, 2006: 86).

De tal forma que el acceso a la vivienda de interés social se ha llevado a cabo con una importante participación del sector inmobiliario privado, por lo que las empresas inmobiliarias suplieron al Estado en su papel de promotor de vivienda de interés social, convirtiéndolo poco a poco en un instrumento que facilita y deja la producción habitacional en manos de los organismos privados.

Esta forma de actuar se ha cristalizado en la construcción de conjuntos habitacionales caracterizados por su localización alejada de los centros de las ciudades. Desarrollados a partir de agrupamientos de viviendas que incluyen menos elementos de equipamiento, servicios de infraestructura, áreas verdes, etc. a través de este diseño se ofrece a los destinatarios la promesa de la mejora de sus condiciones de vida y el sueño de tener una vivienda en propiedad (Esquivel, 2006: 94).

Aunque podemos señalar que en términos cuantitativos, la política habitacional ha tenido éxito (debido a que la construcción de conjuntos habitacionales localizados en la periferia de la ciudad ha permitido reducir el déficit habitacional existente), a nivel cualitativo se trata de una política que no ha tenido los resultados esperados. 
El abandono por parte del Estado de su papel de promotor habitacional ha estimulado el crecimiento de un impresionante número de viviendas; el crecimiento de la producción privada conlleva a riesgos en cuanto a la calidad de éstas y a que no sea precisamente la población más necesitada la que tiene acceso a los beneficios de las instituciones públicas (Puebla, 2006: 137).

Otra de las grandes problemáticas que presenta la política de habitacional actual, se relaciona con su falta total de vinculación con las políticas de desarrollo urbano federal, estatal y municipal mismas que se encuentran también desarticuladas entre sí; lo cual ocasiona que la mancha urbana siga creciendo sin una lógica integral que conlleva a ejercer mayor presión sobre los gobiernos locales que deben asumir la obligación de dotar de servicios a los pobladores (Puebla, 2006:147).

La implementación de la Política de Desarrollo Industrial en el Estado de México, favoreció la migración de la población hacia este territorio, lo cual, llevó al gobierno de este estado a decretar la Ley de Fraccionamientos de Terrenos del Estado de México con la que se modificó el concepto tradicional de la vivienda; dando paso a al concepto de las edificaciones habitacionales con áreas verdes empastadas, lugares de estacionamiento y divisiones establecidas para sala, comedor, recámaras, baños, entre otros dentro de la vivienda (Esquivel: 2006).

A partir de 1975 se construyeron en el Estado de México, los primeros conjuntos multifamiliares de régimen condominal, promovidos principalmente por el INFONAVIT en municipios de alta urbanización como Tlalnepantla y Ecatepec. Durante las décadas siguientes, la tipología de vivienda se trasformó, en respuesta a los programas de financiamiento desarrollados por las instituciones federales de vivienda y su relación con los niveles de ingreso de la población (Ortega y Villafaña, 2007: 52). 
En la década de los años 80 los programas de vivienda de interés social financiados por el INVONAVIT, FOVISSSTE entre otros, configuraron algunos de los espacios del Estado de México con desarrollos multifamiliares en régimen condominal principalmente de tipo vertical, observándose con ello, una reducción paulatina de la superficie cubierta por los programas arquitectónicos, situación que llevó a la modificación e incremento de las densidades habitacionales establecidas en los Planes de Desarrollo Urbano (Ortega y Villafaña, 2007: 52).

Con estos antecedentes y bajo la normatividad que regía a los fraccionamientos, surgen en la década de los años 90 las unidades habitacionales más grandes de la periferia metropolitana, presentando una importante cantidad de problemáticas asociadas a la falta de servicios y equipamiento que eran necesarios para albergar a su población. Para enfrentar esta problemática se promovió la segunda

Bajo esta figura se produjo durante la época de los noventas un boom habitacional que incentivó el desarrollo urbano de determinados municipios, modificando la imagen urbana del Estado de México y trayendo consigo problemáticas para las administraciones municipales que, hasta el momento, cuentan con poca capacidad para incidir en el diseño de dichos proyectos (Esquivel, s.f.: 6).

Con la promoción de la segunda Ley de Asentamientos Humanos en 1993, se crea la figura de Conjunto Urbano como una nueva medida que contempla la dotación obligatoria de infraestructura urbana y que busca responder a las demandas que no habían sido atendidas por los antiguos fraccionamientos (Pedrotti, 2015: 64).

Sin embargo, diversos estudios han demostrado que la política habitacional implementada, ha generado importantes problemáticas que no solamente están relacionadas con su contribución al crecimiento urbano, sino que tienen que ver 
también, con la modificación de los modos de vida de las familias mexiquenses. Algunas de las consecuencias de este tipo de urbanización identificadas hasta el momento son los problemas asociados a la localización, a la accesibilidad, a la inversión de tiempo y dinero para transportarse a la ciudad, a la falta de equipamiento, la calidad de los materiales empleados en la fabricación y a las reducidas dimensiones de la vivienda.

Quizás, el mayor hueco que se puede encontrar en esta reglamentación,, radica en la poca rigurosidad normativa establecida para definir el tamaño máximo y la ubicación de los nuevos conjuntos habitacionales; ya que su autorización depende únicamente de la disponibilidad de agua potable en y no existe algún otro principio que lo limite.

En el caso particular del municipio de Cuautitlán resulta sorprendente encontrar conjuntos habitacionales de más de 5 mil viviendas, construidos no hace más de 16 años, que se encuentran en un estado de deterioro físico y social muy importante, lo cual habla de la necesidad de considerar y cuestionar la calidad de los espacios construidos, así como los mecanismos de asignación de las viviendas y la falta de una política integral que tenga en cuenta lo que sucede a nivel de la vida cotidiana una vez que las casas son entregadas a los beneficiarios.

Esto se debe principalmente a que las políticas habitacionales de la región Latinoamericana, se han caracterizado por la ausencia de una visión integral; en tanto que el diseño de la vivienda se limita a la consideración de los costos económicos y ganancias.

Es por esta razón, que la presente investigación se planteó como objetivo principal, evaluar la satisfacción residencial de las mujeres amas de casa que habitan en el Conjunto Urbano Rancho Santa Elena, ubicado en el municipio de Cuautitlán, Estado de México, buscando identificar elementos que contribuyan a mejorar la política habitacional actual. 
El motivo por el que se escogió a Santa Elena como objeto de estudio, es que éste es uno de los Conjuntos Urbanos más grandes del municipio (en cuanto a tamaño y número de viviendas), y forma parte de los primeros tres autorizados bajo la modalidad de Conjunto Urbano (Rancho San Blas y Paseos de Cuautitlán son los otros conjuntos autorizados durante el mismo periodo).

Para cumplir con los objetivos planteados se partió del análisis de la satisfacción residencial, que se trata de un concepto cuyos orígenes se ubican en la psicología ambiental y que busca indagar en el nivel de agrado o desagrado que sienten los habitantes por su ambiente residencial.

Esta perspectiva resulta de interés para esta investigación, porque permite rescatar las opiniones y valoraciones que los usuarios hacen a su vivienda -que si bien, también parten de una reflexión de aspectos objetivos como son las características de la vivienda y su entorno- incluye otros elementos como la familia y las relaciones vecinales que se desarrollan alrededor del espacio habitable.

Aspectos que se considera, han sido hasta ahora ignorados por las políticas mexicanas de vivienda y que juegan un papel fundamental a la hora de entender los problemas que presentan los espacios habitacionales de gran magnitud, como son los Ilamados Conjuntos Urbanos localizados en la periferia de la Ciudad de México.

El trabajo de investigación cuantitativa y cualitativa que se realizó para propósitos de este trabajo, permite privilegiar la mirada de quienes habitan en este conjunto habitacional y proporciona información valiosa, que va más allá de los resultados cuantitativos de la política habitacional, es decir, nos da acceso a una visión más amplia del problema de la vivienda, ofreciendo elementos que amplían nuestra visión sobre lo que ya conocemos. 
Para llevar a cabo estas tareas, se decidió retomar la metodología propuesta por el Instituto de la Vivienda (INVI) de Santiago de Chile (2002); que fue utilizada, en el análisis de la satisfacción residencial de los usuarios del Programa de Viviendas Básicas de ese país. Aunque se trata de dos soluciones habitacionales distintas, los instrumentos elaborados por el INVI comprenden una guía para la observación del conjunto habitacional y una encuesta diseñada para medir distintos aspectos de la satisfacción residencial (consultar anexo) que pueden ser utilizados sin mayor complicación para el análisis de la satisfacción residencial en los Conjuntos Urbanos mexicanos.

Se decidió retomar esta metodología, debido a que permite el análisis de las tres dimensiones que de acuerdo con autores como Amérigo y Haramoto son esenciales para entender y analizar el grado de satisfacción de los habitantes de determinado espacio: la familia y la vivienda; el entorno cercano a la vivienda y el conjunto habitacional.

Los instrumentos elaborados por el equipo de investigación chileno, se basan en la amplia experiencia que tiene este país en el estudio de la satisfacción residencial y han sido utilizados en diversas ocasiones como la fuente primaria de variadas investigaciones.

De acuerdo con el Doctor Luis Iturra, investigador del INVI Chile, ${ }^{61}$ los primeros trabajos desarrollados en torno al concepto de satisfacción residencial en ese país, nacieron debido a la preocupación de los académicos y autoridades por la calidad de las viviendas construidas, así como por la influencia de las corrientes europeas relacionadas con la llamada psicología ambiental que durante la década de los sesenta, mostraron interés en evaluar las nuevas formas de construcción de la época. Estas corrientes, buscaban rescatar el lado subjetivo del problema de la

${ }^{61}$ Entrevista realizada al Doctor Luis Iturra, investigador del Instituto de la Vivienda, Chile el 2 de junio de 2016. 
vivienda, yendo más allá del análisis del número de viviendas o de las carencias y características físicas del espacio residencial.

La hipótesis que orientó este trabajo investigativo es la que se enuncia a continuación: a mayor tiempo de habitar en Santa Elena, menor es el deseo de permanecer aquí y menor es el grado de satisfacción con el conjunto habitacional, ya que quienes han habitado en este espacio durante un periodo prolongado, han sido testigos de los cambios que ha sufrido el conjunto habitacional y que discrepan con las expectativas que tenían a su llegada. Al respecto los hallazgos son los siguientes:

\section{Hallazgos y conclusiones}

A continuación, se presentan las principales conclusiones de la Encuesta de Satisfacción Residencial, aplicada a 50 mujeres amas de casa que residen en el Conjunto Urbano Rancho Santa Elena y que dan cuenta, de la manera en que perciben y evalúan el conjunto urbano en el que viven.

\section{a) Sobre la vivienda anterior y la vivienda actual}

De acuerdo con los resultados de la Encuesta de Satisfacción Residencial para el Conjunto Urbano Rancho Santa Elena 2016, 32\% de la población llegó a vivir al conjunto en el año 2000, es decir, inmediatamente después de que finalizaron los trabajos de construcción; mientras que $22 \%$ ocupó su vivienda un año después (2001); 10\% llegaron al conjunto en el año 2002 y el resto de las encuestadas lo hizo en los años subsecuentes. 
Lo anterior quiere decir, que la mayoría de las encuestadas tiene un promedio de 15 años viviendo en Santa Elena, por lo que han sido testigos de las transformaciones que ha sufrido el conjunto y su entorno, durante los últimos años.

Sobre la satisfacción con la vivienda anterior, que más de la mitad de las encuestadas considera que su antigua casa les permitía llevar una vida familiar poco satisfactoria.

De acuerdo con las mujeres encuestadas, las actividades que son más difíciles de llevar a cabo debido a las características de las viviendas son: realizar fiestas y reuniones, poner un negocio o taller, trabajar, realizar ejercicio, estacionar su auto y escuchar música.

Las encuestadas perciben una carencia de infraestructura y servicios en el lugar donde fue construido el conjunto habitacional, debido a las irregularidades bajo las cuales edificado este conjunto y que consisten en la falta de supervisión por parte de las autoridades para verificar que este espacio fuese entregado de acuerdo a los planes y diseño bajo el cual se autorizó su construcción. Pese a que en los lineamientos establecidos por la Secretaría de Desarrollo Urbano y Metropolitano del Estado de México, se establece que uno de los requisitos básicos para la autorización de un Conjunto Urbano es que las construcciones deben cumplir con la normatividad establecida en los Planes Municipales de Desarrollo Urbano vigentes y contar con la infraestructura hidráulica, sanitaria y vial; el equipamiento urbano y los servicios públicos necesarios para su ocupación y contribuyan al mejoramiento del orden urbano y de la imagen urbana, se halló que en el caso del Conjunto Urbano Rancho Santa Elena, no se llevaron a cabo todas las obras de urbanización contempladas en un inicio y que además, éste no cumple con el precepto de contribuir al mejoramiento del orden urbano ya que ni siquiera está claro a qué municipio pertenece. 
Esto ha generado que las autoridades municipales, se muestren indiferentes a los conflictos y necesidades de la población, lo que ha orillado a los habitantes a manifestarse en diversas ocasiones -mediante protestas y el cierre de calles- para exigir la resolución de problemas que los aquejan; relacionados principalmente, con la inseguridad, los cortes constantes al suministro de agua, así como con las fuertes inundaciones que sufren durante la temporada de lluvia.

Dicha situación, genera incertidumbre en la población y contribuye a que los residentes perciban que no existe una autoridad oficial a la que puedan acercarse para plantear o resolver sus problemas. Los resultados indican que la población encuestada percibe que el municipio no se interesa en lo absoluto por su conjunto habitacional y las autoridades municipales muestran poco interés en los intereses y conflictos del lugar.

En relación a la infraestructura de servicios, se observa que los rubros peor evaluados son aquellos que se relacionan con las actividades que debe -por Ley- brindar el municipio: como vigilancia policial, alumbrado público y pavimentación de calles y pasajes. Esto se debe, a que comúnmente los planes de desarrollo municipal o estatal, no están vinculados con este tipo de inversiones, lo cual, pone a prueba la capacidad de las autoridades para dar atención a las necesidades y demandas de la nueva población que se instala en estos territorios.

Al preguntar a las entrevistadas sobre el motivo por el que eligieron su vivienda, resulta sorprendente conocer que son muy pocos los residentes que eligieron su vivienda porque les agrada el lugar en la que estaba construida o porque cumpliera con sus exceptivas, sino que en realidad, pocas veces las familias tienen la oportunidad de escoger una vivienda acorde a sus gustos o necesidades y escogen la vivienda de acuerdo a lo que les alcanza y en base a la escasa oferta del mercado inmobiliario; situación que se compensa para los usuarios con la realización del sueño de ser propietarios de su vivienda y 
se refleja en las respuestas que otorgan los usuarios al cuestionarlos sobre los aspectos que más les agradan de su casa actual.

En este sentido la vivienda, aparece como el componente más importante para la satisfacción residencial debido a la importancia que se asigna a la forma de tenencia en propiedad; al respecto se encontró que un porcentaje alto de las mujeres, eligió la opción "Que es propia" como el elemento que más les gusta de su vivienda. También se halló que las encuestadas otorgan una valoración más negativa a aspectos subjetivos del espacio residencial como la sensación de inseguridad y las relaciones vecinales; que a aspectos objetivos propios de la vivienda tales como: la distribución, el número de viviendas en el conjunto urbano o la calidad de las viviendas.

La evaluación de los habitantes de Santa Elena mostró que los aspectos de las viviendas mejor evaluados fueron la iluminación y la ubicación de los espacios de la vivienda, es decir, la distribución; mientras que los peor evaluados por las usuarias fueron el tamaño de la vivienda y el patio.

Sobre el tipo de cambios que realizaran a sus viviendas se hace evidente que las mujeres encuestadas realizan más observaciones relacionadas con el diseño de la vivienda que con el aspecto constructivo (el tipo de materiales, las instalaciones y terminaciones de la vivienda); ya que más de la mitad mencionó que ampliar su vivienda, sería una de las modificaciones principales que realizarían si tuviesen la oportunidad de hacerlo.

Además de los inconvenientes en el diseño de la vivienda, las usuarias lograran identificar otro tipo de problemáticas relacionados con los aspectos constructivos de su casa, problemas relacionados con goteras al poco tiempo de haber recibido su vivienda; problemas asociados a los materiales de construcción; de aislación térmica -sienten mucho calor o mucho frío dependiendo del clima-; 
iluminación y ventilación. Siendo el tamaño reducido de las viviendas, el problema al que le asignan mayor relevancia.

Estos datos reflejan la poca importancia que los programas de vivienda han otorgado al diseño y construcción de las soluciones habitacionales, lo cual incide en el grado de Satisfacción de los usuarios con su vivienda y evidentemente, en la evaluación que realizan su ambiente residencial.

\section{b) Percepción del entorno, relaciones vecinales}

En general, los habitantes del conjunto Rancho Santa Elena presentan poca disposición para relacionarse con sus vecinos ya que consideran que no se puede convivir bien con sus vecinos debido a que "no se conocen" o a que sus vecinos son demasiado conflictivos.

Esto se convierte a su vez, en una barrera que limita y en algunos casos impide, la organización entre los vecinos, ya sea porque éstos no se conocen o porque se han construido barreras sociales entorno a la ubicación de las viviendas. Es decir, la gente "no se junta" o se relaciona con aquellas familias que consideran inferiores o distintas a ellos; porque tienen estilos de vida distintos (costumbres, tradiciones, formas de vestir, hablar y conducirse) o por rencillas que los llevaron a no hablarse, ni querer relacionarse entre sí.

A esto, se suma el desconocimiento de la Ley Condominal y la ausencia de una figura gubernamental o autoridad, que se encargue de sancionar a quienes incumplen este tipo de ordenanzas.

Al cuestionar a las amas de casa sobre la organización vecinal dentro del Conjunto Urbano Santa Elena, más de la mitad de las encuestadas percibieron como una problemática importante, que en su manzana o calle, no se llevan a 
cabo labores de mantenimiento, debido a que existe una mala relación con los vecinos o a que la gran mayoría de los residentes se niegan a pagar las cuotas que se establecen para los gastos comunes, además, de que los vecinos no están dispuestos a asumir la responsabilidad que conlleva el ocupar el cargo de administrador.

\section{c) Percepción del Conjunto}

En general, la valoración que los habitantes realizan hacia el conjunto habitacional es mala; el Índice de Satisfacción con el conjunto es de 2.46, es decir, las mujeres encuestadas consideran que los beneficios que obtienen del conjunto urbanos son insuficientes.

Al preguntar a las encuestadas ¿Qué tan satisfecha se siente de vivir en este conjunto habitacional? 62\% señaló sentirse Poco Satisfecha; 2\% Nada satisfecha, $16 \%$ Satisfecha y $20 \%$ Muy satisfecha.

Estos datos se relacionan con el orgullo que los habitantes sienten o no, de vivir en este Conjunto Urbano ya que de acuerdo con la variable año en que llegó a vivir en el Conjunto Urbano, el orgullo disminuye cuando se lleva más de 10 años residiendo en este lugar e incrementa ligeramente cuando las encuestadas han vivido menos de 7 años en el conjunto, es decir, éstas últimas dijeron sentirse Algo orgullosas de vivir en el Conjunto Urbano Santa Elena.

Por otra parte, se encontró que la limpieza y la seguridad, son los aspectos del conjunto habitacional peor evaluados por las usuarias. En cuanto a las actividades que son difíciles de realizar debido a la ubicación de la vivienda y del Conjunto Urbano, las encuestadas mencionaron que tanto para ellas como para sus familias, resulta complicado: hacer ejercicio, participar en actividades recreativas e ir al parque con sus hijos; debido a que la carencia de equipamiento 
contribuye a disminuir el nivel de agrado que sienten hacia el conjunto habitacional, ya que contrasta con las expectativas que tenían a su llegada.

De acuerdo con los testimonios de las entrevistadas, se les había prometido que contarían con un espacio deportivo dentro del conjunto urbano, sin embargo, sólo cuentan con un terreno baldío que muy pocas personas utilizan debido a que se sienten expuestos a diversos riesgos.

\section{d) Deseo de permanecer o mudarse}

Respecto al deseo de permanecer o mudarse se encontró que más de la mitad de las encuestadas que llegaron al vivir al conjunto hace más de 13 años (entre el 2000-2004), manifestó que se mudarían de su vivienda actual si tuvieran la oportunidad de hacerlo.

Sin embargo, el tiempo de residencia no es una variable que influye en los deseos de permanecer en el conjunto urbano; a diferencia de lo que se planteaba en la hipótesis que orientó este trabajo de investigación ${ }^{62}$, los resultados indican que sin importar el tiempo que las encuestadas y sus familias llevan residiendo en este Conjunto Urbano, existe una sensación de inconformidad generalizada que se deriva de los conflictos o problemas que las familias perciben en su ambiente residencial y que los motiva a sentirse insatisfechos con la solución habitacional que recibieron.

De tal manera, se puede concluir que el tiempo de residencia en el conjunto, no tiene tanto peso sobre la evaluación que las mujeres realizan su ambiente residencial, sino que más bien, su perspectiva se define a partir de los beneficios y las dificultades que los habitantes perciben a nivel del meso y al

\footnotetext{
62 A mayor tiempo de habitar en Santa Elena, menor es el deseo de permanecer aquí y menor es el grado de satisfacción con el conjunto habitacional.
} 
macro sistema, pues aunque se percatan de los defectos o dificultades que se presentan en su vivienda, son -de acuerdo a los testimonios- aspectos sobre los que tienen un alto grado de incidencia (ampliando, reparando o mejorando su casa).

\section{Propuestas generales}

En este apartado, se exponen una serie de recomendaciones basadas en los resultados de la investigación realizada en el Conjunto Urbano Rancho Santa Elena. Estas propuestas pueden ser profundizadas en investigaciones de mayor alcance y aunque no son generalizables para todo un territorio, aportan ideas que pueden contribuir a mejorar la política habitacional actual:

a) En relación al financiamiento y al acceso a créditos hipotecarios, se sugiere ajustar el valor de la vivienda en relación al ingreso de las familias, las características de sus integrantes y las posibilidades de pago; ya que se observa que en un gran número de hogares, se destina la mitad o más de la mitad de los ingresos familiares al pago de la hipoteca o renta. Limitando sus posibilidades de acceder a otro tipo de actividades (recreativas, educativas, deportivas, etc.) que inciden en la valoración que se realiza hacia la vivienda o el conjunto urbano.

b) Mejorar las condiciones de localización de los conjuntos urbanos, es decir, aprobar únicamente aquellos proyectos que verdaderamente contribuyen al ordenamiento del territorio (que no ponen en riesgo la infraestructura disponible, ni rebasan la capacidad de las autoridades para dar respuesta a las necesidades de bienes y servicios de la nueva población). 
c) Detener la expansión de los emplazamientos periféricos y diseñar un programa de vivienda acorde a las características y planes de desarrollo municipales.

d) Permitir que sean los municipios y no el estado (de México) quienes autoricen la construcción de los conjuntos habitacionales; esto implicaría capacitar a los funcionarios municipales y crear un área especializada en desarrollo urbano con facultades para autorizar la edificación de un nuevo conjunto habitacional.

e) Crear una instancia municipal ex profeso para el control y supervisión de las obras de construcción que se realizan en los nuevos conjuntos urbanos, de tal forma, que el municipio no deba esperar hasta la etapa de municipalización del conjunto para constatar el avance físico de las obras de urbanización. Así se podría evitar que las inmobiliarias entreguen inconclusos los conjuntos urbanos.

f) Mejorar el diseño de las vías de comunicación y de las viviendas en sí; estableciendo distintas tipologías de vivienda que se adapten a las necesidades de los hogares (tomar en cuenta a las personas con discapacidad $u$ otros sectores vulnerables de la población, como las mujeres, los niños y los adultos mayores).

g) Flexibilizar el diseño de la vivienda, para que ésta pueda ser adaptada de manera progresiva a las necesidades las familias.

h) Crear programas de asesoramiento profesional para orientar a quienes desean modificar o ampliar su vivienda, con el fin de evitar que estos cambios alteren la estructura de las viviendas o se extiendan a las áreas comunes del conjunto habitacional.

i) Establecer un programa de mantenimiento en coordinación con las autoridades municipales, que considere el mejoramiento de los conjuntos a 
corto plazo, para disminuir las posibilidades de que éstos se deterioren de forma considerable.

j) Proporcionar a los habitantes, asesorías sobre cómo administrar y dar mantenimiento a las áreas comunes del conjunto urbano.

A lo largo de este trabajo, se hizo hincapié en los efectos negativos de la producción en masa de conjuntos habitacionales de interés social. Sin embargo, a la luz de los hallazgos presentados, vale la pena recalcar que desde hace más de dos décadas habíamos sido advertidos sobre las consecuencias económicas, políticas y sociales de este modelo de construcción.

A finales de la década de los noventa y principios del año 2000, algunos autores chilenos (Ducci 1997; Hidalgo 1998; Haramoto 1998) habían evidenciado ya, "el lado oscuro" de la política de vivienda implementada en ese país y que años después sería retomada por países como el nuestro, sin ser cuestionada o replanteada.

Uno de los casos más emblemáticos del problema de la vivienda en América Latina, se ubica en el sector de Bajos de Mena, en la Comuna de Puente Alto; localizada en la periferia de Santiago de Chile. Se trata de un conjunto habitacional de grandes dimensiones que fue resultado de la expansión de la ciudad hacia la periferia de esta región ${ }^{63}$.

Este sector enfrenta diversas problemáticas sociales y funcionales, asociadas al espacio construido; lo cual, to ha convertido en un paradigma habitacional de segregación y marginación urbanas (Hidalgo, Urbina, Alvarado y Paulsen; 2017: 85).

${ }^{63}$ Alberga a poco más de 140 mil personas y está constituido por 25, 000 viviendas. 
Fotografías 24, 25, 26 y 27. Interior y fachadas de las viviendas ubicadas en el Sector de Bajos de Mena, Santiago de Chile.
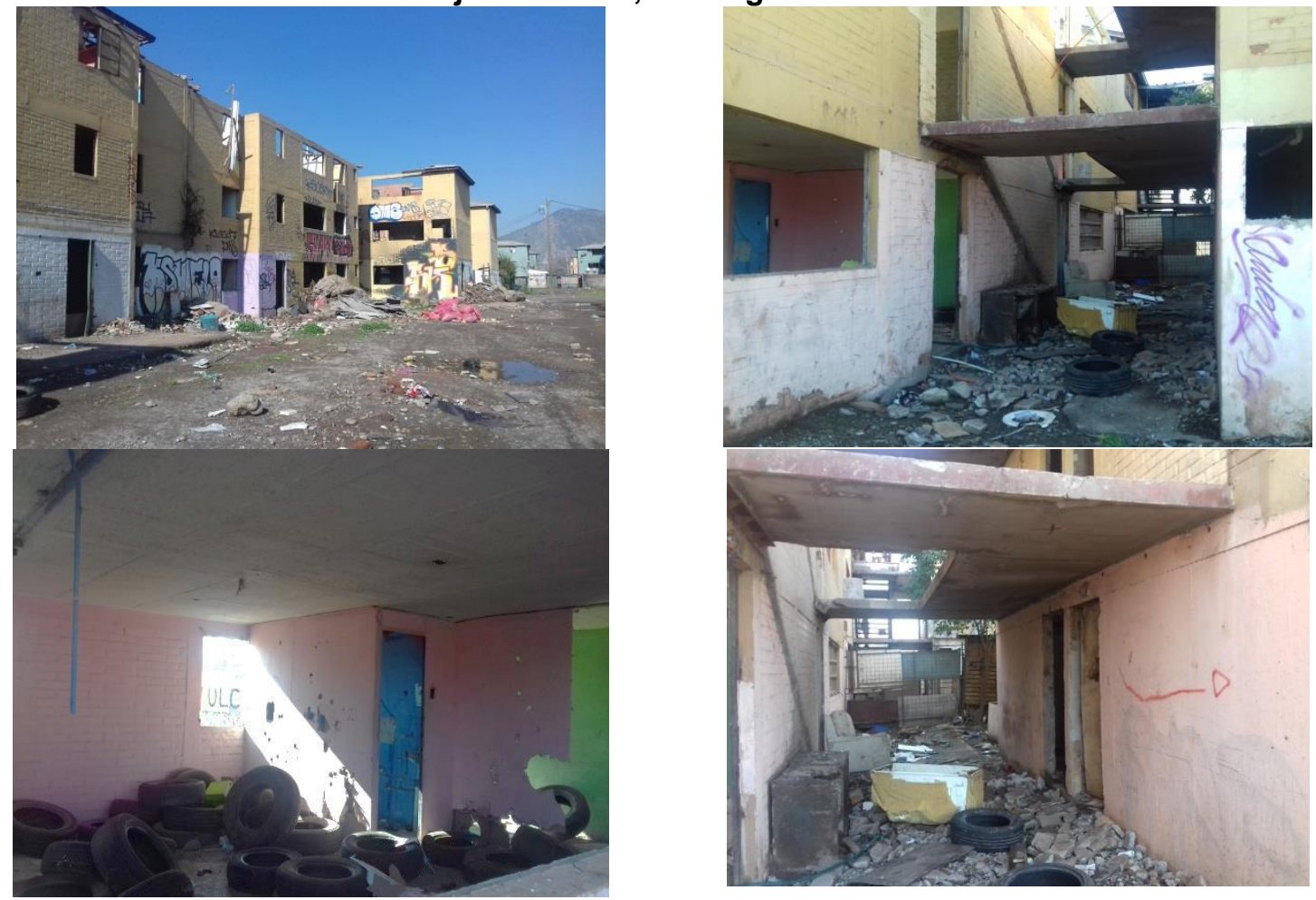

Fotografías propias, tomadas el 6 de junio de 2016 durante un recorrido realizado bajo la guía del Doctor Jorge Larenas Salas, miembro del Instituto de la Vivienda de la Universidad de Chile.

Como se observa en las fotografías $24,25,26$ y 27 , las viviendas ubicadas en este espacio se encuentran en un estado avanzado de deterioro, por lo que un gran número de casas han tenido que ser demolidas o abandonadas, ya que no cumplen con los requisitos necesarios para ser habitadas. De acuerdo con la Unidad de Planes Integrales para Barrios de Alta Complejidad de la Intendencia Metropolitana de Chile ${ }^{64}$, el hacinamiento, la inseguridad (debido a la presencia de pandillas y grupos delictivos), la falta de equipamiento y la carencia de servicios, la mala calidad de las viviendas, la falta de conectividad, la lejanía de este espacio respecto al centro de la ciudad, la violencia y el crecimiento no planificado del

\footnotetext{
64 https://www.camara.cl/pdf.aspx?prmID=97072\&prmTIPO=DOCUMENTOCOMISION
} 
conjunto, son las principales problemáticas a las que se enfrentan los residentes de este sector.

Esto ha llevado a que Bajos de Mena sea sido calificado como "el gueto más extenso de Chile", ya que cuenta con una población similar a la de otras ciudades dentro de ese territorio, pero carece de equipamiento y servicios urbanos (ATISBA, 2010 en Delgado; 2013: 5).

Para resolver los conflictos presentes en este conjunto, el gobierno chileno ha optado por implementar una serie de planes y programas con el objetivo de mejorar las condiciones de vida de quienes habitan en este lugar; uno de estos esfuerzos responde al nombre de Programa de Condominios Sociales de Segunda Oportunidad, el cual ofrece un subsidio habitacional para que las familias puedan trasladarse a otro sector (Delgado; 2013: 5). Actualmente, se encuentra vigente el Plan Integral de Bajos de Mena que tiene como objetivo

\section{[...] articular los programas y planes del Gobierno para mejorar} la calidad de vida de los vecinos del sector de Bajos de Mena, favoreciendo la integración social, reduciendo inequidades $y$ fortaleciendo la participación ciudadana impulsar programas e iniciativas destinadas a asegurar las viviendas de mejor calidad equipados e integrados territorialmente y con mayor seguridad ${ }^{65}$.

No obstante, prevalece el desafío de encontrar una solución eficaz que permita restablecer las condiciones de habitabilidad en este lugar y revertir las consecuencias del desarrollo no planificado.

En general, las políticas habitacionales de la región de América Latina y el Caribe se han caracterizado por la ausencia de una visión a largo plazo (BID, 2011); en tanto que el diseño de la vivienda se limita a la consideración de los

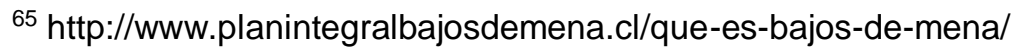


costos económicos y ganancias, sin tener en cuenta que con ello, se traslada a los futuros usuarios diversas problemáticas relacionadas con la reparación y el mantenimiento de los espacios habitacionales. Por lo que es fundamental, atender a las necesidades de vivienda de la población, mediante la implementación de una política de vivienda acorde a los planes municipales y estatales de desarrollo, que contemple una gestión integral e interdisciplinaria de estos espacios.

La experiencia de Bajos de Mena, es un gran ejemplo sobre lo costoso que resulta revertir los problemas que se generan debido a la carencia de una planeación a largo plazo y sobre todo, a la ausencia de programas de mantenimiento que permitan a las familias hacer frente a los conflictos que se les presentan en su andar cotidiano.

Los principales retos a los que se enfrentan los gobiernos de los países latinoamericanos en materia de diseño y planificación de los espacios urbanos, consisten en entender que no existen modelos únicos de diseño y ejecución, que se adapten a todas las necesidades de los habitantes y que puedan ser replicados por toda la ciudad sin tomar en cuenta el contexto en que se inscriben (BID, 2015).

Por lo cual, se debe tener siempre presente que las ciudades son espacios dinámicos que nos exigen considerar las características de los habitantes y su entorno, para así poder comprender el rol que cumple determinado territorio dentro de su comunidad (BID, 2015). Pero sobre todo, el reto principal consiste en encontrar medidas, mecanismos y herramientas que devuelvan a la planeación su sentido esencial: planear para el bien común y en pro de la sostenibilidad ${ }^{66}$ de las ciudades.

\footnotetext{
66 De acuerdo con el Banco Interamericano de Desarrollo, una ciudad sostenible es aquella que garantiza la calidad de vida los ciudadanos presentes sin afectar la de los futuros habitantes y que es capaz de equilibrar las metas económicas, ambientales y sociales entre las generaciones presentes y futuras (BID, 2011).
} 


\section{BIBLIOGRAFÍA}

Abramo Pedro (2002) "La ciudad com-fusa, mercado y producción de la estructura urbana en las grandes metrópolis latinoamericanas", en Eure, Vol. XXXVIII, núm. 111, pp. 35-69.

Algaba, Antonio (2003) "María Amérigo, Satisfacción residencial. Un análisis psicológico de la vivienda y su entorno. Alianza Universidad, Madrid, 1995. 169 p." en Revista Bibliográfica de Geografía y Ciencias Sociales, Universidad de Barcelona, Vol. VIII, n 420, 5 de enero de 2003.

Amado, Jesús (2009) La privacidad en la vivienda de interés social. Tesis de Licenciatura, Instituto Politécnico Nacional, Escuela Superior de Ingeniería y Arquitectura, Tecamachalco.

Amérigo (s/f) "Satisfacción residencial en áreas de vivienda pública", Facultad de Humanidades de Toledo, Departamento de Psicología, Universidad de Castilla-La Mancha, Pp. 8.

Andrade, Manuel, Carlos Aguirre y María Elena Mora (2007) Antecedentes para una Evaluación de la Satisfacción Residencial de los Beneficiarios del Fondo Solidario de Vivienda (FSV) Revista de la Construcción, vol. 6, núm. 2, 2007, pp. 42-51 Pontificia Universidad Católica de Chile, Santiago, Chile. Disponible en: http://www.techo.org/wpcontent/uploads/2013/02/Miguel-Andrade.pdf (Consultado el: 20 de diciembre de 2015).

Ardila, Rubén (2003) Calidad de vida: una definición integradora en: Revista Latinoamericana de Psicología, vol. 35, núm. 2, 2003, pp. 161-164 Fundación Universitaria Konrad Lorenz Bogotá, Colombia

Arends, Lenimar (2012) Satisfacción residencial, encuesta diseñada. Centre de Política de Sòl i Valoracions, Universitat Politècnica de Catalunya. Disponible en: http://upcommons.upc.edu/bitstream/handle/2117/18212/report5_LENIMAR_SATISFACCI ON\%20RESIDENCIAL\%20-\%20ENCUESTA.pdf?sequence=1\&isAllowed=y (Consultado el 29 de noviembre de 2015).

Ayuntamiento de Fuenlabrada España (2007), Concejalía de Igualdad y Empleo, Viviendas que concilian la perspectiva de género aplicada a las viviendas de nueva construcción, Madrid, pp. 48.

Barrera, Juan Manuel (2012) "Viven en Cuautitlán; votarán para elegir edil de Tultepec", El Universal, 14 de junio 2012.2 Disponible en: http://www.eluniversaledomex.mx/home/nota30224.html (Consultado el: 18 de abril de 2016).

BID (2011), Bonet, Jaime (coord.) Sostenibilidad Urbana en América Latina y el Caribe, Banco Interamericano de Desarrollo, Oficina de Relaciones Externas, pp. 1-12.

Disponible en: https://publications.iadb.org/handle/11319/2784?locale-attribute=es (Consultado el: 06 de noviembre de 2015)

BID (2015), Liderando el Desarrollo Sostenible de las Ciudades, Unidad Temática Espacios Públicos, pp. 52.

Cabrero, Enrique y Carlos Gil (2010) "La agenda de políticas públicas en ciudades mexicanas durante el siglo XX: ¿cien años de soledad municipal?, en: Revista Estudios Demográficos y Urbanos, No. 73, enero- abril 2010 
CONAPO (2002), Índice de marginación urbana, 2000, Consejo Nacional de Población, México.

Connolly, Priscila (2005) Tipos de poblamiento en la Ciudad de México, OCIM-SIG, UAM, Azcapotzalco.

Coulomb, R. (2012) "El centro de la ciudad de México frente al desafío de un desarrollo urbano más sustentable. (Elementos para el proyecto de investigación hábitat y centralidad), en Coulomb, Esquivel y Ponce (coord.) Hábitat y centralidad en México. Un desafío sustentable. México, Centro de Estudios Sociales y de Opinión Pública, CESOP, pp. 17-57.

Del Pino, Julio (2014) Sociología de la residencia y residencia móvil: logros teóricos y límites prácticos en: EMPIRIA. Revista de Metodología de Ciencias Sociales. N.o 27, enero-abril, 2014, pp. 21-48.

Dimatre, Norberto (1998) La vivienda desde tiempos remotos hasta nuestros días en el mediterráneo.

Disponible

en:

http://www.tdx.cat/bitstream/handle/10803/6113/04PARTE2_3.pdf;sequence=6

(Consultado el: 12 de julio de 2016).

Delgado, Francisca (2013) Primer llamado 2013: Programa de Recuperación Condominios Sociales Segunda Oportunidad en Bajos de Mena, Santiago de Chile. Facultad de Arquitectura y Urbanismo, Universidad de Chile. Págs. 150.

Ducci, María Elena (1994) Políticas de vivienda y mujer en: Revista EURE, Vol. XXI, № 59, pp. 7391, Santiago de Chile, marzo 1994.

Enciclopedia de los municipios y delegaciones de México, Estado de México, Cuautitlán. Disponible en internet en; http://elocal.gob.mx/work/templates/enciclo/EMM15mexico/municipios/15024a.html (Consultado el: 25 de junio de 2015).

Esquivel, María y Guénola Capron (2016) Capron, Guénola, y María Teresa Esquivel Hernández. 2016. "El enclave urbano, lógica socioespacial de la periferia urbanizada y sus efectos sobre la segregación residencial y la fragmentación urbana." Cuadernos de Geografía: Revista Colombiana de Geografía 25 (2): 125-149. doi: 10.15446/rcdg.v25n2.54720.

Esquivel, María Teresa (2005). La promoción privada y los grandes conjuntos habitacionales: nuevas modalidades de acceso a la vivienda en: Revista electrónica de geografía y ciencias sociales, Universidad de Barcelona. Vol. IX, núm. 194. Disponible en: http://www.ub.edu/geocrit/sn/sn-194-21.htm (Consultado el: 1 de diciembre de 2014)

(2006) Política habitacional y calidad de vida: impacto de los nuevos desarrollos habitacionales, en: La vivienda en México Construyendo análisis y propuestas, CESOP. Pp. 275.

------ (2011) "Los grandes conjuntos urbanos y su espacio en la periferia metropolitana: a una década de San Buenaventura, Ixtapaluca." Ponencia presentada en el Segundo Simposio Internacional de Estudios Vallechalquenses: del Territorio Emergente a las Micrópolis, Universidad Autónoma Metropolitana-Iztapalapa, 3 al 5 de noviembre.

Fernández, Nuria (1996). "La construcción cultural de los dominios masculino y femenino. Espacios habitados, lugares no ocupados" en Revista Astrágalo. Cultura de la arquitectura y la ciudad. Espacio y género. Itinerarios al paraíso. No. 5. Noviembre. Instituto Español de 
Arquitectura. Universidades de Alcalá y Valladolid. Celeste Ediciones. Madrid. Pp. XXIXXIX.

García Héctor y Joaquín López (2014) "Perspectivas de la industria de la construcción en México", Revista Consultoría, Septiembre 2014, pp. 46-48 Disponible en: https://www.ccpm.org.mx/avisos/46-48\%20CIC\%20266\%20BAJA.pdf (Consultado el 1 de febrero de 2017).

García, Silvia (s/f) "Pruitt-Igoe: el día que la arquitectura moderna murió" en: Blog arquitectos Costa Rica. Disponible en: http://www.arquitectoscostarica.com/2013/02/pruitt-igoe-el-dia-que-laarquitectura-moderna-murio/ (Consultado el: 29 de diciembre de 2015).

García Brígida y de Oliveira Orlandina (2005) Mujeres jefas de hogar y su dinámica familiar Papeles de Población, vol. 11, núm. 43, enero-marzo, 2005, pp. 29-5. Universidad Autónoma del Estado de México, Toluca, México.

Gazmuri, Patricia (2013) Familia y habitabilidad en la vivienda. Aproximaciones metodológicas para su estudio desde una perspectiva sociológica. Arquitectura y Urbanismo, 34(1), 32-47. Disponible en: http://scielo.sld.cu/scielo.php?script=sci_arttext\&pid=S1815$58982013000100004 \&$ Ing=es\&tlng=es (Consultado el 9 de julio de 2016).

Haramoto, Edwin (2002) (coord.) SISTEMA MEDICIÓN SATISFACCIÓN BENEFICIARIOS VIVIENDA BÁSICA: SÍNTESIS DEL INFORME DE CONSULTORÍA, Instituto de la Vivienda, FAU - UCH, Santiago de Chile, Marzo de 2002.

Hasse Rodolfo y Dunowicz Renée (2005) Diseño y gestión de la vivienda social, en: Revista INVI №54, Agosto 2005, Volumen 20: 85 A, 85-103).

Hidalgo Rodrigo, Pablo Urbina, Voltaire Alvarado Peterson y Abraham Paulsen (2017) Desplazados y ¿olvidados?: contradicciones respecto de la satisfacción residencial en Bajos de Mena, Puente Alto, Santiago de Chile en: Revista INVI 32(89): 85-110, mayo de 2017.

Hidalgo, Rodrigo (1998) "La satisfacción residencial de los usuarios en los programas de vivienda social en Santiago de Chile", III Congreso de Cealc (Centro de Estudios de América Latina de Cataluña), Universidad de Vic (Barcelona), 3 y 4 de Diciembre de 1998, en: Scripta Vera, Barcelona. Disponible en: http://www.ub.edu/geocrit/sv-83.htm (Consultado el: 20 de diciembre de 2015).

Huerta, Eduardo (2016) "Consorcio ARA empaquetaría sus malls en un CKD", EL ECONOMISTA, 17 de abril 2016 Disponible en: http://eleconomista.com.mx/mercadosestadisticas/2016/04/17/consorcio-ara-empaquetaria-sus-malls-ckd (Consultado el: 18 de junio de 2017).

Instituto Nacional de Estadística y Geografía. Censo de Población y Vivienda 2010. Principales resultados por AGEB y manzana urbana.

INEGI (2011) Censo de Población y Vivienda 2010: marco conceptual / Instituto Nacional de Estadística y Geografía. México: INEGI, c2011, 189 p.

INEGI (2010) Compendio de criterios y especificaciones técnicas para la generación de datos e información de carácter fundamental, Dirección General de Geografía y Medio Ambiente, Dirección General Adjunta de Información Geográfica Básica. Disponible en: 
http://www.inegi.org.mx/inegi/SPC/doc/INTERNET/16-

\%20marco_geoestadistico_nacional.pdf (Consultado el 17 de enero de 2016).

Labastida, Gustavo. (2010). Gestión, uso y significado de la vivienda desde la perspectiva de género. Universidad Iberoamericana, Maestría en Proyectos para el Desarrollo Urbano, Seminario de desarrollo sustentable / Sociología Urbana II. Disponible en: http://www.maestriaenproyectosparaeldesarrollourbano.com/mpdu/images/PDF/Trabajosacademic os2010/sds.socurb.ivarlabastida.pdf (Consultado el 17 de enero de 2016).

Ley que Regula el Régimen de Propiedad en Condominio en el Estado De México (2002), Gaceta del Gobierno del Estado de México, publicada el 11 de abril de 2002. Disponible en: http://legislacion.edomex.gob.mx/sites/legislacion.edomex.gob. mx/files/files/pdf/gct/2002/abr113.pd $\mathrm{f}$ (Consultado el 17 de diciembre de 2017).

Maya, Esther, Jorge Cervantes y Guadalupe Martínez (2001) Evaluación de la habitabilidad de la vivienda social producida industrialmente en México, Universidad Autónoma de Yucatán. Disponible en: ww.uady.mx/.../sacEVALUACION\%20DE\%20LA\%20HABITABILIDAD. pdf (Consultado el 15 de noviembre de 2015).

Molla, Manuel (2006) El crecimiento de los asentamientos irregulares en áreas protegidas. La delegación Tlalpan, Investigaciones geográficas, (60), 83-109. Disponible en: http://www.scielo.org.mx/scielo.php?script=sci_isoref\&pid=S018846112006000200006\&lng =es\&tlng=es (Consultado el: 1 de enero de 2016).

Monterrubio. Anavel. (2014) Factores y actores para la renovación urbana del hábitat popular en barrios céntricos de la ciudad de México 1985-2006, CESOP. Pp. 463.Orozco Martínez, Yuridia, Hacia políticas de urbanización integral: Los programas de Mejoramiento de Barrios en América Latina, México, Centro de Estudios Sociales y de Opinión Pública, 2015, 25 pp.

Moyano, Emilio (1994) "Satisfacción con la vivienda en conjuntos habitacionales de cooperativas y su relación con variables del meso sistema" en: Boletín INVI № 20 ENERO 1994, año 8: 3 a $15 \mathrm{pp}$.

Naciones Unidas (2010), El derecho a una vivienda adecuada, Folleto informativo N ${ }^{\circ} 21 /$ Rev.1, Oficina del Alto Comisionado para los Derechos Humanos, Naciones Unidas. Disponible en: http://www.ohchr.org/Documents/Publications/FS21_rev_1_Housing_sp.pdf (Consultado el: 2 de diciembre de 2014)

Nieto Guzmán Ariadna. Monografía de Cuautitlán México. Trabajo realizado para la UEA Introducción a la Sociología Urbana de la Licenciatura en Sociología. UAM-Azcapotzalco.

ONU- Hábitat (2015) Reporte Nacional de Movilidad Urbana en México 2014-2015, Senado de la República y Grupo Mexicano de Parlamentarios para el Hábitat, México, pp. 100.

------ (2012) ESTADO DE LAS CIUDADES DE AMÉRICA LATINA Y EL CARIBE. Rumbo a una nueva transición urbana, Programa de las Naciones Unidas para los Asentamientos Humanos, 196 páginas.

Osorio Israel (2006) Entre industrias y fraccionamientos: el legado del desarrollo urbano-industrial en Cuautitlán, Boletín №32, Volumen 11, Archivo Histórico del Agua, Secretaría de Medio 
Ambiente y Recursos Naturales, México, págs. 5-22. Disponible en: http://132.248.9.34/hevila/Boletindelarchivohistoricodelagua/2006/vol11/no32/1.pdf (Consultado el: 18 de julio de 2016).

Pedrotti, Carolina (2015) Calidad residencial y condiciones de producción en la vivienda social promovida por el sector privado. Zona Metropolitana de Toluca, 2001-2011. Tesis doctoral, Programa de Maestría y Doctorado en Urbanismo, UNAM.

Plan de Desarrollo Urbano de Cuautitlán, 2008. Disponible en línea en: http://seduv.edomexico.gob.mx/planes_municipales/cuautitlan/PMDUCUAUTITLaN.pdf (Consultado el: 17 de julio de 2016)

Plan de Desarrollo Municipal Cuautitlán 2013-2015. Disponible en línea en: http://cuautitlan.gob.mx/contenidos/cuautitlan/pdfs/subac712165741_1.pdf (Consultado el: 17 de julio de 2016)

Pérez, Salvador. (1999). "El uso y construcción del espacio en la vivienda popular" en Gaceta de Antropología 15, articulo $07 . \quad$ Disponible en: http://www.ugr.es/ pwlac/G15_07Salvador_Perez_Ramirez.html (Consultado el 28 de noviembre de 2016).

Sánchez Corral, Javier (2012) La vivienda "social" en México Pasado- Presente - ¿Futuro?, Sistema Nacional de Creadores de Arte Emisión 2008, Agosto 20009-Julio 2012. Disponible en: http://conurbamx.com/home/wp-content/uploads/2015/05/libro-vivienda-social.pdf

Sánchez Mejorada (1996). "Vida cotidiana, vida de mujer. Roles y espacio de participación de la mujer pobre, vistos desde la vida cotidiana, en Sociológica, año 11 No. 31, Vida cotidiana y sentido común. Enfoques teóricos y aproximaciones empíricas. UAM-A.

SEDESOL (2010). Diagnóstico sobre la falta de certeza jurídica en hogares urbanos en condiciones de pobreza patrimonial en asentamientos irregulares, Disponible en: http://www.sedesol.gob.mx/work/models/SEDESOL/Sedesol/sppe/dgap/diagnostico/D_PAS PRAH_2011.pdf (Consultado el: 1 de enero de 2016).

Secretaría de Desarrollo Urbano y Metropolitano del Estado de México, Conjuntos Urbanos. Disponible en: http://portal2.edomex.gob.mx/sedur/desarrollo_habitacionales/index.htm (Consultado el: 18 de julio de 2016).

Spicker Paul, Sonia Alvarez y David Gordon (editores) (2009) Pobreza: Un glosario internacional, 1a ed. - Buenos Aires: Consejo Latinoamericano de Ciencias Sociales - CLACSO, 2009. Traducido por: Pedro Marcelo Ibarra y Sonia Alvarez Leguizamón. ISBN 978-987-1543-199

Valdeiglesias Susana y Ma. Carmen Aguilar (s/f) Psicología Ambiental. Departamento de Psicología, Universidad de Jaén. Disponible en: http://www4.ujaen.es/ spuertas/Private/Tema\%209.pdf (Consultado el: 1 de enero de 2016).

Vinuesa Julio (Director), José María de la Riva, Antonio J. Palacios (2011) El fenómeno de las viviendas desocupadas, Departamento de Geografía, Universidad Autónoma de Madrid, España. ISBN: 978-84-691-6638-3. Disponible en: http://www.uam.es/personal_pdi/filoyletras/juvian/documentos/DOC\%20Y\%20PUBLIC/2008\%20VI VIENDA\%20DESOCUPADA.pdf (Consultado el: 1 de enero de 2016). 
Mujer y satisfacción residencial. La mirada de quienes habitan en el Conjunto Urbano Rancho Santa Elena. Cuautitlán, Estado de México.

\section{ANEXO 1 CUADROS Y GRÁFICAS}

Cuadro 3. Porcentajes de la Condición de alfabetismo de la población de 15 años y más según sexo y grupos quinquenales de edad municipio de Cuautitlán, 2010

\begin{tabular}{|c|c|c|c|c|c|c|c|}
\hline \multirow{3}{*}{$\begin{array}{c}\text { Grupos } \\
\text { quinquenales } \\
\text { de edad }\end{array}$} & \multirow{3}{*}{$\begin{array}{l}\text { Población } \\
\text { total de } 15 \\
\text { años y más }\end{array}$} & \multicolumn{6}{|c|}{ Condición de alfabetismo } \\
\hline & & \multicolumn{3}{|c|}{ Alfabeta } & \multicolumn{3}{|c|}{ Analfabeta } \\
\hline & & $\begin{array}{c}\% \\
\text { Población } \\
\text { alfabeta }\end{array}$ & $\%$ Hombres & $\%$ Mujeres & $\begin{array}{c}\% \\
\text { Población } \\
\text { analfabeta }\end{array}$ & $\%$ Hombres & $\%$ Mujeres \\
\hline Total & 97,219 & 97.90 & 48.83 & 51.17 & 1.42 & 27.58 & 72.42 \\
\hline 15-19 años & 12,743 & 12.99 & 6.73 & 49.26 & 0.02 & 1.01 & 0.58 \\
\hline 20-24 años & 11,026 & 11.22 & 5.78 & 49.57 & 0.03 & 1.01 & 1.37 \\
\hline 25-29 años & 11,049 & 11.25 & 5.36 & 53.33 & 0.05 & 1.23 & 2.09 \\
\hline 30-34 años & 12,928 & 13.14 & 6.27 & 53.28 & 0.07 & 2.24 & 2.67 \\
\hline 35-39 años & 14,044 & 14.31 & 7.19 & 50.84 & 0.05 & 1.01 & 2.53 \\
\hline 40-44 años & 11,275 & 11.51 & 5.76 & 50.98 & 0.06 & 1.44 & 2.60 \\
\hline $45-49$ años & 8,017 & 8.12 & 4.18 & 49.62 & 0.09 & 1.59 & 4.84 \\
\hline 50-54 años & 5,786 & 5.80 & 2.90 & 51.04 & 0.12 & 1.73 & 6.79 \\
\hline 55-59 años & 3,593 & 3.56 & 1.81 & 50.29 & 0.12 & 2.17 & 5.92 \\
\hline 60-64 años & 2,557 & 2.44 & 1.15 & 53.72 & 0.16 & 2.02 & 9.10 \\
\hline 65-69 años & 1,636 & 1.49 & 0.76 & 50.07 & 0.17 & 3.47 & 8.23 \\
\hline 70-74 años & 1,057 & 0.89 & 0.43 & 52.47 & 0.17 & 3.18 & 8.81 \\
\hline 75-79 años & 682 & 0.56 & 0.26 & 53.94 & 0.12 & 2.38 & 6.35 \\
\hline 80-84 años & 445 & 0.36 & 0.14 & 61.30 & 0.09 & 1.59 & 4.48 \\
\hline 85 años y más & 381 & 0.26 & 0.10 & 61.66 & 0.11 & 1.52 & 6.06 \\
\hline
\end{tabular}

Nota. No se incluyen los datos de la categoría no especificado. Elaboración propia con base en INEGI Censo de Población y Vivienda 2010.

Cuadro 10. Conjuntos Urbanos ubicados en el municipio de Cuautitlán, según fecha de autorización, número de viviendas, tipo de vivienda y empresa promotora

\begin{tabular}{|c|c|c|c|c|}
\hline $\begin{array}{c}\text { Año de } \\
\text { autorización }\end{array}$ & Nombre del Conjunto & Empresa promotora & $\begin{array}{c}\text { Tipo de } \\
\text { vivienda }\end{array}$ & $\begin{array}{c}\mathbf{N}^{\circ} \text { de } \\
\text { viviendas }\end{array}$ \\
\hline 1999 & Paseos de Cuautitlán & $\begin{array}{c}\text { Empresa de servicios Ixtapa } \\
\text { S.A, de C.V. }\end{array}$ & Interés social & 388 \\
\hline 1999 & Rancho San Blas & $\begin{array}{c}\text { Desarrolladora San Blas S.A. } \\
\text { de C.V. }\end{array}$ & Interés social & 3,126 \\
\hline 1999 & Rancho Santa Elena & $\begin{array}{c}\text { Promotora de Hogares } \\
\text { ldeales S.A. de C.V. }\end{array}$ & Interés social & 6,119 \\
\hline 2003 & $\begin{array}{c}\text { Joyas de Cuautitlán } \\
\text { (Primera etapa) }\end{array}$ & $\begin{array}{c}\text { Casas BETA del Centro S.A. } \\
\text { de C.V. }\end{array}$ & Interés social & 1,448 \\
\hline 2004 & $\begin{array}{c}\text { Joyas de Cuautitlán } \\
\text { (Segunda etapa) }\end{array}$ & $\begin{array}{c}\text { Casas BETA del Centro S.A. } \\
\text { de C.V. }\end{array}$ & Interés social & 2,574 \\
\hline 2004 & $\begin{array}{c}\text { Hacienda Cuautitlán } \\
\text { (Primera etapa: 485) }\end{array}$ & $\begin{array}{c}\text { GEO Hogares Ideales, S.A. } \\
\text { DE C.V. }\end{array}$ & Interés social & 3,925 \\
\hline
\end{tabular}


Mujer y satisfacción residencial. La mirada de quienes habitan en el Conjunto Urbano Rancho Santa Elena. Cuautitlán, Estado de México.

\begin{tabular}{|c|c|c|c|c|}
\hline 2004 & Joyas de Cuautitlán II & $\begin{array}{c}\text { Casas BETA del Centro S.A. } \\
\text { de C.V. }\end{array}$ & Interés social & 242 \\
\hline 2004 & Los Olivos & $\begin{array}{c}\text { Operadora HCQC, S.A DE } \\
\text { C.V. }\end{array}$ & Popular & 190 \\
\hline 2005 & Galaxia Cuautitlán & FISARE, S.A. DE C.V. & Interés social & 2,259 \\
\hline 2005 & $\begin{array}{l}\text { La Guadalupana Cuautitlán } \\
\text { (Primera etapa) }\end{array}$ & $\begin{array}{c}\text { Inmobiliaria CAME, S.A. DE } \\
\text { C.V. }\end{array}$ & Interés social & 1,624 \\
\hline 2005 & Los Olivos II & INMCARA, S.A. DE C.V. & Popular & 300 \\
\hline 2006 & Real de San Fernando & $\begin{array}{c}\text { PRODE VIVIENDA, S.A. DE } \\
\text { C.V. }\end{array}$ & Interés social & 379 \\
\hline 2006 & Los Fresnos & $\begin{array}{l}\text { Inmbobiliaria y edificadora } \\
\text { PAMPERO, S.A. DE C.V. }\end{array}$ & Interés social & 289 \\
\hline 2006 & La Alborada (Primera etapa) & $\begin{array}{c}\text { Casas BETA del Centro S.A } \\
\text { de C.V. }\end{array}$ & $\begin{array}{c}\text { Mixto } \\
\text { (popular } \\
\text { comercial y } \\
\text { de servicio) }\end{array}$ & 1,752 \\
\hline 2007 & $\begin{array}{l}\text { La Guadalupana Cuautitlán } \\
\text { (Segunda etapa) }\end{array}$ & $\begin{array}{c}\text { Inmobiliaria CAME, S.A. DE } \\
\text { C.V. }\end{array}$ & Interés social & 639 \\
\hline 2007 & $\begin{array}{c}\text { La Alborada (Segunda } \\
\text { etapa) }\end{array}$ & $\begin{array}{c}\text { Casas BETA del Centro S.A } \\
\text { de C.V. }\end{array}$ & $\begin{array}{c}\text { Mixto } \\
\text { (popular } \\
\text { comercial y } \\
\text { de servicio) }\end{array}$ & 656 \\
\hline 2007 & $\begin{array}{c}\text { La Guadalupana Cuautitlán } \\
\text { (Tercera etapa) }\end{array}$ & $\begin{array}{c}\text { Inmobiliaria CAME, S.A. DE } \\
\text { C.V. }\end{array}$ & Interés social & - \\
\hline 2008 & La Guadalupana Cuautitlán & $\begin{array}{c}\text { Inmobiliaria CAME, S.A. DE } \\
\text { C.V. }\end{array}$ & Interés social & 115 \\
\hline 2009 & Exhacienda San Mateo & $\begin{array}{c}\text { Casas BETA del Centro S. } \\
\text { de R.L. de C.V. }\end{array}$ & $\begin{array}{c}\text { Mixto } \\
\text { (Habitacional } \\
\text { Interés } \\
\text { Social, } \\
\text { Comercial y } \\
\text { de Servicios) }\end{array}$ & 5,919 \\
\hline 2009 & Paseos del Bosque & $\begin{array}{l}\text { Proyectos Inmobiliarios de } \\
\text { Culiacán, S.A. de C.V. }\end{array}$ & $\begin{array}{l}\text { Habitacioal } \\
\text { Popular y } \\
\text { Medio }\end{array}$ & 1,490 \\
\hline 2010 & "La Toscana" & $\begin{array}{c}\text { Grupo BULMAR, S.A. de } \\
\text { C.V. }\end{array}$ & $\begin{array}{l}\text { Habitacional } \\
\text { Popular }\end{array}$ & 864 \\
\hline 2015 & Villas Xaltipa & $\begin{array}{c}\text { MM SAN ANTONIO LA ISLA, } \\
\text { S.A. DE C.V. Y GAVA } \\
\text { HOLDINGS VIVIENDA, S.A. } \\
\text { DE C.V. }\end{array}$ & Interés social & 1,418 \\
\hline
\end{tabular}

Elaboración propia con base en datos de la Secretaría de Desarrollo Urbano y Metropolitano del Estado de México. Disponible en: http://sedur.edomex.gob.mx/autorizaciones 
Mujer y satisfacción residencial. La mirada de quienes habitan en el Conjunto Urbano Rancho Santa Elena. Cuautitlán, Estado de México.

Cuadro 11. Número de personas según tipo de vivienda que ocupaban y satisfacción con la vivienda.

\begin{tabular}{|c|c|c|c|c|c|c|}
\hline & & \multicolumn{4}{|c|}{$\begin{array}{l}\text { ¿Considera que su vivienda anterior le permitía } \\
\text { Ilevar una vida de familia satisfactoria? }\end{array}$} & \multirow{2}{*}{ Total } \\
\hline & & $\begin{array}{c}\text { Muy } \\
\text { satisfactoria }\end{array}$ & Satisfactoria & $\begin{array}{c}\text { Poco } \\
\text { satisfactoria }\end{array}$ & $\begin{array}{c}\text { Nada } \\
\text { satisfactoria }\end{array}$ & \\
\hline \multirow{5}{*}{$\begin{array}{c}\text { ¿Qué tipo de } \\
\text { vivienda } \\
\text { ocupaban? }\end{array}$} & Casa independiente & 17 & 3 & 5 & 4 & 29 \\
\hline & Casa en condominio & 1 & 2 & 1 & 0 & 4 \\
\hline & Departamento en edificio & 5 & 0 & 4 & 1 & 10 \\
\hline & Vivienda en vecindad & 1 & 0 & 4 & 1 & 6 \\
\hline & Vivienda en cuarto de azotea & 0 & 0 & 0 & 1 & 1 \\
\hline \multicolumn{2}{|r|}{ Total } & 24 & 5 & 14 & 7 & 50 \\
\hline
\end{tabular}

Elaboración propia con base en los resultados de la Encuesta de Satisfacción Residencial para el Conjunto Urbano Rancho Santa Elena 2016. 
Mujer y satisfacción residencial. La mirada de quienes habitan en el Conjunto Urbano Rancho Santa Elena. Cuautitlán, Estado de México.

ANEXO 2 INSTRUMENTOS DE INVESTIGACIÓN ANEXO 2 A FICHA DE OBSERVACIÓN EN TERRENO

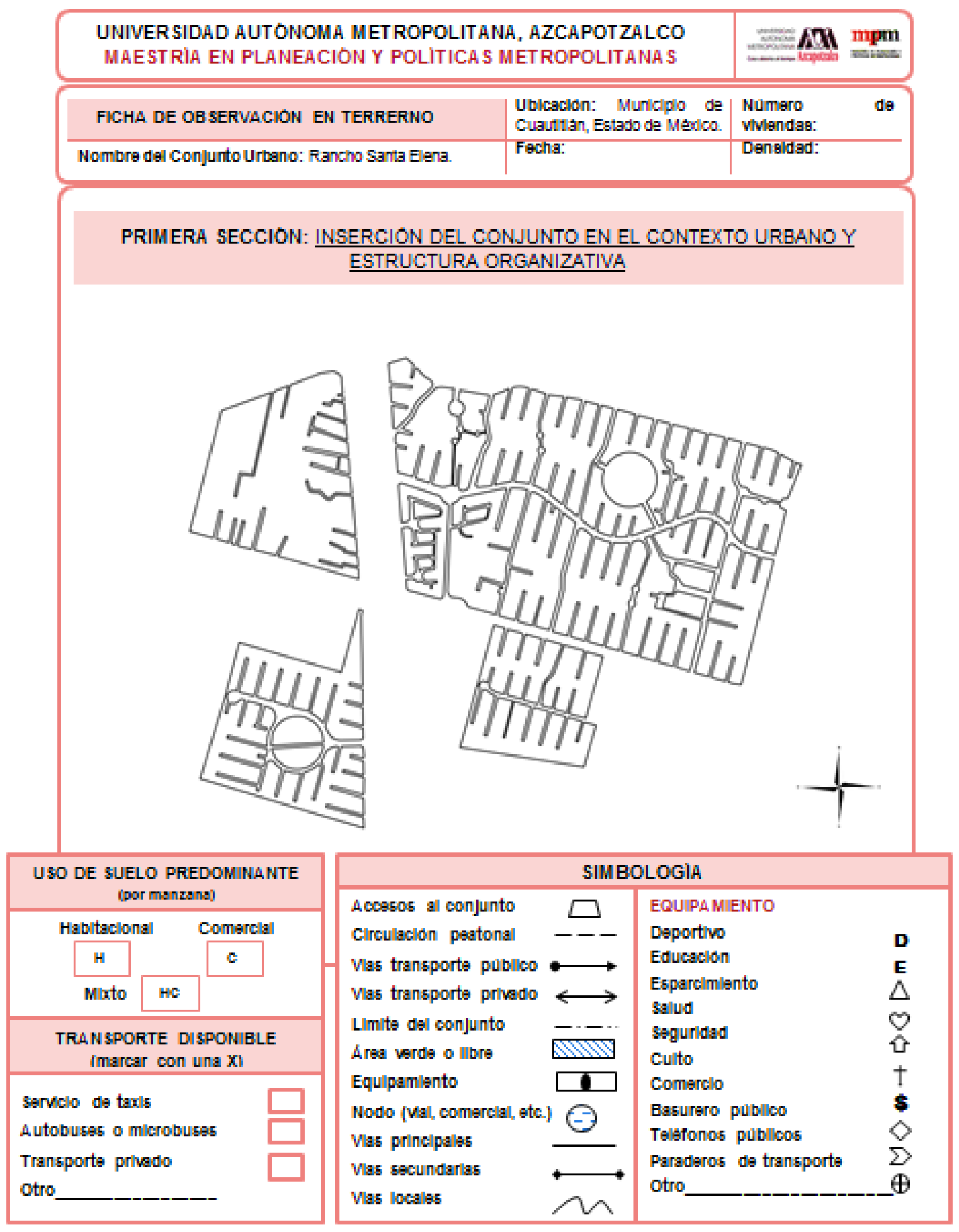


Mujer y satisfacción residencial. La mirada de quienes habitan en el Conjunto Urbano

Rancho Santa Elena. Cuautitlán, Estado de México.

\section{ANEXO 2 B ENCUESTA DE SATISFACCIÓN RESIDENCIAL PARA EL CONJUNTO URBANO RANCHO SANTA ELENA 2016}

mipm

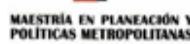

\author{
MAESTRÍA EN PLANEACIÓN Y POLÍTICAS METROPOLITANAS \\ UNIVERSIDAD AUTÓNOMA METROPOLITANA, AZCAPOTZALCO
}

ENCUESTA DE SATISFACCIÓN RESIDENCIAL

Encuesta

Número

ENERO-SEPTIEMBRE 2016

\section{DATOS DEL ENTREVISTADO}

\begin{tabular}{|c|c|c|c|c|c|c|}
\hline \multirow{3}{*}{ 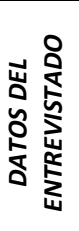 } & Dirección & \multicolumn{5}{|c|}{ Calle, número y manzana } \\
\hline & Nombre & & & & Edad & Sexo \\
\hline & $\begin{array}{c}\text { Fecha de la } \\
\text { entrevista }\end{array}$ & Día & Mes & Año & $\begin{array}{c}\text { Hora de } \\
\text { Inicio/Término }\end{array}$ & \\
\hline
\end{tabular}

Presentación. Buenos Días/tardes. Mi nombre es.

.. y soy alumna de la Universidad Autónoma Metropolitana, unidad Azcapotzalco. Estoy realizando un estudio sobre el conjunto habitacional en el que habita y para mí es muy importante que una mujer ama de casa de esta vivienda responda a esta encuesta, cuya duración máxima es de 15 minutos. Toda la información que usted me proporcione es confidencial y será procesada junto con los datos de otros vecinos como usted.

\begin{tabular}{|c|c|c|c|}
\hline P1 ¿En qué año llegó a vivir a esta vivienda? & Anotar Año & & \\
\hline \multirow{3}{*}{ P2 ¿Antes de vivir usted vivía en el mismo municipio? } & 1 & \multicolumn{2}{|l|}{ Sí } \\
\hline & 2 & \multicolumn{2}{|l|}{ Otro ¿Cuál? Anotar.... } \\
\hline & 99 & \multicolumn{2}{|l|}{ No contestó } \\
\hline \multirow{4}{*}{ P3 ¿Cómo adquirió esta vivienda? } & 1 & $\begin{array}{l}\text { Mediante un } \\
\text { crédito hipotecario }\end{array}$ & $\begin{array}{c}\text { Anotar el nombre de la Institución } \\
\text { otorgante de crédito }\end{array}$ \\
\hline & 2 & \multicolumn{2}{|l|}{ Con mis ahorros } \\
\hline & 3 & \multicolumn{2}{|c|}{ Préstamo de familiares o amigos } \\
\hline & & \multicolumn{2}{|l|}{ Otra (anotar) } \\
\hline
\end{tabular}

SECCIÓN 1. VIVIENDA ANTERIOR A continuación le preguntaré sobre su situación habitacional anterior:

\begin{tabular}{|l|c|l|}
\hline \multirow{4}{*}{$\begin{array}{l}\text { P4 ¿En su vivienda anterior ustedes eran.....? } \\
\text { (Leer alternativas) }\end{array}$} & 1 & Arrendatarios \\
\cline { 2 - 3 } & 2 & Propietarios \\
\cline { 2 - 3 } & 3 & Familiares o amigos del propietario \\
\cline { 2 - 3 } & 4 & Mi vivienda era prestada \\
\cline { 2 - 3 } & 6 & Trabajadores \\
\cline { 2 - 3 } & & Otro ¿Cuál? Anotar.... \\
\hline \multirow{3}{*}{$\begin{array}{l}\text { P5 ¿Qué tipo de vivienda ocupaban? } \\
\text { (Leer alternativas) }\end{array}$} & 98 & No sabe (No leer) \\
\cline { 2 - 3 } & 99 & No contestó (No leer) \\
\cline { 2 - 3 } & 2 & Casa independiente \\
\cline { 2 - 3 } & 3 & Casa en condominio \\
\hline
\end{tabular}




\section{Mujer y satisfacción residencial. La mirada de quienes habitan en el Conjunto Urbano}

Rancho Santa Elena. Cuautitlán, Estado de México.

\begin{tabular}{|l|l|l|}
\hline \multirow{4}{*}{} & 5 & Vivienda en cuarto de azotea \\
\cline { 2 - 3 } & 6 & Local no construido para habitación \\
\cline { 2 - 3 } & 7 & Vivienda móvil \\
\cline { 2 - 3 } & 8 & Refugio \\
\cline { 2 - 3 } & & Otra ¿Cuál? Anotar.... \\
\hline
\end{tabular}

\begin{tabular}{|c|c|c|}
\hline \multirow{3}{*}{$\begin{array}{l}\text { P6 ¿Considera que su vivienda anterior permitía a usted y su familia llevar una vida satisfactoria? (Circular } \\
\text { la respuesta del encuestado) }\end{array}$} & 1 & Muy satisfactoria \\
\hline & 2 & Poco satisfactoria \\
\hline & 3 & Nada Satisf \\
\hline
\end{tabular}

\section{SECCION 2: CARACTERÍSTICAS DE LA VIVIENDA ACTUAL}

Ahora le realizaré algunas preguntas respecto a su vivienda actual:

P7 ¿Cuántos de cada uno de los siguientes habitaciones tiene su actual vivienda? (Leer definición de "recinto", si el entrevistado evidencia incertidumbre)

\begin{tabular}{|c|c|c|c|c|}
\hline Recintos & \multicolumn{4}{|c|}{ Número } \\
\hline 1. Dormitorios independientes & 1 & 2 & 3 & 4 \\
\hline 2. Sala-comedor & 1 & 2 & 3 & 4 \\
\hline 3. Cocina de uso exclusivo & 1 & 2 & 3 & 4 \\
\hline 4. Lavadero & 1 & 2 & 3 & 4 \\
\hline 5. Baño & 1 & 2 & 3 & 4 \\
\hline 6. Taller o estudio & 1 & 2 & 3 & 4 \\
\hline 7. Patio de servicio & 1 & 2 & 3 & 4 \\
\hline Otro ¿Cuál? Anotar.... & & & & \\
\hline
\end{tabular}

P8 Además de las actividades que realiza de manera cotidiana ¿Qué otras actividades le gustaría desarrollar en su casa y que no puede por las características de su vivienda? Mencione las dos más importantes

Fiestas, asados

Comercio

Taller, manualidades

Escuchar música

Ninguna otra actividad

\section{Anotar las actividades mencionadas por el entrevistado}

1.

2.

\section{PREGUNTA}

P9 ¿Cuál de las siguientes mejoras o transformaciones ha realizado en su vivienda? (Leer alternativas. Circular cuando corresponda).

1. Pintura

MEJORAS/ TRANSFORMACIONES

2. Revestimiento de pisos

3. Revestimiento de muros (papel, pintura, mural)

4. Cambio de artefactos o cañerías de baño o cocina

5. Colocación de protecciones o rejas

6. Cambio de puertas

7. Cambio de ventanas

8. Unión de dormitorios

9. Subdivisión de dormitorios

10. Unión de cocina y patio de servicio

Otra ¿Cuál? Anotar....

P10 ¿Luego de recibida su vivienda le ha realizado ampliaciones?

P11 ¿Qué uso le da a su ampliación? (baño, terraza, recámara, jardín, cocina, etc.)

P12 ¿Por qué eligió esta vivienda?

\begin{tabular}{|c|c|}
\hline CIRCULAR \\
\hline 1 \\
\hline 1 \\
\hline 1 \\
\hline 1 \\
\hline 1 \\
\hline 1 \\
\hline 1 \\
\hline 1 \\
\hline 1 \\
\hline
\end{tabular}

2. No (Saltar a la pregunta 11)
1. Sí

Anotar respuesta

$1 \quad$ Me gustó la vivienda Me gustó el conjunto 


\section{Mujer y satisfacción residencial. La mirada de quienes habitan en el Conjunto Urbano}

Rancho Santa Elena. Cuautitlán, Estado de México.

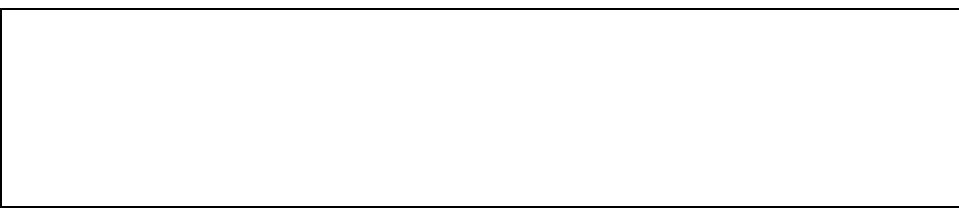

P13 ¿Qué es lo que más le gusta de su vivienda? (anotar respuesta)

\begin{tabular}{|c|}
\hline 3 \\
\hline 4 \\
\hline 5 \\
\hline 6 \\
\hline
\end{tabular}

P14 ¿Qué es lo que menos le gusta? (anotar respuesta)
Porque está cerca (trabajo esposo/escuela hijos)

Para estar cerca de mis familiares o amigos

Por el precio

Otra ¿Cuál? Anotar

\section{SECCION 3: EVALUACIÓN DE LA SATISFACCIÓN CON LA VIVIENDA}

P15 En una nota entera de 1 a 6 ¿a su juicio cómo evaluaría su satisfacción con los siguientes elementos de su vivienda en la actualidad? (Leer alternativas. Circular la nota que corresponda) (MOSTRAR Tarjeta A de equivalencia escala de notas)

\begin{tabular}{|c|c|c|c|c|c|c|}
\hline 1. Dormitorios & 1 & 2 & 3 & 4 & 5 & 6 \\
\hline 2. Sala-comedor & 1 & 2 & 3 & 4 & 5 & 6 \\
\hline 3. Cocina & 1 & 2 & 3 & 4 & 5 & 6 \\
\hline 4. Tamaño del baño & 1 & 2 & 3 & 4 & 5 & 6 \\
\hline 5. Artefactos del baño (W.C., lavamanos, regadera) & 1 & 2 & 3 & 4 & 5 & 6 \\
\hline 6. Muros & 1 & 2 & 3 & 4 & 5 & 6 \\
\hline 7. Ventanas & 1 & 2 & 3 & 4 & 5 & 6 \\
\hline 8. Iluminación & 1 & 2 & 3 & 4 & 5 & 6 \\
\hline 9. Ventilación & 1 & 2 & 3 & 4 & 5 & 6 \\
\hline 10. Puertas & 1 & 2 & 3 & 4 & 5 & 6 \\
\hline 11. Tabiques & 1 & 2 & 3 & 4 & 5 & 6 \\
\hline 12. Ubicación de recintos/cuartos & 1 & 2 & 3 & 4 & 5 & 6 \\
\hline 13. Tamaño de la vivienda & 1 & 2 & 3 & 4 & 5 & 6 \\
\hline 14. Patio & 1 & 2 & 3 & 4 & 5 & 6 \\
\hline 15. Lavadero & 1 & 2 & 3 & 4 & 5 & 6 \\
\hline
\end{tabular}

P16 Pensando en este tipo de vivienda, ¿qué cambio o cosa nueva le haría? Nombre hasta dos en orden de importancia. (No leer alternativas, respuesta espontánea. Anotar la primera mención con 1 y la segunda mención con 2)

1. Ampliaciones

2. Subdivisiones de recintos al interior de la vivienda

3. Cambio de uso de recinto al interior de la vivienda

4. Arreglo de instalaciones eléctricas

5. Arreglo de instalaciones sanitarias (baño, cocina)

6. Revestimiento de pisos

7. Revestimiento de muros

8. Cambio de ventanas y/o puertas

9. Hacer portón

10. Cambiar la ubicación del baño

P17 ¿Ha tenido algunos de estos problemas en su vivienda desde que se la entregaron? (Leer alternativas)

P18 ¿Qué tan grave han sido? (Mostrar tarjeta B. Preguntar sólo por las categorías marcadas en P17)

Códigos: 1 Muy Graves/ 2 Graves/ 3 Leves/ 4 Muy leves, insignificantes.

\begin{tabular}{|l|c|c|}
\multicolumn{1}{|c|}{ ACTIVIDAD } & $\begin{array}{c}\text { P17 } \\
\text { (CIRCULAR) }\end{array}$ & $\begin{array}{c}\text { P18 } \\
\text { (ANOTAR CÓDIGO) }\end{array}$ \\
\hline 1. Lluvia (goteras, filtraciones, humedad) & 1 & \\
\hline 2. Estructura y materiales de construcción (grietas en losas y cadenas, muros) & 1 & \\
\hline
\end{tabular}




\section{Mujer y satisfacción residencial. La mirada de quienes habitan en el Conjunto Urbano}

Rancho Santa Elena. Cuautitlán, Estado de México.

\begin{tabular}{|l|l|}
\hline 3. Instalaciones (cañerías, artefactos, llaves, desagües, funcionamiento) & 1 \\
\hline 4. Aislación acústica (se oye, hay ruidos) & 1 \\
\hline 5. Aislación térmica (frío o calor excesivo) & 1 \\
\hline 6.Terminaciones (puertas, ventanas, marcos, pisos) & 1 \\
\hline 7. lluminación natural (oscuridad) & 1 \\
\hline 8. Ventilación (olores) & 1 \\
\hline 9. Tamaño de los recintos & 1 \\
\hline 10. Instalaciones eléctricas (corto circuito, enchufes en mal estado) & 1 \\
\hline Otra ¿Cuál? Anotar.... & 1 \\
\hline
\end{tabular}

P19 ¿Considera que esta vivienda le permite llevar una vida de familia satisfactoria?

P20 ¿En general que tan satisfecho se siente con su vivienda?

\begin{tabular}{|c|l|}
\hline 1 & Sí \\
\hline 2 & No \\
\hline 98 & No sabe (No leer) \\
\hline 99 & No contestó (No leer) \\
\hline 1 & Muy satisfecho \\
\hline 2 & Poco satisfecho \\
\hline 3 & Nada satisfecho \\
\hline
\end{tabular}

SECCION 4: PERCEPCIÓN DEL ENTORNO INMEDIATO A LA VIVIENDA Y DE LOS VECINOS

A continuación le realizaré algunas preguntas sobre su vecindario, es decir el entorno inmediato a su vivienda y sobre sus vecinos más cercanos:

P21 ¿En este vecindario, se puede convivir bien con sus vecinos?

\begin{tabular}{|l|l|}
\hline 1 & Sí (Saltar a la pregunta 22) \\
\hline 2 & No \\
\hline
\end{tabular}

\begin{tabular}{|l|c|l|}
\hline \multirow{4}{*}{ P21B ¿Por qué? (preguntar, anotar) } & 1 & Demasiados chismes, vecinos mentirosos. \\
\cline { 2 - 3 } & 2 & Mucho alcoholismo. \\
\cline { 2 - 3 } & 3 & Hay demasiada drogas. \\
\cline { 2 - 3 } & 4 & Música muy fuerte, molesta. \\
\cline { 2 - 3 } & 5 & Vecinos conflictivos. \\
\cline { 2 - 3 } & 6 & La gente no se conoce \\
\cline { 2 - 3 } & & Otra ¿Cuál? Anotar.... \\
\hline
\end{tabular}

\section{SECCION 5: PERCEPCIÓN DEL CONJUNTO HABITACIONAL Y DE LA COMUNIDAD}

Piense ahora, en su conjunto habitacional, es decir en su barrio y en su forma de organización que es la comunidad:

P22 El hecho de vivir en este conjunto, lo hace sentir a usted....

(Leer alternativas)

\begin{tabular}{|l|l|}
\hline $\mathbf{1}$ & Nada orgulloso \\
\hline $\mathbf{2}$ & Poco orgulloso \\
\hline $\mathbf{3}$ & Algo orgulloso \\
\hline $\mathbf{4}$ & Muy orgulloso \\
\hline
\end{tabular}

P24 Por vivir en este conjunto, usted y su familia se siente expuesto a: (Leer alternativas. Circular si el encuestado indica que se siente expuesto a peligro).
P23 En una nota entera de 1 a 6 ¿qué nota pondría a los siguientes aspectos y elementos de su conjunto habitacional?

(Leer alternativas. Circular la nota que corresponda) (MOSTRAR Tarjeta A de equivalencia escala de notas)

\begin{tabular}{|l|c|c|c|c|c|c|}
\hline \multicolumn{1}{|c|}{ ELEMENTOS } & \multicolumn{7}{c|}{ NOTA } \\
\hline 1 Tranquilidad & 1 & 2 & 3 & 4 & 5 & 6 \\
\hline 2 Seguridad & 1 & 2 & 3 & 4 & 5 & 6 \\
\hline 3 Privacidad & 1 & 2 & 3 & 4 & 5 & 6 \\
\hline 4 Belleza & 1 & 2 & 3 & 4 & 5 & 6 \\
\hline 5 Limpieza & 1 & 2 & 3 & 4 & 5 & 6 \\
\hline
\end{tabular}

P25 ¿Usted o alguien de su casa actualmente participa en alguna de las siguientes organizaciones comunitarias que le voy a nombrar? (Leer alternativas circular según respuestas del encuestado).

P26 ¿Y antes de llegar aquí usted o alguien de su familia participaban en....? (Leer 


\section{Mujer y satisfacción residencial. La mirada de quienes habitan en el Conjunto Urbano}

Rancho Santa Elena. Cuautitlán, Estado de México.

\begin{tabular}{|c|c|}
\hline ELEMENTOS & $\begin{array}{c}\text { P26 } \\
\text { (CIRCULAR) }\end{array}$ \\
\hline 1 Agresiones sexuales & 1 \\
\hline 2 Riesgo de accidentes & 1 \\
\hline 3 Asaltos & 1 \\
\hline 4 Robos & 1 \\
\hline 5 Peleas y riñas & 1 \\
\hline 6 Alcoholismo y drogadicción & 1 \\
\hline
\end{tabular}

\begin{tabular}{|c|c|c|}
\hline ORGANIZACIÓN & $\begin{array}{c}\text { P25 } \\
\text { (ACTUALMENTE) }\end{array}$ & $\begin{array}{c}\text { P26 } \\
\text { (ANTES) }\end{array}$ \\
\hline 1 Asociación vecinal & 1 & 1 \\
\hline 2 Junta de Padres de Familia (escuela) & 1 & 1 \\
\hline 3 Iglesia & 1 & 1 \\
\hline 4 Club Deportivo & 1 & 1 \\
\hline 5 Partido Político & 1 & 1 \\
\hline 6 Junta de Vigilancia & 1 & 1 \\
\hline 7 Actividades recreativas & 1 & 1 \\
\hline Otra ¿Cuál? Anotar.... & & \\
\hline
\end{tabular}

(Si no participa actualmente en ninguna organización preguntar. Si participa en alguna organización saltar a pregunta 28)

P27 ¿Por qué usted o su familia no participan en ninguna organización?

\begin{tabular}{|l|l|}
\hline 1 & Trabaja \\
\hline 2 & No tiene tiempo \\
\hline 3 & No le llama la atención \\
\hline 4 & Hay poca organización en la comunidad \\
\hline 5 & Hay demasiados problemas o pelas entre los vecinos \\
\hline 6 & No participa para evitar problemas \\
\hline 7 & Por enfermedad \\
\hline & Otra ¿Cuál? Anotar.... \\
\hline
\end{tabular}

P28 ¿Hay algún tipo de organización en la cual usted estaría interesado en participar?

Si la respuesta es afirmativa continuar con la preguntar P28B.

\begin{tabular}{|c|l|}
\hline 1 & Sí (Continuar) \\
\hline 2 & $\begin{array}{l}\text { No (saltar a la pregunta } \\
29)\end{array}$ \\
\hline
\end{tabular}

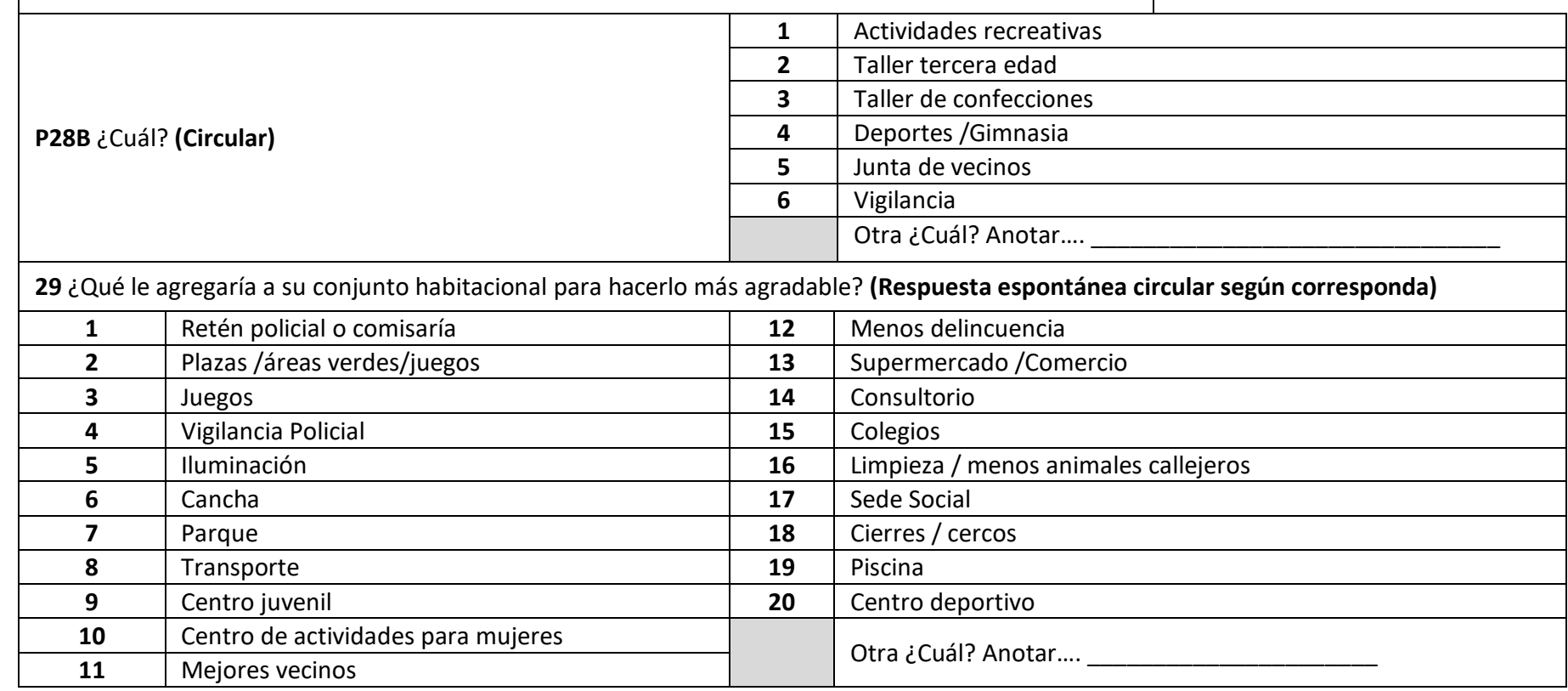

\section{SECCION 6: EVALUACIÓN DE LA SATISFACCIÓN CON EL CONJUNTO HABITACIONAL}

P30 En una nota entera de 1 a 6 ¿Cómo calificaría usted a los siguientes aspectos de su conjunto habitacional? (Leer alternativas. Circular la nota que corresponda) (MOSTRAR Tarjeta A de equivalencia escala de notas). 


\section{Mujer y satisfacción residencial. La mirada de quienes habitan en el Conjunto Urbano}

Rancho Santa Elena. Cuautitlán, Estado de México.

\begin{tabular}{|c|c|c|c|c|c|c|c|}
\hline 1. & Distancia de su casa al trabajo & 1 & 2 & 3 & 4 & 5 & 6 \\
\hline 2. & Transporte público & 1 & 2 & 3 & 4 & 5 & 6 \\
\hline 3. & Teléfonos públicos & 1 & 2 & 3 & 4 & 5 & 6 \\
\hline 4. & Comercio, almacenes, supermercados, farmacias.... & 1 & 2 & 3 & 4 & 5 & 6 \\
\hline 5. & Consultorios & 1 & 2 & 3 & 4 & 5 & 6 \\
\hline 6. & Colegios y jardines infantiles & 1 & 2 & 3 & 4 & 5 & 6 \\
\hline 7. & Bomberos & 1 & 2 & 3 & 4 & 5 & 6 \\
\hline 8. & Servicios como bancos, registro civil, pago de cuentas, trámites en general & 1 & 2 & 3 & 4 & 5 & 6 \\
\hline 9. & Vegetación en calles y pasajes & 1 & 2 & 3 & 4 & 5 & 6 \\
\hline 10. & Áreas verdes, plazas y parques & 1 & 2 & 3 & 4 & 5 & 6 \\
\hline 11. & Espacios deportivos y de recreación & 1 & 2 & 3 & 4 & 5 & 6 \\
\hline 12. & Pavimentación de calles y pasajes & 1 & 2 & 3 & 4 & 5 & 6 \\
\hline 13. & Desagüe de aguas lluvias & 1 & 2 & 3 & 4 & 5 & 6 \\
\hline 14. & Alumbrado público & 1 & 2 & 3 & 4 & 5 & 6 \\
\hline 15. & Vigilancia policial & 1 & 2 & 3 & 4 & 5 & 6 \\
\hline 16. & Condiciones ambientales, como aire, olores, ruidos, focos de peligro.... & 1 & 2 & 3 & 4 & 5 & 6 \\
\hline 17. & Basureros y servicio de recolección & 1 & 2 & 3 & 4 & 5 & 6 \\
\hline 18. & En general que nota le pone al conjunto y su entorno & 1 & 2 & 3 & 4 & 5 & 6 \\
\hline
\end{tabular}

P31 ¿Siente que el gobierno municipal se preocupa por ustedes? 1 Nada, 2) Poco 3) En ocasiones 4) Mucho

P32 ¿Siente que el gobierno municipal soluciona los problemas de su conjunto? 1) Sí, 2) No, 3) En ocasiones

Escribir

respuesta

P33 ¿Qué actividades para usted y su familia son difíciles de realizar fuera del conjunto, debido a que se encuentran distantes de su vivienda? (Respuesta abierta, anotar hasta tres alternativas).

1. 2.

3.

P34 Considerando todo lo conversado ¿qué tan satisfecho se siente de vivir en este conjunto habitacional?

\section{SECCION 7: GASTOS EN LA VIVIENDA}

P35 ¿Podría decirme qué proporción de los ingresos de la vivienda, se designan al pago de la hipoteca de la vivienda o renta?

\begin{tabular}{|l|l|}
\hline 1 Más de la mitad & 1 \\
\hline 2 Menos de la mitad & 1 \\
\hline 3 Casi todo el ingreso & 1 \\
\hline 98 No sabe (No leer) & 1 \\
\hline 99 No contestó (No leer) & 1 \\
\hline
\end{tabular}

P37 ¿Desde que se mudaron a esta vivienda aumentaron sus gastos básicos, respecto a lo que pagaba en su vivienda anterior de:

P38 ¿En relación a su permanencia en esta vivienda usted quiere...? (Leer alternativas)
P36 ¿Usted considera que el dinero que destina (o destinó) al pago es adecuado en relación a la vivienda que tiene?
Muy satisfecho Poco satisfecho Nada satisfecho 


\section{SECCION 8: COPROPIEDAD - ADMINISTRACION Y ORGANIZACION DE LOS BIENES DE LA COMUNIDAD}

Por último, le voy hacer dos preguntas sobre la Ley Condominal. Esta ley es una norma que regula el uso de las edificaciones y las áreas comunes, que los vecinos administran a través de las organizaciones comunitarias. Dichas edificaciones y áreas comunes, corresponden a circulaciones, recintos y espacios abiertos, que la comunidad de vecinos usa y comparte...

P39 ¿Usted conoce esta Ley?

P40 ¿La gente respeta la Ley en este conjunto habitacional?

P41 ¿Los vecinos se organizan de alguna manera para dar mantenimiento al conjunto habitacional?

\begin{tabular}{|l|l|l|}
\hline 1 & \multicolumn{2}{|l|}{ Sí } \\
\hline 2 & \multicolumn{2}{|l|}{ No (Saltar a la pregunta 41) } \\
\hline 1 & Sí \\
\hline 2 & No \\
\hline 1 & Si & ¿Cómo? (Anotar) \\
\hline 2 & No & \\
\hline
\end{tabular}

Finalmente le pido que por favor me conteste las siguientes preguntas sobre su grupo familiar:

\begin{tabular}{|c|c|c|c|c|c|c|}
\hline \multicolumn{5}{|c|}{ P42 ¿Cuántas personas habitan en esta vivienda actualmente? } & \multirow{2}{*}{$\begin{array}{c}\mathbf{N}^{\circ} \\
\text { Último Grado } \\
\text { de Estudios }\end{array}$} & \multirow[b]{2}{*}{$\begin{array}{l}\text { Ocupación en el } \\
\text { último mes } \\
\text { (mayores } 14 \\
\text { años) }\end{array}$} \\
\hline & Sexo & Años cumplidos & Estado Civil & $\begin{array}{c}\text { Parentesco con el } \\
\text { Jefe de Hogar }\end{array}$ & & \\
\hline \multicolumn{7}{|l|}{ Persona 1} \\
\hline \multicolumn{7}{|l|}{ Persona 2} \\
\hline \multicolumn{7}{|l|}{ Persona 3} \\
\hline \multicolumn{7}{|l|}{ Persona 4} \\
\hline \multicolumn{7}{|l|}{ Persona 5} \\
\hline \multicolumn{7}{|l|}{ Persona 6} \\
\hline \multicolumn{7}{|l|}{ Persona 7} \\
\hline \multicolumn{7}{|l|}{ Persona 8} \\
\hline \multicolumn{7}{|l|}{ Persona 9} \\
\hline Persona 10 & & & & & & \\
\hline
\end{tabular}

(Señalar a la entrevistada con un asterisco*)

Agradecimiento y Despedida: Con esto hemos terminado de responder a la encuesta, le agradezco mucho que me haya brindado parte de su tiempo.

Nota: La encuesta y el instrumento de observación de campo (disponible en el anexo 2) fueron retomados de la metodología propuesta por el INVI Chile (2002), algunas preguntas fueron modificadas para adaptarlas a los objetivos de la presente investigación. 


\section{ANEXO 2 C GUIÓN DE ENTREVISTAS EN PROFUNDIDAD}

El objetivo de esta entrevista, es conocer el grado de satisfacción de las mujeres con su vivienda, el conjunto habitacional, cómo es la relación con sus vecinos y la forma en la que se organizan para dar mantenimiento al conjunto habitacional, identificando cuáles son los factores que influyen en su opinión.

Este instrumento, consta de cuatro grupos de preguntas orientadas a conocer información sobre su vivienda anterior, su vivienda actual, las relaciones vecinales y su opinión sobre el conjunto y sus alrededores.

\section{Entrevista $\mathbf{N}^{\circ}$}

Antes de comenzar con la entrevista le voy a pedir que me proporcione algunos datos:

\begin{tabular}{|l|l|l|l|l|}
\hline Nombre & Sexo & Edad & $\begin{array}{c}\text { Tiempo de vivir en el } \\
\text { conjunto }\end{array}$ & $\begin{array}{c}\text { Número de personas que } \\
\text { integran su grupo familiar }\end{array}$ \\
\hline & & & & \\
\hline
\end{tabular}

Vamos a comenzar con la entrevista. 
1. Vivienda anterior: platíqueme por favor ¿Qué opina de su vivienda anterior? ¿Qué le gustaba y que no? ¿Qué tan satisfecha se sentía con su vivienda (Muy satisfecha, poco satisfecha, nada satisfecha) y por qué?

2. Vivienda actual: ¿Cómo llegó a vivir aquí? ¿Cómo adquirió su vivienda? ¿Por qué eligió Santa Elena? ¿Qué le gusta de su vivienda actual y qué no? ¿Qué tan satisfecha se siente con su vivienda y por qué? Si tuviera la posibilidad de mudarse de casa ¿Se cambiaría? ¿A dónde y por qué?

3. Relaciones vecinales y administración del conjunto habitacional: ¿Cómo es su relación con sus vecinos? ¿De qué manera se organizan para dar mantenimiento al conjunto? (En caso de que mencione que no hay organización, indagar por qué).

4. Sobre el Conjunto Urbano Rancho Santa Elena: ¿Qué opina del conjunto habitacional? ¿Qué actividades son difíciles de realizar para usted y su familia debido a que los espacios destinados para ellas se encuentran distantes a su vivienda? ¿Qué tan satisfecho se siente de vivir en Santa Elena? ¿Le gusta el municipio en donde se encuentra su vivienda y por qué? 
Mujer y satisfacción residencial. La mirada de quienes habitan en el Conjunto Urbano Rancho Santa Elena. Cuautitlán, Estado de México.

\section{ANEXO 3 CUADRO RESUMEN DE LAS ENTREVISTAS A PROFUNDIDAD Y DATOS DE LAS ENTREVISTADAS}

\begin{tabular}{|c|c|c|c|}
\hline Nombre & Edad & Tiempo de vivir en el conjunto & $\begin{array}{c}\text { Número de personas que } \\
\text { integran su grupo familiar }\end{array}$ \\
\hline Aurora & 46 años & 16 años & 3 personas \\
\hline Maribel & 40 años & 8 años & 5 personas \\
\hline Mónica & 47 años & 16 años & 10 personas \\
\hline Ofelia & 82 años & 16 años & 1 personas \\
\hline Rebeca & 47 años & 16 años & 4 personas \\
\hline
\end{tabular}

\begin{tabular}{|c|c|c|c|c|c|}
\hline \multirow{2}{*}{ PREGUNTA } & \multicolumn{5}{|c|}{ MUJERES ENTREVISTADAS } \\
\hline & Aurora (46 años) & Maribel (40 años) & Mónica (45 años) & Ofelia (82 años) & Rebeca (47 años) \\
\hline $\begin{array}{l}\text { 1. Vivienda anterior: } \\
\text { platíqueme por favor ¿Qué opina } \\
\text { de su vivienda anterior? ¿Qué le } \\
\text { gustaba y que no? ¿Qué tan } \\
\text { satisfecha se sentía con su } \\
\text { vivienda (Muy satisfecha, poco } \\
\text { satisfecha, nada satisfecha) y por } \\
\text { qué? }\end{array}$ & $\begin{array}{l}\text { Mi vivienda anterior era casa propia, es un } \\
\text { terreno. La casa no tiene mucho valor porque es } \\
\text { de lámina de asbesto pero el terreno... eso sí } \\
\text { vale. Lo que me gustaba de vivir ahí es que era } \\
\text { mía... bueno era mía y no, porque era de mi papá } \\
\text { y mamá pero era lo que me gustaba porque } \\
\text { cuando era niña podía jugar ahí. De hecho } \\
\text { todavía viven mi mamá y mis hermanos. } \\
\text { La casa está ubicada en Ecatepec en la colonia } \\
\text { Granjas Valle de Guadalupe o sea donde está la } \\
\text { avenida Morelos y del otro lado la avenida } \\
\text { Central, digo no están pegaditas ni están cerca } \\
\text { pero la colonia queda en medio de esas dos } \\
\text { avenidas que son las más conocidas. } \\
\text { Me gustaba mucho mi casa, pero como soltera... } \\
\text { porque para ese entonces cubría lo que yo } \\
\text { necesitaba, nada más que ya casada y con un } \\
\text { hijo ya no fue.... no es que no fuera suficiente } \\
\text { aunque mi mamá me dice que me quedó chica la } \\
\text { casa no era eso, sino que yo no iba a poder } \\
\text { lograr lo que yo quería para mi hijo estando ahí, } \\
\text { porque al ser familiares estaban mis hermanos y } \\
\text { mi mamá, mi papa ya no porque él se murió en } \\
\text { febrero y yo me casé en junio, entonces mi hijo ya } \\
\text { no lo conoció. Pero lo que yo quería para mi hijo } \\
\text { mi mamá no me lo iba a permitir, o sea de mi } \\
\text { casa a mí no me interesa el valor económico, yo }\end{array}$ & $\begin{array}{l}\text { Llegué a vivir al } \\
\text { conjunto hace } 8 \\
\text { años, antes vivíamos } \\
\text { en Naucalpan. De mi } \\
\text { vivienda anterior, no } \\
\text { me gustaba nada } \\
\text { porque era un } \\
\text { vínculo social ya muy } \\
\text { pesado, } \\
\text { drogadicción, } \\
\text { violencia, bandas... } \\
\text { Tomé la decisión de } \\
\text { venir a venir acá para } \\
\text { darles otro tipo de } \\
\text { vida social a mis } \\
\text { hijos, tengo dos } \\
\text { chicos jóvenes de } 18 \\
\text { y de } 17 \text { y la pequeña } \\
\text { de } 7 \text { años; como yo } \\
\text { crecí, yo sabía lo que } \\
\text { era vivir en ese } \\
\text { vínculo de amistades } \\
\text { o de sociedad, yo no } \\
\text { quería eso1ßåd mis } \\
\text { hijos. }\end{array}$ & $\begin{array}{l}\text { En mi casa anterior } \\
\text { teníamos tres recamaras } \\
\text { una sala comedor igual, } \\
\text { cocina, pero, vivíamos varios } \\
\text { éramos bastantes no eran } \\
\text { poquitos y este nosotros } \\
\text { teníamos cada quien pues } \\
\text { un cuarto, y era } 1,2,3,4, \\
\text { como } 6 \text { familias entonces } \\
\text { este, pero antes nada más } \\
\text { eran mis } 3 \text { hijos, y como } \\
\text { quiera que sea pues ya este } \\
\text { era menos el espacio pero } \\
\text { éramos menos, pero ya } \\
\text { después este, adquirió mi } \\
\text { esposo esta casa, entonces } \\
\text { por eso nos cambiamos. }\end{array}$ & $\begin{array}{l}\text { Tengo } 16 \text { años viviendo aquí, } \\
\text { cuando empezó Santa Elena. } \\
\text { Que no había nada aquí, ni } \\
\text { tortillas ni nada... yo le } \\
\text { preguntaba a una señora joiga! } \\
\text { ¿Qué aquí no hay nada? Y me } \\
\text { dijo -iNo señora, aquí no hay } \\
\text { nada tiene que ir al pueblito o al } \\
\text { mercado negro! Mi hijo me tenía } \\
\text { que traer las tortillas del Distrito, } \\
\text { aquí llegamos a sufrir un poco. } \\
\text { Yo antes vivía cerca de la } \\
\text { avenida México en un parque } \\
\text { que está muy grande, ahí viví } \\
\text { como } 60 \text { años. Todo era muy } \\
\text { tranquilo, todavía vivía mi esposo } \\
\text { que en paz descanse; si yo } \\
\text { tuviera dinero me regresaba al } \\
\text { Distrito con los ojos cerrados } \\
\text { porque aquí la gente es muy } \\
\text { problemática. Allá en el Distrito } \\
\text { vivía en un departamentito, todo } \\
\text { encontraba por allá y nunca me } \\
\text { perdí; aunque la colonia ha } \\
\text { cambiado porque hace } 15 \text { días } \\
\text { fui a una comida con mis hijos y } \\
\text { me enteré de que en la tienda }\end{array}$ & $\begin{array}{l}\text { Antes de vivir aquí, vivíamos en } \\
\text { Tlalnepantla en casa de mis } \\
\text { papás... era un poco incómodo } \\
\text { porque éramos } 4 \text { personas } \\
\text { viviendo en un cuarto que tiene } \\
\text { mi papá en su casa y aunque } \\
\text { pues es un cuarto grande y } \\
\text { teníamos cocina y baño } \\
\text { independientes a la casa de mi } \\
\text { papá pues no dejaba de ser un } \\
\text { cuarto. El techo era de lámina y } \\
\text { cuando hacía calor parecía } \\
\text { sauna, todo el calor se encerraba } \\
\text { y pues si llovía era muy } \\
\text { escandaloso, teníamos que } \\
\text { subirle a la tele para escuchar } \\
\text { porque con la lámina hacía } \\
\text { mucho ruido. }\end{array}$ \\
\hline
\end{tabular}


Mujer y satisfacción residencial. La mirada de quienes habitan en el Conjunto Urbano Rancho Santa Elena. Cuautitlán, Estado de México.

\begin{tabular}{|c|c|c|c|c|c|}
\hline & lo quería para vivir y punto. & & & $\begin{array}{l}\text { Naval donde antes vendían } \\
\text { puras cosas españolas ya } \\
\text { venden de todo hasta frijoles y } \\
\text { jergas (se ríe); porque todo lo } \\
\text { que viene de España es muy } \\
\text { caro. Todo se extraña, porque } \\
\text { todo se encuentra... ahí nacieron } \\
\text { mis hijos, ahí se criaron pero } \\
\text { pues ni modo, aquí estaremos } \\
\text { hasta que Dios nos tenga con } \\
\text { vida. }\end{array}$ & \\
\hline $\begin{array}{l}\text { 2. Vivienda actual: ¿Cómo } \\
\text { llegó a vivir aquí? ¿Cómo } \\
\text { adquirió su vivienda? ¿Por qué } \\
\text { eligió Santa Elena? ¿Qué le } \\
\text { gusta de su vivienda actual y qué } \\
\text { no? ¿Qué tan satisfecha se } \\
\text { siente con su vivienda y por qué? } \\
\mathrm{Si} \text { tuviera la posibilidad de } \\
\text { mudarse de casa ¿Se } \\
\text { cambiaría? ¿A dónde y por qué? }\end{array}$ & $\begin{array}{l}\text { Exactamente aquí no, tenía idea de que iba a ser } \\
\text { aquí... pero por presiones de la mamá de mi } \\
\text { esposo porque él se va a vivir a donde me dejó } \\
\text { mi mamá, entonces su mamá sentía que él } \\
\text { estaba manteniendo a mi mamá y a todos mis } \\
\text { hermanos, cosa que no era cierto porque yo no } \\
\text { iba a permitir -se ríe- pero bueno su mamá lo } \\
\text { presionó para que pagara renta, entonces yo iba } \\
\text { a permitir que él pagara renta teniendo casa yo } \\
\text { con mi mamá y el con su mamá... entonces él me } \\
\text { dice ¿y si sacó el crédito del INFONAVIT? Y que } \\
\text { le digo ¿tú tienes derecho a eso? Y que me } \\
\text { contesta que sí... entonces le digo ihazlo! Y me } \\
\text { pregunta pero ¿si te irías a vivir conmigo? Y le } \\
\text { contestó pues claro que sí. } \\
\text { Y de ahí metió los papeles, hizo los trámites y } \\
\text { todo... se lo dieron y ya fue como compró la casa, } \\
\text { pero en sín no conocíamos el lugar. Andábamos } \\
\text { en la López Portillo [la avenida] y nos fuimos a } \\
\text { meter a las oficinas de GEO porque su mamá } \\
\text { primero lo mandó a los Héroes de Ecatepec, pero } \\
\text { llegamos y le dije jno!, esta casa está demasiado } \\
\text { chiquita para nosotros y en entonces no } \\
\text { pensábamos sólo tener un hijo, bueno ya lo } \\
\text { teníamos, pero todavía había planes de otro, } \\
\text { entonces le dije [se refiere a su esposo] no está } \\
\text { demasiado pequeña, no me gustó y dije ino y no! } \\
\text { Entonces después [su suegra] nos mandó a Villas } \\
\text { de San José... ahí vamos a ver la casa y nunca } \\
\text { encontramos la casa, ni quien nos diera razón ni } \\
\text { nada -se ríe-, nos regresamos a la López Portillo } \\
\text { y nos metimos a las oficinas de GEO y ahí ya } \\
\text { hizo el trámite y ahí compramos la casa y ahí fue } \\
\text { todo, pero sin saber dónde era. El trámite creo yo } \\
\text { que fue demasiado sencillo, muy fácil... después } \\
\text { ya que llegué aquí me enteré que no era fácil } \\
\text { pero ya que estaba yo aquí con la casa y todo me } \\
\text { enteré que no era un trámite sencillo... ¿por qué } \\
\text { se nos dio fácil?, no tengo la mejor idea. Y no } \\
\text { conocíamos aquí, de hecho ya habíamos firmado, } \\
\text { ya nos iban a entregar la casa y un compañero } \\
\text { del trabajo le dio a mi esposo un pequeño croquis }\end{array}$ & $\begin{array}{l}\text { Mi papá compró esta } \\
\text { casa con su crédito y } \\
\text { pues yo me vine a } \\
\text { vivir aquí; cuando } \\
\text { llegamos apenas se } \\
\text { estaban detonando } \\
\text { los problemas, pero } \\
\text { al principio todo } \\
\text { estaba bien. } \\
\text { A mí las casas se me } \\
\text { hacen muy } \\
\text { pequeñas... para } \\
\text { empezar la sociedad } \\
\text { no la puedes } \\
\text { cambiar, vienen con } \\
\text { su cultura y su } \\
\text { educación, tienes } \\
\text { que adaptarte a } \\
\text { veces a las cosas, de } \\
\text { ahí en fuera ya está } \\
\text { muy feo, aquí Santa } \\
\text { Elena ya está feo }\end{array}$ & $\begin{array}{l}\text { La casa era de mis suegros, } \\
\text { entonces éramos varios, } \\
\text { entonces por eso ya también } \\
\text { él hizo por comprar esta } \\
\text { vivienda, para que nosotros } \\
\text { estuviéramos mejor. Al } \\
\text { principio nos gustaba porque } \\
\text { por lo menos ya no éramos } \\
\text { tantos en la misma casa, } \\
\text { pero pues a lo mejor ahorita } \\
\text { si te pesa un poco porque a } \\
\text { lo mejor nosotros con otro } \\
\text { cuarto pues si la haríamos } \\
\text { un poquito más; pero pues } \\
\text { no tenemos lo } \\
\text { económicamente necesario } \\
\text { para poder hacer todo esto. }\end{array}$ & $\begin{array}{l}\text { Yo me vine a vivir para acá } \\
\text { porque era conserje de un } \\
\text { edificio y llegó el momento en } \\
\text { que me cansé y que ya no podía } \\
\text { y dejé el trabajo, me liquidaron y } \\
\text { todo. Entonces yo tuve que } \\
\text { pensar en qué rumbo iba a } \\
\text { agarrar y mi hija la que falleció, } \\
\text { que en paz descanse porque } \\
\text { murió de cáncer... ella me dijo } \\
\text { mamá ahí está la casa si quieres } \\
\text { vete para allá, pero yo ni conocía } \\
\text { este lugar (se ríe) y ya me trajo y } \\
\text { me dijo -mira mamá esta es la } \\
\text { casa, nosotros no nos vamos a } \\
\text { venir a vivir aquí- pero en ese } \\
\text { entonces creo que les metieron } \\
\text { la casa a fuerza en el trabajo y } \\
\text { aquí estoy, aquí me tocó vivir } \\
\text { hasta que Dios quizás me recoja. }\end{array}$ & $\begin{array}{l}\text { nos venimos a vivir para acá, } \\
\text { gracias a mi mamá porque antes } \\
\text { de fallecer me dejó un dinerito y } \\
\text { me hizo prometerle que lo iba a } \\
\text { utilizar para salirme de ahi... yo } \\
\text { ya sabía que en cuanto mi mamá } \\
\text { muriera los pelitos con mis } \\
\text { hermanas iban a ser más graves } \\
\text { y mi papá siempre tuvo un } \\
\text { carácter horrible, así que un día } \\
\text { un amigo de mi esposo que vivía } \\
\text { en Melchor Ocampo le dijo que } \\
\text { viviéramos a ver las casas y pues } \\
\text { no estaban tan mal, todavía } \\
\text { estaban terminando de construir } \\
\text { y sólo vimos la maqueta que nos } \\
\text { enseñó GEO, años después nos } \\
\text { daríamos cuenta de que el } \\
\text { fraccionamiento no era como lo } \\
\text { habían prometido, pero pues ya } \\
\text { qué podemos hacer ya estamos } \\
\text { aquí. }\end{array}$ \\
\hline
\end{tabular}


Mujer y satisfacción residencial. La mirada de quienes habitan en el Conjunto Urbano Rancho Santa Elena. Cuautitlán, Estado de México.

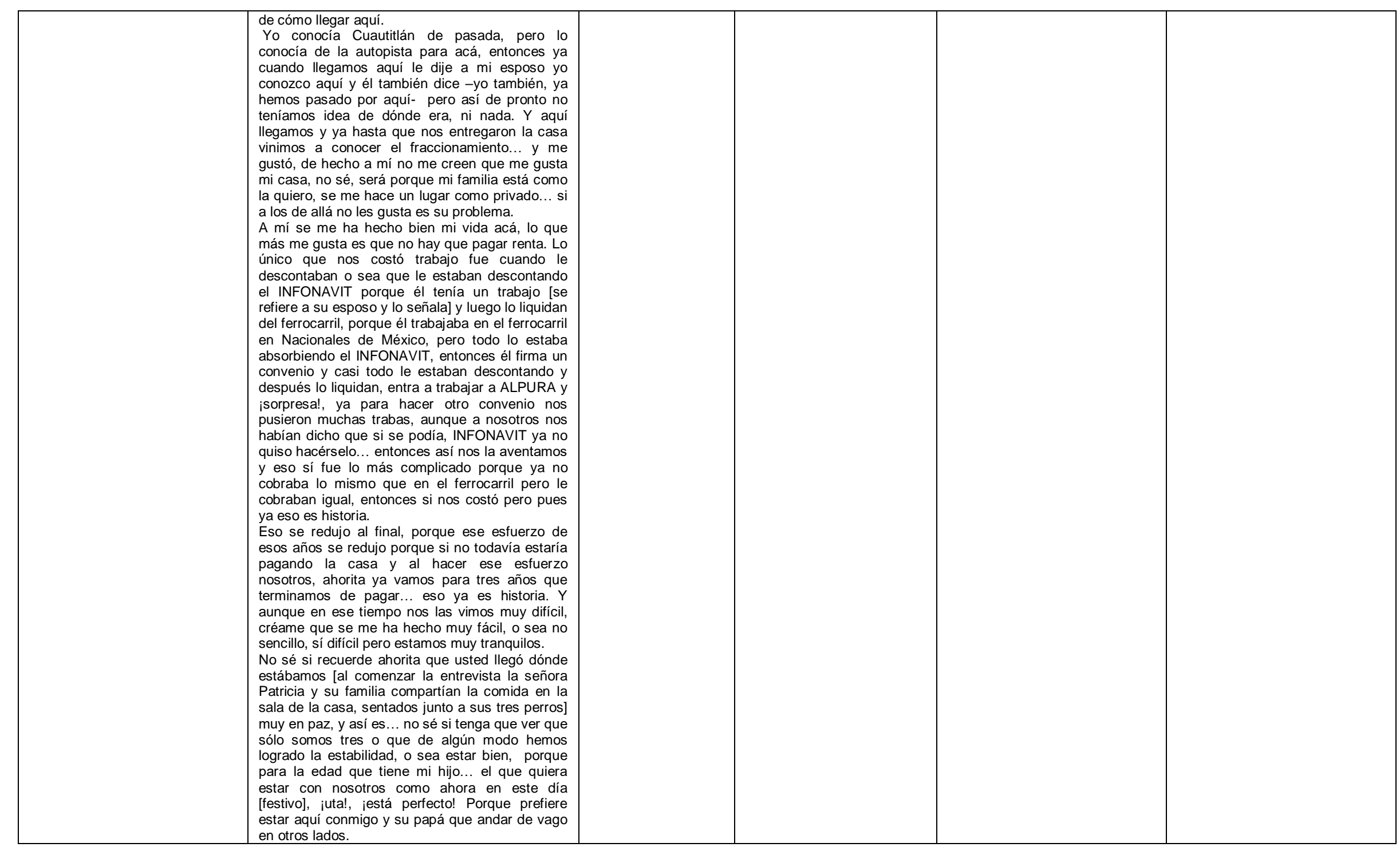


Mujer y satisfacción residencial. La mirada de quienes habitan en el Conjunto Urbano Rancho Santa Elena. Cuautitlán, Estado de México.

\begin{tabular}{|c|c|c|c|c|c|}
\hline $\begin{array}{l}\text { 3. Relaciones vecinales y } \\
\text { administración del conjunto } \\
\text { habitacional: ¿Cómo es su } \\
\text { relación con sus vecinos? ¿De } \\
\text { qué manera se organizan para } \\
\text { dar mantenimiento al } \\
\text { conjunto? (En caso de que } \\
\text { mencione que no hay } \\
\text { organización, indagar por qué). }\end{array}$ & 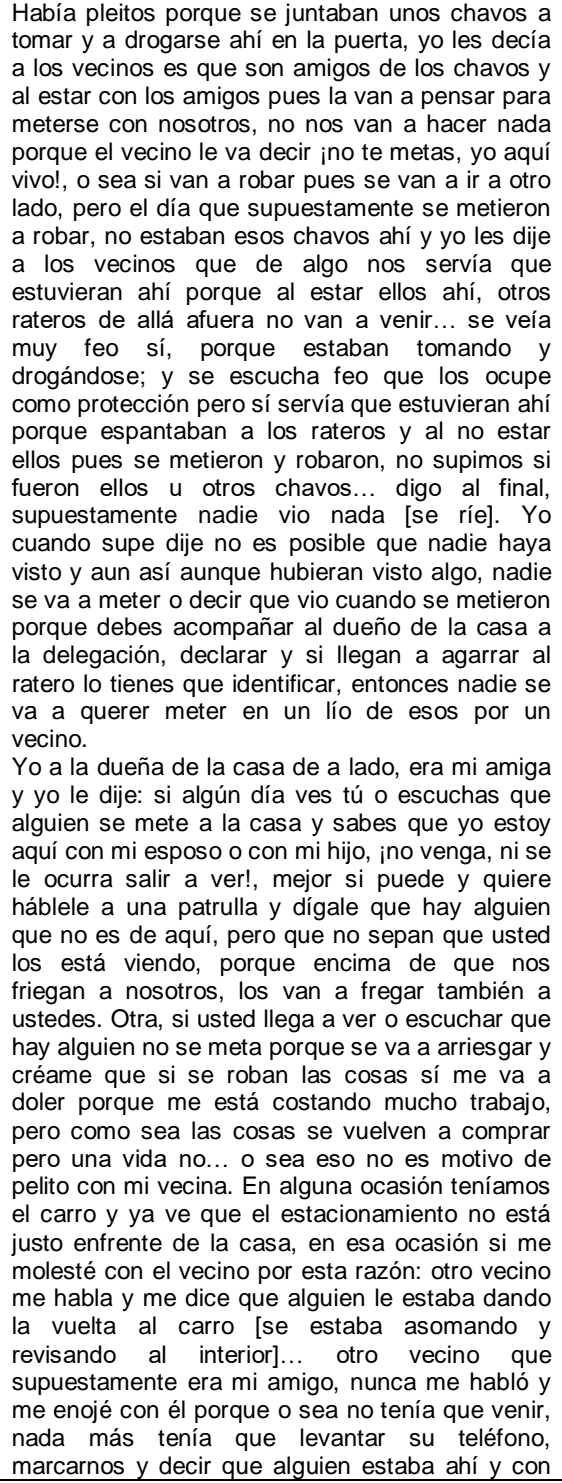 & $\begin{array}{l}\text { Convivir con los } \\
\text { vecinos es difícil } \\
\text { porque tenemos } \\
\text { diferentes } \\
\text { costumbres, es } \\
\text { cuestión de cultura }\end{array}$ & $\begin{array}{l}\text { A veces te digo que te } \\
\text { sientes bien, pero ya cuando } \\
\text { ves que hay problemas o } \\
\text { cualquier cosa, dices tú pues } \\
\text { me quisiera ir de aquí. } \\
\text { Porque hay muchos } \\
\text { conflictos porque la gente } \\
\text { cree que porque no está el } \\
\text { papá de mis hijo luego cree } \\
\text { que los va a mandar, osea } \\
\text { no porque como yo les he } \\
\text { dicho, tengo cosas más } \\
\text { importantes que hacer ¿no?, } \\
\text { Y hay otras que creen que } \\
\text { por él, según ellas, por la } \\
\text { manera de ser tienen dinero, } \\
\text { creo que si la gente tuviera } \\
\text { dinero no estaríamos } \\
\text { viviendo aquí, creo que } \\
\text { tuviéramos una casa, y } \\
\text { donde nadie nos molestara, } \\
\text { entonces cuando se meten } \\
\text { con los niños, o sea, ya es } \\
\text { cuando ahí si me molesta } \\
\text { mucho, y me enoja bastante, } \\
\text { y más cuando se meten con } \\
\text { mi niña, eso es muy molesto } \\
\text { y entonces te digo no estas } \\
\text { para saberlo pero aquí } \\
\text { tuvieron todos a comer la } \\
\text { mayoría de aquí, cuando yo } \\
\text { estaba bien yo les ayudaba, } \\
\text { y ahora ya se ponen en su } \\
\text { plan y yo como les he dicho } \\
\text { a mi nada más respeten a } \\
\text { mis niños, no les pido más, } \\
\text { la verdad no les pido más, } \\
\text { entonces a veces creen que } \\
\text { por verte en esa situación } \\
\text { creen que te pueden } \\
\text { pisotear. }\end{array}$ & $\begin{array}{l}\text { Aquí estoy tranquila porque } \\
\text { como no me molesta nadie ni yo } \\
\text { molesto a nadie, luego mis } \\
\text { pleitos son por mis plantitas que } \\
\text { ya ni tengo porque me las han } \\
\text { acabado los chamacos, estoy } \\
\text { tranquila porque hasta ahorita } \\
\text { todo bien. Con mis vecinos nada } \\
\text { más de -ibuenos días y buenos } \\
\text { días!, pero nada de que yo me } \\
\text { salga a platicar. Con la única que } \\
\text { tenía yo muy buena amistad era } \\
\text { con Chonita que vivía aquí } \\
\text { adelantito y que en paz } \\
\text { descanse, falleció ya también; y } \\
\text { hasta ahí se acabó mi amistad y } \\
\text { como éramos las dos iguales } \\
\text { viejitas yo creo que por eso nos } \\
\text { llevábamos bien. }\end{array}$ & $\begin{array}{l}\text { Al principio estaba feliz con mi } \\
\text { casa, aún lo tengo mucho cariño } \\
\text { no sólo porque fue como un } \\
\text { regalo de mi mamá, sino por el } \\
\text { trabajo que nos costó hacernos } \\
\text { de ella. Incluso ya andamos } \\
\text { viendo si nos cambiamos porque } \\
\text { los problemas con los vecinos } \\
\text { muchos y el ambiente es horrible, } \\
\text { hay mucha inseguridad y todo... } \\
\text { lo único que me frena un poco es } \\
\text { el cariño que le tengo a mi casa, } \\
\text { pero aun así nos vamos a ir en } \\
\text { cuento podamos. }\end{array}$ \\
\hline
\end{tabular}


Mujer y satisfacción residencial. La mirada de quienes habitan en el Conjunto Urbano Rancho Santa Elena. Cuautitlán, Estado de México.

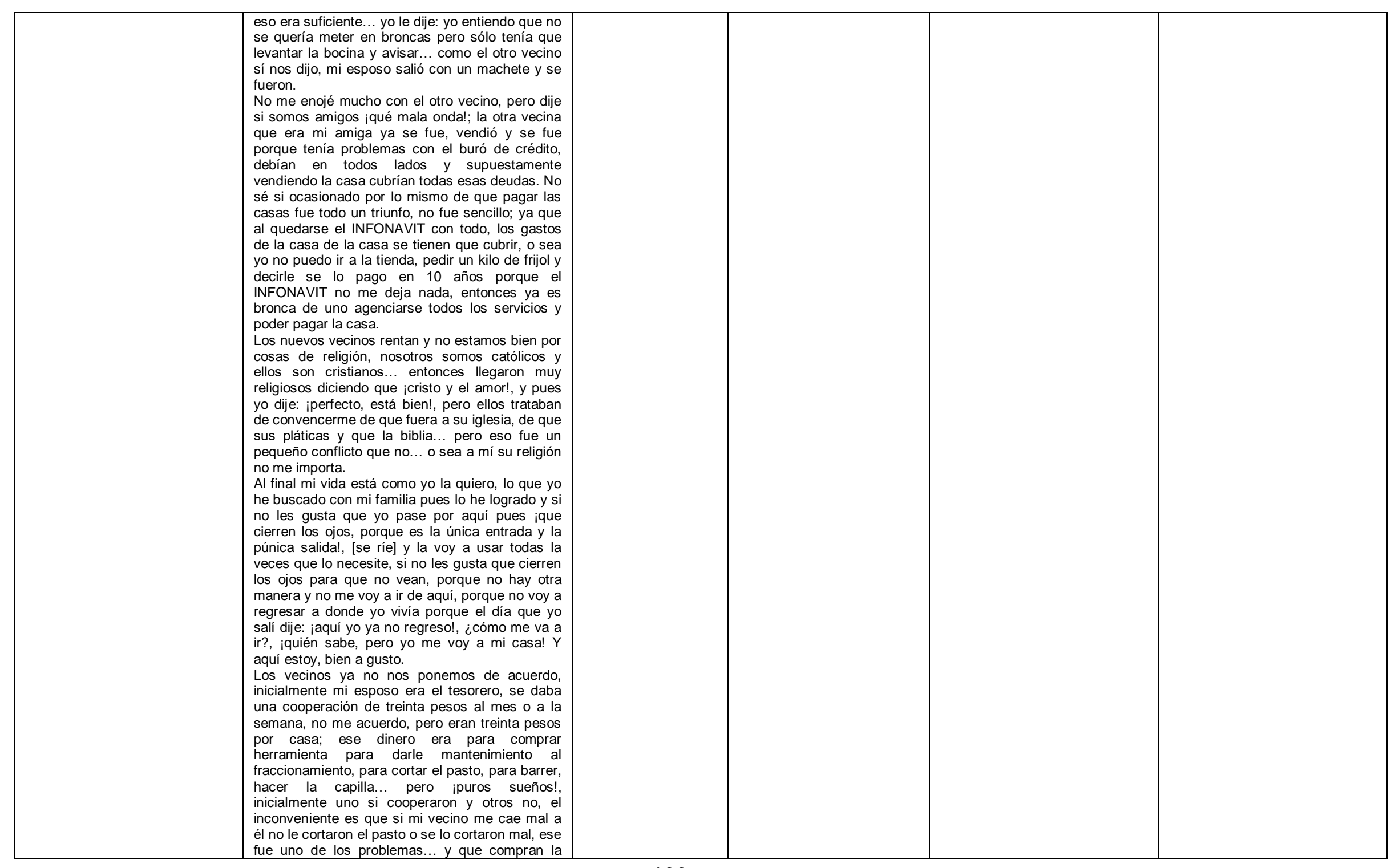


Mujer y satisfacción residencial. La mirada de quienes habitan en el Conjunto Urbano Rancho Santa Elena. Cuautitlán, Estado de México.

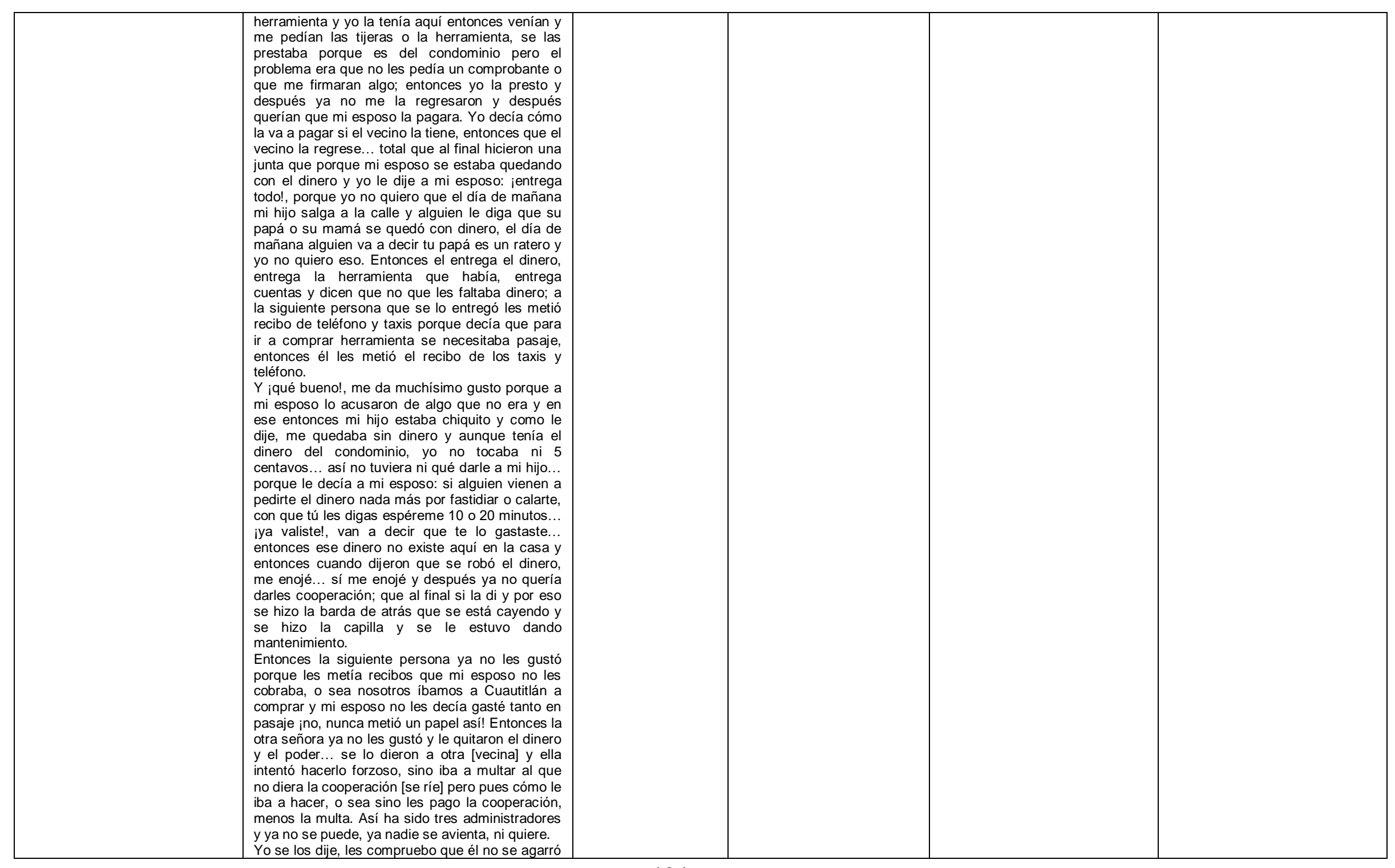


Mujer y satisfacción residencial. La mirada de quienes habitan en el Conjunto Urbano Rancho Santa Elena. Cuautitlán, Estado de México.

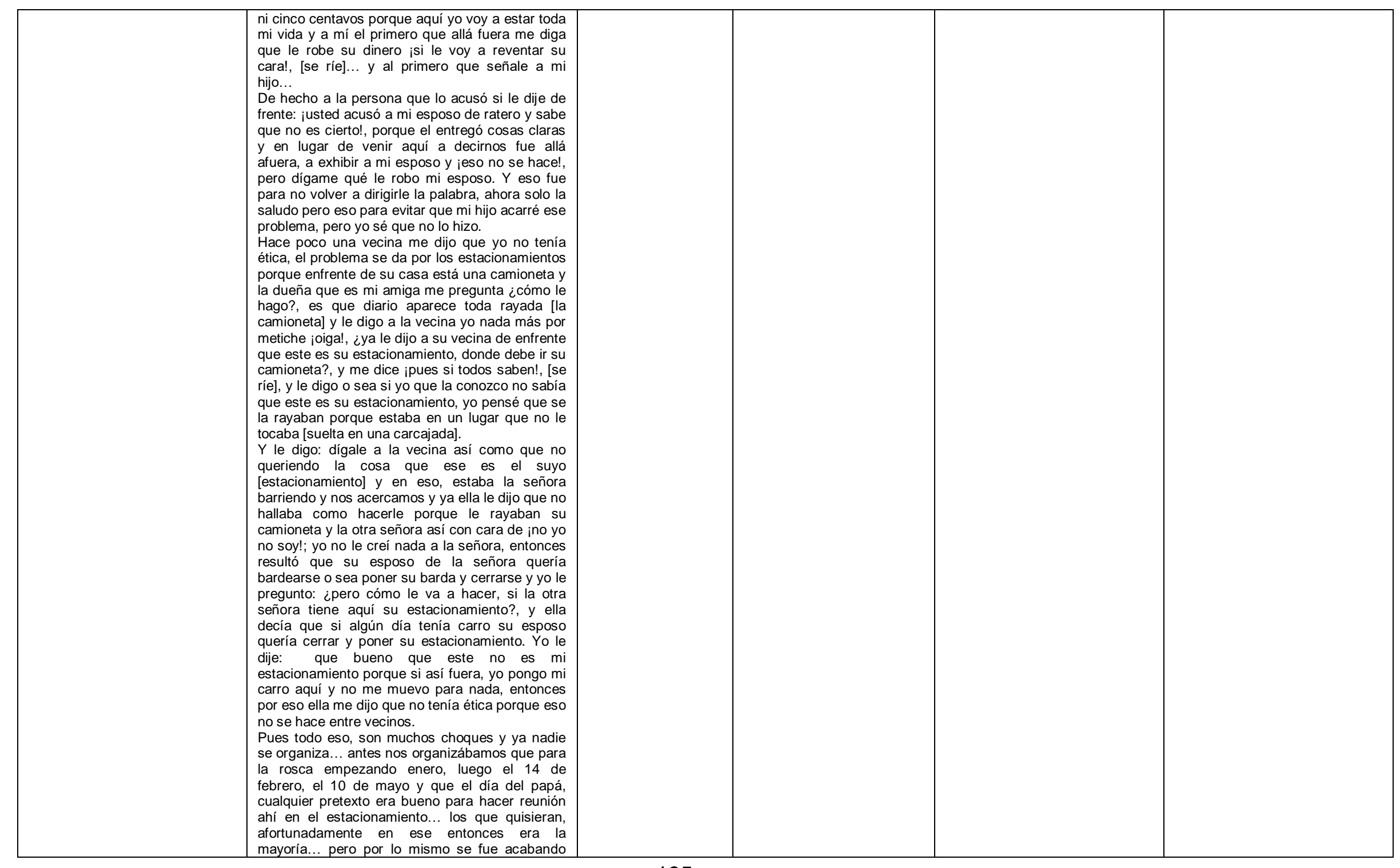


Mujer y satisfacción residencial. La mirada de quienes habitan en el Conjunto Urbano Rancho Santa Elena. Cuautitlán, Estado de México.

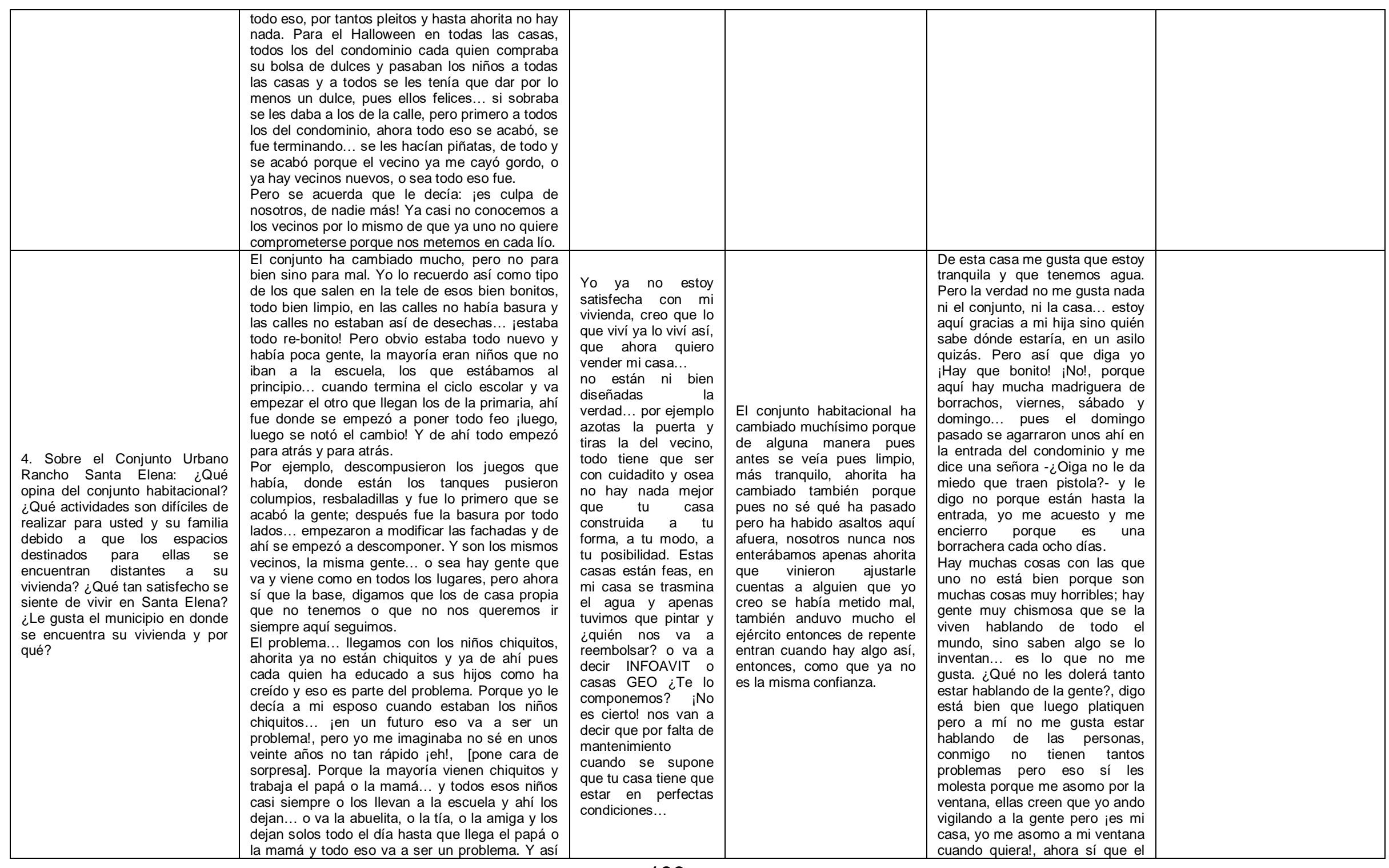




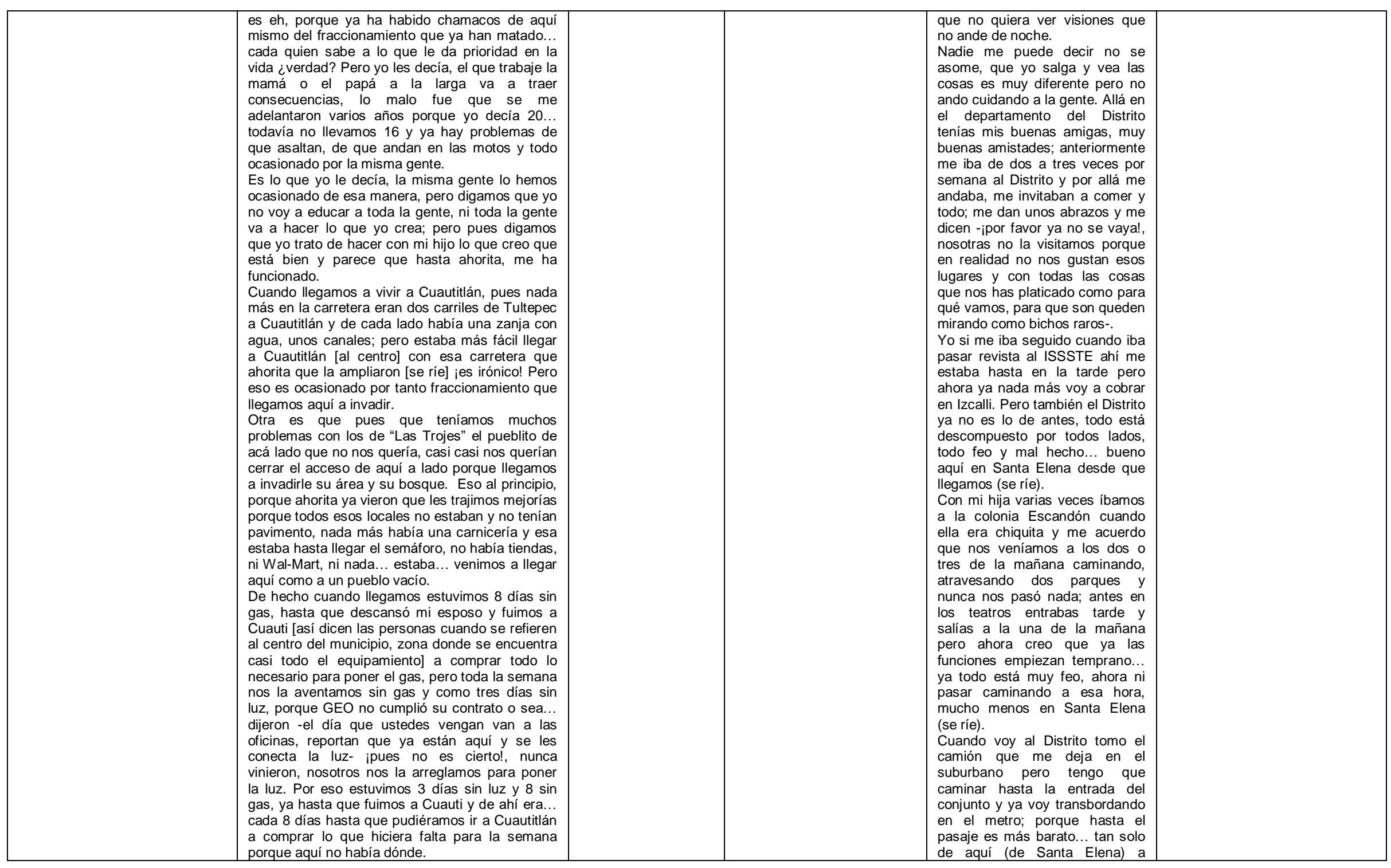




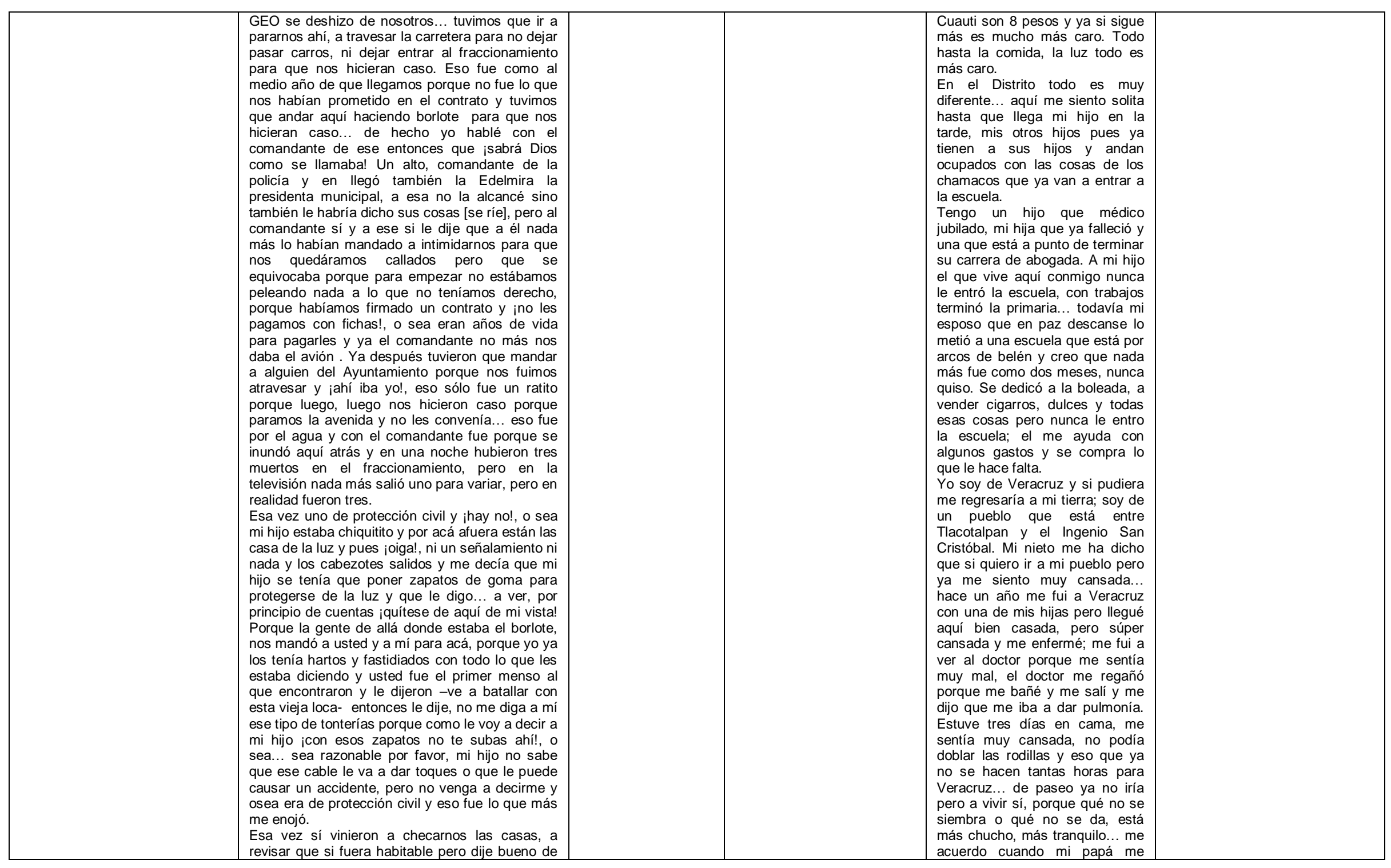




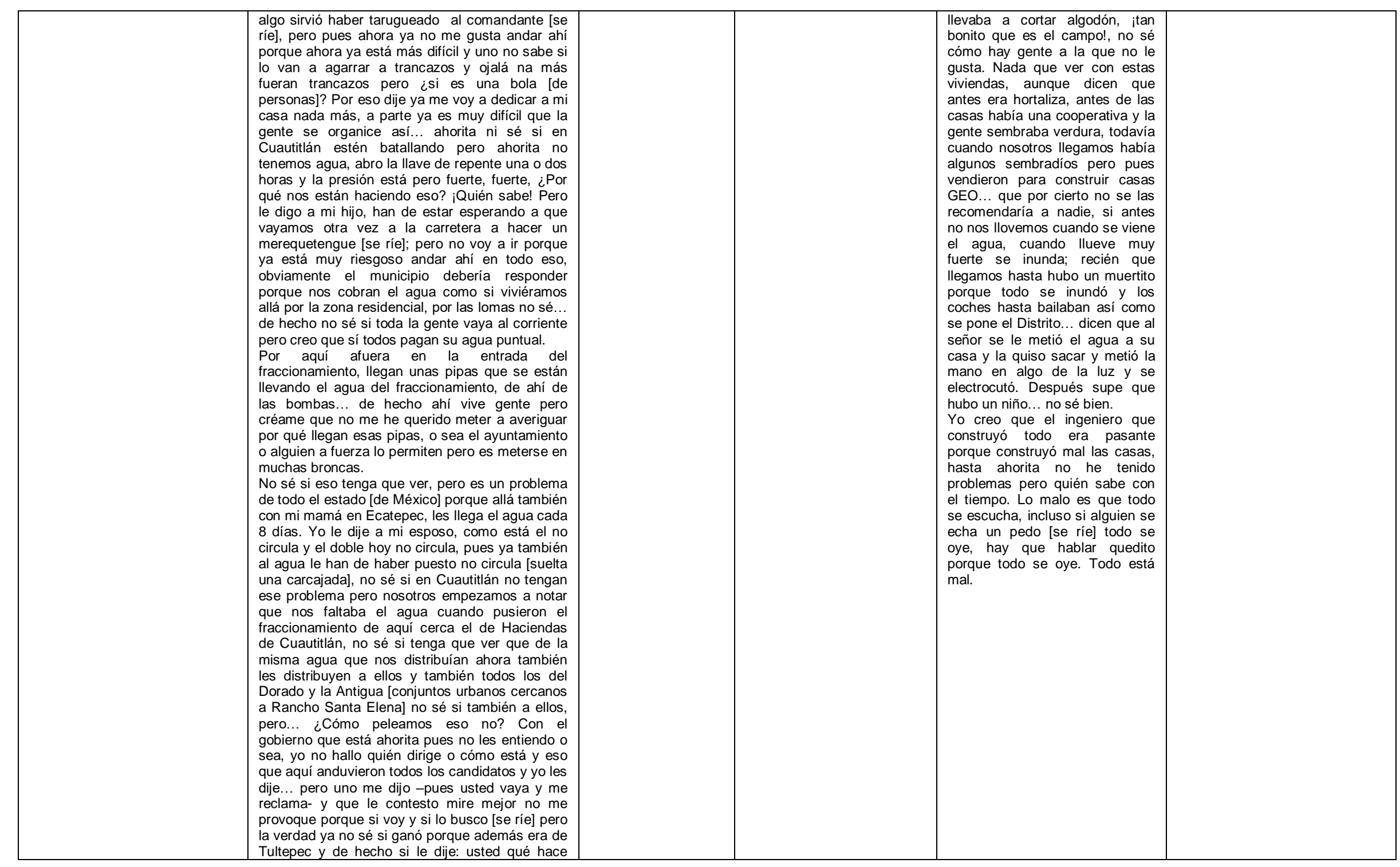


Mujer y satisfacción residencial. La mirada de quienes habitan en el Conjunto Urbano Rancho Santa Elena. Cuautitlán, Estado de México.

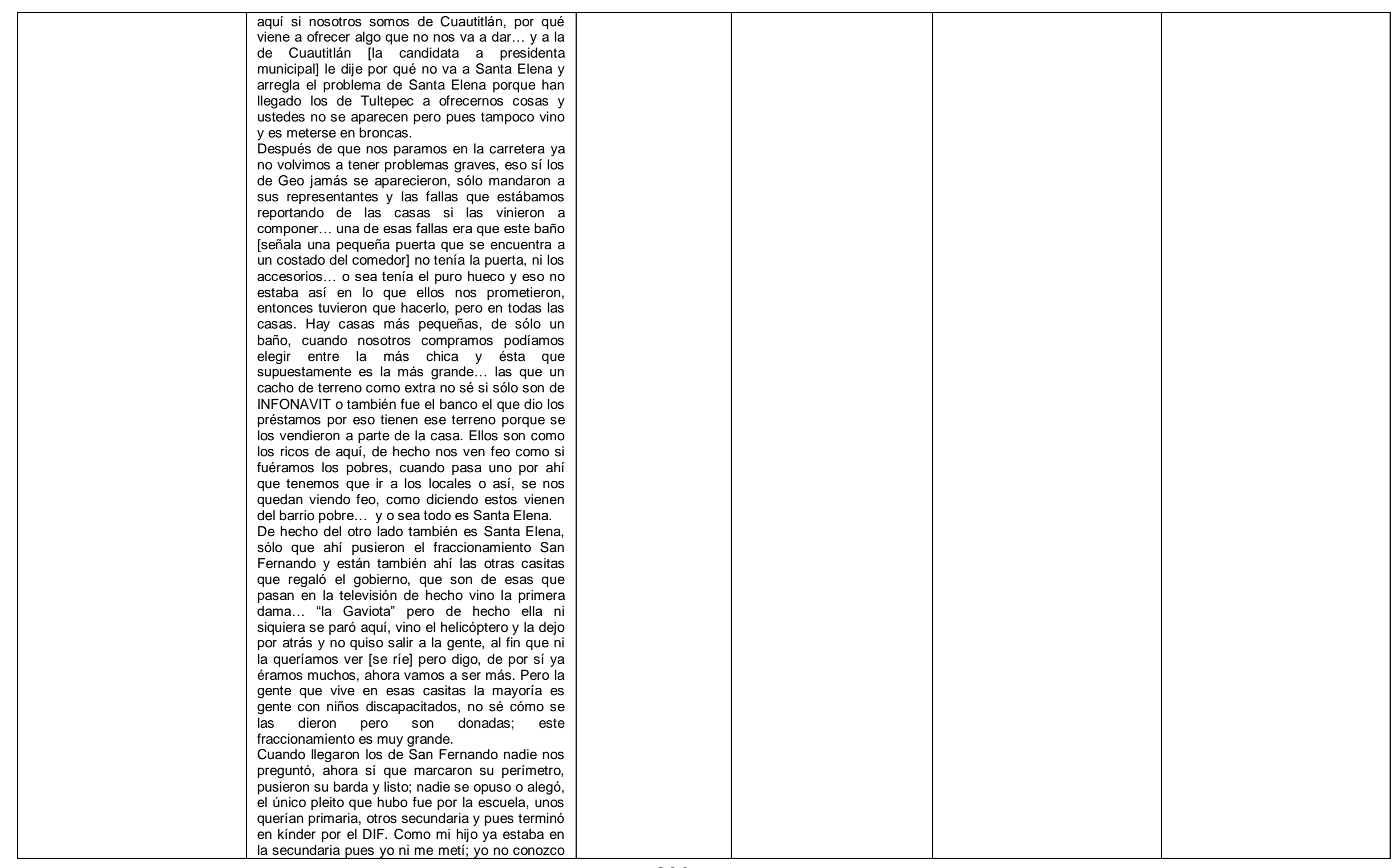


Mujer y satisfacción residencial. La mirada de quienes habitan en el Conjunto Urbano Rancho Santa Elena. Cuautitlán, Estado de México.

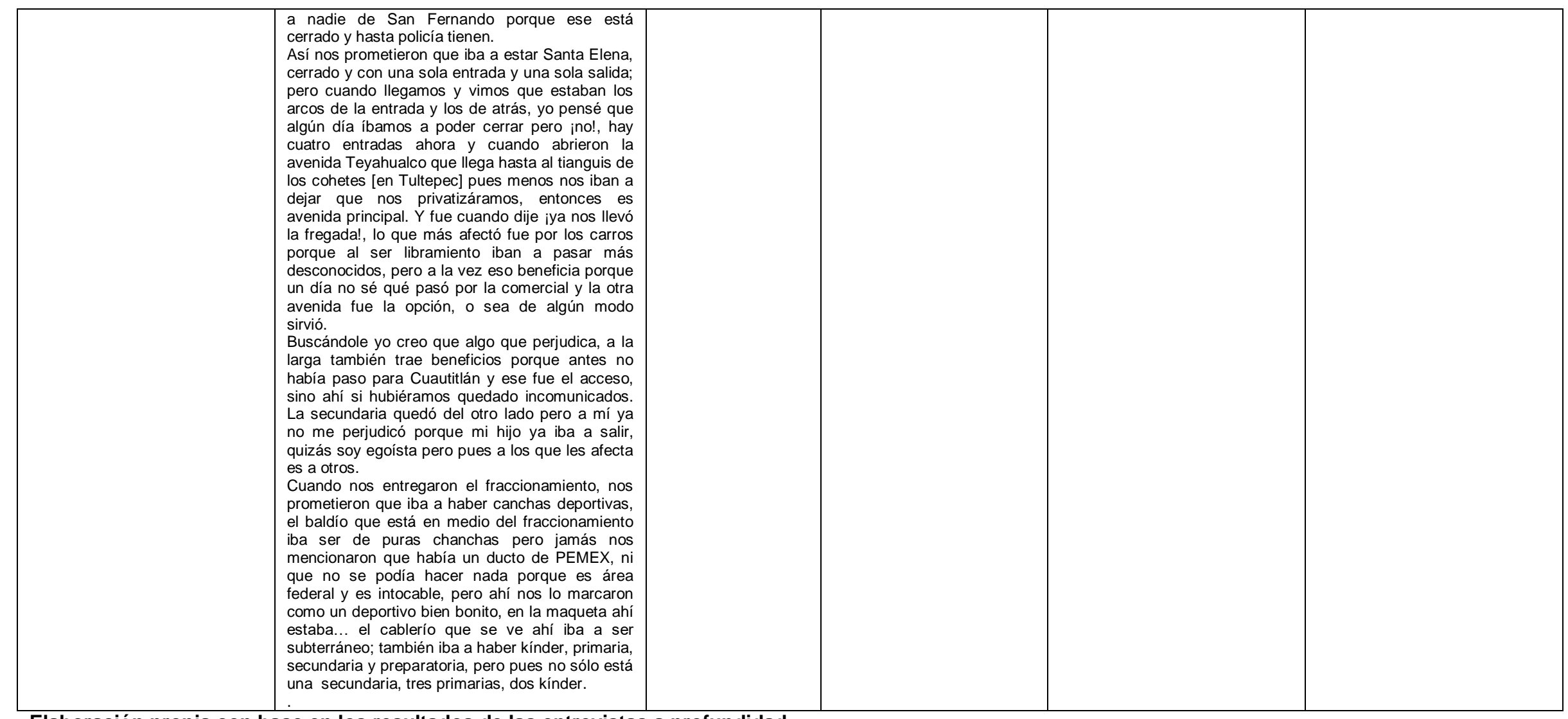

Elaboración propia con base en los resultados de las entrevistas a profundidad. 